\title{
Hemodynamic adjustments during pregnancy
}

Citation for published version (APA):

Mulder, E. G. (2022). Hemodynamic adjustments during pregnancy: opportunities for tailored treatment to prevent preeclampsia. [Doctoral Thesis, Maastricht University]. Optima Grafische Communicatie. https://doi.org/10.26481/dis.20220107em

Document status and date:

Published: 01/01/2022

DOI:

10.26481/dis.20220107em

Document Version:

Publisher's PDF, also known as Version of record

\section{Please check the document version of this publication:}

- A submitted manuscript is the version of the article upon submission and before peer-review. There can be important differences between the submitted version and the official published version of record.

People interested in the research are advised to contact the author for the final version of the publication, or visit the DOI to the publisher's website.

- The final author version and the galley proof are versions of the publication after peer review.

- The final published version features the final layout of the paper including the volume, issue and page numbers.

Link to publication

\footnotetext{
General rights rights.

- You may freely distribute the URL identifying the publication in the public portal. please follow below link for the End User Agreement:

www.umlib.nl/taverne-license

Take down policy

If you believe that this document breaches copyright please contact us at:

repository@maastrichtuniversity.nl

providing details and we will investigate your claim.
}

Copyright and moral rights for the publications made accessible in the public portal are retained by the authors and/or other copyright owners and it is a condition of accessing publications that users recognise and abide by the legal requirements associated with these

- Users may download and print one copy of any publication from the public portal for the purpose of private study or research.

- You may not further distribute the material or use it for any profit-making activity or commercial gain

If the publication is distributed under the terms of Article $25 \mathrm{fa}$ of the Dutch Copyright Act, indicated by the "Taverne" license above, 


\section{Hemodynamic adjustments during pregnancy}

Opportunities for tailored treatment to prevent preeclampsia

Eva G. Mulder 
(C) 2021 E.G. Mulder

ISBN: $\quad 978-94-6361-592-1$

Lay-out: $\quad$ Optima Grafische Communicatie

Printing: $\quad$ Optima Grafische Communicatie

\section{Cover image: Antoinette Nausikaä, Summer Solstice figurine \#02}

Amsterdam 2021 | Earthware, golden glazed 12\%, 24 carats | Approx.

$10 \times 10 \times 10 \mathrm{~cm}$ | Unique

Image courtesy of Antoinette Nausikaä 


\section{HEMODYNAMIC ADJUSTMENTS DURING PREGNANCY}

Opportunities for tailored treatment to prevent preeclampsia

\section{PROEFSCHRIFT}

ter verkrijging van de graad van doctor aan de Universiteit Maastricht, op gezag van de Rector Magnificus, Prof. dr. Rianne M. Letschert volgens het besluit van het College van Decanen, in het openbaar te verdedigen op vrijdag 07 januari 2022 om 10.00 uur

door

Eva Gerdien Mulder 


\section{Promotor}

Prof. dr. M.E.A. Spaanderman

\section{Copromotores}

Dr. C. Ghossein-Doha

Dr. S.M.J. van Kuijk

\section{Beoordelingscommissie}

Prof. dr. R.F.P.M. Kruitwagen (voorzitter)

Prof. dr. W. Gyselaers (Ziekenhuis Oost-Limburg, België)

Prof. dr. C.C. Lees (Imperial College London, United Kingdom)

Prof. dr. P.W. Teunissen

Prof. dr. K. Vernooy

Financial support by the Dutch Heart Foundation for the publication of this thesis is gratefully acknowledged.

Financial support by the $\mathrm{SBOH}$ for the publication of this thesis is gratefully acknowledged.

\section{SBOHK}

voor artsen in opleiding 


\section{TABLE OF CONTENTS}

Chapter 1 General introduction

Chapter 2 Effect of pregnancy prolongation in early-onset preeclampsia on postpartum maternal cardiovascular, renal and metabolic function in primiparous women: an observational study

Chapter 3 Recurrence rates of preeclampsia over the past 20 years in women assessed for non-pregnant cardiovascular risk factors

Chapter 4 Cardiac output and peripheral vascular resistance during normotensive and hypertensive pregnancy - a systematic review and meta-analysis

Chapter 5 Study protocol for the randomized controlled EVA (early vascular adjustments) trial: tailored treatment of mild hypertension in pregnancy to prevent severe hypertension and preeclampsia

Chapter 6 Preventing recurrent preeclampsia by tailored treatment of 155 non-physiological hemodynamic adjustments to pregnancy

Chapter 7 Accuracy and precision of USCOM versus transthoracic echocardiography before and during pregnancy

Chapter 8 General discussion

Chapter 9 Impact

Chapter 10 Summary

Samenvatting

Appendices List of publications 



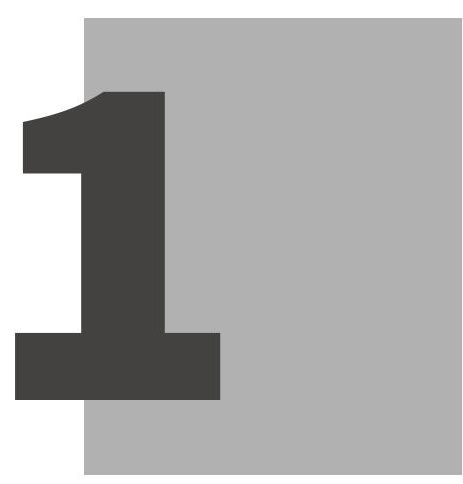

General introduction 



\section{INTRODUCTION}

Blood pressure is regulated by our cardiovascular system within narrow boundaries by alteration of its main determinants: cardiac output and peripheral vascular resistance. During healthy pregnancy, major changes in these hemodynamic parameters take place that benefit the uteroplacental circulation. Preeclampsia, a hypertensive pregnancy complication, is often preceded by heterogeneous deviant hemodynamic changes before overt clinical disease. Tailored interventions targeting these deviant changes could be a key modality in preventing preeclampsia.

\section{Preeclampsia and its burdens}

Preeclampsia, a pregnancy-related multisystem disorder, affects approximately 3-5\% of pregnant women worldwide. ${ }^{1}$ It is characterized by hypertension along with de novo proteinuria or other maternal organ dysfunction in previously normotensive women, or superimposed upon chronic hypertension. ${ }^{2}$ Preeclampsia associates with impaired foetal growth, preterm birth, stillbirth, placental abruption and other adverse maternal and offspring outcomes, and is therewith a leading cause of maternal and neonatal mortality and morbidity in the Western world. ${ }^{1}$

Low birthweight of affected neonates associates with long-term cardiovascular morbidity. ${ }^{3}$ Women with a history of preeclampsia have an increased risk for premature cardiovascular and metabolic diseases later in life. Hypertension is prevalent in $25 \%$ of women within a few years after their preeclamptic pregnancy, and up to one fifth of women meet the criteria for metabolic syndrome by that time. ${ }^{4,5}$ Preeclampsia relates to a 2 - to 7 -fold increased risk of coronary heart disease, stroke and related death within 15 years. ${ }^{4,6}$ It is not evident whether the postpartum sequelae are a consequence of overlapping pre-existing risk factors that also contribute to the development of preeclampsia, and/ or due to the deleterious effects of the gestational disease itself. ${ }^{7-9}$

Pathogenesis of preeclampsia involves a combination of defective placentation and functioning, deviant cardiovascular adjustments to pregnancy and pre-existing (subclinical) cardiovascular and cardiometabolic risk factors. ${ }^{10-12}$ Not surprisingly, many different risk factors related to these aspects have been identified. ${ }^{13,14}$ Most women develop preeclampsia after 34 weeks of gestation, generally referred to as late-onset preeclampsia, while approximately $10 \%$ of women develop early-onset preeclampsia, which often coincidences with impaired foetal growth. Birthweight of neonates born to women with early-onset preeclampsia are up to over a pound less in weight compared with normotensive gestational-age matched women. ${ }^{15,16}$ Early-onset preeclampsia with foetal growth restriction is hypothesized to be placental mediated, while later onset of 
preeclampsia is mainly linked to maternal constitutional factors including higher BMI and insulin resistance. ${ }^{17-19}$ The excess of large-for-gestational-age neonates observed in a subset of preeclamptic women delivering at term is attributed to maternal obesity. ${ }^{20-22}$

Currently the only definite treatment of preeclampsia is delivery of foetus and placenta, which may induce a management dilemma at preterm gestational ages. Preterm scheduled birth, especially before 34 weeks of pregnancy, increases the risk of neonatal morbidity and mortality, whereas deferred delivery puts the mother and foetus at jeopardy from deterioration of the preeclamptic condition. ${ }^{23}$ Moreover, deferred delivery seems to be associated with persistent postpartum hypertension, and a relatively small, but significantly increased risk of severe cardiovascular diseases in the years following delivery (21 cardiovascular events/10.000 person-years in women who delivered within a week after diagnosis versus 46 cardiovascular events/10.000 person-years in women whose pregnancy was prolonged more than a week after diagnosis). ${ }^{24,25}$ Ancillary treatment options when delivery is deferred include antihypertensive medication to control blood pressure, tailored fluid management to balance between oliguria and pulmonary oedema and administration of magnesium sulphate to prevent eclampsia. ${ }^{26,27}$ These symptomatic interventions may allow additional time for foetal development or administration of antenatal corticosteroids for foetal lung maturation when scheduled birth is imminent. Since present treatment results are suboptimal, measures to prevent preeclampsia would have a significant impact on maternal and neonatal health worldwide.

\section{Preventing preeclampsia by treating blood pressure}

Although elevated blood pressure is one of the clinical hallmarks of preeclampsia, there is a lot of controversy on antihypertensive drug treatment during pregnancy. In 2017, the American College of Cardiology / American Heart Association (ACC/AHA) updated their blood pressure management guidelines in adults, lowering thresholds to define hypertension (Table 1). ${ }^{28}$ Adoption of these guidelines almost doubles the prevalence of hypertension in women in the reproductive age, but this does not inevitably result in an increasing number of women becoming pregnant on antihypertensive medication. ${ }^{29}$ The guideline recommends antihypertensive drug treatment only in individuals with clinical atherosclerotic cardiovascular disease or an increased cardiovascular disease risk, which is often not the case in these young, otherwise-healthy women. ${ }^{30}$ Nonetheless, women with elevated blood pressure or stage 1 hypertension in the first trimester have a significantly increased risk to develop preeclampsia compared with women with normal blood pressure, with an adjusted relative risk of $1.50(95 \% \mathrm{Cl} 1.01-2.22)$ and 2.92 (95\% Cl 1.44-5.95), respectively. ${ }^{31}$ In women with pharmacologically treated chronic hypertension, discontinuation of antihypertensive medication showed no effect on the incidence of superimposed preeclampsia (31\% versus $47 \%$ in the treated versus non- 
treated group), but significantly higher incidences of severe hypertension ( $25 \%$ versus $67 \%$ ), placental abruption ( $8 \%$ versus $22 \%$ ) and preterm delivery (23\% versus $53 \%$ ) were observed in the non-treated women, favouring continuation of antihypertensive medication. $^{32}$

Table 1. Blood pressure thresholds defining elevated blood pressure and hypertension according to the ACC/AHA- and obstetric guidelines.

\begin{tabular}{lcll}
\hline ACC/AHA guideline & Threshold & Obstetric guidelines & Threshold \\
\hline Normal blood pressure & $<120$ and $<80 \mathrm{mmHg}$ & & \\
Elevated blood pressure & $120-129$ and $<80 \mathrm{mmHg}$ & & \\
Stage $\mathbf{1}$ hypertension & $130-139$ or $80-89 \mathrm{mmHg}$ & Normal blood pressure & $<140$ and $<90 \mathrm{mmHg}$ \\
Stage $\mathbf{2}$ hypertension & $\geq 140$ or $\geq 90 \mathrm{mmHg}$ & Mild to moderate hypertension & $\geq 140$ or $\geq 90 \mathrm{mmHg}$ \\
& & Severe hypertension & $\geq 160$ or $\geq 110 \mathrm{mmHg}$ \\
\hline
\end{tabular}

During pregnancy, for its well-established maternal benefits, it is generally accepted to treat blood pressure when it reaches the threshold of severe hypertension (defined in Table 1). ${ }^{33}$ In contrast, effectiveness of antihypertensive medication in mild to moderate gestational hypertension is subject of debate and medication is not uniformly initiated because of different effects on maternal disease evolvement and alleged poorer foetal outcomes, mainly related to foetal growth. ${ }^{34,35}$ In mild to moderate hypertension, the use of any antihypertensive drug halves the risk of developing severe hypertension (relative risk of $0.49 ; 95 \% \mathrm{Cl} 0.40-0.60$ ), while it neither prevents progression to preeclampsia (relative risk of $0.92 ; 95 \% \mathrm{Cl} 0.75-1.14$ ), nor reduces the risk of offspring complications (relative risk for small-for-gestational-age neonate 0.96 ; $95 \% \mathrm{Cl} 0.78-1.18$, relative risk for stillbirth $1.15 ; 95 \% \mathrm{Cl} 0.58-2.30$, and relative risk for neonatal death $0.60 ; 95 \% \mathrm{Cl}$ $0.19-1.87) .{ }^{34}$ As a consequence, international guidelines recommend to initiate medication only in severe hypertension, repeatedly measured moderate gestational hypertension, or in case of comorbidities. ${ }^{36}$ When mild to moderate hypertension is pharmacologically treated, guidelines advise a stepwise medication approach including labetalol, nifedipine and methyldopa as first-line agents, with potential adverse effects, contraindications, and clinician's experience and familiarity with a particular drug as leading criteria on which the medication choice is based. However, these pregnancy-compatible antihypertensive drugs have different targets and mechanisms to lower blood pressure, and this stepwise treatment approach is not in favour of all hypertensive women.

\section{Basic aspects of blood pressure regulation}

Arterial blood pressure is generated by the heart, pumping blood from the left ventricle into the aorta and following distributing arteries, exerting pressure on the vessel walls. Accordingly, blood pressure is established by two adaptable determinants: cardiac out- 
put and peripheral vascular resistance. Cardiac output is the product of stroke volume and heart rate. Stroke volume is determined by the preload, contractility and afterload. In turn, peripheral vascular resistance is determined by the blood vessel diameter, tone and blood viscosity.

Hemodynamic and vascular regulating mechanisms with neural and humoral mediators, and feedback loops are all set to maintain blood pressure at a constant level. In the short term, nervous reflex mechanisms contribute to rapid blood pressure regulation primarily via the sympathetic and parasympathetic autonomic nervous system. The sympathetic system excites the heart and constricts vasculature, resulting in an increased cardiac output and peripheral vascular resistance, respectively, elevating blood pressure. The parasympathetic system has the opposite effect by lowering cardiac function, resulting in a blood pressure decrease. Important humoral factors include the renin-angiotensinaldosterone system, antidiuretic hormone, circulating catecholamines and atrial natriuretic peptide. In the long-term, each of these humoral systems directly or indirectly alters cardiac function, vascular function, and subsequently blood pressure. Increase in blood pressure is only notable when cardiac output and peripheral vascular resistance are unable to fully compensate deteriorations in these aforementioned systems. In all above-mentioned considerations, it is important to notice that healthy cardiac functioning is assumed.

\section{Cardiac or vascular driven hypertension}

In gestational hypertensive complications, the equilibrium between cardiac output and peripheral vascular resistance is not uniformly affected. On the one hand, gestational hypertension may originate from a high cardiac output-low vascular resistance (hyperdynamic) circulation, a profile often accompanied by late-onset preeclampsia and normal foetal growth (Figure 1). On the other hand, a high vascular resistance (hypodynamic) profile is associated with earlier onset of maternal complications and impaired foetal growth. ${ }^{12,37,38}$ This heterogeneous nature of underlying circulatory profile may be responsible for the variable results of stepwise choice of antihypertensive therapy during pregnancy. Women with hyperdynamic hypertension might profit most from reducing cardiac output, while this may be detrimental in women with a hypodynamic profile, who may instead benefit from reduction in peripheral resistance as first-line therapy.

Following this line of reasoning, it may be possible to detect upcoming complications while blood pressure is yet within the normotensive range by assessing hemodynamic functioning and adjustments in pregnancy. In-depth insight in magnitude and timing in physiologic adjustments of cardiovascular parameters during normotensive pregnancy is required to recognize aberrant adjustment patterns. 


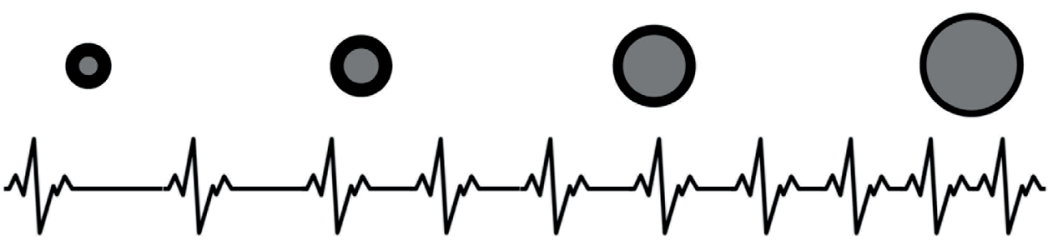

High peripheral resistance

Low peripheral resistance

Circulatory profile

Appropriate treatment

clinical

features

\section{Hypodynamic}

Hyperdynamic

Low cardiac output

High cardiac output

Late-onset preeclampsia

Figure 1. Underlying circulatory profile in gestational hypertension, associated clinical features and anticipated appropriate treatment.

\section{Hemodynamic adjustments during pregnancy}

Non-physiologic hemodynamic changes during pregnancy might have a prominent role in the pathogenesis of preeclampsia. Healthy, normotensive pregnancy is accompanied by major hemodynamic changes that benefit the uteroplacental circulation and perfusion and with it, foetal development by ensuring appropriate oxygenation and nutrient delivery to the foetus. A drop in systemic vascular resistance during the first trimester triggers several compensatory mechanisms to maintain blood pressure, such as an increase in plasma volume and cardiac output. ${ }^{39,40}$ Heterogeneous deviant changes in these hemodynamic parameters prelude different phenotypes of preeclampsia. Women who develop preeclampsia at the end of pregnancy have normal to elevated cardiac output throughout gestation, while in women who develop early-onset preeclampsia with impaired foetal growth, cardiac output is low and peripheral vascular resistance is high over the course of pregnancy. ${ }^{12,}{ }^{41-45}$ An altered pre-pregnant hemodynamic phenotype, inadequate cardiovascular adjustments to pregnancy or crossover from hyperdynamic to the more unfavourable hypodynamic circulation as a consequence of endothelial derangement and loss of intravascular fluid, are thought to underlie divergent hemodynamic profiles. In-depth insight in magnitude and timing in physiologic changes of cardiovascular parameters during normotensive pregnancy relative to 
prepregnant values is required to recognize abnormal changes to pregnancy. Reference curves of cardiac output and total peripheral vascular resistance values over the course of pregnancy may enhance detection of women at risk for hypertensive complications. Generic preventive measures may be initiated in women expected to be at higher risk. Even more sophisticated, tailored pharmacological circulatory correction to the expected physiologic values in maladaptive pregnancy might prevent development of hypertensive complications. Currently, there is a paucity of evidence on the effect of tailored treatment correcting deviant hemodynamic circulatory profiles on pregnancy outcome.

\section{Cardiac output assessment during pregnancy}

Determination whether gestational hypertension is cardiac or vascular driven, and recognition of non-physiologic adjustments to pregnancy has great potential to improve intervention and prevention opportunities. It seems therefore highly relevant to assess cardiac output and peripheral vascular resistance during regular pregnancy check-ups, at least in women with risk factors for preeclampsia. ${ }^{43}$ Currently, hemodynamic assessments in addition to blood pressure measurements are not routinely performed. This might be due to the lack of an optimal measurement method for this purpose, the absence of physiologic reference values encompassing the period from non-pregnant to pregnant to post-gestation, and the lack of clinical evidence of effectiveness of hemodynamic-guided treatment that lowers the risk on preeclampsia without negatively affecting offspring health.

The generally considered gold standard for cardiac output measurement is the pulmonary artery catheter method, but the invasiveness of the procedure and associated risks of injury and infection make longitudinal and out-patient use not feasible. In response, the interest in minimally- and non-invasive techniques to measure cardiac output efficiently in the obstetric population has remarkably increased in the recent years. ${ }^{46}$ Transthoracic echocardiography is the most commonly used non-invasive imaging modality in obstetric practice, but this method is labour-intensive and expertise-dependent, and results are not readily available. Evaluation of other non-invasive methods during pregnancy with immediately readable results and quickly acquired skills to perform measurements are necessary for implementation and applicability of hemodynamic parameters in obstetric clinical practice. Optimization of these 'point-of-care' devices facilitates routine utilization of hemodynamic parameters during pregnancy. 


\section{AIMS AND OUTLINE OF THIS THESIS}

This thesis aims to provide enhanced insight in healthy maternal hemodynamic adjustments to pregnancy, and to delineate non-physiological adjustments in relation to the development of gestational hypertensive complications. Two tailored hemodynamicaffecting interventions to prevent development of incident and recurrent preeclampsia are outlined, and we focused on facilitating the measurement of hemodynamic parameters in daily obstetric clinical practice. These elaborations are of great importance in order to reduce the direct and remote burden of preeclampsia.

Chapter 2 evaluates the effect of pregnancy prolongation after diagnosis of early-onset preeclampsia on offspring outcome and postpartum maternal cardiovascular, metabolic and renal function.

Chapter 3 estimates whether the incidence of recurrent preeclampsia and associated offspring complications decreased in the past two decades in women who had an extensive non-pregnant cardiovascular and cardiometabolic risk factor assessment.

Chapter 4 systematically reviews current literature on cardiac output, its determinants heart rate and stroke volume, and total peripheral vascular resistance during pregnancy, estimates the timing and magnitude of changes over the course of normotensive and hypertensive singleton pregnancies, and establishes reference curves for these hemodynamic parameters in normotensive pregnancy.

Chapter 5 presents a study protocol to investigate whether treatment of mild to moderate gestational hypertension based on underlying hemodynamic profile and anticipated response to antihypertensive medication prevents maternal disease progression to severe hypertension and preeclampsia.

Chapter 6 presents the effect of timely tailored treatment of early non-physiologic hemodynamic changes in pregnancy on maternal and foetal outcome in a high-risk population.

Chapter 7 compares cardiac output measurements obtained by the Ultrasonic Cardiac Output Monitor, a new non-invasive 'point-of-care' device, and transthoracic echocardiography, the most commonly used method to assess cardiac function in pregnancy.

Chapter 8 summarizes and elaborates on the main findings of the studies in this thesis. 


\section{REFERENCES}

1. Abalos E, Cuesta C, Grosso AL, Chou D and Say L. Global and regional estimates of preeclampsia and eclampsia: a systematic review. Eur J Obstet Gynecol Reprod Biol 2013; 170: 1-7.

2. Tranquilli AL, Dekker G, Magee L, Roberts J, Sibai BM, Steyn W, et al. The classification, diagnosis and management of the hypertensive disorders of pregnancy: A revised statement from the ISSHP. Pregnancy Hypertens 2014; 4: 97-104.

3. Fox R, Kitt J, Leeson P, Aye CYL and Lewandowski AJ. Preeclampsia: Risk Factors, Diagnosis, Management, and the Cardiovascular Impact on the Offspring. $J$ Clin Med 2019; 8

4. Melchiorre K, Sutherland GR, Liberati M and Thilaganathan B. Preeclampsia is associated with persistent postpartum cardiovascular impairment. Hypertension 2011; 58: 709-715.

5. Hooijschuur MC, Ghossein-Doha C, AlNasiry S and Spaanderman ME. Maternal metabolic syndrome, preeclampsia, and small for gestational age infancy. Am J Obstet Gynecol 2015; 213: 370 e371-377.

6. Wu P, Haththotuwa R, Kwok CS, Babu A, Kotronias RA, Rushton C, et al. Preeclampsia and Future Cardiovascular Health: A Systematic Review and Meta-Analysis. Circ Cardiovasc Qual Outcomes 2017; 10

7. Romundstad PR, Magnussen EB, Smith GD and Vatten LJ. Hypertension in pregnancy and later cardiovascular risk: common antecedents? Circulation 2010; 122: 579-584.

8. Cho GJ, Jung US, Sim JY, Lee YJ, Bae NY, Choi $\mathrm{HJ}$, et al. Is preeclampsia itself a risk factor for the development of metabolic syndrome after delivery? Obstet Gynecol Sci 2019; 62: 233-241.

9. Vikse BE. Pre-eclampsia and the risk of kidney disease. Lancet 2013; 382: 104-106.

10. Burton GJ and Jauniaux E. Placental oxidative stress: from miscarriage to pre- eclampsia. J Soc Gynecol Investig 2004; 11: 342-352.

11. Magnussen EB, Vatten LJ, Lund-Nilsen TI, Salvesen KA, Davey Smith G and Romundstad PR. Prepregnancy cardiovascular risk factors as predictors of pre-eclampsia: population based cohort study. BMJ 2007; 335: 978.

12. Bosio PM, McKenna PJ, Conroy R and O'Herlihy C. Maternal central hemodynamics in hypertensive disorders of pregnancy. Obstet Gynecol 1999; 94: 978-984.

13. Bartsch E, Medcalf KE, Park AL, Ray JG and High Risk of Pre-eclampsia Identification G. Clinical risk factors for pre-eclampsia determined in early pregnancy: systematic review and meta-analysis of large cohort studies. BMJ 2016; 353: i1753.

14. Giannakou K, Evangelou $\mathrm{E}$ and $\mathrm{Pa}$ patheodorou SI. Genetic and non-genetic risk factors for pre-eclampsia: umbrella review of systematic reviews and metaanalyses of observational studies. Ultrasound Obstet Gynecol 2018; 51: 720-730.

15. Lisonkova $\mathrm{S}$ and Joseph KS. Incidence of preeclampsia: risk factors and outcomes associated with early- versus late-onset disease. Am J Obstet Gynecol 2013; 209: 544 e541-544 e512.

16. Xiong $X$, Demianczuk NN, Saunders LD, Wang FL and Fraser WD. Impact of preeclampsia and gestational hypertension on birth weight by gestational age. Am J Epidemiol 2002; 155: 203-209.

17. D’Anna R, Baviera G, Corrado F, Giordano D, De Vivo A, Nicocia G, et al. Adiponectin and insulin resistance in early- and late-onset pre-eclampsia. BJOG 2006; 113: 1264-1269.

18. Bicocca MJ, Mendez-Figueroa $\mathrm{H}$, Chauhan SP and Sibai BM. Maternal Obesity and the Risk of Early-Onset and Late-Onset Hypertensive Disorders of Pregnancy. Obstet Gynecol 2020; 136: 118-127. 
19. Khalil A, Garcia-Mandujano R, Maiz N, Elkhouli $\mathrm{M}$ and Nicolaides $\mathrm{KH}$. Longitudinal changes in uterine artery Doppler and blood pressure and risk of pre-eclampsia. Ultrasound Obstet Gynecol 2014; 43: 541547.

20. Xiong $X$, Demianczuk NN, Buekens $P$ and Saunders LD. Association of preeclampsia with high birth weight for age. Am J Obstet Gynecol 2000; 183: 148-155.

21. Rasmussen S, Irgens LM and Espinoza J. Maternal obesity and excess of fetal growth in pre-eclampsia. BJOG 2014; 121: 13511357.

22. Verlohren S, Melchiorre K, Khalil A and Thilaganathan B. Uterine artery Doppler, birth weight and timing of onset of preeclampsia: providing insights into the dual etiology of late-onset pre-eclampsia. Ultrasound Obstet Gynecol 2014; 44: 293298.

23. Wang Y, Hao M, Sampson S and Xia J. Elective delivery versus expectant management for pre-eclampsia: a meta-analysis of RCTs. Arch Gynecol Obstet 2017; 295: 607-622.

24. Berks D, Steegers EA, Molas M and Visser W. Resolution of hypertension and proteinuria after preeclampsia. Obstet Gynecol 2009; 114: 1307-1314.

25. Rosenbloom JI, Lewkowitz AK, Lindley KJ, Nelson DM, Macones GA, Cahill AG, et al. Expectant Management of Hypertensive Disorders of Pregnancy and Future Cardiovascular Morbidity. Obstet Gynecol 2020; 135: 27-35.

26. Pretorius $T$, van Rensburg G, Dyer RA and Biccard BM. The influence of fluid management on outcomes in preeclampsia: a systematic review and meta-analysis. Int J Obstet Anesth 2018; 34: 85-95.

27. Duley L, Gulmezoglu AM, Henderson-Smart DJ and Chou D. Magnesium sulphate and other anticonvulsants for women with preeclampsia. Cochrane Database Syst Rev 2010: CD000025.
28. Whelton PK, Carey RM, Aronow WS, Casey DE, Collins KJ, Himmelfarb CD, et al. 2017 ACC/AHA/AAPA/ABC/ACPM/AGS/APhA/ ASH/ASPC/NMA/PCNA guideline for the prevention, detection, evaluation, and management of high blood pressure in adults: a report of the American College of Cardiology/American Heart Association Task Force on Clinical Practice Guidelines. Journal of the American College of Cardiology 2018; 71: e127-e248.

29. Topel ML, Duncan EM, Krishna I, Badell ML, Vaccarino V and Quyyumi AA. Estimated Impact of the 2017 American College of Cardiology/American Heart Association Blood Pressure Guidelines on Reproductive-Aged Women. Hypertension 2018; 72: e39-e42.

30. Muntner P, Carey RM, Gidding S, Jones DW, Taler SJ, Wright JT, Jr., et al. Potential US Population Impact of the 2017 ACC/AHA High Blood Pressure Guideline. Circulation 2018; 137: 109-118.

31. Hauspurg A, Parry S, Mercer BM, Grobman W, Hatfield T, Silver RM, et al. Blood pressure trajectory and category and risk of hypertensive disorders of pregnancy in nulliparous women. Am J Obstet Gynecol 2019; 221: 277 e271-277 e278.

32. Rezk M, Ellakwa H, Gamal A and Emara M. Maternal and fetal morbidity following discontinuation of antihypertensive drugs in mild to moderate chronic hypertension: A 4-year observational study. Pregnancy Hypertens 2016; 6: 291-294.

33. Duley L, Meher S and Jones L. Drugs for treatment of very high blood pressure during pregnancy. Cochrane Database Syst Rev 2013: CD001449.

34. Abalos E, Duley L, Steyn DW and Gialdini C. Antihypertensive drug therapy for mild to moderate hypertension during pregnancy. Cochrane Database Syst Rev 2018; 10: CD002252.

35. von Dadelszen $P$ and Magee LA. Fall in mean arterial pressure and fetal growth 
restriction in pregnancy hypertension: an updated metaregression analysis. J Obstet Gynaecol Can 2002; 24: 941-945.

36. Braunthal $\mathrm{S}$ and Brateanu A. Hypertension in pregnancy: Pathophysiology and treatment. SAGE Open Med 2019; 7 : 2050312119843700.

37. Valensise $H$, Vasapollo B, Novelli GP, Pasqualetti P, Galante A and Arduini D. Maternal total vascular resistance and concentric geometry: a key to identify uncomplicated gestational hypertension. BJOG 2006; 113: 1044-1052.

38. Mei S, Gu H, Wang Q, Zhang S and Zeng Y. Pre-eclampsia outcomes in different hemodynamic models. J Obstet Gynaecol Res 2008; 34: 179-188.

39. de Haas S, Ghossein-Doha C, van Kuijk SM, van Drongelen $\mathrm{J}$ and Spaanderman ME. Physiologic adaptation of plasma volume during pregnancy: a systematic review and meta-analysis. Ultrasound Obstet Gynecol 2016

40. Meah VL, Cockcroft JR, Backx K, Shave $\mathrm{R}$ and Stohr EJ. Cardiac output and related haemodynamics during pregnancy: a series of meta-analyses. Heart 2016; 102: 518-526.

41. Rang S, van Montfrans GA and Wolf H. Serial hemodynamic measurement in normal pregnancy, preeclampsia, and intrauterine growth restriction. Am J Obstet Gynecol 2008; 198: 519 e511-519.
42. Valensise H, Vasapollo B, Gagliardi $G$ and Novelli GP. Early and late preeclampsia: two different maternal hemodynamic states in the latent phase of the disease. Hypertension 2008; 52: 873-880.

43. Khaw A, Kametas NA, Turan OM, Bamfo JE and Nicolaides KH. Maternal cardiac function and uterine artery Doppler at 11-14 weeks in the prediction of pre-eclampsia in nulliparous women. BJOG 2008; 115: 369-376.

44. Stott D, Nzelu O, Nicolaides KH and Kametas NA. Maternal hemodynamics in normal pregnancy and in pregnancy affected by pre-eclampsia. Ultrasound Obstet Gynecol 2018; 52: 359-364.

45. Foo FL, Mahendru AA, Masini G, Fraser A, Cacciatore S, Maclntyre DA, et al. Association Between Prepregnancy Cardiovascular Function and Subsequent Preeclampsia or Fetal Growth Restriction. Hypertension 2018; 72: 442-450.

46. Armstrong S, Fernando R and Columb M. Minimally- and non-invasive assessment of maternal cardiac output: go with the flow! Int J Obstet Anesth 2011; 20: 330-340. 




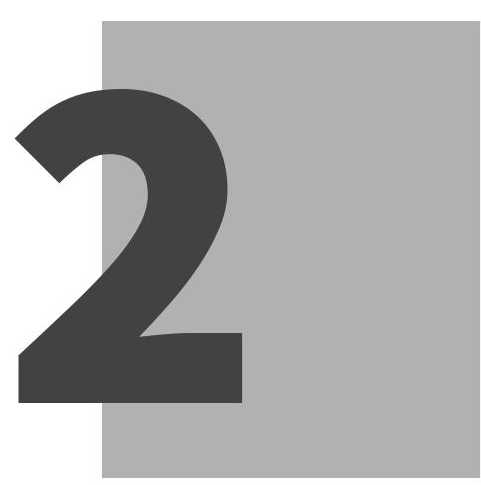

\title{
EFFECT OF PREGNANCY PROLONGATION IN EARLY-ONSET PRE-ECLAMPSIA ON POSTPARTUM MATERNAL
} CARDIOVASCULAR, RENAL AND METABOLIC FUNCTION IN PRIMIPAROUS WOMEN: AN OBSERVATIONAL STUDY

\author{
Eva G. Mulder \\ Chahinda Ghossein-Doha \\ Janneke R.W. Crutsen \\ Sander M.J. van Kuijk \\ Basky Thilaganathan \\ Marc E.A. Spaanderman
}




\section{ABSTRACT}

Objective: To evaluate the association between deferred delivery in early-onset preeclampsia and offspring outcome and maternal cardiovascular, renal and metabolic function in the postpartum period.

Design: Observational study

Setting: Tertiary referral hospital

Population: Nulliparous women diagnosed with preeclampsia before 34 weeks' gestation who participated in a routine postpartum cardiovascular risk assessment programme. Women with hypertension, diabetes mellitus or renal disease prior to pregnancy were excluded.

Methods: Regression analyses were performed to assess the association between pregnancy prolongation and outcome measures.

Main outcome measures: Offspring outcome and prevalence of deviant maternal cardiovascular, renal and metabolic function.

Results: The study population included 564 women with a median pregnancy prolongation of 10 days (interquartile range (IQR) 4-18) who were assessed at on average 8 months (IQR 6-12) postpartum. Pregnancy prolongation after diagnosis resulted in a decrease in infant mortality (adjusted odds ratio (aOR) 0.907; 95\% Cl 0.852-0.965 per day prolongation). This improvement in offspring outcome was associated with an elevated risk of moderately increased albuminuria (aOR 1.025; 95\% Cl 1.006-1.045 per day prolongation), but not with aberrant cardiac geometry, cardiac systolic or diastolic dysfunction, persistent hypertension or metabolic syndrome.

Conclusion: Pregnancy prolongation in early-onset preeclampsia is associated with improved offspring outcome and survival. These effects do not appear to be deleterious to short-term maternal cardiovascular and metabolic function, but are associated with a modest increase in risk of residual albuminuria.

Keywords: Early-onset preeclampsia, deferred delivery, cardiovascular health, hypertension, albuminuria, metabolic syndrome. 


\section{INTRODUCTION}

Preeclampsia, a gestational hypertensive disorder, substantially increases maternal and offspring morbidity and mortality. ${ }^{1}$ It is thought to be an endothelial disease where pathogenesis involves suboptimal placental function and cardiovascular maladaptation, mostly superimposed upon subclinical pre-existing cardiovascular and cardiometabolic risk factors. ${ }^{2,3}$ Forty percent of women with preterm preeclampsia have asymptomatic structural cardiac alterations or dysfunction at 1 year postpartum, and within 15 years after delivery, preeclampsia relates to a two- to seven-fold increased risk of coronary heart disease, stroke and related death, and a four-fold increased risk of end-stage renal disease. ${ }^{4,5}$ Hypertension is prevalent in $25 \%$ of women within a few years after pregnancy and up to $20 \%$ of women meet the criteria for metabolic syndrome by that time. ${ }^{4,6}$ It is not evident whether the postpartum sequelae are a consequence of the pre-existing underlying maternal cardiovascular risk factors or due to the deleterious effects of the gestational disease itself on the maternal cardiovascular system. ${ }^{7-9}$

Delivery is currently the only definite treatment of preeclampsia and scheduled delivery is clinically dependent on gestation at diagnosis, severity of maternal disease and foetal condition. This decision often presents a management dilemma because premature birth increases the risk of neonatal morbidity and mortality, whereas expectant management increases maternal jeopardy from deterioration of the preeclamptic condition. ${ }^{10}$ International guidelines generally recommend expectant management with continued, vigilant surveillance of mother and foetus, with scheduled delivery for features of severe maternal disease or signs of foetal compromise. ${ }^{11,12}$ Risk of maternal peripartum complications can be estimated by the PIERS model which predicts adverse maternal outcomes based on few parameters that are readily obtainable in clinical practice. ${ }^{13}$

Prolongation of pregnancy by a week in women with gestational hypertensive disorders at term did not relate to increased prevalence of metabolic syndrome. ${ }^{14}$ However, it does seem to be associated with persistence of postpartum hypertension, and with the risk of severe cardiovascular diseases, suggesting that prolonged exposure to preeclampsia affects remote maternal cardiovascular health. ${ }^{15,16}$ There is a real paucity of evidence on the effect of expectant management of severe, early-onset preeclampsia on postpartum maternal cardiovascular recovery and function. The objective of this observational study was to evaluate the association between duration of gestational disease exposure and offspring outcome and maternal cardiovascular, renal and metabolic function in primiparous women. 


\section{MATERIAL AND METHODS}

\section{Study population}

There were no patients involved, or public involvement in the design and conduct of this research. No core outcome set has been used. Informed consent related to the use of clinically acquired data for scientific analysis was obtained as is customary in the Maastricht University Medical Centre (MUMC). From 1996, postpartum assessment was offered to all women with preeclampsia and related complications during pregnancy. The clinical service was accessible to all women in the country and approximately $65 \%$ of women were referred by physicians from other hospitals, who mainly refer women with severe complications during their pregnancy. The assessment took place at least 4 , but preferably 6 months postpartum, and women were only scheduled when not breastfeeding to measure plasma volume by the lodine ${ }^{125}$ albumin indicator dilution technique (not evaluated in this study). For our analysis, we included only women admitted to the assessment within 2 years after delivery, and with onset of preeclampsia before 34 weeks of gestation, as in these women, pregnancy prolongation is assumed to benefit offspring outcome. General management of these women was according to international guidelines, recommending a temporising management plan in women without features of severe disease, and an individualised approach in women with features of severe disease. Women who presented with preeclampsia before 24 weeks were excluded, as expectant management was not typically offered as a standard treatment option. ${ }^{17}$ Women who presented with stillbirth at time of admission were excluded as the clinical consideration of whether to terminate pregnancy for the benefit of the foetus is no longer an issue. Multiparous women and women with pre-pregnancy hypertension, diabetes mellitus or renal disease were also excluded.

\section{Postpartum assessment}

Assessment of cardiovascular, renal and metabolic risk factors was performed in standardised conditions at a morning clinic after an overnight fast. Clinical data on obstetric history, medical history and use of medication were collected from medical files, referral letters and direct patient enquiry. Diagnosis of preeclampsia was taken as the gestational age at which hypertension and proteinuria were observed for the first time. Glucose, insulin, creatinine and lipid-spectrum levels were obtained from fasting blood samples. Urine was collected in the 24 hours preceding the measurements, and was assayed for albumin, creatinine and total protein. Body mass index (BMI) was calculated by dividing the bodyweight in kilograms by the squared height in meters. Arterial blood pressure was measured in sitting position by a semiautomatic oscillometric device (Dinamap Vital Signs Monitor 1846; Critikon, Tampa, FL) every 3 minutes. The median value of 11 measurements was reported. Transthoracic echocardiography 
was performed according to the American Society of Echocardiography (ASE) guidelines using a commercially available phased-array echocardiographic Doppler system (iE33 system with S5-1 or X5-1 transducers, Philips Medical Systems, Best, Netherlands). ${ }^{18}$ All images were acquired in left lateral position, recorded as ECG-gated digital loops and stored for off-line analysis. Using M-mode in the parasternal long-axis view, we measured left ventricular end-diastolic (LVEDd) and end-systolic (LVESd) diameters, end-diastolic interventricular septum thickness (IVST) and the posterior (inferolateral) wall thickness (PWT). As recommended by the ASE, left ventricular mass (LVM; g) was determined using the Devereux formula: $0.8 \times\left(1.04\left((\text { LVEDd }+ \text { PWT + IVST })^{3}-(\text { LVEDd })^{3}\right)\right)+0.6$, indexed for body surface area. ${ }^{19,20}$ Relative wall thickness (RWT) was computed using the formula: $2 \times$ PWT / LVEDd. ${ }^{20}$ Left ventricular end-diastolic (EDV) and end-systolic volumes (ESV) were determined using the Teichholz formula. Left ventricular ejection fraction (\%) was calculated using the formula: ((EDV-ESD)/EDV) $\times 100$.

\section{Definitions}

Preeclampsia was defined as new-onset hypertension with a systolic blood pressure $\geq 140 \mathrm{mmHg}$ and/or diastolic blood pressure $\geq 90 \mathrm{mmHg}$ in two repeated measurements along with de novo proteinuria ( $\geq 0.3 \mathrm{~g} / 24 \mathrm{~h}$ or $\geq 2+$ on dipstick analysis) after 20 weeks of gestation. Early-onset preeclampsia was defined as diagnosis before 34 weeks' gestation. HELLP-syndrome was defined as haemolysis ( $\mathrm{LDH}>600 \mathrm{U} / \mathrm{L}$ ), elevated liver enzymes (AST and ALT $>70 \mathrm{U} / \mathrm{L}$ ) and low platelets (platelet count $<100.10^{9} / \mathrm{L}$ ). Small-forgestational-age (SGA) birth was defined as neonatal birthweight below the $10^{\text {th }}$ percentile of the national birthweight charts, and corrected for sex of the neonate and parity. ${ }^{21}$ Infant mortality was defined as death within 1 year after delivery.

Cardiac systolic dysfunction was defined as an ejection fraction $\leq 55 \%$ and aberrant cardiac geometry was defined by left ventricular mass index $>95 \mathrm{~g} / \mathrm{m}^{2}$, or RWT $>0.42$. Kidney function was evaluated based on the Kidney Disease Improving Global Outcomes (KDIGO) criteria, indicating that monitoring of kidney function at least once a year is required for women with a glomerular filtration rate $<60 \mathrm{~mL} / \mathrm{min} / 1.73 \mathrm{~m}^{2}$ or an albuminto-creatinine ratio $\geq 3.0 \mathrm{~g} / \mathrm{mol}$ creatinine. ${ }^{22}$

Constituents of the metabolic syndrome were defined based on World Health Organization criteria as follows: hyperinsulinemia (fasting insulin $>9.2 \mathrm{mU} / \mathrm{L}$, fasting glucose $>6.1 \mathrm{mmol} / \mathrm{L}$, and/or homeostasis model assessment for insulin resistance (HOMA-IR) $>2.2$ ), obesity (BMI $>30 \mathrm{~kg} / \mathrm{m}^{2}$ ), dyslipidaemia (triglycerides $\geq 1.7 \mathrm{mmol} / \mathrm{L}$ or HDL-cholesterol $<0.9 \mathrm{mmol} / \mathrm{L}$ ), hypertension (systolic blood pressure $\geq 140 \mathrm{mmHg}$, diastolic blood pressure $\geq 90 \mathrm{mmHg}$ and/or the use of antihypertensive medication) and proteinuria 
(albuminuria $>2.5 \mathrm{~g} / \mathrm{mol}$ creatinine or proteinuria $>0.3 \mathrm{~g} / 24 \mathrm{~h}$ ). ${ }^{23}$ Metabolic syndrome was defined as hyperinsulinemia along with two or more of the other constituents.

\section{Statistical analysis}

Women were divided into three groups based on duration of preeclampsia to give a general insight in the study population characteristics. Trends in difference between groups were analysed with pregnancy prolongation in days between diagnosis and delivery as a continuous variable, and not categorically. Logistic and linear regression analysis, whenever applicable, was performed to estimate the associations between duration of preeclampsia and offspring outcome, and maternal deviant cardiovascular, renal and metabolic function. Because postpartum time intervals could differ between women, we corrected for time-interval between delivery and postpartum assessment by adding time as a covariate in the multivariable regression analysis when analysing the maternal effects. In addition, adjusted odds ratios (aOR) were calculated with multivariable regression analysis. We adjusted for gestational age at delivery, maternal age, year of assessment and the presence of metabolic syndrome factors at evaluation. A two-sided P-value of 0.05 or below was considered statistically significant. All statistical analyses were performed using IBM SPSS Statistics version 24.0 (IBM Corp., Armonk, NY, USA).

\section{RESULTS}

Between September 1996 and July 2018, 709 women with a history of early-onset preeclampsia were admitted to the MUMC for postpartum cardiovascular and metabolic risk assessment (Figure 1). Selecting primiparous women without pre-existing diseases resulted in 594 eligible women. Characteristics of women with onset of preeclampsia before 24 weeks' gestation ( $n=23$ ) or who presented with stillbirth $(n=7)$ are presented in Table S1. In the analysis were 564 women whose obstetric characteristics are presented in Table 1. Median pregnancy prolongation was 10 days, gestational age at diagnosis was lower in the group of women with the longest pregnancy prolongation, and prevalence of HELLP syndrome was highest in the group with short pregnancy prolongation.

\section{Postpartum maternal status}

Regression analysis showed no differences in postpartum cardiac geometry and function, vascular function, renal function or metabolic syndrome components with pregnancy prolongation (Table 2 and Table S2). The OR adjusted for the interval between delivery and postpartum assessment showed that pregnancy prolongation was associated with moderately increased postpartum albuminuria (OR 1.022; 95\% Cl 1.005-1.040 per day prolongation), but not with severely increased proteinuria (Table 3). After adjustments 
for gestational age at delivery, maternal age, year of postpartum assessment and metabolic syndrome constituents, the association with moderately increased albuminuria persisted. Pregnancy prolongation was not associated with reduced creatinine clearance, annual monitoring of kidney function advice, deviant cardiac parameters or hypertension postpartum.

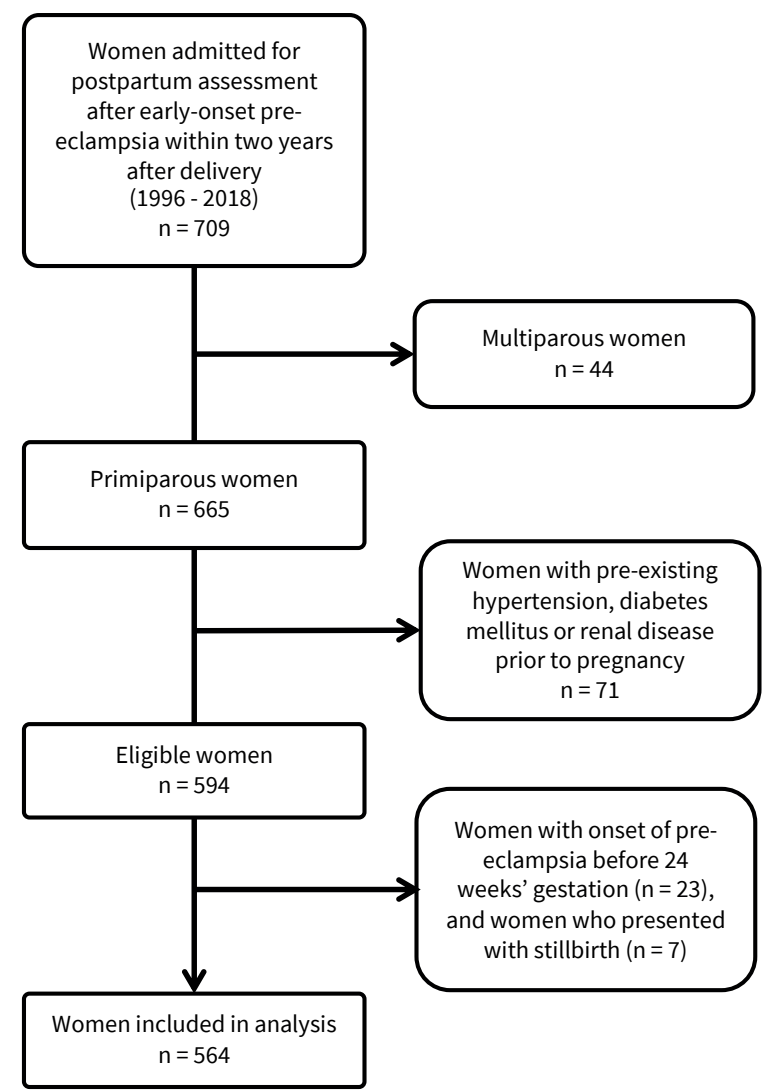

Figure 1. Flowchart for selection of women.

\section{Offspring outcome}

There were no offspring outcomes associated with pregnancy prolongation, apart from higher absolute birthweight in women whose pregnancy was prolonged longer (Table 1). Pregnancy prolongation did not increase the risk of placental abruption, stillbirth or prevalence of SGA neonates but was associated with a significant decrease in infant mortality (OR 0.952; 95\% Cl 0.909-0.998) (Table S3). When adjusted for gestational age at diagnosis, concurrent HELLP syndrome and eclampsia, and year of assessment, the beneficial effect of pregnancy prolongation on infant survival persisted (aOR 0.907; 95\% Cl 0.852-0.965). 
Table 1. Obstetric characteristics of study population categorized by duration of pregnancy prolongation

\begin{tabular}{|c|c|c|c|c|c|}
\hline \multirow[t]{3}{*}{ Pregnancy outcome } & \multirow[t]{2}{*}{ Total } & \multicolumn{3}{|c|}{ Pregnancy prolongation } & \multirow[b]{3}{*}{$P$-value* } \\
\hline & & $\leq 6$ days & $7-13$ days & $\geq 14$ days & \\
\hline & $n=564$ & $n=186$ & $n=173$ & $n=205$ & \\
\hline Prolongation in days & $10[4-18]$ & $3[1-4]$ & $9[7-11]$ & $21[17-30]$ & \\
\hline GA at diagnosis & $30^{0}\left[28^{0}-32^{0}\right]$ & $31^{0}\left[29^{0}-32^{5}\right]$ & $30^{0}\left[28^{0}-32^{0}\right]$ & $30^{0}\left[27^{0}-32^{0}\right]$ & $<0.001$ \\
\hline GA at delivery & $32^{0}\left[29^{5}-33^{6}\right]$ & $31^{5}\left[29^{2}-33^{1}\right]$ & $31^{2}\left[29^{0}-33^{0}\right]$ & $33^{0}\left[30^{5}-35^{1}\right]$ & $<0.001$ \\
\hline HELLP syndrome & $404 / 564(72 \%)$ & $134 / 186(72 \%)$ & $131 / 173(76 \%)$ & $139 / 205(68 \%)$ & 0.017 \\
\hline Eclampsia & $34 / 564(6 \%)$ & $17 / 186(9 \%)$ & $5 / 173(3 \%)$ & $13 / 205(6 \%)$ & 0.690 \\
\hline Birthweight, g & $1400[1000-1810]$ & 1348 [975-1677] & $1270[875-1680]$ & 1620 [1165-2060] & $<0.001$ \\
\hline Birthweight centile & $16[8-30]$ & 18 [8-32] & $16[8-25]$ & $15[8-31]$ & 0.805 \\
\hline Multifetal pregnancy & $20 / 564(4 \%)$ & $7 / 186(4 \%)$ & $5 / 173(3 \%)$ & $8 / 205(4 \%)$ & 0.936 \\
\hline SGA birth/neonate & $179 / 564(32 \%)$ & $54 / 186(29 \%)$ & $55 / 173(32 \%)$ & $70 / 205$ (34\%) & 0.255 \\
\hline Placental abruption & $19 / 564(3 \%)$ & $10 / 186(5 \%)$ & $5 / 173(3 \%)$ & $4 / 205(2 \%)$ & 0.109 \\
\hline Offspring demise & $36 / 564(6 \%)$ & $15 / 186(8 \%)$ & $13 / 173(8 \%)$ & $8 / 205(4 \%)$ & 0.036 \\
\hline Stillbirth & $8 / 564(1 \%)$ & $2 / 186(1 \%)$ & $4 / 173(2 \%)$ & $2 / 205(1 \%)$ & 0.559 \\
\hline Infant mortality & $28 / 564(5 \%)$ & $13 / 186(7 \%)$ & 9/173 (5\%) & $6 / 205(2 \%)$ & 0.042 \\
\hline
\end{tabular}

Data are presented as median [interquartile range] or number/known outcome (percentage in group). ${ }^{*}$-value indicates trend based on regression analysis with pregnancy prolongation used as a continuous variable. GA indicates gestational age; SGA, small-for-gestational-age

\section{DISCUSSION}

\section{Main findings}

This observational study demonstrates that pregnancy prolongation in early-onset preeclampsia is related to improved offspring outcome and survival but is not associated with deleterious effects on maternal cardiovascular, renal and metabolic function in the postpartum period, other than an increased risk of moderately increased albuminuria.

\section{Strengths and limitations}

The strength of our study is the extensive postpartum assessment of risk factors, which enabled us to correct for cardiovascular and renal risk factors. Some limitations also need to be addressed. Firstly, detailed information on antihypertensive treatment, target blood pressure and other treatment goals during pregnancy is lacking. Therefore, we are not able to evaluate the effect of specific treatment on pregnancy prolongation and outcomes. In addition, as we do not have detailed information on maternal condition that contributed to the physicians' decision to terminate pregnancy, it could be possible that immediate scheduled birth was planned because of rapid deterioration of maternal condition. This would mitigate the association between pregnancy prolongation and maternal outcomes. On the other hand, pregnancy prolongation might be associated with more advanced maternal disease contributing to residual albuminuria postpartum. 
Table 2. Pregnancy prolongation and postpartum maternal cardiovascular, renal and metabolic function

\begin{tabular}{|c|c|c|c|c|c|}
\hline & Total & $\leq 6$ days & 7-13 days & $\geq 14$ days & \\
\hline & $n=564$ & $n=186$ & $n=173$ & $n=205$ & $P$-value* \\
\hline Time to assessment (months) & $8[6-12]$ & $8[6-12]$ & $7[6-12]$ & $8[6-14]$ & 0.006 \\
\hline Maternal age (years) & $30.4(4.2)$ & $29.9(4.0)$ & $30.6(4.1)$ & $30.8(4.5)$ & 0.090 \\
\hline \multicolumn{6}{|l|}{ Cardiac parameters } \\
\hline LVM index $\left(g / m^{2}\right)$ & $70[61-79]$ & $69[61-79]$ & $69[60-78]$ & $71[61-80]$ & 0.916 \\
\hline Relative wall thickness & $0.33[0.30-0.35]$ & $0.33[0.30-0.35]$ & $0.32[0.30-0.35]$ & $0.33[0.30-0.35]$ & 0.698 \\
\hline Ejection fraction (\%) & $64[61-67]$ & $64[61-67]$ & $64[60-67]$ & $64[60-67]$ & 0.861 \\
\hline \multicolumn{6}{|l|}{ Renal parameters } \\
\hline Albuminuria ( $\mathrm{g} / \mathrm{mol}$ creatinine) & $1.0[0.5-2.3]$ & $0.8[0.4-1.9]$ & $1.0[0.6-2.2]$ & $1.2[0.5-2.7]$ & 0.643 \\
\hline Proteinuria (g/mol creatinine) & $8.2[6.7-10.5]$ & $8.0[6.7-10.3]$ & $7.9[6.4-10.3]$ & $8.9[7.0-11.4]$ & 0.941 \\
\hline $\mathrm{CC}\left(\mathrm{ml} / \mathrm{min} / 1.73 \mathrm{~m}^{2}\right)$ & $106[95-117]$ & $107[97-118]$ & $105[93-117]$ & 104 [93-115] & 0.209 \\
\hline \multicolumn{6}{|l|}{ Vascular function } \\
\hline Systolic blood pressure (mmHg) & $116[109-124]$ & 114 [108-123] & $116[109-124]$ & 117 [109-125] & 0.784 \\
\hline Diastolic blood pressure (mmHg) & $73[68-78]$ & $72[67-78]$ & $74[67-80]$ & $73[68-77]$ & 0.725 \\
\hline Hypertension & $98 / 559(18 \%)$ & $35 / 185(19 \%)$ & $25 / 170(15 \%)$ & $38 / 204(19 \%)$ & 0.716 \\
\hline Pulse pressure & $43[39-49]$ & $43[39-48]$ & 43 [39-49] & 44 [38-49] & 0.971 \\
\hline Stroke volume/pulse pressure & $1.64[1.43-1.95]$ & $1.68[1.43-2.02]$ & $1.63[1.43-1.89]$ & $1.63[1.43-1.96]$ & 0.783 \\
\hline Metabolic syndrome & $82 / 560(15 \%)$ & $26 / 185(14 \%)$ & $21 / 171(12 \%)$ & $35 / 204(17 \%)$ & 0.321 \\
\hline Hyperinsulinemia & $295 / 560(53 \%)$ & $98 / 185(53 \%)$ & $91 / 172(53 \%)$ & $106 / 203(52 \%)$ & 0.720 \\
\hline Obesity & $124 / 564(22 \%)$ & $42 / 186(23 \%)$ & $34 / 173(20 \%)$ & $48 / 205(23 \%)$ & 0.265 \\
\hline Dyslipidaemia & $109 / 563(19 \%)$ & $34 / 186(18 \%)$ & $33 / 173(19 \%)$ & $42 / 204(21 \%)$ & 0.956 \\
\hline Albuminuria or proteinuria & $121 / 544(22 \%)$ & $31 / 178(17 \%)$ & $32 / 168(19 \%)$ & $58 / 203(29 \%)$ & 0.061 \\
\hline
\end{tabular}

Data are presented as mean (standard deviation), median [interquartile range] or number/valid measurements (percentage in group). ${ }^{\star} P$-value indicates trend based on regression analysis with pregnancy prolongation (days) used as a continuous variable. LVM indicates left ventricular mass; CC, creatinine clearance

However, the decision to end pregnancy is often not based on increase or magnitude of proteinuria, as this does not affect maternal or perinatal outcome. ${ }^{24}$ Lastly, as women had to attend the postpartum evaluation, we were not able to assess maternal death as outcome of a temporising management plan. Although absolute numbers of maternal deaths are low, and most maternal deaths occur after 34 weeks of pregnancy, postponing delivery in early-onset preeclampsia exposes the women to increased risk of mortality. $^{25,26}$

\section{Interpretation}

In preeclampsia diagnosed before 34 weeks' gestation, immediate induction of labour increases the risk of neonatal mortality and morbidity, and pregnancy prolongation is preferred as long as maternal and foetal condition permits. ${ }^{27,28}$ In our sample, pregnancy was prolonged for 10 days, which is slightly longer than in other studies despite the rela- 
tive high incidence of HELLP syndrome. ${ }^{28-30}$ Women whose pregnancy was prolonged the longest, had earlier onset of preeclampsia, which probably explains the observed neonatal health gain of postponing delivery. Clinicians are more likely to take the risk of short-term maternal and foetal complications when the survival rate of the neonate is expected to be considerably improved with pregnancy prolongation. ${ }^{31}$ Deferred delivery was associated with a decreased risk of infant mortality and resulted in higher absolute birthweight, which in turn also contributes to an increased survival rate. ${ }^{32}$ The presumption that the in utero environment may be suboptimal for the growth potential of the foetus could not be substantiated by our observations, as the relative birthweight did not deteriorate with prolonged pregnancy. ${ }^{33,34}$

Table 3. Association between pregnancy prolongation after preeclampsia diagnosis (per day prolongation) and maternal cardiovascular, renal and metabolic function.

\begin{tabular}{|c|c|c|c|c|}
\hline & OR $(95 \% \mathrm{Cl})$ & $P$-value & $\begin{array}{l}\text { Adjusted OR } \\
(95 \% \mathrm{CI})\end{array}$ & $P$-value \\
\hline \multicolumn{5}{|l|}{ Cardiac parameters } \\
\hline Left ventricular mass index $>95 \mathrm{~g} / \mathrm{m}^{2}$ & $1.005(0.956-1.056)$ & ) 0.853 & $0.987(0.928-1.050)$ & 0.677 \\
\hline Relative wall thickness $>0.42$ & $1.023(0.971-1.078)$ & 0.398 & $1.001(0.932-1.074)$ & 0.987 \\
\hline Ejection fraction $<55 \%$ & $0.956(0.873-1.047)$ & ) 0.333 & $0.931(0.840-1.031)$ & 0.170 \\
\hline \multicolumn{5}{|l|}{ Renal parameters } \\
\hline Albuminuria $>2.5 \mathrm{~g} / \mathrm{mol}$ creatinine ${ }^{\star}$ & $1.022(1.005-1.040)$ & 0.011 & $1.025(1.006-1.045)$ & 0.010 \\
\hline Proteinuria $>30 \mathrm{~g} / \mathrm{mol}$ creatinine ${ }^{\star}$ & $0.998(0.932-1.069)$ & 0.995 & $0.994(0.924-1.071)$ & 0.994 \\
\hline Creatinine clearance $<90 \mathrm{ml} / \mathrm{min} / 1.73 \mathrm{~m}^{2}$ & $1.011(0.993-1.029)$ & ) 0.234 & $1.001(0.981-1.022)$ & 0.904 \\
\hline Annual monitoring necessary according to KDIGO* & $1.013(0.995-1.031)$ & ) 0.173 & $1.013(0.993-1.034)$ & 0.211 \\
\hline Metabolic syndrome* & $1.012(0.993-1.032)$ & 0.228 & $1.014(0.993-1.036)$ & 0.182 \\
\hline Hyperinsulinemia* & $0.998(0.984-1.012)$ & ) 0.774 & $1.005(0.988-1.023)$ & 0.540 \\
\hline Obesity* & $1.005(0.989-1.022)$ & 0.534 & $1.008(0.988-1.028)$ & 0.450 \\
\hline Dyslipidaemia* & $1.003(0.985-1.021)$ & 0.755 & $0.996(0.975-1.017)$ & 0.702 \\
\hline Hypertension* & $1.004(0.986-1.023)$ & 0.653 & $1.010(0.989-1.032)$ & 0.339 \\
\hline Albuminuria or proteinuria* & $1.021(1.004-1.039)$ & ) 0.014 & $1.024(1.005-1.044)$ & 0.015 \\
\hline
\end{tabular}

KDIGO indicates Kidney Disease Improving Global Outcomes. ORs are adjusted for months between delivery and postpartum assessment. aOR are adjusted for gestational age at delivery, maternal age, year of postpartum assessment, hyperinsulinemia, hypertension, obesity, dyslipidaemia, and moderately increased albuminuria or severely increased proteinuria. *Not adjusted for specific metabolic syndrome component(s)

Prevalence of hypertension and blood pressure levels did not relate to pregnancy prolongation, nor did estimates of arterial compliance. The reason might be that clinical preeclampsia does not induce persistent vascular alterations, or that this contribution is minor compared with disease evolution prior to diagnosis. The changes in cardiac geometry during normotensive pregnancy generally recover in the postpartum period. ${ }^{35}$ In contrast, after preterm preeclampsia, about half of women show asymptomatic 
structurally altered cardiac geometrics consisting mainly of concentric left ventricular remodelling, even after several years. ${ }^{4}$ Concentric remodelling is known for its association with increased myocardial fibrosis which decreases left ventricular compliance and consequently impairing diastolic function. ${ }^{4,}{ }^{36}$ About a quarter of women in our population had a left ventricle mass index $>80 \mathrm{~g} / \mathrm{m}^{2}$, which is above the upper limit of non-pregnant reference values. ${ }^{37}$ In addition, the RWT of our women was comparable to other formerly preeclamptic women, being substantially higher than the postpartum RWT in women with uncomplicated pregnancies. ${ }^{38}$ There was no association between pregnancy prolongation and deviant cardiac geometric indices and prevalence of global left ventricular dysfunction. A possible explanation could be that the known association with unfavourable structural alteration in preeclampsia may have already occurred by the time the diagnosis was made. A meta-analysis showed that the steepest change in left ventricular remodelling occurs before 30 weeks. ${ }^{37}$ Moreover, when preeclampsia is diagnosed, blood pressure-lowering medication is initiated, which may temper further geometrical changes and myocardial damage. ${ }^{39}$ It is also conceivable that the time-span of estimated disease prolongation is too short to result in deleterious effects on cardiac geometry.

The median albumin-to-creatinine ratio in our population was $1.0 \mathrm{~g} / \mathrm{mol}(0.5-2.3 \mathrm{~g} / \mathrm{mol})$, which is slightly higher than the normal range in healthy women aged between 20 and 40 years $(0.7 \mathrm{~g} / \mathrm{mol} ; 0.4-1.1 \mathrm{~g} / \mathrm{mol}){ }^{40}$ Preeclamptic women with prolonged pregnancy have a slightly higher risk of residual moderately increased albuminuria postpartum, but glomerular filtration rate and serum creatinine level were not affected. Also, pregnancy prolongation did not increase the prevalence of severely increased proteinuria, which usually resolves within weeks to months postpartum. ${ }^{15}$ These observations suggest a higher risk on moderate endothelial dysfunction when a policy of pregnancy prolongation is pursued. It is uncertain whether residual albuminuria reflects incomplete recovery from permanent damage incurred during pregnancy or undetected pre-existing endothelial dysfunction predisposing to preeclampsia and postpartum diagnosis of albuminuria. ${ }^{41,42}$ Preeclampsia is associated with an upregulation of placental sFlt-1, which scavenges vascular endothelial growth factor (VEGF). Reduction of VEGF in mice results in proteinuria and glomerular endotheliosis, resembling preeclampsia. ${ }^{43}$ VEGF is a signal protein produced by podocytes with autocrine function to support cell survival, and paracrine function on the glomerular endothelial cells. ${ }^{44}$ The degree of damaged podocytes correlates with the intensity of proteinuria, and depletion up to $20 \%$ results in a transient increase in proteinuria, with preserved creatinine clearance. ${ }^{45}$ Proteinuria itself is potentially harmful to the proximal tubule and podocytes, as proteins in the glomerular ultrafiltrate activate inflammation and fibrosis, and presence of proteins impairs podocyte regeneration. ${ }^{46,47}$ 
Our results emphasise the importance of monitoring the presence of moderately increased albuminuria in women with early-onset preeclampsia, especially in women whose pregnancy is prolonged by several weeks. To date, no specific interventions to improve long-term outcomes are evidenced, but adequate blood pressure control in hypertension, lifestyle and exercise advise might lower albuminuria in screen-positive women. ${ }^{48,49}$ Postpartum metabolic syndrome was observed in $15 \%$ of women in our population, compared with a prevalence of $5 \%$ in Dutch women of similar age. ${ }^{50}$ Prevalence was not related to duration of preeclampsia - nor were the individual components of the metabolic syndrome other than albuminuria. Similar results were found in women with gestational hypertensive disorders at term whose induction of labour was postponed for a week compared with immediate delivery. ${ }^{14}$ As hypertensive complications during pregnancy are associated with exaggerated metabolic changes prior to overt clinical disease, it might be unlikely that duration of preeclampsia affects the development of metabolic syndrome postpartum..$^{51-53}$ These findings support the concept of Romundstad et al. who suggested that postpartum development of metabolic syndrome is attributable to shared pre-pregnancy risk factors rather than a direct influence of gestational hypertensive disorders. ${ }^{7}$

\section{CONCLUSION}

Prolongation of pregnancy in early-onset preeclampsia with consideration of individual context at the discretion of the attending obstetrician relates to reduced infant mortality. Moreover, it is associated with a raised prevalence of moderately increased albuminuria but does not seem to have an adverse effect on cardiovascular function and metabolic status. It is unknown how these findings translate to long-term cardiovascular morbidity. Our findings should also be evaluated in a setting with detailed information on disease severity at presentation and peripartum management. 


\section{REFERENCES}

1. Magnussen EB, Vatten LJ, Lund-Nilsen TI, Salvesen KA, Davey Smith G and Romundstad PR. Prepregnancy cardiovascular risk factors as predictors of pre-eclampsia: population based cohort study. BMJ 2007; 335: 978.

2. Burton GJ and Jauniaux E. Placental oxidative stress: from miscarriage to preeclampsia. J Soc Gynecol Investig 2004; 11: 342-352.

3. Bosio PM, McKenna PJ, Conroy R and O'Herlihy C. Maternal central hemodynamics in hypertensive disorders of pregnancy. Obstet Gynecol 1999; 94: 978-984.

4. Melchiorre K, Sutherland GR, Liberati M and Thilaganathan B. Preeclampsia is associated with persistent postpartum cardiovascular impairment. Hypertension 2011; 58: 709-715.

5. Wu P, Haththotuwa R, Kwok CS, Babu A, Kotronias RA, Rushton C, et al. Preeclampsia and Future Cardiovascular Health: A Systematic Review and Meta-Analysis. Circ Cardiovasc Qual Outcomes 2017; 10

6. Hooijschuur MC, Ghossein-Doha C, AlNasiry S and Spaanderman ME. Maternal metabolic syndrome, preeclampsia, and small for gestational age infancy. Am J Obstet Gynecol 2015; 213: 370 e371-377.

7. Romundstad PR, Magnussen EB, Smith GD and Vatten LJ. Hypertension in pregnancy and later cardiovascular risk: common antecedents? Circulation 2010; 122: 579-584.

8. Cho GJ, Jung US, Sim JY, Lee YJ, Bae NY, Choi $\mathrm{HJ}$, et al. Is preeclampsia itself a risk factor for the development of metabolic syndrome after delivery? Obstet Gynecol Sci 2019; 62: 233-241.

9. Vikse BE. Pre-eclampsia and the risk of kidney disease. Lancet 2013; 382: 104-106.

10. Wang Y, Hao M, Sampson S and Xia J. Elective delivery versus expectant management for pre-eclampsia: a meta-analysis of RCTs. Arch Gynecol Obstet 2017; 295: 607-622.

11. National Institute for Health and Clinical Excellence Hypertension in pregnancy: the management of hypertensive disorders of pregnancy NICE clinical guideline 107, August 2010.

12. ACOG Practice Bulletin No. 202: Gestational Hypertension and Preeclampsia. Obstet Gynecol 2019; 133: e1-e25.

13. Ukah UV, Payne B, Hutcheon JA, Ansermino JM, Ganzevoort W, Thangaratinam $\mathrm{S}$, et al. Assessment of the fullPIERS Risk Prediction Model in Women With EarlyOnset Preeclampsia. Hypertension 2018; 71: 659-665.

14. Hermes $W$, Koopmans CM, van Pampus MG, Franx A, Bloemenkamp KW, van der Post J, et al. Induction of labour or expectant monitoring in hypertensive pregnancy disorders at term: do women's postpartum cardiovascular risk factors differ between the two strategies? Eur J Obstet Gynecol Reprod Biol 2013; 171: 30-34.

15. Berks D, Steegers EA, Molas $M$ and Visser W. Resolution of hypertension and proteinuria after preeclampsia. Obstet Gynecol 2009; 114: 1307-1314

16. Rosenbloom JI, Lewkowitz AK, Lindley KJ, Nelson DM, Macones GA, Cahill AG, et al. Expectant Management of Hypertensive Disorders of Pregnancy and Future Cardiovascular Morbidity. Obstet Gynecol 2020; 135: 27-35.

17. Gaugler-Senden IP, Huijssoon AG, Visser W, Steegers EA and de Groot CJ. Maternal and perinatal outcome of preeclampsia with an onset before 24 weeks' gestation. Audit in a tertiary referral center. Eur J Obstet Gynecol Reprod Biol 2006; 128: 216-221.

18. Mitchell C, Rahko PS, Blauwet LA, Canaday B, Finstuen JA, Foster MC, et al. Guidelines for Performing a Comprehensive Transthoracic Echocardiographic Examination 
in Adults: Recommendations from the American Society of Echocardiography. $J$ Am Soc Echocardiogr 2018

19. Devereux RB, Alonso DR, Lutas EM, Gottlieb GJ, Campo E, Sachs I, et al. Echocardiographic assessment of left ventricular hypertrophy: comparison to necropsy findings. Am J Cardiol 1986; 57: 450-458.

20. Lang RM, Bierig M, Devereux RB, Flachskampf FA, Foster E, Pellikka PA, et al. Recommendations for chamber quantification: a report from the American Society of Echocardiography's Guidelines and Standards Committee and the Chamber Quantification Writing Group, developed in conjunction with the European Association of Echocardiography, a branch of the European Society of Cardiology. J Am Soc Echocardiogr 2005; 18: 1440-1463.

21. Kloosterman GJ. [Intrauterine growth and intrauterine growth curves]. Ned Tijdschr Verloskd Gynaecol 1969; 69: 349-365.

22. Stevens PE, Levin A and Kidney Disease: Improving Global Outcomes Chronic Kidney Disease Guideline Development Work Group M. Evaluation and management of chronic kidney disease: synopsis of the kidney disease: improving global outcomes 2012 clinical practice guideline. Ann Intern Med 2013; 158: 825-830.

23. Alberti KG and Zimmet PZ. Definition, diagnosis and classification of diabetes mellitus and its complications. Part 1 : diagnosis and classification of diabetes mellitus provisional report of a WHO consultation. Diabet Med 1998; 15: 539-553.

24. Lindheimer MD and Kanter D. Interpreting abnormal proteinuria in pregnancy: the need for a more pathophysiological approach. Obstet Gynecol 2010; 115: 365-375.

25. Schutte JM, Schuitemaker NW, van Roosmalen J, Steegers EA and Dutch Maternal Mortality C. Substandard care in maternal mortality due to hypertensive disease in pregnancy in the Netherlands. BJOG 2008; 115: 732-736.
26. Ackerman CM, Platner MH, Spatz ES, IIluzzi JL, Xu X, Campbell KH, et al. Severe cardiovascular morbidity in women with hypertensive diseases during delivery hospitalization. Am J Obstet Gynecol 2019; 220: 582 e581-582 e511.

27. Magee LA, Yong PJ, Espinosa V, Cote AM, Chen I and von Dadelszen P. Expectant management of severe preeclampsia remote from term: a structured systematic review. Hypertens Pregnancy 2009; 28: 312-347.

28. Ganzevoort W and Sibai BM. Temporising versus interventionist management (preterm and at term). Best Pract Res Clin Obstet Gynaecol 2011; 25: 463-476.

29. Churchill D, Duley L, Thornton JG, Moussa M, Ali HS and Walker KF. Interventionist versus expectant care for severe preeclampsia between 24 and 34 weeks' gestation. Cochrane Database Syst Rev 2018; 10: CD003106.

30. Abramovici D, Friedman SA, Mercer BM, Audibert F, Kao L and Sibai BM. Neonatal outcome in severe preeclampsia at 24 to 36 weeks' gestation: does the HELLP (hemolysis, elevated liver enzymes, and low platelet count) syndrome matter? Am J Obstet Gynecol 1999; 180: 221-225.

31. Haddad B, Deis S, Goffinet F, Paniel BJ, Cabrol D and Siba BM. Maternal and perinatal outcomes during expectant management of 239 severe preeclamptic women between 24 and 33 weeks' gestation. Am J Obstet Gynecol 2004; 190: 1590-1595; discussion 1595-1597.

32. Draper ES, Manktelow B, Field DJ and James D. Prediction of survival for preterm births by weight and gestational age: retrospective population based study. BMJ 1999; 319: 1093-1097.

33. Witlin AG, Saade GR, Mattar F and Sibai BM. Predictors of neonatal outcome in women with severe preeclampsia or eclampsia between 24 and 33 weeks' gestation. Am J Obstet Gynecol 2000; 182: 607-611. 
34. Mateus J, Newman RB, Zhang C, Pugh SJ, Grewal J, Kim S, et al. Fetal growth patterns in pregnancy-associated hypertensive disorders: NICHD Fetal Growth Studies. Am J Obstet Gynecol 2019; 221: 635 e631-635 e616.

35. Melchiorre K, Sharma R, Khalil A and Thilaganathan B. Maternal Cardiovascular Function in Normal Pregnancy: Evidence of Maladaptation to Chronic Volume Overload. Hypertension 2016; 67: 754-762.

36. Orabona R, Sciatti E, Vizzardi E, Bonadei I, Prefumo F, Valcamonico A, et al. Ultrasound evaluation of left ventricular and aortic fibrosis after pre-eclampsia. Ultrasound Obstet Gynecol 2018; 52: 648-653.

37. de Haas S, Ghossein-Doha C, Geerts L, van Kuijk SM, van Drongelen J and Spaanderman ME. Cardiac remodelling during normotensive and hypertensive complicated pregnancies: a systematic review and meta-analysis. Ultrasound Obstet Gynecol 2017

38. Valensise H, Lo Presti D, Gagliardi G, Tiralongo GM, Pisani I, Novelli GP, et al. Persistent Maternal Cardiac Dysfunction After Preeclampsia Identifies Patients at Risk for Recurrent Preeclampsia. Hypertension 2016; 67: 748-753.

39. Fagard $\mathrm{RH}$, Celis $\mathrm{H}$, Thijs $\mathrm{L}$ and Wouters $\mathrm{S}$. Regression of left ventricular mass by antihypertensive treatment: a meta-analysis of randomized comparative studies. Hypertension 2009; 54: 1084-1091.

40. Chong J, Fotheringham J, Tomson C and Ellam T. Renal albumin excretion in healthy young adults and its association with mortality risk in the US population. Nephrol Dial Transplant 2018

41. Hladunewich MA, Myers BD, Derby GC, Blouch KL, Druzin ML, Deen WM, et al. Course of preeclamptic glomerular injury after delivery. Am J Physiol Renal Physiol 2008; 294: F614-620.

42. Stehouwer CD and Smulders YM. Microalbuminuria and risk for cardiovascular dis- ease: Analysis of potential mechanisms. $J$ Am Soc Nephrol 2006; 17: 2106-2111.

43. Eremina V, Sood M, Haigh J, Nagy A, Lajoie $\mathrm{G}$, Ferrara $\mathrm{N}$, et al. Glomerular-specific alterations of VEGF-A expression lead to distinct congenital and acquired renal diseases. J Clin Invest 2003; 111: 707-716.

44. Foster RR, Hole R, Anderson K, Satchell SC, Coward RJ, Mathieson PW, et al. Functional evidence that vascular endothelial growth factor may act as an autocrine factor on human podocytes. Am J Physiol Renal Physiol 2003; 284: F1263-1273.

45. Wharram BL, Goyal M, Wiggins JE, Sanden SK, Hussain S, Filipiak WE, et al. Podocyte depletion causes glomerulosclerosis: diphtheria toxin-induced podocyte depletion in rats expressing human diphtheria toxin receptor transgene. J Am Soc Nephrol 2005; 16: 2941-2952.

46. Erkan E. Proteinuria and progression of glomerular diseases. Pediatr Nephrol 2013; 28: 1049-1058.

47. Peired A, Angelotti ML, Ronconi E, la Marca G, Mazzinghi B, Sisti A, et al. Proteinuria impairs podocyte regeneration by sequestering retinoic acid. J Am Soc Nephrol 2013; 24: 1756-1768.

48. Scholten RR, Hopman MT, Lotgering FK and Spaanderman ME. Aerobic Exercise Training in Formerly Preeclamptic Women: Effects on Venous Reserve. Hypertension 2015; 66: 1058-1065.

49. Parati G, Ochoa JE and Bilo G. Blood pressure variability, cardiovascular risk, and risk for renal disease progression. Curr Hypertens Rep 2012; 14: 421-431.

50. Bos MB, de Vries JH, Wolffenbuttel BH, Verhagen $\mathrm{H}$, Hillege $\mathrm{JL}$ and Feskens EJ. [The prevalence of the metabolic syndrome in the Netherlands: increased risk of cardiovascular diseases and diabetes mellitus type 2 in one quarter of persons under 60]. Ned Tijdschr Geneeskd 2007; 151: 2382-2388. 
51. Solomon CG, Graves SW, Greene MF and Seely EW. Glucose intolerance as a predictor of hypertension in pregnancy. Hypertension 1994; 23: 717-721.

52. Wiznitzer A, Mayer A, Novack V, Sheiner E, Gilutz H, Malhotra A, et al. Association of lipid levels during gestation with preeclampsia and gestational diabetes mellitus: a population-based study. $\mathrm{Am} \mathrm{J}$ Obstet Gynecol 2009; 201: 482 e481-488.
53. Adank MC, Benschop L, Peterbroers KR, Smak Gregoor AM, Kors AW, Mulder MT, et al. Is maternal lipid profile in early pregnancy associated with pregnancy complications and blood pressure in pregnancy and long term postpartum? Am J Obstet Gynecol 2019; 221: 150 e151-150 e113. 


\section{SUPPLEMENTAL MATERIAL}

Table S1. Characteristics of women with preeclampsia before 24 weeks' gestation or who presented with stillbirth admitted to the postpartum assessment within 2 years after delivery.

\begin{tabular}{|c|c|c|}
\hline & $\begin{array}{l}\text { Women presenting with } \\
\text { stillbirth }\end{array}$ & $\begin{array}{l}\text { Women with onset of } \\
\text { preeclampsia before } \\
24 \text { weeks' gestation }\end{array}$ \\
\hline Pregnancy outcome & $\mathrm{n}=7$ & $n=23$ \\
\hline Gestational age at diagnosis & $28^{3}\left[26^{4}-32^{0}\right]$ & $22^{3}\left[21^{1}-23^{0}\right]$ \\
\hline Gestational age at delivery & $28^{4}\left[27^{0}-32^{0}\right]$ & $25^{2}\left[24^{0}-27^{4}\right]$ \\
\hline HELLP syndrome & $5 / 7(71 \%)$ & $14 / 23(61 \%)$ \\
\hline Eclampsia & $0 / 7$ & $2 / 23(9 \%)$ \\
\hline Birthweight (grams) & $840[770-1352]$ & $520[380-790]$ \\
\hline Birthweight centile & $5[3-25]$ & $4[0-7]$ \\
\hline Multifetal pregnancy & $0 / 7$ & $0 / 23$ \\
\hline SGA neonate & $4 / 7(57 \%)$ & $19 / 23(83 \%)$ \\
\hline Placental abruption & $1 / 7(14 \%$ & $2 / 22(9 \%)$ \\
\hline \multicolumn{3}{|l|}{ Offspring demise } \\
\hline Stillbirth & $7 / 7$ & $15 / 23(65 \%)$ \\
\hline Infant mortality & NA & $1 / 23(4 \%)$ \\
\hline Time to assessment (months) & $6[5-7]$ & $6[5-10]$ \\
\hline \multicolumn{3}{|l|}{ Cardiac parameters } \\
\hline Left ventricular mass index $\left(\mathrm{g} / \mathrm{m}^{2}\right)$ & $68[48-83]$ & $69[57-83]$ \\
\hline Relative wall thickness & $0.36[0.32-0.38]$ & $0.34[0.31-0.36]$ \\
\hline Ejection fraction (\%) & 63 [59-65] & $64[62-67]$ \\
\hline \multicolumn{3}{|l|}{ Renal parameters } \\
\hline Albuminuria (g/mol creatinine) & $0.9[0.3-1.5]$ & $1.5[0.6-8.7]$ \\
\hline Proteinuria (g/mol creatinine) & $8.2[6.8-38.6]$ & $10.9[6.1-19.0]$ \\
\hline Creatinine clearance $\left(\mathrm{ml} / \mathrm{min} / 1.73 \mathrm{~m}^{2}\right)$ & $101[90-107]$ & $100[93-117]$ \\
\hline \multicolumn{3}{|l|}{ Vascular function } \\
\hline Systolic blood pressure (mmHg) & $113[112-117]$ & 117 [114-129] \\
\hline Diastolic blood pressure (mmHg) & $73[65-76]$ & 78 [64-82] \\
\hline Pulse pressure & $44[40-48]$ & $45[37-55]$ \\
\hline Hypertension & $1 / 7(14 \%)$ & $8 / 22(36 \%)$ \\
\hline Antihypertensive medication & $0 / 7$ & $7 / 23(30 \%)$ \\
\hline \multicolumn{3}{|l|}{ Compliance } \\
\hline Stroke volume/pulse pressure & $1.47[1.31-1.55]$ & $1.46[1.23-1.77]$ \\
\hline Metabolic syndrome & $2 / 7(29 \%)$ & $4 / 23(17 \%)$ \\
\hline Hyperinsulinemia & $3 / 7(43 \%)$ & $10 / 23(43 \%)$ \\
\hline Insulin (mU/L) & $6.6[6.1-10.5]$ & $9.2[6.1-15.0]$ \\
\hline Glucose (mmol/L) & $5.0[4.7-5.4]$ & $4.9[4.8-5.1]$ \\
\hline
\end{tabular}


Table S1. (continued)

\begin{tabular}{|lll}
\hline & $\begin{array}{l}\text { Women presenting with } \\
\text { stillbirth }\end{array}$ & $\begin{array}{l}\text { Women with onset of } \\
\text { preeclampsia before } \\
\text { 24 weeks' gestation }\end{array}$ \\
\hline HOMA-IR & $1.70[1.27-2.22]$ & $1.97[1.31-3.35]$ \\
\hline Obesity & $3 / 7(43 \%)$ & $4 / 23(17 \%)$ \\
\hline Body mass index $\left(\mathbf{k g} / \mathbf{m}^{2}\right)$ & $29.2[19.5-35.2]$ & $25.2[20.8-27.5]$ \\
\hline Dyslipidaemia & $3 / 7(43 \%)$ & $6 / 23(26 \%)$ \\
\hline Triglycerides $(\mathbf{m m o l} / \mathbf{L})$ & $1.24[0.83-2.46]$ & $1.11[0.77-1.84]$ \\
\hline HDL-cholesterol (mmol/L) & $1.5[1.1-1.8]$ & $1.3[1.1-1.4]$ \\
\hline Albuminuria or proteinuria & $1 / 7(14 \%)$ & $8 / 23(35 \%)$ \\
\hline
\end{tabular}

Data are presented as mean (standard deviation), median [interquartile range], or number/valid measurements (percentage in group). HOMA-IR indicates homeostatic model assessment for insulin resistance; HDL, high-density lipoprotein.

Table S2. Pregnancy prolongation and postpartum maternal cardiovascular, renal and metabolic function

\begin{tabular}{|c|c|c|c|c|c|}
\hline & \multirow[t]{2}{*}{ Total } & \multicolumn{3}{|c|}{ Pregnancy prolongation after diagnosis } & \multirow[b]{3}{*}{$P$-value ${ }^{\star}$} \\
\hline & & $\leq 6$ days & 7-13 days & $\geq 14$ days & \\
\hline & $n=564$ & $n=186$ & $n=173$ & $n=205$ & \\
\hline Antihypertensive medication & $69 / 564(12 \%)$ & $24 / 186(13 \%)$ & $17 / 173(10 \%)$ & $28 / 205(14 \%)$ & 0.451 \\
\hline Insulin (mU/L) & $9.4[6.6-14.0]$ & $9.3[6.5-14.0]$ & $9.8[6.8-15.0]$ & $9.4[6.5-13.7]$ & 0.304 \\
\hline Glucose (mmol/L) & $5.1[4.8-5.4]$ & $5.0[4.8-5.4]$ & $5.1[4.8-5.4]$ & $5.1[4.9-5.3]$ & 0.716 \\
\hline HOMA-IR & $2.13[1.47-3.21]$ & $2.11[1.46-3.27]$ & $2.14[1.51-3.33]$ & $2.14[1.43-3.18]$ & 0.354 \\
\hline BMI $\left(\mathrm{kg} / \mathrm{m}^{2}\right)$ & $25.1[22.2-28.9]$ & $26.3(5.2)$ & $25.8(5.3)$ & $26.3(5.2)$ & 0.862 \\
\hline Triglycerides (mmol/L) & $0.93[0.67-1.33]$ & $0.96[0.68-1.28]$ & $0.94[0.69-1.37]$ & $0.92[0.64-1.36]$ & 0.466 \\
\hline HDL-cholesterol (mmol/L) & $1.3[1.1-1.5]$ & $1.3[1.1-1.5]$ & $1.3[1.2-1.5]$ & $1.3[1.1-1.6]$ & 0.125 \\
\hline
\end{tabular}

Data are presented as median [interquartile range], or number/valid measurements (percentage in group). ${ }^{\star} P$-value indicates trend based on regression analysis with pregnancy prolongation (days) used as a continuous variable. HOMA-IR indicates homeostatic model assessment for insulin resistance; HDL, high-density lipoprotein. 
Table S3. Association between pregnancy prolongation after preeclampsia diagnosis (days) and offspring outcome.

\begin{tabular}{|c|c|c|c|c|}
\hline & Odds ratio $(95 \% \mathrm{Cl})$ & $P$-value & $\begin{array}{l}\text { Adjusted odds ratio* } \\
(95 \% \mathrm{CI})\end{array}$ & $P$-value \\
\hline Small-for-gestational-age neonate & $1.009(0.994-1.024)$ & 0.255 & $0.997(0.981-1.013)$ & 0.704 \\
\hline Placental abruption & $0.956(0.904-1.010)$ & 0.109 & $0.947(0.892-1.005)$ & 0.070 \\
\hline \multicolumn{5}{|l|}{ Offspring demise } \\
\hline Stillbirth & $0.979(0.912-1.051)$ & 0.559 & $0.869(0.758-0.995)$ & 0.042 \\
\hline Infant mortality & $0.952(0.909-0.998)$ & 0.042 & $0.907(0.852-0.965)$ & 0.002 \\
\hline & \multicolumn{4}{|c|}{ Univariate linear regression } \\
\hline & \multicolumn{2}{|l|}{$\beta$-coefficient $(95 \% \mathrm{CI})$} & \multicolumn{2}{|c|}{ Adjusted $\beta$-coefficient* $(95 \% \mathrm{CI})$} \\
\hline Birthweight (grams) & $14.8(11.1-18.5)$ & $<0.001$ & $24.3(22.4-26.1)$ & $<0.001$ \\
\hline Birthweight centile & $-0.02(-0.14-0.11)$ & 0.805 & $0.09(-0.03-0.21)$ & 0.154 \\
\hline
\end{tabular}

*Adjusted for gestational age at onset preeclampsia, concomitant HELLP syndrome and/or eclampsia, and year of postpartum assessment 



\title{
RECURRENCE RATES OF PREECLAMPSIA OVER THE PAST 20 YEARS IN WOMEN ASSESSED FOR NON-PREGNANT CARDIOVASCULAR RISK FACTORS
}

\author{
Eva G. Mulder \\ Chahinda Ghossein-Doha \\ Frederique E.M. Froeling \\ Sander M.J. van Kuijk \\ Marc E.A. Spaanderman
}

Pregnancy Hypertension. 2018 October 14: 150-155. doi: 10.1016/j.preghy.2018.09.006. 


\section{ABSTRACT}

Objective: Several efforts to reduce recurrent preeclampsia have been implemented in clinical practice in the past decades. We assessed whether recurrence rates of preeclampsia and related offspring complications decreased in the past 20 years in women who received tailored preventive advices.

Study design: In this observational cohort study, we included 752 women who had their first pregnancy complicated by preeclampsia between 1996 and 2012, and who participated in a non-pregnant risk factor assessment. A questionnaire was sent to women to follow-up on their next pregnancy outcome.

Main outcome measures: Prevalence of preeclampsia and related offspring complications in the subsequent pregnancy.

Results: 467 (62\%) women responded to the questionnaire of which two-thirds had a subsequent ongoing pregnancy. Recurrent preeclampsia occurred in $29 \%$ of women who delivered between 1997 and 2004, in 20\% of women who delivered between 2005 and 2009, and in 24\% of women who delivered between 2010 and 2016 (overall $P$-value $=0.319$ ). Combined maternal complications did not change over time (OR 0.98 per year, $95 \% \mathrm{Cl} 0.93-1.04, P$-value $=0.503)$. Offspring complications in the subsequent pregnancy decreased over time with an OR of $0.92(95 \% \mathrm{Cl} 0.86-0.98, P=0.009)$ per year.

Conclusion: Recurrence rates of preeclampsia did not decrease over the past 20 years in women who have been extensively assessed on cardiovascular risk factors. In the same period, foetal and neonatal outcomes improved substantially. Efforts to extend and improve strategies to reduce recurrence risk of preeclampsia still seem to be necessary.

Keywords: Preeclampsia, recurrent disease; cardiovascular assessment, metabolic syndrome. 


\section{INTRODUCTION}

Preeclampsia (PE) is one of the leading causes of maternal and neonatal morbidity and mortality in the Western world, complicating 5-10\% of all pregnancies. ${ }^{1}$ Recurrence rates of $\mathrm{PE}$ in studies range from 7 to $80 \%$, depending on studied population., ${ }^{2}$ On the one hand, recurrence rates are related to outcome of the first pregnancy, and rise with earlier onset of PE, co-occurrence of the HELLP syndrome (Haemolysis, Elevated Liver enzymes, Low Platelet count), and delivery of a small-for-gestational-age (SGA) infant. ${ }^{2}$ On the other hand, underlying maternal constitutional factors consistent with the metabolic syndrome, including high body mass index (BMI), insulin resistance, unfavourable lipid profile and elevated blood pressure, relate to an elevated risk of recurrent disease. ${ }^{3-6}$ Increased recognition of these metabolic risk factors offers the possibility to counsel on lifestyle adjustments, even before the next pregnancy.

Over the recent decennia, diverse other measures to prevent recurrent PE have been evaluated and partly implemented in clinical practice. If initiated timely, low-dose aspirin and calcium supplementation improve pregnancy outcome regarding hypertensive complications. ${ }^{7,8}$ Physicians often advise high-risk women to take these preventive measures, but in absence of recommendations in national guidelines, penetrance is far from complete. Prophylactic anticoagulation, even in women with hereditary thrombophilia, is controversial, and conflicting results of studies may withhold physicians to prescribe low-molecular-weight heparins. ${ }^{9}$ Once hypertensive complications arise during pregnancy, women may benefit from antihypertensive treatment and timely induction of labour. ${ }^{10-12}$ In the meantime, measures to improve neonatal outcome have also emerged, including corticosteroid courses when preterm birth is imminent, surfactant therapy since the early 1990 s and development of enhanced neonatal ventilation techniques. ${ }^{13-15}$

In this study, we assessed whether the precautions and taken efforts to improve health care resulted in a decline in recurrence rates of PE and improved offspring outcome over the past 20 years.

\section{METHODS}

\section{Study Population}

The hospital medical ethical committee of the Maastricht University Medical Centre (MUMC) approved the study protocol (MEC azM/UM 17-4-004). This study was conducted in women admitted to a cardiovascular and cardiometabolic risk assessment in the 
MUMC after their first pregnancy was complicated by PE. This assessment took place at least 4 months, but more often longer postpartum. Studying this population overcomes the effect of increasing prevalence of metabolic syndrome in young women on recurrence rates. ${ }^{16}$ Evaluation is accessible to all women in the country, and approximately $75 \%$ of women are referred by physicians of other hospitals, who mainly refer women with a history of severe PE. Over the years, the number of referrals has increased, and capacity for assessment was enlarged. All women assessed between 1996 and 2012 received a short questionnaire per electronic mail or post mail, designed to evaluate outcome of possible subsequent pregnancies, including information on date of birth, gestational age at delivery, birthweight and sex of the neonate, and the occurrence of any complications during that pregnancy. Data of women who responded to the questionnaire were used in the analysis.

\section{Definitions}

PE was defined based on the International Society for the Study of Hypertension in Pregnancy criteria as de novo hypertension with a systolic blood pressure (BP) $\leq 140 \mathrm{mmHg}$ and/or diastolic BP $\geq 90 \mathrm{mmHg}$ in 2 repeated measurements (at least $6 \mathrm{~h}$ apart) and the co-occurrence of proteinuria ( $\geq 0.3 \mathrm{~g} / 24 \mathrm{~h}$ or $\geq 2+$ on dipstick analysis) occurring after 20 weeks of gestation in previously normotensive women or when proteinuria developed $>20$ weeks of gestation in women with pre-existing hypertension. ${ }^{17}$ Early-onset PE was defined as PE diagnosed before 34 weeks of pregnancy. ${ }^{18}$ SGA infancy was defined as neonatal birthweight below the $10^{\text {th }}$ percentile of the national birthweight charts, and corrected for sex of the neonate and parity. ${ }^{19}$ Offspring complications were foetal and neonatal complications, and were defined as placental abruption, stillbirth, SGA and/or neonatal death (within the first 28 days of life). Preterm delivery was defined as delivery before 37 weeks and extreme preterm delivery before 34 weeks of gestational age.

\section{Cardiovascular assessment}

Assessment of cardiovascular and metabolic risk factors was performed in one session. Glucose, insulin, triglycerides and high-density lipoprotein (HDL) cholesterol levels were obtained from fasting blood samples. BMI was calculated by dividing bodyweight (kg) by the square height (meters). Arterial blood pressure was measured in sitting position by a semiautomatic oscillometric device (Dinamap Vital Signs Monitor 1846; Critikon, Tampa, FL). The median value of 11 measurements was reported. Urine was collected in the $24 \mathrm{~h}$ preceding the measurements, and assayed for micro-albumin, creatinine and total protein. Metabolic syndrome was diagnosed based on slightly adjusted World Health Organization criteria as follows: hyperinsulinemia (fasting insulin $>9.2 \mathrm{mU} / \mathrm{L}$, fasting glucose $>6.1 \mathrm{mmol} / \mathrm{L}$, and/or homeostasis model assessment-insulin resistance (HOMA-IR) $>2.2$ ) along with 2 or more of the following: (1) obesity (BMI $\left.>30 \mathrm{~kg} / \mathrm{m}^{2}\right),(2)$ 
dyslipidaemia (triglycerides $\geq 1.7 \mathrm{mmol} / \mathrm{L}$ or HDL-cholesterol $<0.9 \mathrm{mmol} / \mathrm{L}$ ), (3) hypertension (systolic blood pressure $\geq 140 \mathrm{mmHg}$, diastolic blood pressure $\geq 90 \mathrm{mmHg}$ and/or the use of antihypertensive medication), (4) microalbuminuria (>2.5 g/mol creatinine) or proteinuria $(>0.3 \mathrm{~g} / 24 \mathrm{~h}) .{ }^{20}$ The adjustment relates to including BMI instead of abdominal circumference. After assessment, women were counselled and advised on the risk factors and possibilities to modify them (i.e. regularly exercise, dietary advice) in a single consultation. Moreover, general preventive measures in the next pregnancy applicable at time of assessment were advised. No standardized advice on birth spacing was given to the women. If indicated, treatment was initiated or intensified in consultation with the woman's referring physician, who was responsible for the subsequent care.

\section{Statistical analysis}

We divided women who responded to the questionnaire in three subgroups based on year of second delivery. Group 1 delivered between 1997 and 2004, group 2 between 2005 and 2009, and group 3 between 2010 and 2016. Categorical variables were compared between the 3 groups using Pearson's Chi-square test if more than 5 cases were present in each group, and Fishers Exact test if less than 5 cases were present. Normally distributed continuous data were compared using analysis of variance (ANOVA), and expressed as mean with standard deviations. Kruskal Wallis test was used in case of skewness, and results were reported as median with interquartile range. Multiple logistic regression was performed to adjust for differences between groups in pregnancy characteristics and metabolic syndrome determined during the inter-pregnancy cardiovascular assessment. In addition, with logistic regression the association between year of delivery as a continuous variable and PE and related offspring complications was estimated. A two-sided p-value $\leq 0.05$ was considered statistically significant. Missing values of less than $5 \%$ within a variable were considered acceptable and subsequently complete case analysis was used. All statistical analyses were performed using IBM SPSS Statistics version 20.

\section{RESULTS}

Of the 752 women who were admitted for postpartum assessment after their first pregnancy complicated by PE, 467 (62\%) women responded to the questionnaire (Figure 1). Table 1 presents the characteristics of women who responded to the questionnaire and women who did not. Non-responders were slightly younger at delivery (29.0 vs. 30.0 years, $p<0.001$ ). Neither gestational age at delivery nor early-onset PE, co-occurrence of eclampsia, placental abruption, stillbirth, SGA or neonatal death in the first pregnancy was different between the responders and non-responders. Prevalence of concomitant HELLP syndrome in the index pregnancy was lower in the non-responders group $63 \%$ 
vs. $74 \%$, respectively, $p=0.001$ ). Non-responders had an unfavourable cardio-metabolic profile during the postpartum assessment compared with the responders. Of the 467 responders, 147 (31\%) did not conceive again or had a miscarriage. Three subsequent pregnancies were excluded because of congenital or chromosomal foetal abnormalities, resulting in 317 (68\%) women who had an ongoing second pregnancy. Between 1997 and 2004 (group 1), 99 women (31\%) delivered again, between 2005 and 2009 (group 2), 99 women (31\%) and between 2010 and 2016 (group 3), 119 women (37\%) delivered a second time.

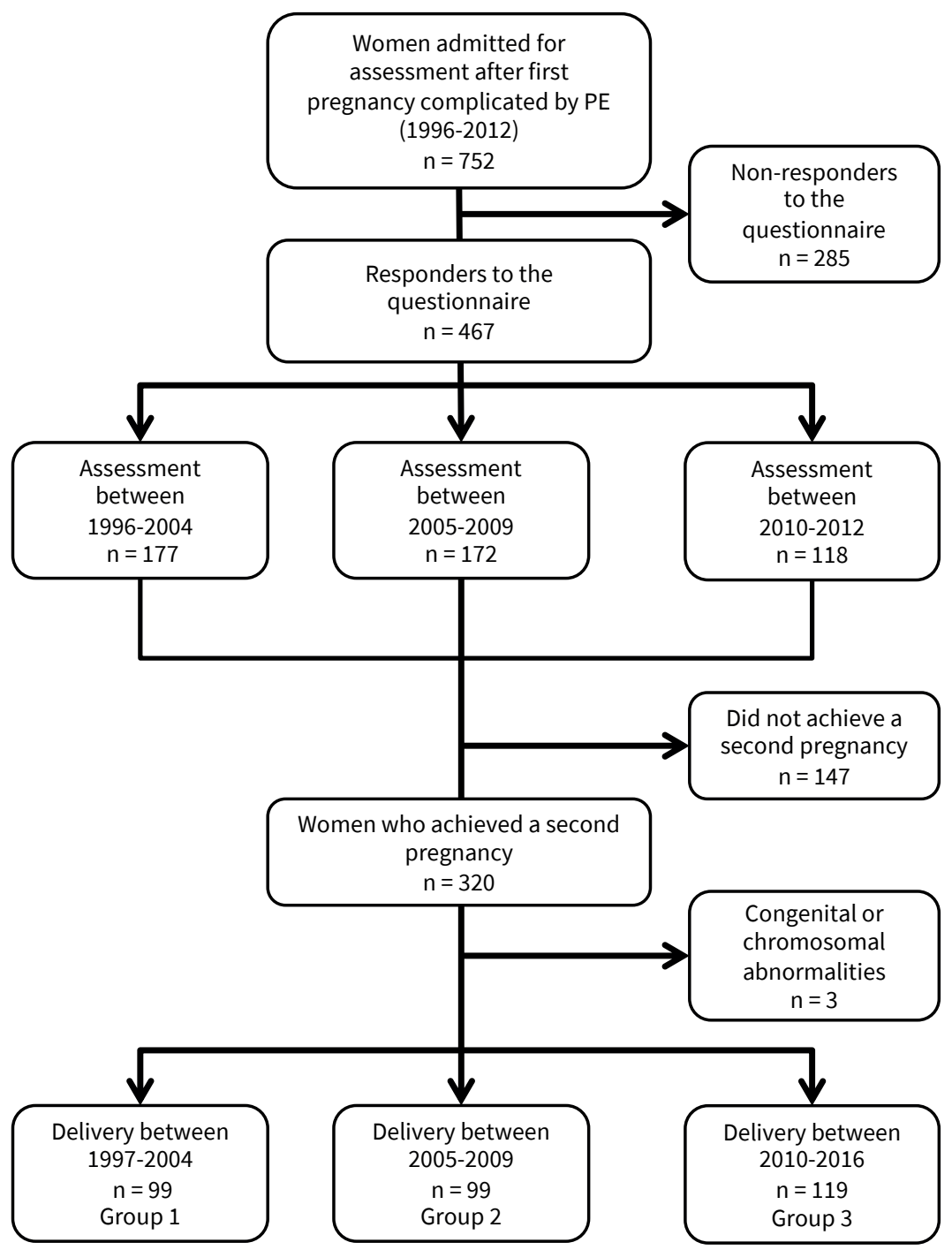

Figure 1. Flow diagram of study population enrolment. 
Table 1. Obstetric history and cardiovascular risk factors at assessment of women who responded to the questionnaire and the non-responders.

\begin{tabular}{|c|c|c|c|}
\hline Characteristic & $\begin{array}{l}\text { Responders } \\
(n=467)\end{array}$ & $\begin{array}{l}\text { Non-responders } \\
(n=285)\end{array}$ & p-value \\
\hline \multicolumn{4}{|l|}{ Index pregnancy } \\
\hline Maternal age, y & $30.0[27.0-32.0]$ & $29.0[25.0-31.0]$ & $<0.001$ \\
\hline Multifetal pregnancies, \% & 3 & 4 & 0.952 \\
\hline GA at delivery, w & $33^{4}\left[30^{2}-36^{0}\right]$ & $33^{1}\left[30^{0}-36^{0}\right]$ & 0.737 \\
\hline Early-onset PE, \% & 67 & 69 & 0.487 \\
\hline HELLP syndrome, \% & 74 & 63 & 0.001 \\
\hline Eclampsia, \% & 10 & 8 & 0.337 \\
\hline SGA, \% & 29 & 33 & 0.221 \\
\hline Placental abruption, \% & 4 & 2 & 0.147 \\
\hline Stillbirth, \% & 5 & 5 & 0.837 \\
\hline Neonatal death, $\%$ & 3 & 5 & 0.140 \\
\hline \multicolumn{4}{|l|}{ Characteristics at evaluation } \\
\hline Interval between delivery - evaluation, m & $9[6-17]$ & $11[6-24]$ & 0.095 \\
\hline Metabolic syndrome, \% & 12 & 16 & 0.156 \\
\hline Glucose, mmol/l & $5.1[4.8-5.4]$ & $5.1[4.8-5.5]$ & 0.942 \\
\hline Insulin, iU/L & $8.7[6.1-13.0]$ & $9.9[6.6-14.9]$ & 0.019 \\
\hline HOMA-IR & $2.0[1.4-3.0]$ & $2.2[1.5-3.4]$ & 0.041 \\
\hline $\mathrm{BMI}, \mathrm{kg} / \mathrm{m}^{2}$ & $24.3[21.6-27.7]$ & $25.1[22.3-28.9]$ & 0.026 \\
\hline Triglycerides, mmol/l & $0.83[0.61-1.19]$ & $0.91[0.68-1.30]$ & 0.025 \\
\hline $\mathrm{HDL}, \mathrm{mmol} / \mathrm{l}$ & $1.30[1.10-1.50]$ & $1.30[1.10-1.50]$ & 0.033 \\
\hline Systolic blood pressure, $\mathrm{mmHg}$ & 114 [108-123] & $116[108-126]$ & 0.279 \\
\hline Diastolic blood pressure, $\mathrm{mmHg}$ & $72[66-77]$ & $72[67-78]$ & 0.491 \\
\hline Antihypertensive medication, \% & 14 & 14 & 0.964 \\
\hline $24 \mathrm{~h}$ protein excretion, $\mathrm{g} / 24 \mathrm{~h}$ & $0.07[0.05-0.12]$ & $0.08[0.06-0.14]$ & 0.022 \\
\hline Microalbuminuria, $\mathrm{g} / \mathrm{mol}$ creatinine & $1.0[0.5-2.2]$ & $1.0[0.6-2.2]$ & 0.945 \\
\hline
\end{tabular}

Data are presented as percentage, mean (SD) or median [interquartile range] within group. GA indicates gestational age; $P E$, preeclampsia; HELLP syndrome, Haemolysis, Elevated Liver Enzymes, Low Platelets syndrome; SGA, small-for-gestationalage; HOMA-IR, Homeostatic Model Assessment-Insulin Resistance; BMI, body mass index; HDL, high-density lipoprotein

Table 2 presents the obstetric characteristics of the index pregnancy and postpartum cardiovascular and metabolic risk factors categorized in groups by year of second delivery. Maternal age, prevalence of multifetal pregnancies, eclampsia, stillbirth and placental abruption at index pregnancy did not differ between the three groups. Group 1 had the lowest gestational age at delivery, and the highest prevalence of early-onset PE, concurrent HELLP syndrome, SGA and neonatal death in the index pregnancy. With respect to the metabolic variables, group 1 had the highest levels of fasting insulin and HOMA-IR values, and the highest HDL levels. Blood pressure was higher in women in group 1. BMI, glucose, triglycerides, $24 \mathrm{~h}$ protein excretion and microalbuminuria did not differ between groups. 
Table 2. Obstetric characteristics of the index pregnancy and cardiovascular characteristics at postpartum assessment.

\begin{tabular}{|c|c|c|c|c|}
\hline Characteristic & $\begin{array}{l}\text { Group } 1 \\
\text { 1997-2004 } \\
n=99\end{array}$ & $\begin{array}{l}\text { Group } 2 \\
2005-2009 \\
n=99\end{array}$ & $\begin{array}{l}\text { Group } 3 \\
2010-2016 \\
n=119\end{array}$ & p-value \\
\hline \multicolumn{5}{|l|}{ Index pregnancy } \\
\hline Maternal age, y & $29.0[26.0-30.0]$ & $29.0[27.0-31.0]$ & $29.0[26.0-31.0]$ & 0.142 \\
\hline Multifetal pregnancy, \% & 0 & 2 & 0 & 0.109 \\
\hline GA at delivery, w & $32^{0}\left[28^{3}-35^{2}\right]$ & $34^{0}\left[31^{6}-36^{5}\right]$ & $33^{4}\left[30^{5}-36^{2}\right]$ & 0.002 \\
\hline Early-onset PE, \% & 78 & 63 & 64 & 0.037 \\
\hline HELLP syndrome, $\%$ & 80 & 77 & 66 & 0.028 \\
\hline Eclampsia, \% & 8 & 14 & 8 & 0.272 \\
\hline SGA, \% & 40 & 30 & 23 & 0.026 \\
\hline Placental abruption, \% & 6 & 4 & 5 & 0.810 \\
\hline Stillbirth, \% & 6 & 5 & 7 & 0.874 \\
\hline Neonatal death, \% & 11 & 0 & 3 & $<0.001$ \\
\hline \multicolumn{5}{|l|}{ Characteristics at evaluation } \\
\hline Interval between delivery and evaluation, $\mathrm{m}$ & $10[6-18]$ & $9[7-14]$ & $8[6-14]$ & 0.205 \\
\hline Metabolic syndrome, \% & 12 & 8 & 13 & 0.522 \\
\hline Glucose, mmol/l & $5.1[4.8-5.4]$ & $5.0[4.8-5.2]$ & $5.1[4.9-5.4]$ & 0.062 \\
\hline Insulin, iU/L & $9.6[7.5-15.0]$ & $9.0[6.1-14.0]$ & $7.5[5.3-11.0]$ & $<0.001$ \\
\hline HOMA-IR & $2.3[1.7-3.4]$ & $2.1[1.3-3.2]$ & $1.7[1.2-2.6]$ & 0.002 \\
\hline $\mathrm{BMI}, \mathrm{kg} / \mathrm{m}^{2}$ & $23.7[21.5-26.9]$ & $24.4[21.5-27.8]$ & $24.1[21.8-27.6]$ & 0.432 \\
\hline Triglycerides, mmol/l & $0.83[0.54-1.18]$ & $0.77[0.56-1.18]$ & $0.86[0.69-1.21]$ & 0.107 \\
\hline $\mathrm{HDL}, \mathrm{mmol} / \mathrm{l}$ & $1.4[1.2-1.6]$ & $1.3[1.1-1.5]$ & $1.3[1.1-1.5]$ & 0.002 \\
\hline Systolic blood pressure, $\mathrm{mmHg}$ & $119[111-129]$ & $115[107-126]$ & $113[106-120]$ & $<0.001$ \\
\hline Diastolic blood pressure, $\mathrm{mmHg}$ & 75 [67-82] & 71 [66-77] & 72 [67-75] & 0.020 \\
\hline Antihypertensive medication, $\%$ & 11 & 9 & 16 & 0.278 \\
\hline $24 \mathrm{~h}$ protein excretion, $\mathrm{g} / 24 \mathrm{~h}$ & $0.06[0.05-0.11]$ & $0.07[0.05-0.10]$ & $0.07[0.05-0.13]$ & 0.127 \\
\hline Microalbuminuria, g/mol creatinine & $1.1[0.6-2.2]$ & $0.9[0.5-2.2]$ & $1.1[0.6-2.7]$ & 0.795 \\
\hline
\end{tabular}

Data are presented as percentage, mean (SD) or median [interquartile range] within group. GA indicates gestational age; PE, preeclampsia; HELLP syndrome, Haemolysis, Elevated Liver Enzymes, Low Platelets syndrome; SGA, small-for-gestational-age; m, months; HOMA-IR, homeostatic model assessment-Insulin Resistance; BMI, body mass index; HDL, highdensity lipoprotein

Table 3 presents the prevalence of the obstetric complications in the subsequent pregnancy. The overall recurrence rate of PE in our population was $24.3 \%$ (77/317). The prevalence of recurrent PE did not differ between the three groups, nor did the prevalence of recurrent early-onset PE. In addition, the prevalence of HELLP syndrome and eclampsia in the subsequent pregnancy did not differ. After adjustment for HELLP syndrome and SGA in index pregnancy (yes/no), metabolic syndrome at non-pregnant assessment (yes/no), inter-delivery interval (months), and the use of aspirin and/or calcium (yes/no) 
Table 3. Outcome of the subsequent ongoing pregnancy in women with history of preeclampsia.

\begin{tabular}{|c|c|c|c|c|}
\hline & $\begin{array}{l}\text { Group } 1 \\
1997-2004 \\
n=99\end{array}$ & $\begin{array}{l}\text { Group } 2 \\
2005-2009 \\
n=99\end{array}$ & $\begin{array}{l}\text { Group } 3 \\
2010-2016 \\
n=119\end{array}$ & $P$ value \\
\hline \multicolumn{5}{|l|}{ Maternal complications } \\
\hline Total, \% & 31 & 23 & 24 & 0.328 \\
\hline aOR $(95 \% \mathrm{Cl})$ & Ref & $0.90(0.43-1.89)$ & $0.89(0.64-1.23)$ & \\
\hline Recurrent PE, \% & 29 & 20 & 24 & 0.319 \\
\hline aOR $(95 \% \mathrm{Cl})$ & Ref & $0.88(0.41-1.90)$ & $0.91(0.65-1.27)$ & \\
\hline HELLP syndrome, \% & 10 & 6 & 6 & 0.420 \\
\hline aOR $(95 \% \mathrm{Cl})$ & Ref & $0.52(0.15-1.79)$ & $0.98(0.54-1.76)$ & \\
\hline Eclampsia, \% & 2 & 1 & 0 & 0.307 \\
\hline aOR $(95 \% \mathrm{Cl})$ & Ref & $0.33(0.02-5.27)$ & NA & \\
\hline GA onset of PE, w & $34^{4}\left[32^{2}-37^{0}\right]$ & $36^{0}\left[30^{0}-37^{0}\right]$ & $35^{0}\left[32^{2}-37^{5}\right]$ & 0.943 \\
\hline Recurrent early-onset PE, \% & 12 & 6 & 6 & 0.180 \\
\hline Interval diagnosis PE - delivery, $d$ & $12[2-26]$ & $15[1-42]$ & $8[2-23]$ & 0.682 \\
\hline GA at delivery, w & $38^{4}\left[37^{0}-40^{0}\right]$ & $39^{1}\left[37^{4}-40^{1}\right]$ & $38^{1}\left[37^{2}-39^{1}\right]$ & 0.036 \\
\hline Inter-delivery interval, m & $30[26-40]$ & $36[26-48]$ & $36[28-48]$ & 0.034 \\
\hline Aspirin use, $\%$ & 76 & 44 & 63 & $<0.001$ \\
\hline Calcium use, $\%$ & 35 & 16 & 35 & 0.004 \\
\hline \multicolumn{5}{|l|}{ Foetal and neonatal complications } \\
\hline Total, \% & 25 & 15 & 11 & 0.016 \\
\hline aOR $(95 \% \mathrm{Cl})$ & Ref & $0.56(0.24-1.31)$ & $0.60(0.38-0.95)$ & \\
\hline Placental abruption, $\%$ & 4 & 2 & 0 & 0.092 \\
\hline aOR $(95 \% \mathrm{Cl})$ & Ref & $0.60(0.09-4.12)$ & NA & \\
\hline Stillbirth, \% & 5 & 0 & 0 & 0.004 \\
\hline aOR $(95 \% \mathrm{Cl})$ & Ref & NA & NA & \\
\hline SGA, $\%$ & 22 & 13 & 11 & 0.054 \\
\hline $\mathrm{aOR}(95 \% \mathrm{Cl})$ & Ref & $0.56(0.22-1.43)$ & $0.69(0.43-1.13)$ & \\
\hline Neonatal death, $\%$ & 1 & 1 & 0 & 0.546 \\
\hline aOR $(95 \% \mathrm{Cl})$ & Ref & $3.39(0.1-100.2)$ & NA & \\
\hline Pre-term birth, $\%$ & 16 & 13 & 15 & 0.830 \\
\hline aOR $(95 \% \mathrm{Cl})$ & Ref & $1.02(0.41-2.54)$ & $1.04(0.68-1.59)$ & \\
\hline Extreme pre-term birth, \% & 5 & 3 & 3 & 0.573 \\
\hline aOR $(95 \% \mathrm{Cl})$ & Ref & $0.61(0.13-2.88)$ & $0.83(0.36-1.92)$ & \\
\hline
\end{tabular}

Data are presented as percentage, mean (SD) or median [interquartile range] within group. PE indicates preeclampsia; aOR, adjusted odds ratio; $\mathrm{Cl}$, confidence interval; HELLP syndrome, Haemolysis, Elevated Liver Enzymes, Low Platelets syndrome; d, days; SGA, small-for-gestational-age; GA, gestational age; d, days; w, weeks; m, months; NA, not assessed. Adjustments are made for metabolic syndrome at evaluation (yes/no), early-onset PE in index pregnancy (yes/no), HELLP syndrome in index pregnancy (yes/no), SGA in index pregnancy (yes/no), inter-delivery interval in months, calcium and/or aspirin use in the subsequent pregnancy (yes/no). 
in the subsequent pregnancy, there was still no difference between prevalence of PE, HELLP syndrome or eclampsia in the different groups. Logistic regression revealed that year of delivery did not influence maternal complications in the second pregnancy (odds ratio $(\mathrm{OR})=0.98$ per year, $95 \% \mathrm{Cl} 0.93-1.04, \mathrm{p}=0.503)$. In case $\mathrm{PE}$ developed, gestational age at onset, and duration of $\mathrm{PE}$, that is the interval between diagnosis and delivery, did not differ between groups. A significant difference was found in aspirin and calcium use, wherein women in the first group reported to use these preventive measures the most.

In contrast to the maternal sequelae, the prevalence of related offspring complications in subsequent pregnancy was less in group 3 compared to groups 1 and 2. As compared to women delivering in 1995, each subsequent year improved offspring outcome (OR $=0.92$ per year, $95 \% \mathrm{Cl} 0.86-0.98, \mathrm{p}=0.009)$. Though not statistically significant, SGA prevalence seems to decrease over the time from $22 \%$ to $13 \%$ to $11 \%$ in time period 1 , 2 and 3 respectively $(p=0.054)$. There was more stillbirth in women assigned to group 1 compared to women assigned to group 2 and $3,5 \%$ versus $0 \%$ and $0 \%(p=0.004)$. The prevalence of pre-term birth and extreme pre-term birth did not differ between the three groups.

Women in group 1 delivered at earlier gestational age and had more frequent earlyonset PE during their index pregnancy compared with women in the other time periods (Table 2). Therefore, we repeated analyses in a subgroup of women with early-onset PE in the index pregnancy. With respect to next pregnancy outcome, there was still no difference between PE, HELLP syndrome and/or eclampsia prevalence in the different time periods (Table 4). At any rate, offspring outcome still improved over time, even when accounted for severity of obstetric history, inter-delivery interval, underlying metabolic syndrome, and preventive measures in the next pregnancy.

\section{DISCUSSION}

In contrast to our expectations, even when adjusted for obstetric history, underlying metabolic risk factors and use of preventive measures in the subsequent pregnancy, recurrence rates of PE did not improve over the past two decades. Foetal and neonatal outcomes in the subsequent pregnancy after PE improved substantially in the same era.

The overall recurrence rate of PE in our population was 24.3\%, which is higher compared with the $13.8 \%$ recurrence rate described in a recent meta-analysis. ${ }^{2}$ Our population had a high prevalence of early-onset PE (68\%) and concurrent HELLP-syndrome (74\%) in the index pregnancy, which has probably contributed to high prevalence of recurrent 
Table 4. Outcome of the subsequent ongoing pregnancy in women with history of early-onset preeclampsia.

\begin{tabular}{|c|c|c|c|c|}
\hline & $\begin{array}{l}\text { Group } 1 \\
1997-2004 \\
n=77\end{array}$ & $\begin{array}{l}\text { Group } 2 \\
2005-2009 \\
n=62\end{array}$ & $\begin{array}{l}\text { Group } 3 \\
2010-2016 \\
n=76\end{array}$ & P value \\
\hline \multicolumn{5}{|l|}{ Maternal complications } \\
\hline Total, \% & 31 & 21 & 29 & 0.381 \\
\hline aOR $(95 \% \mathrm{Cl})$ & Ref & $0.81(0.32-2.02)$ & $1.01(0.68-1.48)$ & \\
\hline Recurrent PE, \% & 29 & 21 & 29 & 0.502 \\
\hline aOR $(95 \% \mathrm{Cl})$ & Ref & $0.93(0.37-2.34)$ & $1.05(0.71-1.55)$ & \\
\hline HELLP syndrome, \% & 10 & 3 & 7 & 0.254 \\
\hline aOR $(95 \% \mathrm{Cl})$ & Ref & $0.31(0.05-1.88)$ & $1.10(0.53-2.31)$ & \\
\hline Eclampsia, \% & 3 & 0 & 0 & 0.164 \\
\hline aOR $(95 \% \mathrm{Cl})$ & Ref & NA & NA & \\
\hline GA onset of PE, w & $33^{0}\left[30^{6}-37^{0}\right]$ & $35^{\circ}\left[30^{\circ}-37^{0}\right]$ & $34^{0}\left[32^{0}-37^{0}\right]$ & 0.878 \\
\hline Recurrent early-onset PE, \% & 15 & 10 & 9 & 0.556 \\
\hline Interval diagnosis PE - delivery, $d$ & 14 [3-25] & 35 [3-51] & $8[3-24]$ & 0.265 \\
\hline GA at delivery, w & $38^{0}\left[37^{0}-40^{0}\right]$ & $39^{0}\left[37^{2}-40^{2}\right]$ & $38^{0}\left[37^{1}-39^{1}\right]$ & 0.137 \\
\hline Interdelivery interval, m & $30[24-42]$ & $36[26-52]$ & $36[28-49]$ & 0.062 \\
\hline Aspirin use, $\%$ & 82 & 64 & 71 & 0.060 \\
\hline Calcium use, $\%$ & 41 & 21 & 41 & 0.037 \\
\hline \multicolumn{5}{|l|}{ Foetal and neonatal complications } \\
\hline Total, \% & 30 & 16 & 13 & 0.024 \\
\hline $\operatorname{aOR}(95 \% \mathrm{Cl})$ & Ref & $0.42(0.16-1.11)$ & $0.58(0.35-0.96)$ & \\
\hline Placental abruption, \% & 5 & 3 & 0 & 0.145 \\
\hline aOR $(95 \% \mathrm{Cl})$ & Ref & $0.60(0.09-4.12)$ & NA & \\
\hline Stillbirth, \% & 6 & 0 & 0 & 0.010 \\
\hline aOR $(95 \% \mathrm{Cl})$ & Ref & NA & NA & \\
\hline SGA, $\%$ & 26 & 13 & 13 & 0.058 \\
\hline $\mathrm{aOR}(95 \% \mathrm{Cl})$ & Ref & $0.45(0.15-1.40)$ & $0.76(0.44-1.31)$ & \\
\hline Neonatal death, \% & 1 & 2 & 0 & 0.565 \\
\hline aOR $(95 \% \mathrm{Cl})$ & Ref & $3.39(0.1-100.2)$ & NA & \\
\hline Pre-term birth, \% & 18 & 13 & 18 & 0.630 \\
\hline $\mathrm{aOR}(95 \% \mathrm{Cl})$ & Ref & $0.71(0.24-2.06)$ & $1.03(0.64-1.67)$ & \\
\hline Extreme pre-term birth, \% & 6 & 3 & 4 & 0.619 \\
\hline aOR $(95 \% \mathrm{Cl})$ & Ref & $0.39(0.07-2.29)$ & $0.83(0.36-1.92)$ & \\
\hline
\end{tabular}

Data are presented as percentage and odds ratio with $(95 \% \mathrm{CI})$. PE indicates preeclampsia; aOR, adjusted odds ratio; HELLP syndrome, Haemolysis Elevated Liver Enzymes Low Platelets syndrome; d, days; SGA, small-for-gestational-age; GA, gestational age; w, weeks; m, months; NA, not assessed.

Adjustments are made for metabolic syndrome at evaluation (yes/no), HELLP syndrome in index pregnancy (yes/no), SGA in index pregnancy (yes/no), inter-delivery interval in months, calcium and/or aspirin use in the subsequent pregnancy (yes/no). 
disease. To our knowledge, only one other study investigated recurrence rates of PE over time, showing a reduction of early preterm PE from 1993 onwards, attributed to the introduction of prophylaxis with low-dose aspirin in women with a history of early-onset PE.

Total recurrence rates irrespectively of gestational age at onset of disease did not decrease, which is in line with our findings. ${ }^{21}$ In contrast to the study of Ebbing et al. we were able to correct for the presence of underlying metabolic syndrome by computing adjusted odds ratios, which minimizes the influence of increasing prevalence of metabolic syndrome on the development of recurrent PE. ${ }^{16}$

In the consultation after assessment, most women were advised to use aspirin and calcium during the subsequent pregnancy. Aspirin reduces the risk of PE 10 to $40 \%{ }^{7,22}$ Calcium supplementations may half the risk of PE, especially in high-risk women and in women with low calcium intake. ${ }^{8}$ Adherence to these preventive measures in our cohort appeared to be low, only $60 \%$ and $28 \%$ of the women reported to have used aspirin and calcium, respectively, during their second pregnancy. We hypothesized that besides absence of recommendations in the national guidelines, physicians might have been reserved in prescribing aspirin and calcium in women with a history of late-onset PE. All the more because an increased intake was noted in women with early-onset compared with late-onset PE in the first pregnancy ( $71 \%$ and $34 \%$ respectively). Recurrence rates could be improved by emphasizing the importance of effective preventive measures nationwide, not limited to selected highest risk populations.

Women in group 3 delivered earlier in their second pregnancy than women in groups 1 and 2, possibly masking an even higher prevalence of PE in this group that might have developed by expectant management. Earlier delivery could be a consequence of the in 2009 published multicentre HYPITAT trial showing advantages of labour induction at 37 weeks of gestational age, instead of watchful waiting in pregnancies complicated by hypertension. ${ }^{12}$ As this study ran in about a quarter of all national hospitals, induction of labour in case of gestational hypertension at term was rapidly implemented throughout the country.

Later onset of disease could also be a reflection of improved health care. However, gestational age at onset of recurrent disease was similar between the three groups. Treatment of hypertension might prevent progression to PE, although the effect of antihypertensive medication is debated. ${ }^{10}$ Physicians only prescribing antihypertensive medication in severe hypertension follow national guidelines. The comparable duration of PE in the different groups could relate to the physicians' preference, since a temporiz- 
ing management plan instead of induction of labour, especially at advanced gestational age, is controversial. ${ }^{23,24}$

In contrast to maternal outcome, the unfavourable offspring outcomes related to PE have decreased substantially over time. Growth restriction, placental abruption and stillbirth are all linked to placental dysfunction. Consequently, preventive measures for maternal complications could have affected offspring outcome. In high-risk women daily lowdose aspirin favours foetal growth ${ }^{7}$, and as an effect of increased growth, a decrease in stillbirth and neonatal death could be expected. ${ }^{25}$ Improved surveillance strategies most likely have contributed to the decreased prevalence of stillbirth. Formerly preeclamptic women are often subjected to an increased frequency of consultation during their next pregnancy, and content of check-ups is expanding. Assessment of foetal well-being by Doppler measurements in the umbilical artery and middle cerebral artery, and biophysical parameters (amniotic fluid index, foetal movements, and cardio-tocography) might have resulted in earlier intervention as soon as (multiple) deteriorations of the mentioned parameters were identified. ${ }^{26}$ In addition, knowledge by the clinicians of improved neonatal facilities that result in better survivability of the pre-term delivered neonate, may have contributed to the clinician's decision to terminate the pregnancy instead of expectant management, thereby reducing prevalence of stillbirth. Finally, the reduced prevalence of SGA could be partly attributed to earlier induced, though still at term, delivery. ${ }^{27}$

The response rate of the questionnaire was over $60 \%$, and even data of women who had their assessment almost 20 years ago was available, reflecting the commitment of these women to aid in research regarding PE. Even though almost $40 \%$ of women were lost to follow-up, the response rate did not change proportionally over time. Another shortcoming refers to the extensive post-partum assessment, which is not considered standard health care. Having more in-depth sight on underlying disorders might increase awareness, and with it, interventions to optimize health before the next pregnancy. Therefore, findings cannot be extrapolated to the general population. Unfortunately, because this study did not have a prospective design, we were not able to monitor compliance to given advices during the postpartum evaluation. Women with a worse metabolic state may be less compliant to lifestyle modification advice, but at the same time, this same group is expected to benefit the most of lifestyle changes. However, the extent of compliance or non-compliance could be expected for the groups equally and is therefore estimated to influence the outcomes of the second pregnancy to a similar extent. Index pregnancy characteristics were different between the groups to the detriment of women in the first group. Adjustments for characteristics in the index pregnancy did not change our main findings, and subgroups analysis in women with early-onset PE in their index pregnancy 
showed similar outcomes. We therefore are confident that the severity of disease in the index pregnancy had not affected our conclusions. We compared recurrence rates between different chosen time interval groups, in order to create groups of similar sizes. Shorter time periods resulted in the inability to analyse outcomes with low prevalence. To overcome this limitation, logistic regression was performed, showing similar effects of year of delivery on the maternal and offspring complications.

As components of the metabolic syndrome are highly prevalent in women after PE, and often associated with recurrent disease and remote cardiovascular disease, metabolic syndrome assessment postpartum is likely to be profitable in identifying women at risk for recurrent pregnancy complications and women at risk for associated cardiovascular disease in the long-term. The general practitioner could be involved in this necessary assessment instead of the obstetrician or vascular medicine specialist. Whether this approach may improve cost/benefit ratio needs to be modulated by experts.

\section{CONCLUSION}

Despite several available preventive measures to diminish the risk of recurrent PE and maternal sequelae, the recurrence rates did not decrease over the past 20 years in women who have been evaluated and counselled on risk factors. However, offspring outcomes improved substantially over this timespan. Efforts to extend and improve preventive strategies and especially, to implement already proven preventive measures in clinical practice are still necessary to reduce recurrence risk of PE. 


\section{REFERENCES}

1. Abalos E, Cuesta C, Grosso AL, Chou D and Say L. Global and regional estimates of preeclampsia and eclampsia: a systematic review. Eur J Obstet Gynecol Reprod Biol 2013; 170: 1-7.

2. van Oostwaard MF, Langenveld J, Schuit E, Papatsonis DN, Brown MA, Byaruhanga RN, et al. Recurrence of hypertensive disorders of pregnancy: an individual patient data metaanalysis. Am J Obstet Gynecol 2015; 212: 624 e621-617.

3. Duckitt $K$ and Harrington D. Risk factors for pre-eclampsia at antenatal booking: systematic review of controlled studies. BMJ 2005; 330: 565.

4. Dekker GA and Sibai BM. Etiology and pathogenesis of preeclampsia: current concepts. Am J Obstet Gynecol 1998; 179: 1359-1375.

5. Scholten RR, Sep S, Peeters L, Hopman MT, Lotgering FK and Spaanderman ME. Prepregnancy low-plasma volume and predisposition to preeclampsia and fetal growth restriction. Obstet Gynecol 2011; 117: 1085-1093.

6. Stekkinger $E$, Scholten R, van der Vlugt MJ, van Dijk AP, Janssen MC and Spaanderman ME. Metabolic syndrome and the risk for recurrent pre-eclampsia: a retrospective cohort study. BJOG 2013; 120: 979-986.

7. Roberge S, Nicolaides K, Demers S, Hyett J, Chaillet $\mathrm{N}$ and Bujold $\mathrm{E}$. The role of aspirin dose on the prevention of preeclampsia and fetal growth restriction: systematic review and meta-analysis. Am J Obstet Gynecol 2017; 216: 110-120 e116.

8. Hofmeyr GJ, Lawrie TA, Atallah AN, Duley L and Torloni MR. Calcium supplementation during pregnancy for preventing hypertensive disorders and related problems. Cochrane Database Syst Rev 2014: CD001059.

9. Rodger MA, Gris JC, de Vries JIP, Martinelli I, Rey E, Schleussner E, et al. Low-molecular-weight heparin and recurrent placenta- mediated pregnancy complications: a meta-analysis of individual patient data from randomised controlled trials. Lancet 2016; 388: 2629-2641.

10. Abalos E, Duley L and Steyn DW. Antihypertensive drug therapy for mild to moderate hypertension during pregnancy. Cochrane Database Syst Rev 2014: CD002252.

11. Magee LA, Singer J, von Dadelszen $P$ and Group CS. Less-tight versus tight control of hypertension in pregnancy. N Engl J Med 2015; 372: 2367-2368.

12. Koopmans CM, Bijlenga D, Groen H, Vijgen SM, Aarnoudse JG, Bekedam DJ, et al. Induction of labour versus expectant monitoring for gestational hypertension or mild pre-eclampsia after 36 weeks' gestation (HYPITAT): a multicentre, open-label randomised controlled trial. Lancet 2009; 374: 979-988.

13. Mohangoo AD, Hukkelhoven CW, Achterberg PW, Elferink-Stinkens PM, Ravelli AC, Rijninks-van Driel GC, et al. [Decline in foetal and neonatal mortality in the Netherlands: comparison with other EuroPeristat countries between 2004 and 2010]. Ned Tijdschr Geneeskd 2014; 158: A6675.

14. Claas MJ, Bruinse HW, van der HeideJalving M, Termote JU and de Vries LS. Changes in survival and neonatal morbidity in infants with a birth weight of $750 \mathrm{~g}$ or less. Neonatology 2010; 98: 278-288.

15. Engle WA, American Academy of Pediatrics Committee on F and Newborn. Surfactantreplacement therapy for respiratory distress in the preterm and term neonate. Pediatrics 2008; 121: 419-432.

16. Ford ES, Giles WH and Mokdad AH. Increasing prevalence of the metabolic syndrome among u.s. Adults. Diabetes Care 2004; 27 : 2444-2449.

17. Roberts JM, Pearson G, Cutler J, Lindheimer $M$ and Pregnancy NWGoRoHD. Summary of the NHLBI Working Group on 
Research on Hypertension During Pregnancy. Hypertension 2003; 41: 437-445.

18. von Dadelszen P, Magee LA and Roberts JM. Subclassification of preeclampsia. Hypertens Pregnancy 2003; 22: 143-148.

19. Kloosterman GJ. [Intrauterine growth and intrauterine growth curves]. Ned Tijdschr Verloskd Gynaecol 1969; 69: 349-365.

20. Alberti KG and Zimmet PZ. Definition, diagnosis and classification of diabetes mellitus and its complications. Part 1: diagnosis and classification of diabetes mellitus provisional report of a WHO consultation. Diabet Med 1998; 15: 539-553.

21. Ebbing C, Rasmussen S, Skjaerven R and Irgens LM. Risk factors for recurrence of hypertensive disorders of pregnancy, a population based cohort study. Acta Obstet Gynecol Scand 2016

22. Meher S, Duley L, Hunter K and Askie L. Antiplatelet therapy before or after 16 weeks' gestation for preventing preeclampsia: an individual participant data meta-analysis. Am J Obstet Gynecol 2017; 216: 121-128 e122.

23. Ganzevoort W, Rep A, de Vries JI, Bonsel $\mathrm{GJ}$, Wolf $\mathrm{H}$ and investigators $\mathrm{P}$. Prediction of maternal complications and adverse infant outcome at admission for temporizing management of early-onset severe hypertensive disorders of pregnancy. Am J Obstet Gynecol 2006; 195: 495-503.
24. Broekhuijsen $\mathrm{K}$, van Baaren $\mathrm{GJ}$, van Pampus MG, Ganzevoort W, Sikkema JM, Woiski MD, et al. Immediate delivery versus expectant monitoring for hypertensive disorders of pregnancy between 34 and 37 weeks of gestation (HYPITAT-II): an openlabel, randomised controlled trial. Lancet 2015; 385: 2492-2501.

25. Bukowski R, Hansen NI, Willinger M, Reddy UM, Parker CB, Pinar H, et al. Fetal growth and risk of stillbirth: a population-based case-control study. PLoS Med 2014; 11: e1001633.

26. Alfirevic Z, Stampalija T and Dowswell T. Fetal and umbilical Doppler ultrasound in high-risk pregnancies. Cochrane Database Syst Rev 2017; 6: CD007529.

27. Boers KE, Vijgen SM, Bijlenga $D$, van der Post JA, Bekedam DJ, Kwee A, et al. Induction versus expectant monitoring for intrauterine growth restriction at term: randomised equivalence trial (DIGITAT). BMJ 2010; 341: c7087. 




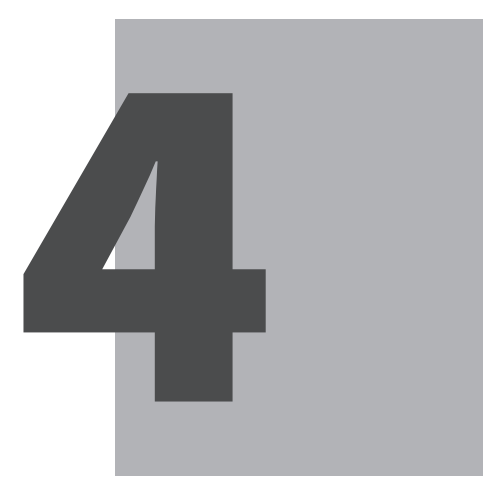

\title{
CARDIAC OUTPUT AND PERIPHERAL VASCULAR RESISTANCE DURING NORMOTENSIVE AND HYPERTENSIVE PREGNANCY - A SYSTEMATIC REVIEW AND META-ANALYSIS
}

\author{
Eva G. Mulder* \\ Sander de Haas* \\ Zenab Mohseni \\ Niklas Schartmann \\ Fatimah Abo Hasson \\ Fatimah Alsadah \\ Sander M.J. van Kuijk \\ Joris van Drongelen \\ Marc E.A. Spaanderman \\ Chahinda Ghossein-Doha \\ * Both authors contributed equally
}




\section{ABSTRACT}

Background: In-depth insight into hemodynamic changes during normotensive pregnancy may help identify women at risk for gestational hypertensive complications.

Objectives: To determine the magnitude of changes in cardiac output and its determinants stroke volume and heart rate, and total peripheral vascular resistance during singleton normotensive and hypertensive pregnancies.

Search Strategy: PubMed (NCBI) and Embase (Ovid) databases were searched from their inception up to November 2019.

Selection Criteria: Studies reporting original measurements of hemodynamic parameters during pregnancy together with a non-pregnant reference measurement. Studies including women using antihypertensive medication were excluded.

Data Collection and Analysis: Pooled mean differences between pregnant and nonpregnant women, and absolute values of hemodynamic parameters were calculated for predefined gestational intervals using a random-effects model in normotensive and hypertensive pregnancy. Meta-regression analysis was used to analyse group differences in adjustments and absolute values during pregnancy.

Main Results: In normotensive pregnancies, cardiac output increased from the first weeks on, reaching its highest level early in the third trimester (mean difference, 1.41 L. $\mathrm{min}^{-1} ; 95 \% \mathrm{Cl}$ 1.18-1.63 L. $\mathrm{min}^{-1}$ ). In parallel, vascular resistance decreased progressively until its nadir in the early third trimester (mean difference, $-331 \mathrm{dyn} \cdot \mathrm{sec} \cdot \mathrm{cm}^{-5} ; 95 \% \mathrm{Cl}$ -384 to -277 dyn.sec $\cdot \mathrm{cm}^{-5}$ ) and then increased slightly at term. In hypertensive pregnancies, the initial cardiac output increase was higher and vascular resistance did not change throughout gestation compared with reference values.

Conclusions: Hemodynamic changes in women who eventually develop hypertensive complications are substantially different. Serial monitoring and plotting against developed normograms can identify women at risk and may allow timely intervention.

\section{Funding: NA}

Keywords: Pregnancy, gestational hypertension, preeclampsia, cardiovascular disease 


\section{INTRODUCTION}

Healthy pregnancy is accompanied by major hemodynamic changes that benefit the uteroplacental circulation. A drop in systemic vascular resistance during the first trimester triggers several compensatory mechanisms to maintain blood pressure, such as an increase in plasma volume and cardiac output (CO)., 2 Pregnancies complicated by gestational hypertension and/or preeclampsia may show deviant hemodynamic changes long before clinical presentation. An exaggerated rise in $\mathrm{CO}$ is associated with gestational hypertension and late-onset preeclampsia, whereas a shallow rise in $\mathrm{CO}$ with no drop in vascular resistance predisposes to the much less common earlyonset preeclampsia along with impaired foetal growth. ${ }^{3-6}$ Recognition of hemodynamic changes during normal pregnancy may identify early deviant hemodynamic changes in women destined to develop severe maternal hypertensive complications, enhancing possibilities for early prevention and intervention. This study aimed to assess adjustments in $\mathrm{CO}$ and its determinants stroke volume (SV) and heart rate (HR), and total peripheral vascular resistance (TPVR) during singleton normotensive and hypertensive pregnancies. We performed a systematic review and meta-analysis of existing data to provide detailed insight into the magnitude and moment of hemodynamic changes during normotensive and hypertensive pregnancies, and to construct reference curves for normotensive gestation.

\section{METHODS}

No patients or public were involved in the design and conduct of this research. There was no specific funding for this research, and no core outcome set was used.

\section{Data sources and searches}

This article follows the previously designed series of meta-analyses on physiologic adjustments of maternal cardiovascular and cardiometabolic parameters during pregnancy, and follows the Preferred Reporting Guidelines for Systematic Reviews and Meta-Analyses (PRISMA). ${ }^{1,7,8}$ We conducted an extensive literature search of studies evaluating CO, TPVR, SV, and HR during normotensive and hypertensive pregnancies in the MEDLINE (PubMed) and Embase (Ovid) electronic databases. We included articles published from inception (1946 in PubMed and 1974 in Embase) to November 2019. Part one of the search string consisted of pregnancy and hypertensive complications of pregnancy and was similar to the search string used in previously published systematic reviews. Part two of the search string focused on hemodynamic parameters: CO, TPVR, SV, HR, and blood pressure (Appendix S1). Filters were used to limit the search to studies 
that included human participants and journal articles as publication type, and the studies had to be published in English or Dutch to be able to assess quality.

\section{Study selection}

The identified studies were assessed for eligibility in two phases. First, every study was screened independently for eligibility by two investigators based on the title and abstract. Several investigators participated in this process (EM, SdH, ZM, NS, FAH, FA). Secondly, full-text articles were obtained and screened for eligibility based on the inclusion and exclusion criteria by two of four investigators (EM, SdH, ZM, NS). Discrepancies were resolved by mutual agreement or by consulting a third investigator. Studies were included if they were original studies measuring haemodynamic parameters during human singleton pregnancies. To be included, studies had to report a reference measurement, either measured before conception, $\geq 6$ weeks postpartum in the same study group, or in a non-pregnant control group. Moreover, hemodynamic parameters had to be reported as numerical values (mean with standard deviation [SD], standard error [SE] or $95 \%$ confidence interval $[\mathrm{Cl}]$ ). Requests were made to retrieve additional information from authors if data were graphically presented, if hemodynamic indices were indexed for anthropometric measures or if data were incomplete. We excluded case reports, and studies with unknown pregnancy outcome. We also excluded studies that included a proportion of women with a history of cardiovascular complications, including chronic hypertension, diabetes mellitus, gestational diabetes, and thyroid disease. Studies of complicated pregnancies were excluded if women could have used antihypertensive medication.

\section{Data extraction and quality assessment}

Data from included articles were extracted and entered in predesigned data collection forms. We registered study characteristics (study design, sample size, measurement method and maternal position during measurement), participant characteristics (age, non-pregnant body mass index [BMI] and parity), whether women had a normotensive or hypertensive pregnancy and how the latter was defined, and outcome measures. We chose to analyse crude values of hemodynamic parameters, unadjusted for body surface area or other anthropometric measurements. Hemodynamic parameters of interest were CO (L. $\left.\mathrm{min}^{-1}\right)$, TPVR (dyne. $\left.\mathrm{sec} \cdot \mathrm{cm}^{-5}\right)$, SV $(\mathrm{mL})$ and HR (bpm). Detailed data on systolic and diastolic blood pressure, and mean arterial pressure have been handled in a separate manuscript. When studies had focused on position-dependent or exercisedependent changes of hemodynamic parameters during pregnancy, only baseline values measured at rest were extracted. If the exact gestational age when the measurements were collected was not mentioned, they were included as 7 weeks for the first trimester, 21 weeks for the second trimester, and 34 weeks for the third trimester. If both 
non-pregnant controls and a postpartum reference measurement were given, the latter was selected to reduce between-subject variance due to unpaired measurements. When a study provided multiple postpartum values, the last measurement after delivery was used as the reference measurement.

Quality of the included studies was assessed using a modified list of items described in the Quality In Prognosis Studies tool, made most suitable for the purpose of this review. ${ }^{9}$ Studies were scored with a plus or minus in six domains including study participation, study attrition, variable measurement, data reporting and study design. Items that were not mentioned or not applicable received a negative score. Cross-sectional studies were scored negative for study attrition because loss-to-follow-up reporting is not applicable for this study design. Studies with a score $>60 \%$ were defined as high quality, between $30 \%$ and $60 \%$ as moderate quality, and $<30 \%$ as low quality.

\section{Data synthesis and analysis}

The hemodynamic parameters were categorized into five different predefined intervals of gestational age: first trimester (up to 14 weeks), early second trimester (15-21 weeks), late second trimester (22-28 weeks), early third trimester (29-35 weeks) and late third trimester (36-41 weeks). The primary outcome was the weighted mean difference of the hemodynamic parameters, and the relative change presented as a percentage with a $95 \% \mathrm{Cl}$ between pregnant women and a non-pregnant reference group. In these, measurements from pre-pregnant and postpartum women and non-pregnant controls were combined in the non-pregnant group. Pooled estimates of the absolute values with a $95 \% \mathrm{Cl}$ for the hemodynamic parameters were also analysed. SE or $95 \% \mathrm{Cl}$ values were converted to SD according to the Cochrane Handbook for Systematic Reviews of Interventions. ${ }^{10}$ If data were reported as median with interquartile range, we inquired whether the data were normally distributed. If so, studies were included and the SD was calculated by dividing the difference of the $25^{\text {th }}$ and the $75^{\text {th }}$ percentile by $1.35 .{ }^{10}$ If a study reported multiple measurements in the same women at one gestational interval, the mean and SD were pooled into one combined measurement according to the Cochrane Handbook. Pooled mean differences in CO, TPVR, SV and HR were calculated separately for these intervals using a random-effects meta-analysis as described by DerSimonian and Laird. ${ }^{11}$ This random-effects model allows inter-study variation and was chosen, as observational data on study and characteristics from different populations were used and heterogeneity was anticipated between studies. Publication bias was evaluated for each gestational interval in normotensive pregnancies by Egger's regression test for funnel plot asymmetry. ${ }^{12}$ If present, the pooled effect sizes were corrected for publication bias using the trim-and-fill method described by Duval and Tweedie. ${ }^{13}$ The ratio between total heterogeneity and total variability ( $I^{2}$ statistic) is presented as a 
measure of heterogeneity. $I^{2}$ can distinguish true heterogeneity from sampling variance and is expressed as a percentage. ${ }^{14}$ Sources of heterogeneity (type of reference group, quality of study, measurement method, position during measurement, parity, and differences between normotensive and hypertensive pregnancies) were analysed by metaregression analyses using a mixed-effects model. Reference curves were constructed assuming that changes were normally distributed over the course of the pregnancy. To establish reference curves, we computed the $5^{\text {th }}, 50^{\text {th }}$, and $95^{\text {th }}$ percentiles weighted by study sample size, using a restricted cubic splines model. All analyses were performed in $\mathrm{R}$ version 4.0.2. ${ }^{15}$ The meta-analyses and meta-regression analyses were performed using the meta package. ${ }^{16}$

\section{RESULTS}

\section{Study selection}

The search strategy in PubMed and Embase yielded 32604 unique articles (Figure 1), 3934 of which were excluded based on language restrictions. After screening of title and abstracts, we excluded 27558 articles that concerned other topics. This left 1112 articles for full text evaluation, 17 of which could not be retrieved despite attempts to obtain them from other libraries in the Netherlands or by contacting the authors via Research Gate. ${ }^{17-33}$ Of the 1095 manuscripts with full text available, 981 were excluded. Studies were excluded because a reference group was absent $(n=526)$, the study design was unsuitable $(n=166)$, the data were unusable $(n=152)$, the data was not original $(n=44)$, only blood pressure was reported $(n=43)$ and for other reasons $(n=51)$. Often, contacted authors could not provide the requested data, such as unindexed parameters, because the data were stored on storage media incompatible with modern computers.

Of the 113 eligible articles, nine were suspected to report data from previously published samples because the authors, method and/or study period were similar. ${ }^{34-42}$ Eight of these studies were excluded; one was included because supplemental data on hypertensive pregnancies were provided. ${ }^{40}$ In total, 105 studies were included, and the full references are presented in Appendix S2. Eighteen studies reported data on pregnancies complicated by hypertension. Thirteen studies reported on pregnancies complicated by preeclampsia, and five studies included women with pregnancy-induced hypertension or combined complications. The criteria used to define hypertension and preeclampsia are reported in Table S2. One study did not report the non-pregnant SD for HR, so the ratio between non-pregnant and pregnant SD in the complete dataset was used to estimate the SD. ${ }^{43}$ Three studies compared different measurement methods, and Doppler echocardiography measurements were extracted, as most other studies used this method. ${ }^{44-46}$ 


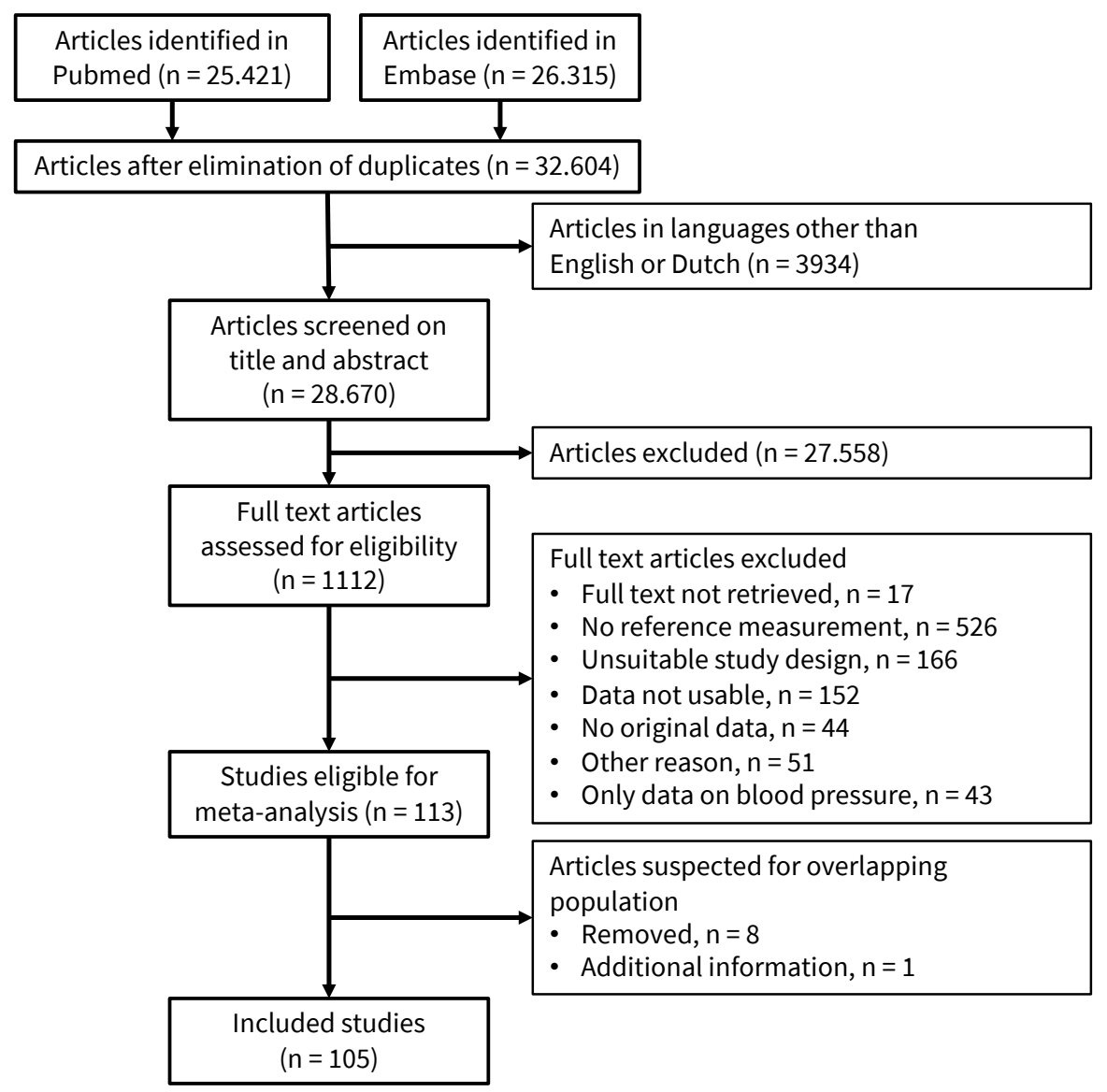

Figure 1. Flowchart summarizing selection of studies in the meta-analysis.

\section{Summary of studies}

A summary of included studies and their population is presented in Table S1. More than half of the studies reported gravidity or parity of women. Most studies included a mixed parous group, whereas 14 studies included only nulliparous women.

\section{Quality assessment of included studies}

The quality assessment is summarized in Table S3. Of the 105 included studies, 13 (12\%) were scored as low quality, $70(67 \%)$ as moderate quality, and $22(21 \%)$ as high quality. The items that scored the lowest among all studies were: (1) reporting baseline characteristics of participants who were lost to follow-up (4\%), and (2) the use of a preconception measurement as the reference value (13\%). Items that scored the highest were: (1) methods and setting are the same for all participants and throughout followup (88\%) and (2) clear reporting of gestational age at measurement (88\%). 


\section{Synthesis of results}

\section{Normotensive pregnancies}

During normotensive pregnancies, $\mathrm{CO}$ started to increase from the first trimester, reaching a maximum mean difference of $1.41 \mathrm{~L}^{\mathrm{min}} \mathrm{m}^{-1}$ between 29 and 35 weeks of pregnancy (Table 1, Figure 2). In parallel, TPVR decreased in the first 14 weeks by $188 \mathrm{dyne} \cdot \mathrm{sec} \cdot \mathrm{cm}^{-5}$ and continued to decrease, reaching its minimum between 22 and 28 weeks. SV started to increase in the first trimester and peaked between 15 and 21 weeks of pregnancy. In the second half of the pregnancy, the increase in SV diminished and between 36 and 41 weeks of pregnancy, SV did not differ between pregnant and non-pregnant women. HR started to increase in the first trimester and peaked in the early third trimester with a mean difference of $14.6 \mathrm{bpm}$, after which the increase plateaued. Forest plots of weighted mean differences and absolute values per gestational age interval of all hemodynamic parameters in normotensive pregnancies are presented in Figures S1-S8. During early normotensive pregnancy, both systolic and diastolic blood pressure significantly decreased, reaching their nadir in the second trimester $(-4 \mathrm{mmHg}, 95 \% \mathrm{Cl}-6$ to $-2 \mathrm{mmHg}$ and $-4 \mathrm{mmHg}, 95 \% \mathrm{Cl}$ -5 to $-3 \mathrm{mmHg}$ respectively). Thereafter, blood pressure gradually increased towards nonpregnant values at term (detailed data presented in other manuscript). ${ }^{47}$

In case of significant funnel plot asymmetry, which indicates publication bias, corrected mean differences were calculated (Table 1). Meta-regression analysis showed a significant contribution of the measurement method to the heterogeneity of CO, TPVR and SV measurements. In addition, the type of reference group contributed significantly to heterogeneity in CO measurements. Study quality contributed significantly to heterogeneity in HR measurements, and maternal position contributed significantly to heterogeneity in SV measurements. Parity did not contribute to heterogeneity in any of the parameters.

\section{Hypertensive pregnancies}

The CO increase observed during the first trimester of hypertensive pregnancies was higher than the increase observed in normotensive pregnancies, on top of a higher absolute CO value in the non-pregnant state (Table 2). TPVR and SV values in hypertensive pregnancies were not different from non-pregnant reference values. In the last trimester, $\mathrm{HR}$ values in hypertensive pregnancies were substantially higher than non-pregnant reference values. Meta-regression analysis showed that changes in CO, TPVR and HR during complicated pregnancies were significantly different from changes during normotensive pregnancies. Forest plots of weighted mean differences and absolute values per gestational interval of hemodynamic parameters in hypertensive pregnancies are presented in Figures S9-S16. Pregnancies eventually complicated by hypertension and/or preeclampsia lacked an early decrease in systolic blood pressure, even though 
diastolic blood pressure dropped to a greater extent compared with normotensive pregnancies. In the second half of pregnancy, systolic and diastolic blood pressure increased tremendously (detailed data presented in other manuscript). ${ }^{47}$

normotensive pregnancies $-\bullet$ hypertensive pregnancies
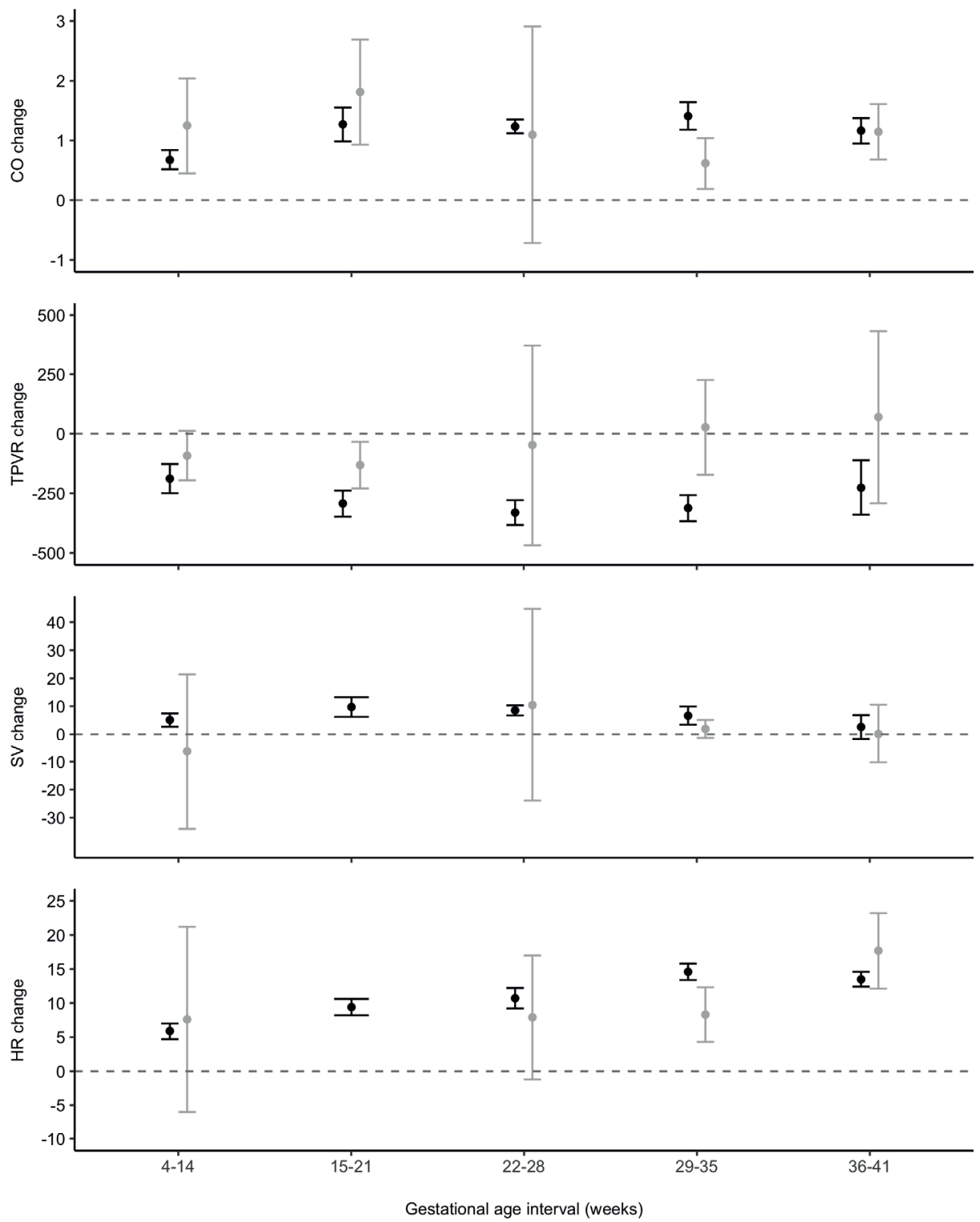

Figure 2. Mean differences and $95 \% \mathrm{Cl}$ as error bar of hemodynamic parameters compared with non-pregnant reference values (pre-conceptional, postpartum or non-pregnant control group) in normotensive and hypertensive pregnancies per gestational interval. 


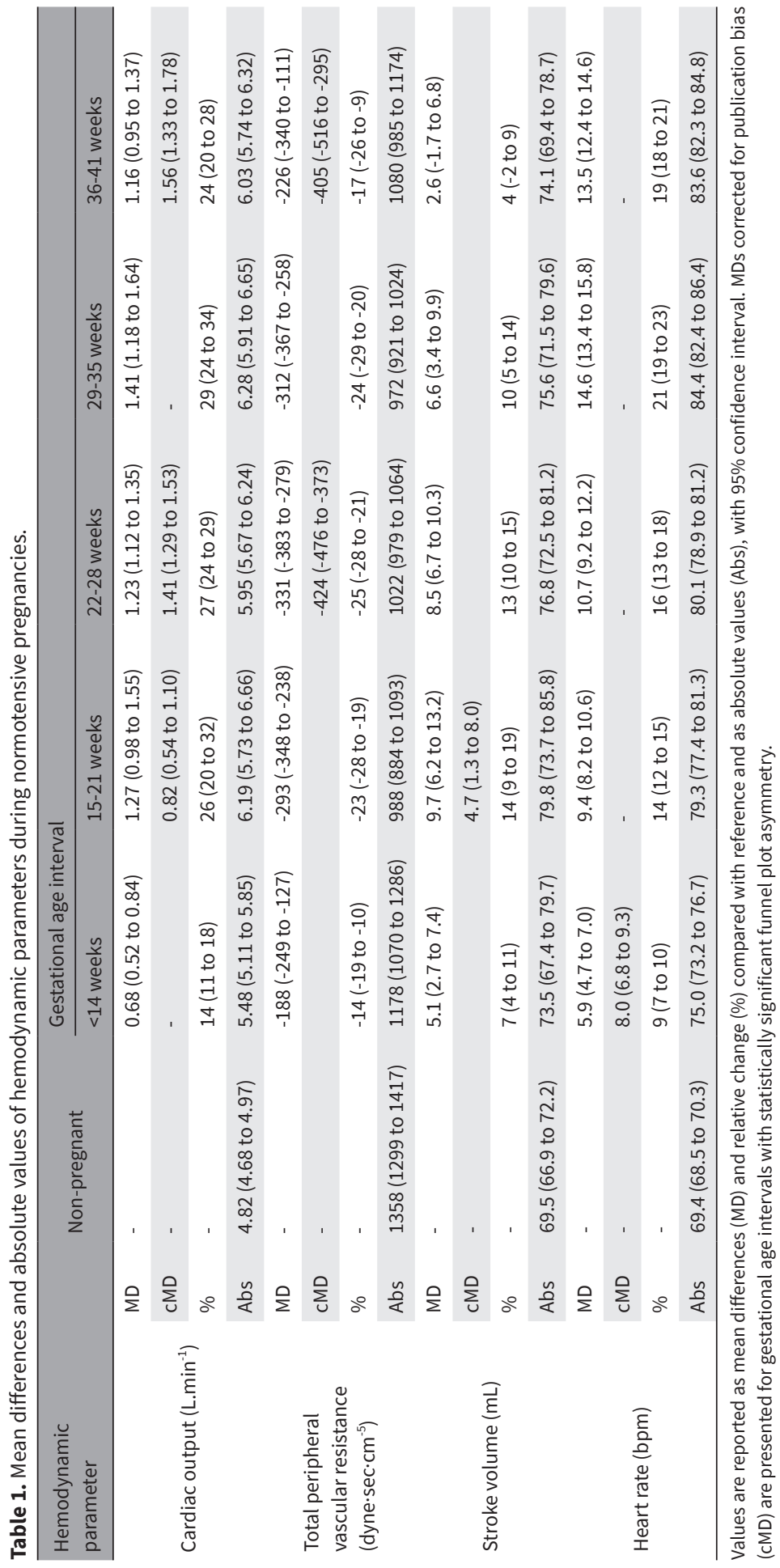




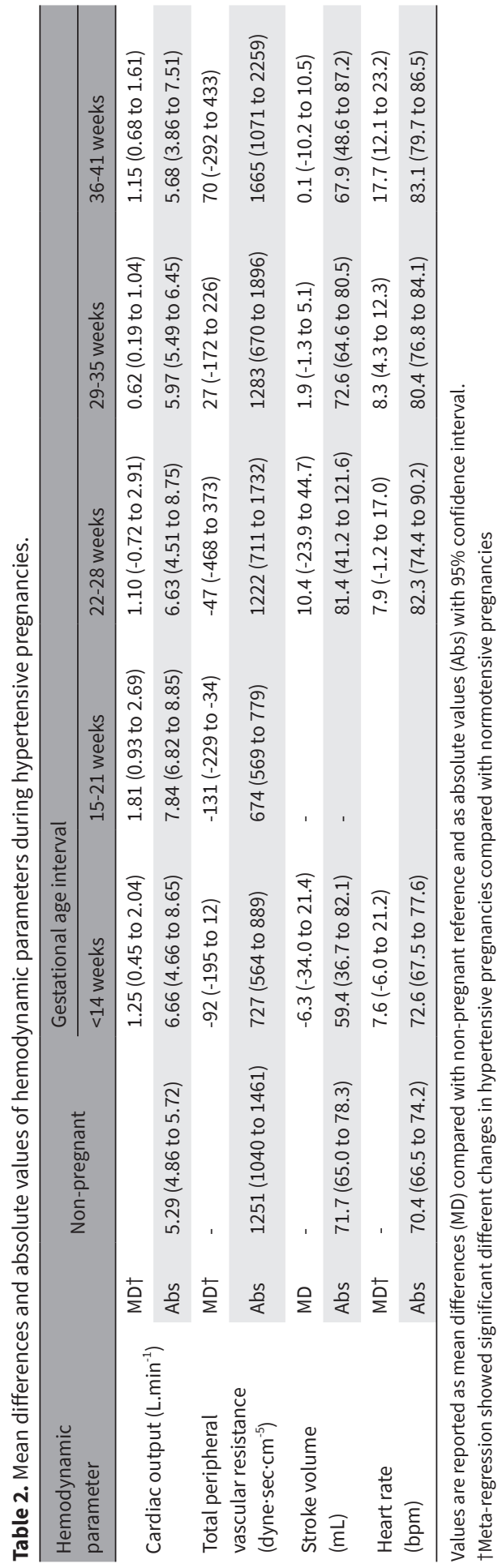




\section{Reference curves}

Reference curves for absolute CO, TPVR, SV and HR values during pregnancy and in the postpartum period were constructed with data from normotensive pregnancies (Figure 3, Figures S17-19).
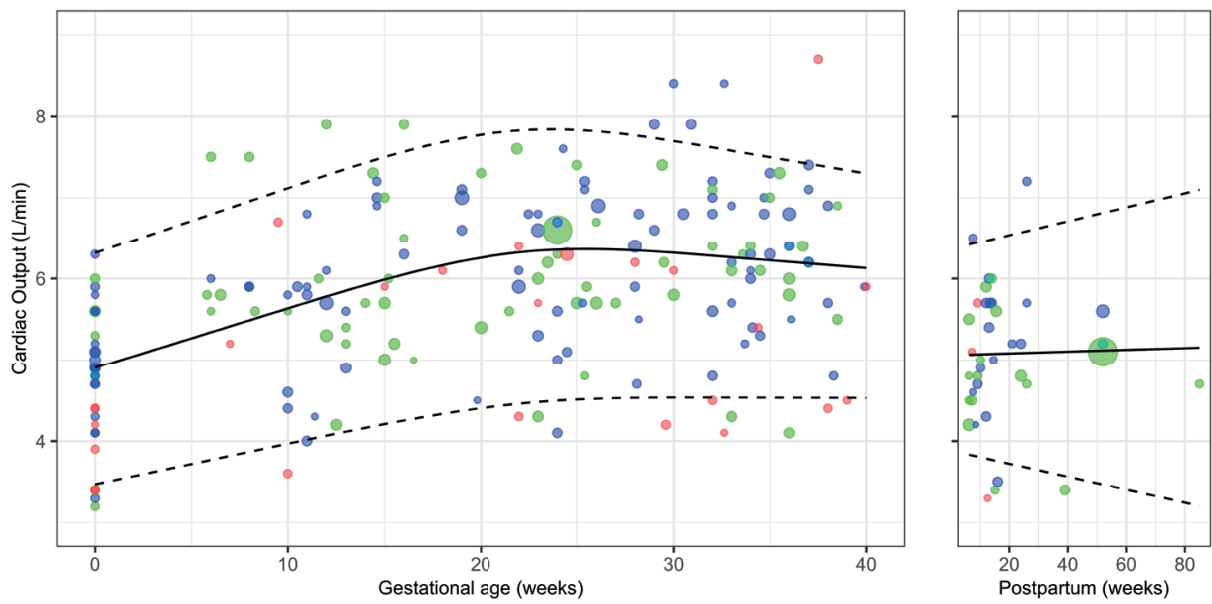

Figure 3. Reference curve of absolute $\mathrm{CO}$ values during pregnancy and in the postpartum period, with mean (solid line), and $5^{\text {th }}$ and $95^{\text {th }}$ percentiles (dashed lines) weighted by study sample size. Size of individual plots indicates sample size of point estimate and their colour indicates study quality: red, low quality; green, moderate quality; blue, high quality. Studies with multiple measurements during pregnancy are plotted per measurement.

\section{DISCUSSION}

\section{Main findings}

This study comprehensively describes the magnitude and time-point of changes in CO, its determinants SV and HR, and TPVR during normotensive and hypertensive pregnancies. During hypertensive pregnancies, the initial increase in CO is augmented, established merely by an elevation in HR, and this increase is not sustained over the course of pregnancy. In contrast to normotensive pregnancies, TPVR does not decrease much in hypertensive pregnancies.

\section{Strength and limitations}

The strength and novelty of this work is that we included only studies with a nonpregnant reference measurement. Therefore, we provide general mean differences as our primary outcome, which makes usability method- and device-independent. There are some limitations to our study. First, the postpartum reference group may have attenuated the mean differences in our outcome parameters due to the residual time- 
effect of pregnancy and breast-feeding on hemodynamic parameters. ${ }^{2,48-51}$ However, we performed a meta-regression analysis to identify parameters that affected the observed changes, and found no effect of the kind of reference group on heterogeneity. Secondly, we were not able to analyse nulliparous and multiparous women separately, although the magnitude of hemodynamic changes is thought to be more pronounced in multiparous women. ${ }^{50,52,53}$ Meta-regression analysis did not show an effect of parity on the tested parameters, although this could be due to the inclusion of nulliparous women in the mixed parous group. Thirdly, we could not assess the effect of age and BMI on hemodynamic parameters during pregnancy, as these factors were inconsistently reported. Fourthly, our references curves are constructed based on aggregated data per study and are weighted on sample size. We made assumptions on the normality of data distribution. This limitation can only be overcome with an individual patient data meta-analysis. Finally, for funnel plot asymmetry, corrected mean differences were calculated. These are based on the assumption that publication bias is present and therefore should be interpreted with some caution.

It is well accepted that the increase of $\mathrm{CO}$ in normotensive pregnancy results from an increase in both SV and HR. ${ }^{2,46,54-56}$ Our study confirmed that HR increased over the course of a normotensive pregnancy. This is most likely explained by an increased sympathetic activity and involvement of the Bainbridge reflex, which is an increase in HR to prevent damming of blood in response to increased venous filling. In contrast, the SV increase lessens in the second half of pregnancy, which may be the resultant of several factors. First, preload might be hampered because the enlarged uterus compresses the inferior vena cava at the end of pregnancy. ${ }^{57,58}$ Secondly, a higher HR decreases the diastolic period, which may impair filling of the left ventricle. ${ }^{7}$ Thirdly, cardiac remodelling during pregnancy may reduce compliance of the extensively stretched sarcomeres, which may reduce the $\mathrm{SV}^{49}$

In a healthy pregnancy, $\mathrm{CO}$ increase and TPVR decrease are thought to be caused by several early adaptations following conception. These include increased arterial compliance, decreased vascular tone, decreased vascular responsiveness to vasoconstrictors, increased release of and sensitivity to vasodilatory substances (including relaxin, nitric oxide, progesterone, and oestrogen), and the opening of maternal protective regulatory micro-circulatory and placental arterio-venous shunts. ${ }^{59-62}$ The subsequent relative circulatory underfill is counterbalanced by activation of the renin-angiotensin-aldosterone system, which stimulates renal volume retention, and expands plasma volume, supporting a rise in SV and, with it, increased $\mathrm{CO}^{63,64}$ Plasma volume expansion leads to dilutional anaemia, which may reduce TPVR by reducing blood viscosity. ${ }^{65,66}$ Marked sympathetic activation in favour of elevated inotropy and chronotropy may be a com- 
pensatory mechanism to maintain blood pressure at pre-pregnancy levels, although resetting of baroreceptor sensitivity and reduction of neurovascular transduction in pregnancy blunts the effect of sympathetic regulation on arterial blood pressure. ${ }^{37,67-69}$ The mechanisms responsible for healthy vascular adjustments might be compromised in gestational hypertensive diseases.

\section{Hypertensive pregnancies}

Pregnancies ending in hypertensive complications show an altered vascular response to conception. In addition to a higher $\mathrm{CO}$ at baseline, the initial increase in $\mathrm{CO}$ is more pronounced. The rise in CO predominantly originates from increased HR rather than SV, suggesting sympathetic over-activity to counterbalance hemodynamic changes in the first trimester. Because sympathetic activation is usually accompanied by a raised SV, the absence of an SV increase in women destined to develop hypertension may originate from other factors, such as diminished circulating plasma volume resulting in shallow preload, reduced left ventricle compliance, increased afterload due to increased vascular resistance or reduced arterial compliance. ${ }^{1,70}$ Concurrently, TPVR does not decrease, suggesting blunted vascular adjustments, and no change or even rise in blood pressure at any time during pregnancy before the clinical onset of hypertensive complications. Previous longitudinal studies have shown similar deviant hemodynamic changes preceding hypertensive complications. Easterling et al. showed that preeclamptic women had a higher $\mathrm{CO}$ over the course of pregnancy than normotensive women did. ${ }^{3}$ Bosio et al. showed that evolving of gestational hypertension to preeclampsia was accompanied by a crossover from a high output, low resistance circulation to a low output, high resistance circulation. ${ }^{4}$ Other studies have shown that severe, early-onset preeclampsia and associated foetal growth restriction may result from an initial and consistent low output, high resistance vasoconstricted circulation. ${ }^{5,71}$ Because the systemic-biological pathways to complications are so divergent, combining measurements of women at different pathophysiologic time points results in the wide confidence intervals found in hypertensive pregnancies. Unfortunately, we were not able to perform subgroup analyses on gestational hypertension, early-onset preeclampsia or late-onset preeclampsia because of combined complications and inconsistent definitions among the included studies.

\section{Interpretation}

Hemodynamic differences between normotensive and hypertensive pregnancies can be detected early in pregnancy, even when blood pressure is still within the normotensive range. Recognizing abnormal changes in hemodynamic parameters during pregnancy has great potential to improve prevention and intervention opportunities. ${ }^{72}$ Preventive measures may include daily low-dose aspirin and calcium supplementation in women 
at higher risk for hypertensive complications. Even more sophisticated, tailored pharmaceutical correction of deviant hemodynamic changes towards the expected normal values could be a key modality in preventing hypertensive complications. In this line of reasoning, timely initiation of beta-blockade in women with exaggerated high CO seems to reduce hypertensive complications during pregnancy. ${ }^{73}$ Additional vasodilatory therapy in women with an unfavourable low output and high resistance circulation could improve flow and with it maternal and foetal outcomes. ${ }^{74}$ Devices that are easy to use have been developed to assess $\mathrm{CO}$, so it is now feasible to measure $\mathrm{CO}$ in the outpatient setting along with blood pressure to determine gestational hemodynamic changes in clinical practice.

\section{CONCLUSION}

In normotensive pregnancy, resting $\mathrm{CO}$ increases from the first trimester to the early third trimester by almost $1.5 \mathrm{~L}^{\mathrm{min}} \mathrm{mi}^{-1}$ above non-pregnant values, and both SV and HR contribute to this increase. In parallel, TPVR decreases, reaching its nadir in the late second trimester. Monitoring these hemodynamic changes during pregnancy can help identify those women at risk of developing hypertensive complications, as in these women the change in CO, TPVR, and HR are deviant from that observed in normotensive pregnancy. Serial measurements are necessary to detect aberrant changes that precede hypertension during pregnancy. 


\section{REFERENCES}

1. de Haas S, Ghossein-Doha C, van Kuijk SMJ, van Drongelen $\mathrm{J}$ and Spaanderman MEA. Physiologic adaptation of plasma volume during pregnancy: a systematic review and meta-analysis. Ultrasound Obstet Gynecol 2017; 49(2): 177-187.

2. Meah VL, Cockcroft JR, Backx K, Shave $\mathrm{R}$ and Stohr EJ. Cardiac output and related haemodynamics during pregnancy: a series of meta-analyses. Heart 2016; 102: 518-526.

3. Easterling TR, Benedetti TJ, Schmucker BC and Millard SP. Maternal hemodynamics in normal and preeclamptic pregnancies: a longitudinal study. Obstet Gynecol 1990; 76: 1061-1069.

4. Bosio PM, McKenna PJ, Conroy R and O'Herlihy C. Maternal central hemodynamics in hypertensive disorders of pregnancy. Obstet Gynecol 1999; 94: 978-984.

5. Valensise H, Vasapollo B, Gagliardi G and Novelli GP. Early and late preeclampsia: two different maternal hemodynamic states in the latent phase of the disease. Hypertension 2008; 52: 873-880.

6. Stott D, Nzelu O, Nicolaides KH and Kametas NA. Maternal hemodynamics in normal pregnancy and in pregnancy affected by pre-eclampsia. Ultrasound Obstet Gynecol 2018; 52: 359-364.

7. de Haas S, Ghossein-Doha C, Geerts L, van Kuijk SMJ, van Drongelen J and Spaanderman MEA. Cardiac remodelling during normotensive and hypertensive complicated pregnancies: a systematic review and meta-analysis. Ultrasound Obstet Gynecol 2017; 50(6): 683-696.

8. Lopes van Balen VA, van Gansewinkel TA, de Haas S, van Kuijk SM, van Drongelen J, Ghossein-Doha C, et al. Physiologic adaptation of endothelial function to pregnancy: a systematic review and metaanalysis. Ultrasound Obstet Gynecol 2017; 50(6): 697-708.
9. Hayden JA, van der Windt DA, Cartwright $\mathrm{JL}$, Cote $\mathrm{P}$ and Bombardier C. Assessing bias in studies of prognostic factors. Ann Intern Med 2013; 158: 280-286.

10. Cochrane Handbook for Systematic Reviews of Interventions. In: Higgins JPT and S G, (eds.). The Cochrane Collaboration, 2011.

11. DerSimonian R and Laird N. Meta-analysis in clinical trials revisited. Contemp Clin Trials 2015; 45: 139-145.

12. Egger M, Davey Smith G, Schneider M and Minder C. Bias in meta-analysis detected by a simple, graphical test. BMJ 1997; 315: 629-634.

13. Duval S and Tweedie R. Trim and fill: A simple funnel-plot-based method of testing and adjusting for publication bias in meta-analysis. Biometrics 2000; 56: 455463.

14. Higgins JP, Thompson SG, Deeks JJ and Altman DG. Measuring inconsistency in meta-analyses. BMJ 2003; 327: 557-560.

15. Team RC. R: A Language and Environment for Statistical Computing. Vienna, Austria: R Foundation for Statistical Computing, 2015.

16. Schwarzer G. meta: General Package for Meta-Analysis, https://CRAN.R-project. org/package=meta (2015)

17. Siamopoulos KC, Papanikolaou S, Elisaf M, Theodorou J, Pappas $\mathrm{H}$ and Papanikolaou N. Ambulatory blood pressure monitoring in normotensive pregnant women. J Hum Hypertens 1996; 10 Suppl 3: S51-54.

18. Welt SI, Nagey DA, Mull CG, Pupkin VX and Crenshaw C, Jr. Postpartum blood pressure patterns in patients with hypertensive complications of pregnancy. Md Med J 1986; 35: 483-486.

19. Ihrman K. A clinical and physiological study of pregnancy in a material from northern Sweden. VI. The arterial blood pressures at rest and in orthostatic test 
during and after pregnancy. Acta Soc Med Ups 1960; 65: 314-325.

20. Salvatore CA. Capillary resistance during pregnancy. Obstet Gynecol 1961; 18: 96102.

21. Walters WA, MacGregor WG and Hills $M$. Cardiac output at rest during pregnancy and the puerperium. Clin Sci 1966; 30: 1-11.

22. Rovinsky JJ and Jaffin H. Cardiovascular Hemodynamics in Pregnancy. I. Blood and Plasma Volumes in Multiple Pregnancy. Am J Obstet Gynecol 1965; 93: 1-15.

23. Nisell $H$, Hjemdahl $P$, Linde $B$ and Lunell NO. Cardiovascular responses to isometric handgrip exercise: an invasive study in pregnancy-induced hypertension. Obstet Gynecol 1987; 70: 339-343.

24. Kuzniar J, Piela A, Skret A, Szmigiel Z and Zaczek T. Hemodynamic determinants of fetal outcome in preeclampsia. Ginekol Pol 1985; 56: 268-274.

25. Meher $\mathrm{S}$ and Neilson J. Hypertension in pregnancy. Practitioner 2004; 248: 720, 722, 724 passim.

26. Suonio $\mathrm{S}$, Olkkonen $\mathrm{H}$ and Lahtinen $\mathrm{T}$. Maternal circulatory response to a single dose of ritodrine hydrochloride during orthostasis in normal and hypertensive late pregnancy. Am J Obstet Gynecol 1978; 130: 745-747.

27. Burgess HA. Parameters of normotensive women and women with pregnancy induced hypertension (PIH) in Lusaka. East Afr Med J 1991; 68: 727-734.

28. Masson GM. Plasma oestriol in preeclampsia. J Obstet Gynaecol Br Commonw 1973; 80: 206-209.

29. Easterling TR and Benedetti TJ. Preeclampsia: a hyperdynamic disease model. Am J Obstet Gynecol 1989; 160: 1447-1453.

30. Assali NS, Holm LW and Parker HR. Systemic and Regional Hemodynamic Alterations in Toxemia. Circulation 1964; 30: SUPPL 2:53-62.
31. Ritmiller LF, Messmore IL and Nicodemus RE. The significance of hypertension in pregnancy. Pa Med J 1948; 51: 771-775.

32. Krieger $\mathrm{VI}$ and Weiden $\mathrm{S}$. The value of the cold pressor test in the prediction of hypertension and toxaemia in pregnancy. Med J Aust 1947; 1: 417-423.

33. Fernandes RM, Franchini E, Elliott-Sale KJ and Takito MY. Does pregnancy affect the metabolic equivalent at rest and during low intensity exercise? Current Women's Health Reviews 2017; 13: 38-43.

34. Rovinsky JJ and Jaffin H. Cardiovascular hemodynamics in pregnancy. II. Cardiac output and left ventricular work in multiple pregnancy. Am J Obstet Gynecol 1966; 95: 781-786.

35. Pandey AK, Banerjee AK, Das A, Bhawani G, Kumar A, Majumadar B, et al. Evaluation of maternal myocardial performance during normal pregnancy and post partum. Indian Heart J 2010; 62: 64-67.

36. Mahendru AA, Everett TR, Wilkinson IB, Lees CC and McEniery CM. Maternal cardiovascular changes from pre-pregnancy to very early pregnancy. J Hypertens 2012; 30: 2168-2172.

37. Usselman CW, Wakefield PK, Skow RJ, Stickland MK, Chari RS, Julian CG, et al. Regulation of sympathetic nerve activity during the cold pressor test in normotensive pregnant and nonpregnant women. Hypertension 2015; 66: 858-864.

38. Estensen ME, Grindheim G, Remme EW, Swillens A, Smiseth OA, Segers P, et al. Systemic arterial response and ventriculoarterial interaction during normal pregnancy. Am J Hypertens 2012; 25: 672-677.

39. Kametas NA, Savvidou MD, Donald AE, McAuliffe $F$ and Nicolaides $\mathrm{KH}$. Flowmediated dilatation of the brachial artery in pregnancy at high altitude. BJOG 2002; 109: 930-937.

40. Cong J, Yang X, Zhang N, Shen J, Fan T and Zhang Z. Quantitative analysis of left atrial volume and function during normotensive 
and preeclamptic pregnancy: a real-time three-dimensional echocardiography study. Int J Cardiovasc Imaging 2015; 31: 805-812.

41. Carpenter RE, Emery SJ, Uzun O, Rassi D and Lewis MJ. Influence of physical exercise on baroreceptor sensitivity during pregnancy. J Matern Fetal Neonatal Med 2017; 30: 514-519.

42. Schmidt SML, Usselman CW, Martinek E, Stickland MK, Julian CG, Chari R, et al. Activity of muscle sympathetic neurons during normotensive pregnancy. Am J Physiol Regul Integr Comp Physiol 2018; 314: R153-R160.

43. Larkin H, Gallery ED, Hunyor SN, Gyory AZ and Boyce ES. Cardiac and haemodynamic measurements in hypertensive pregnancy. Clin Sci (Lond) 1980; 59 Suppl 6: 357s-360s.

44. Ducas RA, Elliott JE, Melnyk SF, Premecz S, daSilva M, Cleverley K, et al. Cardiovascular magnetic resonance in pregnancy: insights from the cardiac hemodynamic imaging and remodeling in pregnancy (CHIRP) study. J Cardiovasc Magn Reson 2014; 16: 1.

45. Rang $S$, de Pablo Lapiedra B, van Montfrans $\mathrm{GA}$, Bouma BJ, Wesseling $\mathrm{KH}$ and Wolf $\mathrm{H}$. Modelflow: a new method for noninvasive assessment of cardiac output in pregnant women. Am J Obstet Gynecol 2007; 196: 235 e231-238.

46. Petersen JW, Liu J, Chi YY, Lingis $M$, Williams RS, Rhoton-Vlasak A, et al. Comparison of multiple non-invasive methods of measuring cardiac output during pregnancy reveals marked heterogeneity in the magnitude of cardiac output change between women. Physiol Rep 2017; 5

47. de Haas S, Mulder EG, Schartmann N, Mohseni Z, Abo Hasson F, Alsadah F, et al. Blood Pressure Adjustments Throughout Healthy and Hypertensive Pregnancy: A Systematic Review and Meta-analysis. Submitted manuscript
48. Morris EA, Hale SA, Badger GJ, Magness RR and Bernstein IM. Pregnancy induces persistent changes in vascular compliance in primiparous women. Am J Obstet Gynecol 2015; 212: 633 e631-636.

49. Melchiorre K, Sharma R, Khalil A and Thilaganathan B. Maternal Cardiovascular Function in Normal Pregnancy: Evidence of Maladaptation to Chronic Volume Overload. Hypertension 2016; 67: 754-762.

50. Clapp JF, 3rd and Capeless E. Cardiovascular function before, during, and after the first and subsequent pregnancies. $A m \mathrm{~J}$ Cardiol 1997; 80: 1469-1473.

51. Mezzacappa ES, Kelsey RM, Myers MM and Katkin ES. Breast-feeding and maternal cardiovascular function. Psychophysiology 2001; 38: 988-997.

52. Turan OM, De Paco C, Kametas N, Khaw $A$ and Nicolaides KH. Effect of parity on maternal cardiac function during the first trimester of pregnancy. Ultrasound Obstet Gynecol 2008; 32: 849-854.

53. Ling HZ, Guy GP, Bisquera A, Poon LC, Nicolaides KH and Kametas NA. The effect of parity on longitudinal maternal hemodynamics. Am J Obstet Gynecol 2019; 221: 249 e241-249 e214.

54. Savu O, Jurcut R, Giusca S, van Mieghem T, Gussi I, Popescu BA, et al. Morphological and functional adaptation of the maternal heart during pregnancy. Circ Cardiovasc Imaging 2012; 5: 289-297.

55. Robson SC, Hunter S, Boys RJ and Dunlop W. Serial study of factors influencing changes in cardiac output during human pregnancy. Am J Physiol 1989; 256: H10601065.

56. Andreas M, Kuessel L, Kastl SP, Wirth S, Gruber K, Rhomberg F, et al. Bioimpedance cardiography in pregnancy: A longitudinal cohort study on hemodynamic pattern and outcome. BMC Pregnancy Childbirth 2016; 16: 128.

57. Clark SL, Cotton DB, Pivarnik JM, Lee W, Hankins GD, Benedetti TJ, et al. Position 
change and central hemodynamic profile during normal third-trimester pregnancy and post partum. Am J Obstet Gynecol 1991; 164: 883-887.

58. Bamber JH and Dresner M. Aortocaval compression in pregnancy: the effect of changing the degree and direction of lateral tilt on maternal cardiac output. Anesth Analg 2003; 97: 256-258, table of contents.

59. Spaanderman ME, Willekes C, Hoeks AP, Ekhart TH and Peeters LL. The effect of pregnancy on the compliance of large arteries and veins in healthy parous control subjects and women with a history of preeclampsia. Am J Obstet Gynecol 2000; 183: 1278-1286.

60. Leo $\mathrm{CH}$, Jelinic $\mathrm{M}, \mathrm{Ng} \mathrm{HH}$, Marshall SA, Novak J, Tare M, et al. Vascular actions of relaxin: nitric oxide and beyond. $\mathrm{Br} J$ Pharmacol 2017; 174: 1002-1014.

61. Spaanderman ME, Meertens M, van Bussel M, Ekhart TH and Peeters LL. Cardiac output increases independently of basal metabolic rate in early human pregnancy. Am J Physiol Heart Circ Physiol 2000; 278 : H1585-1588.

62. Jaffe R, Jauniaux E and Hustin J. Maternal circulation in the first-trimester human placenta--myth or reality? Am J Obstet Gynecol 1997; 176: 695-705.

63. Chapman AB, Zamudio S, Woodmansee W, Merouani A, Osorio F, Johnson A, et al. Systemic and renal hemodynamic changes in the luteal phase of the menstrual cycle mimic early pregnancy. Am J Physiol 1997; 273: F777-782.

64. Duvekot JJ, Cheriex EC, Pieters FA, Menheere PP and Peeters LH. Early pregnancy changes in hemodynamics and volume homeostasis are consecutive adjustments triggered by a primary fall in systemic vascular tone. Am J Obstet Gynecol 1993; 169: 1382-1392.

65. Linde T, Sandhagen B, Hägg A, Mörlin C, Wikström B and Danielson BG. Blood viscosity and peripheral vascular resistance in patients with untreated essential hypertension. J Hypertens 1993; 11: 731-736.

66. Whittaker PG, Macphail S and Lind T. Serial hematologic changes and pregnancy outcome. Obstet Gynecol 1996; 88: 33-39.

67. Jarvis SS, Shibata S, Bivens TB, Okada Y, Casey BM, Levine BD, et al. Sympathetic activation during early pregnancy in humans. J Physiol 2012; 590: 3535-3543.

68. Okada Y, Best SA, Jarvis SS, Shibata S, Parker RS, Casey BM, et al. Asian women have attenuated sympathetic activation but enhanced renal-adrenal responses during pregnancy compared to Caucasian women. J Physiol 2015; 593: 1159-1168.

69. Usselman CW, Skow RJ, Matenchuk BA, Chari RS, Julian CG, Stickland MK, et al. Sympathetic baroreflex gain in normotensive pregnant women. J Appl Physiol (1985) 2015; 119: 468-474.

70. Thadhani R, Ecker JL, Kettyle E, Sandler $\mathrm{L}$ and Frigoletto FD. Pulse pressure and risk of preeclampsia: a prospective study. Obstet Gynecol 2001; 97: 515-520.

71. Foo FL, Mahendru AA, Masini G, Fraser A, Cacciatore S, Macintyre DA, et al. Association Between Prepregnancy Cardiovascular Function and Subsequent Preeclampsia or Fetal Growth Restriction. Hypertension 2018; 72: 442-450.

72. McLaughlin K, Scholten RR, Kingdom JC, Floras JS and Parker JD. Should Maternal Hemodynamics Guide Antihypertensive Therapy in Preeclampsia? Hypertension 2018; 71: 550-556

73. Easterling TR, Brateng D, Schmucker B, Brown Z and Millard SP. Prevention of preeclampsia: a randomized trial of atenolol in hyperdynamic patients before onset of hypertension. Obstet Gynecol 1999; 93: 725-733.

74. Chaffin DG and Webb DG. Outcomes of pregnancies at risk for hypertensive complications managed using impedance cardiography. Am J Perinatol 2009; 26: 717721. 


\section{SUPPLEMENTAL MATERIAL}

Appendix S1. Literature search: strategy for PubMed (NCBI) and Embase (Ovid) databases. Limits: Species: Humans and Article type: Journal Article.

\begin{tabular}{lll}
\hline Component & PubMed & Embase \\
\hline Pregnancy & "Pregnancy" [Mesh] OR "pregnancy" [Title/Abstract] & exp pregnancy/ or exp gravidity/ or exp \\
& OR "pregnancies" [Title/Abstract] OR "pregnant" & gestation/ or (pregnancy or pregnancies \\
& [Title/Abstract] OR "gestation" [Title/Abstract] OR & or pregnant or gestation or gestations or \\
& "gestations" [Title/Abstract] OR "gestational” [Title/ & gestational or gravidity or gravidities or \\
& Abstract] OR "gravidity" [Mesh] OR "gravidity" & gravid).ti,ab. \\
& [Title/Abstract] OR "gravidities" [Title/Abstract] OR
\end{tabular}

\begin{tabular}{|c|c|}
\hline $\begin{array}{l}\text { Pregnancy- } \\
\text { induced } \\
\text { hypertension }\end{array}$ & $\begin{array}{l}\text { "Hypertension, pregnancy-induced" [Mesh] } \\
\text { OR "pregnancy induced hypertension" [Title/ } \\
\text { Abstract] OR "pregnancy associated hypertension" } \\
\text { [Title/Abstract] OR “PIH" [Title/Abstract] OR } \\
\text { "hypertensive pregnancy" [Title/Abstract] OR } \\
\text { "pregnancy hypertension" [Title/Abstract] OR } \\
\text { "gestational hypertension" [Title/Abstract] OR } \\
\text { "HELLP syndrome" [Mesh] OR "HELLP" [Title/ } \\
\text { Abstract] OR "Hemolysis, Elevated Liver Enzymes, } \\
\text { Lowered Platelets" [Title/Abstract] }\end{array}$ \\
\hline Preeclampsia & $\begin{array}{l}\text { "Pre-eclampsia" [Mesh] OR "pre-eclampsia" [Title/ } \\
\text { Abstract] OR "preeclampsia" [Title/Abstract] OR } \\
\text { "preeclamptic" [Title/Abstract] OR "pre-eclamptic" } \\
\text { [Title/Abstract] or "PE" [Title/Abstract] OR } \\
\text { "Eclampsia" [Mesh] OR "eclampsia" [Title/Abstract] } \\
\text { OR "eclampsias" [Title/Abstract] OR "eclamptic" } \\
\text { [Title/Abstract] OR "toxemia" [Title/Abstract] OR } \\
\text { "toxemias" [Title/Abstract] }\end{array}$ \\
\hline
\end{tabular}

Foetal growth "Fetal Growth Retardation" [Mesh] OR "foetal restriction growth retardation" [Title/Abstract] OR "fetal growth restriction" [Title/Abstract] OR "FGR" [Title/ Abstract] OR "intrauterine growth retardation" [Title/Abstract] OR "intrauterine growth restriction" [Title/Abstract] OR “IUGR" [Title/Abstract] OR "Infant, Small for Gestational Age" [Mesh] OR "small ).ti,ab. for gestational age" [Title/Abstract] OR "SGA" [Title/ Abstract]

Cardiac "cardiac output" [MeSH Terms] OR "cardiac output output"[Title/Abstract] OR "heart minute volume"[Title/Abstract]

$\begin{array}{ll}\text { Total } & \text { "vascular resistance"[MeSH] OR "vascular } \\ \text { peripheral } & \text { resistance "[Title/Abstract] OR "peripheral } \\ \text { vascular } & \text { resistance"[Title/Abstract] OR "total peripheral } \\ \text { resistance } & \text { resistance"[Title/Abstract] OR "total vascular } \\ & \text { resistance"[Title/Abstract] OR "total peripheral } \\ & \text { vascular resistance"[Title/Abstract] }\end{array}$

exp maternal hypertension/ or exp HELLP syndrome/ or (pregnancy induced hypertension or pregnancy associated hypertension or $\mathrm{PIH}$ or hypertensive pregnancy or pregnancy hypertension or gestational hypertension or HELLP or Hemolysis, Elevated Liver Enzymes, Lowered Platelets).ti,ab.

exp preeclampsia/ or exp eclampsia/ or (pre-eclampsia or preeclampsia or pre-eclamptic or preeclamptic or PE or eclampsia or eclampsias or eclamptic or toxemia or toxemias).ti,ab.

exp intrauterine growth retardation/ or exp small for date infant/ or (fetal growth retardation or fetal growth restriction or FGR or intrauterine growth retardation or intrauterine growth restriction or IUGR or small for gestational age or SGA

Exp heart output/ OR (cardiac minute volume or cardiac output or cardiac ventricle output or heart minute volume or heart ventricle output or heart output or cardiac output).ti,ab

Exp vascular resistance/ or (total peripheral vascular resistance or total vascular resistance or total peripheral resistance or vascular resistance or peripheral resistance).ti,ab. 
Appendix S1. (continued)

\begin{tabular}{|c|c|c|}
\hline Component & PubMed & Embase \\
\hline Stroke volume & $\begin{array}{l}\text { "stroke volume"[MeSH Terms] OR "ejection } \\
\text { fraction"[Title/Abstract]OR "stroke volume"[Title/ } \\
\text { Abstract] OR "end systolic volume"[Title/Abstract] } \\
\text { OR "end diastolic volume"[Title/Abstract] }\end{array}$ & $\begin{array}{l}\text { Exp stroke volume/ OR exp ejection } \\
\text { fraction/ OR exp heart left ventricle } \\
\text { endsystolic volume/ OR exp heart left } \\
\text { ventricle enddiastolic volume/ OR } \\
\text { (stroke volume or ejection fraction or } \\
\text { endsystolic volume or enddiastolic } \\
\text { volume).ti,ab }\end{array}$ \\
\hline Heart rate & $\begin{array}{l}\text { "heart rate"[MeSH] OR "heart rate"[Title/Abstract] } \\
\text { OR "cardiac frequency"[Title/Abstract] OR "cardiac } \\
\text { rate"[ Title/Abstract] OR "heart frequency" [Title/ } \\
\text { Abstract] }\end{array}$ & $\begin{array}{l}\text { Exp heart rate/ or (heart rate or cardiac } \\
\text { frequency or cardiac rate or heart } \\
\text { frequency).ti,ab. }\end{array}$ \\
\hline $\begin{array}{l}\text { Blood } \\
\text { pressure }\end{array}$ & $\begin{array}{l}\text { "blood pressure"[MeSH] OR "blood pressure"[Title/ } \\
\text { Abstract] OR "vascular pressure"[Title/Abstract] } \\
\text { OR "arterial pressure"[MeSH] OR "arterial } \\
\text { pressure"[Title/Abstract] OR "diastolic blood } \\
\text { pressure"[Title/Abstract] OR "systolic blood } \\
\text { pressure"[Title/Abstract] OR "mean arterial } \\
\text { pressure"[Title/Abstract] }\end{array}$ & $\begin{array}{l}\text { Exp blood pressure/ OR mean arterial } \\
\text { pressure/ or (blood pressure or blood } \\
\text { tension or vascular pressure or arterial } \\
\text { pressure or diastolic blood pressure or } \\
\text { systolic blood pressure or mean arterial } \\
\text { pressure).ti,ab }\end{array}$ \\
\hline
\end{tabular}


Appendix S2. References included in the meta-analysis in alphabetical order

- Ahmad HR, Akhtar S, Khan MA, et al. Dynamic and steady state response of heart rate to orthostatic stress in normotensive and hypertensive pregnant women. European journal of obstetrics, gynecology, and reproductive biology 1996; 66: 31-37.

- Airaksinen KE, Ikaheimo MJ, Salmela PI, et al. Impaired cardiac adjustment to pregnancy in type I diabetes. Diabetes care 1986; 9: 376-383.

- Andreas M, Kuessel L, Kastl SP, et al. Bioimpedance cardiography in pregnancy: A longitudinal cohort study on hemodynamic pattern and outcome. BMC pregnancy and childbirth 2016; 16: 128.

- Badrov MB, Park SY, Yoo JK, et al. Role of Corin in Blood Pressure Regulation in Normotensive and Hypertensive Pregnancy. Hypertension 2019; 73: 432-439.

- Bamfo JE, Kametas NA, Nicolaides KH, et al. Reference ranges for tissue Doppler measures of maternal systolic and diastolic left ventricular function. Ultrasound in obstetrics \& gynecology 2007; 29: 414-420.

- Bamfo JE, Kametas NA, Nicolaides KH, et al. Maternal left ventricular diastolic and systolic longaxis function during normal pregnancy. European journal of echocardiography 2007; 8: 360-368.

- Borghi C, Esposti DD, Immordino V, et al. Relationship of systemic hemodynamics, left ventricular structure and function, and plasma natriuretic peptide concentrations during pregnancy complicated by preeclampsia. American journal of obstetrics and gynecology 2000; 183: 140-147.

- Burg JR, Dodek A, Kloster FE, et al. Alterations of systolic time intervals during pregnancy. Circulation 1974; 49: 560-564.

- Campos O. Doppler Echocardiography During Pregnancy: Physiological and Abnormal Findings. Echocardiography 1996; 13: 135-146.

- Capeless EL and Clapp JF. Cardiovascular changes in early phase of pregnancy. American journal of obstetrics and gynecology 1989; 161: 1449-1453.

- Carpenter RE, Emery SJ, Uzun O, et al. Influence of antenatal physical exercise on haemodynamics in pregnant women: a flexible randomisation approach. BMC pregnancy and childbirth 2015; 15: 186

- Chamchad D, Horrow JC, Nakhamchik L, et al. Heart rate variability changes during pregnancy: an observational study. International journal of obstetric anesthesia 2007; 16: 106-109.

- Charkoudian N, Usselman CW, Skow RJ, et al. Muscle sympathetic nerve activity and volumeregulating factors in healthy pregnant and nonpregnant women. American journal of physiology Heart and circulatory physiology 2017; 313: H782-H787.

- Clapp JF, 3rd. Maternal heart rate in pregnancy. American journal of obstetrics and gynecology 1985; 152: 659-660.

- Clapp JF, 3rd and Capeless E. Cardiovascular function before, during, and after the first and subsequent pregnancies. The American journal of cardiology 1997; 80: 1469-1473.

- Cong J, Fan T, Yang X, et al. Structural and functional changes in maternal left ventricle during pregnancy: a three-dimensional speckle-tracking echocardiography study. Cardiovascular ultrasound 2015; $13: 6$.

- Cong J, Yang X, Zhang N, et al. Quantitative analysis of left atrial volume and function during normotensive and preeclamptic pregnancy: a real-time three-dimensional echocardiography study. The international journal of cardiovascular imaging 2015; 31: 805-812.

- Conrad KP, Petersen JW, Chi YY, et al. Maternal Cardiovascular Dysregulation During Early Pregnancy After In Vitro Fertilization Cycles in the Absence of a Corpus Luteum. Hypertension 2019; 74: 705-715. 
- Del Bene R, Barletta G, Mello G, et al. Cardiovascular function in pregnancy: effects of posture. BJOG: an international journal of obstetrics and gynaecology 2001; 108: 344-352.

- Dennis AT, Castro J, Carr C, et al. Haemodynamics in women with untreated pre-eclampsia. Anaesthesia 2012; 67: 1105-1118.

- Desai DK, Moodley J and Naidoo DP. Echocardiographic assessment of cardiovascular hemodynamics in normal pregnancy. Obstetrics and gynecology 2004; 104: 20-29.

- Dorup I, Skajaa K and Sorensen KE. Normal pregnancy is associated with enhanced endotheliumdependent flow-mediated vasodilation. The American journal of physiology 1999; 276: H821-825.

- Droste S, Sorensen T, Price T, et al. Maternal and fetal hemodynamic effects of autologous blood donation during pregnancy. American journal of obstetrics and gynecology 1992; 167: 89-93.

- Correa MDS, Catai AM, Milan-Mattos JC, et al. Cardiovascular autonomic modulation and baroreflex control in the second trimester of pregnancy: A cross sectional study. PloS one. 2019;14(5):e0216063.

- D'Silva LA, Davies RE, Emery SJ, et al. Influence of somatic state on cardiovascular measurements in pregnancy. Physiological measurement 2014; 35: 15-29.

- Ducas RA, Elliott JE, Melnyk SF, et al. Cardiovascular magnetic resonance in pregnancy: insights from the cardiac hemodynamic imaging and remodeling in pregnancy (CHIRP) study. Journal of cardiovascular magnetic resonance 2014; $16: 1$.

- Dyer RA, Anthony J, Ledeboer Q, et al. Cardiovascular responses to the change from the left lateral to the upright position in pregnant hypertensives. International journal of gynaecology and obstetrics 2004; 84: 208-213.

- Ekholm EM, Piha SJ, Antila KJ, et al. Cardiovascular autonomic reflexes in mid-pregnancy. British journal of obstetrics and gynaecology 1993; 100: 177-182.

- Eneroth-Grimfors E, Westgren M, Ericson M, et al. Autonomic cardiovascular control in normal and pre-eclamptic pregnancy. Acta obstetricia et gynecologica Scandinavica 1994; 73: 680-684.

- Estensen ME, Beitnes JO, Grindheim G, et al. Altered maternal left ventricular contractility and function during normal pregnancy. Ultrasound in obstetrics \& gynecology 2013; 41: 659-666.

- Fok WY, Chan LY, Wong JT, et al. Left ventricular diastolic function during normal pregnancy: assessment by spectral tissue Doppler imaging. Ultrasound in obstetrics \& gynecology 2006; 28: 789-793.

- Geva T, Mauer MB, Striker L, et al. Effects of physiologic load of pregnancy on left ventricular contractility and remodeling. American heart journal 1997; 133: 53-59.

- Giannubilo SR, Pasculli A, Tidu E, et al. Relationship between maternal hemodynamics and plasma natriuretic peptide concentrations during pregnancy complicated by preeclampsia and fetal growth restriction. Journal of perinatology 2017; 37: 484-487.

- Gilson GJ, Samaan S, Crawford MH, et al. Changes in hemodynamics, ventricular remodeling, and ventricular contractility during normal pregnancy: a longitudinal study. Obstetrics and gynecology 1997; 89: 957-962.

- Greenwood JP, Scott EM, Stoker JB, et al. Sympathetic neural mechanisms in normal and hypertensive pregnancy in humans. Circulation 2001; 104: 2200-2204.

- Hale S, Choate M, Schonberg A, et al. Pulse pressure and arterial compliance prior to pregnancy and the development of complicated hypertension during pregnancy. Reproductive sciences 2010; 17: 871-877.

- Hart MV, Morton MJ, Hosenpud JD, et al. Aortic function during normal human pregnancy. American journal of obstetrics and gynecology 1986; 154: 887-891. 
- Hasan KM, Manyonda IT, Ng FS, et al. Skin capillary density changes in normal pregnancy and pre-eclampsia. Journal of hypertension 2002; 20: 2439-2443.

- Heiskanen N, Saarelainen H, Karkkainen H, et al. Cardiovascular autonomic responses to headup tilt in gestational hypertension and normal pregnancy. Blood pressure 2011 ; 20: 84-91.

- Hennessy TG, MacDonald D, Hennessy MS, et al. Serial changes in cardiac output during normal pregnancy: a Doppler ultrasound study. European journal of obstetrics, gynecology, and reproductive biology 1996; 70: 117-122.

- lacobaeus C, Andolf E, Thorsell M, et al. Cardiac function, myocardial mechano-energetic efficiency, and ventricular-arterial coupling in normal pregnancy. Journal of hypertension 2018; 36 : 857-866.

- Jarvis SS, Shibata S, Bivens TB, et al. Sympathetic activation during early pregnancy in humans. The Journal of physiology 2012; 590: 3535-3543.

- Kaaja RJ, Leinonen A, Moore P, et al. Effect of changes in body posture on vasoactive hormones in pre-eclamptic women. Journal of human hypertension 2004; 18: 789-794.

- Kametas NA, McAuliffe F, Cook B, et al. Maternal left ventricular transverse and long-axis systolic function during pregnancy. Ultrasound in obstetrics \& gynecology 2001; 18: 467-474.

- Kametas NA, McAuliffe F, Krampl E, et al. Maternal cardiac function during pregnancy at high altitude. BJOG : an international journal of obstetrics and gynaecology 2004; 111: 1051-1058.

- Karkkainen H, Saarelainen H, Laitinen T, et al. Ambulatory arterial stiffness index and nocturnal blood pressure dipping in pregnancies complicated by hypertension. Clinical physiology and functional imaging 2014; 34: 39-46.

- Khan F, Mires G, Macleod M, et al. Relationship between maternal arterial wave reflection, microvascular function and fetal growth in normal pregnancy. Microcirculation 2010; 17: 608-614.

- Khodiguian N, Jaque-Fortunato SV, Wiswell RA, et al. A comparison of cross-sectional and longitudinal methods of assessing the influence of pregnancy on cardiac function during exercise. Seminars in perinatology 1996; 20: 232-241.

- Kishan A, Shastry N, Moodithaya SS, et al. Diminished vagal tone and enhanced sympathetic drive during third trimester of gestation among healthy women. Indian journal of physiology and pharmacology 2018; 62: 407-412.

- Kolovetsiou-Kreiner V, Moertl MG, Papousek I, et al. Maternal cardiovascular and endothelial function from first trimester to postpartum. PloS one. 2018;13(5):e0197748.

- Larkin H, Gallery ED, Hunyor SN, et al. Cardiac and haemodynamic measurements in hypertensive pregnancy. Clinical science 1980; 59 Suppl 6: 357s-360s.

- Lechmanova M, Kittnar O, Mlcek M, et al. QT dispersion and T-loop morphology in late pregnancy and after delivery. Physiological research 2002; 51: 121-129.

- Lewinsky RM and Riskin-Mashiah S. Autonomic imbalance in preeclampsia: evidence for increased sympathetic tone in response to the supine-pressor test. Obstetrics and gynecology 1998; 91: 935-939.

- Lim YL and Walters WA. Systolic time intervals in normotensive and hypertensive human pregnancy. American journal of obstetrics and gynecology 1976; 126: 26-32.

- Lof M, Olausson H, Bostrom K, et al. Changes in basal metabolic rate during pregnancy in relation to changes in body weight and composition, cardiac output, insulin-like growth factor I, and thyroid hormones and in relation to fetal growth. The American journal of clinical nutrition 2005; 81: 678-685.

- Mabie WC, DiSessa TG, Crocker LG, et al. A longitudinal study of cardiac output in normal human pregnancy. American journal of obstetrics and gynecology 1994; 170: 849-856. 
- Macedo ML, Luminoso D, Savvidou MD, et al. Maternal wave reflections and arterial stiffness in normal pregnancy as assessed by applanation tonometry. Hypertension 2008; 51: 1047-1051.

- Mahendru AA, Everett TR, Wilkinson IB, et al. A longitudinal study of maternal cardiovascular function from preconception to the postpartum period. Journal of hypertension 2014; 32: 849856.

- Mangos JG, Pettit F, Preece R, et al. Repeatability of USCOM(R)-measured cardiac output in normotensive non-pregnant and pregnant women. Pregnancy hypertension. 2018;12:71-4.

- Martin RB, Nelson DB, Stewart R, et al. Impact of Pregnancy on Maternal Cardiac Atria. American journal of perinatology 2017; 34: 1097-1101.

- Mashini IS, Albazzaz SJ, Fadel HE, et al. Serial noninvasive evaluation of cardiovascular hemodynamics during pregnancy. American journal of obstetrics and gynecology 1987; 156: 1208-1213.

- McHugh A, El-Khuffash A, Bussmann N, et al. Hyperoxygenation in pregnancy exerts a more profound effect on cardiovascular hemodynamics than is observed in the nonpregnant state. American journal of obstetrics and gynecology. 2019 Apr;220(4):397 e1- e8.

- Meah VL, Backx K, Cockcroft JR, et al. Left ventricular mechanics in late second trimester of healthy pregnancy. Ultrasound in obstetrics \& gynecology 2019 Sep;54(3):350-8.

- Melchiorre K, Sharma R, Khalil A, et al. Maternal Cardiovascular Function in Normal Pregnancy: Evidence of Maladaptation to Chronic Volume Overload. Hypertension 2016; 67: 754-762.

- Mersich B, Rigo J, Jr., Besenyei C, et al. Opposite changes in carotid versus aortic stiffness during healthy human pregnancy. Clinical science 2005; 109: 103-107.

- Mesa A, Jessurun C, Hernandez A, et al. Left ventricular diastolic function in normal human pregnancy. Circulation 1999; 99: 511-517.

- Miyake Y, Ohnishi M, Fujii TK, et al. The effects of postural changes of baroreflex gain in normal and hypertensive pregnancies. Clinical and experimental hypertension 2002; 24: 23-31.

- Mone SM, Sanders SP and Colan SD. Control mechanisms for physiological hypertrophy of pregnancy. Circulation 1996; 94: 667-672.

- Niemczyk NA, Catov JM, Desai MM, et al. Brachial artery stiffening in healthy primigravidas is associated with weight gain and increased cardiac output. Hypertension in pregnancy. 2018;37(4):204-11.

- $\quad$ Nii M, Ishida M, Dohi K, et al. Myocardial tissue characterization and strain analysis in healthy pregnant women using cardiovascular magnetic resonance native T1 mapping and feature tracking technique. Journal of cardiovascular magnetic resonance 2018 Aug 2;20(1):52.

- Ogueh O, Brookes C and Johnson MR. A longitudinal study of the maternal cardiovascular adaptation to spontaneous and assisted conception pregnancies. Hypertension in pregnancy 2009; 28 : 273-289.

- Ohashi Y, Ibrahim H, Furtado L, et al. Non-invasive hemodynamic assessment of non-pregnant, healthy pregnant and preeclamptic women using bioreactance. Revista brasileira de anestesiologia 2010; 60: 603-613, 335-640.

- Pandey A, Das A, Srinivas C, et al. Maternal Myocardial Performance in Various Stages of Pregnancy and Post-Partum. Research Journal of Cardiology 2010; 3: 9-16.

- Pandey AK, Siwach S, Sangwan V, et al. Assessment of maternal vascular stiffness indices in three trimesters of normal pregnancy. Indian journal of physiology and pharmacology 2014; 58: 197205.

- Papadopoulou E, Kaladaridou A, Agrios J, et al. Factors Influencing the twisting and untwisting properties of the left ventricle during normal pregnancy. Echocardiography 2014; 31: 155-163. 
- Petersen JW, Liu J, Chi YY, et al. Comparison of multiple non-invasive methods of measuring cardiac output during pregnancy reveals marked heterogeneity in the magnitude of cardiac output change between women. Physiological reports 2017; 5.

- Pivarnik JM, Stein AD and Rivera JM. Effect of pregnancy on heart rate/oxygen consumption calibration curves. Medicine and science in sports and exercise 2002; 34: 750-755.

- Purdy GM, James MA, Wakefield PK, et al. Maternal cardioautonomic responses during and following exercise throughout pregnancy. Applied physiology, nutrition, and metabolism 2019; 44: 263-270.

- Rang S, de Pablo Lapiedra B, van Montfrans GA, et al. Modelflow: a new method for noninvasive assessment of cardiac output in pregnant women. American journal of obstetrics and gynecology 2007; 196: 235 e231-238.

- Rang S, van Montfrans GA and Wolf H. Serial hemodynamic measurement in normal pregnancy, preeclampsia, and intrauterine growth restriction. American journal of obstetrics and gynecology 2008; 198: 519 e511-519.

- Rovinsky JJ and Jaffin H. Cardiovascular hemodynamics in pregnancy. 3. Cardiac rate, stroke volume, total peripheral resistance, and central blood volume in multiple pregnancy. Synthesis of results. American journal of obstetrics and gynecology 1966; 95: 787-794.

- Rubler S, Damani PM and Pinto ER. Cardiac size and performance during pregnancy estimated with echocardiography. The American journal of cardiology 1977; 40: 534-540.

- Sadaniantz A, Kocheril AG, Emaus SP, et al. Cardiovascular changes in pregnancy evaluated by two-dimensional and Doppler echocardiography. Journal of the American Society of Echocardiography 1992; 5: 253-258.

- San-Frutos LM, Fernandez R, Almagro J, et al. Measure of hemodynamic patterns by thoracic electrical bioimpedance in normal pregnancy and in preeclampsia. European journal of obstetrics, gynecology, and reproductive biology 2005; 121: 149-153.

- Savu O, Jurcut R, Giusca S, et al. Morphological and functional adaptation of the maternal heart during pregnancy. Circulation Cardiovascular imaging 2012; 5: 289-297.

- Sengupta SP, Bansal M, Hofstra L, et al. Gestational changes in left ventricular myocardial contractile function: new insights from two-dimensional speckle tracking echocardiography. The international journal of cardiovascular imaging 2017; 33: 69-82.

- Simmons LA, Gillin AG and Jeremy RW. Structural and functional changes in left ventricle during normotensive and preeclamptic pregnancy. American journal of physiology Heart and circulatory physiology 2002; 283: H1627-1633.

- Smith SA, Morris JM and Gallery ED. Methods of assessment of the arterial pulse wave in normal human pregnancy. American journal of obstetrics and gynecology 2004; 190: 472-476.

- Sorensen B, Laursen K, Rasmussen JP, et al. Changes in cardiac function during and after pregnancy expressed by systolic time intervals. Acta obstetricia et gynecologica Scandinavica 1976; 55: 447-451.

- Spaanderman MEA, Meertens M, van Bussel M, et al. Cardiac output increases independently of basal metabolic rate in early human pregnancy. American journal of physiology Heart and circulatory physiology 2000; 278: H1585-1588.

- Speranza G, Verlato $G$ and Albiero A. Autonomic changes during pregnancy: assessment by spectral heart rate variability analysis. Journal of electrocardiology 1998; 31: 101-109.

- Teli A, Bagali S and Ghatanatti R. A Prediction Formula for Double Product in Pregnancy. Journal of clinical and diagnostic research 2016; 10: CC20-22. 
- Thomsen JK, Storm TL, Thamsborg G, et al. Increased concentration of circulating atrial natriuretic peptide during normal pregnancy. European journal of obstetrics, gynecology, and reproductive biology 1988; 27: 197-201.

- Tihtonen KM, Koobi T and Uotila JT. Arterial stiffness in preeclamptic and chronic hypertensive pregnancies. European journal of obstetrics, gynecology, and reproductive biology 2006; 128: 180-186.

- Tso G LJ, Shaban NM, Lui GK, et al. Normal Echocardiographic Measurements in Uncomplicated Pregnancy, a Single Center Experience. Journal of Cardiovascular Disease Research 2014; 5.

- Ueland K, Novy MJ, Peterson EN, et al. Maternal cardiovascular dynamics. IV. The influence of gestational age on the maternal cardiovascular response to posture and exercise. American journal of obstetrics and gynecology 1969; 104: 856-864.

- Vaha-Eskeli KK, Erkkola RU, Seppanen A, et al. Haemodynamic response to moderate thermal stress in pregnancy. Annals of medicine 1991; 23: 121-126.

- Valensise H, Vasapollo B, Gagliardi G, et al. Early and late preeclampsia: two different maternal hemodynamic states in the latent phase of the disease. Hypertension 2008; 52: 873-880.

- van Oppen AC, van der Tweel I, Alsbach GP, et al. A longitudinal study of maternal hemodynamics during normal pregnancy. Obstetrics and gynecology 1996; 88: 40-46.

- Vartun A, Flo K and Acharya G. Effect of passive leg raising on systemic hemodynamics of pregnant women: a dynamic assessment of maternal cardiovascular function at 22-24 weeks of gestation. PloS one 2014; 9: e94629.

- Visontai Z, Lenard Z, Studinger P, et al. Impaired baroreflex function during pregnancy is associated with stiffening of the carotid artery. Ultrasound in obstetrics \& gynecology 2002; 20: 364-369.

- Wykretowicz M, Krauze T, Guzik P, et al. Arterial stiffness, central hemodynamics and wave reflection in normal pregnancy and control nonpregnant women. European journal of obstetrics, gynecology, and reproductive biology 2011; 159: 49-52.

- Yosefy C, Shenhav S, Feldman V, et al. Left atrial function during pregnancy: a three-dimensional echocardiographic study. Echocardiography 2012; 29: 1096-1101.

- Yu L, Zhou Q, Peng Q, et al. Left ventricular function of patients with pregnancy-induced hypertension evaluated using velocity vector imaging echocardiography and $\mathrm{N}$-terminal pro-brain natriuretic peptide. Echocardiography 2018; 35: 459-466.

- Yuan LJ, Xue D, Duan YY, et al. Maternal carotid remodeling and increased carotid arterial stiffness in normal late-gestational pregnancy as assessed by radio-frequency ultrasound technique. BMC pregnancy and childbirth 2013; 13: 122. 
Study

$<14$ weeks

Conrad 2019

Niemczyk 2018

lacobaeus 2017

Petersen 2017

Sengupta 2017

Andreas 2016

Melchiorre 2016

Carpenter 2015

Mahendru 2014

Papadopoulou 2014

Jarvis 2012

Savu 2012

Hale 2010

Ogueh 2009

Rang 2008

Rang 2007

Lof 2005

Del Bene 2001

Spaanderman 2000

Mesa 1999

Clapp 1997

Geva 1997

Campos 1996

Mone 1996

van Oppen 1996

Mabie 1994

Capeless 1989

Mashini 1987

Airaksinen 1986

Summary

$I^{2}=71 \%$

15-21 weeks

Conrad 2019

Andreas 2016

D'Silva 2014

Estensen 2013

Ogueh 2009

Rang 2008

Desai 2004

Kametas 2001

Clapp 1997

Geva 1997

Gilson 1997

Mone 1996

van Oppen 1996

Capeless 1989

Mashini 1987

Rubler 1977

Summary

$l^{2}=89 \%$

\section{Sample size}

Pregnant Reference

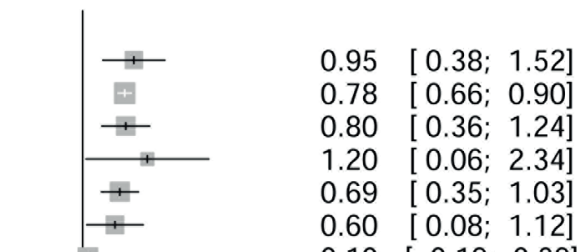

$0.10 \quad[-0.19 ; 0.39]$

$1.40 \quad$ [0.96; 1.84$]$

$0.20 \quad[-0.22 ; 0.62]$

$-0.53[-1.26 ; 0.20]$

$0.30 \quad[-0.14 ; 0.74]$

$0.60 \quad[0.30 ; 0.90]$

$0.60 \quad[-0.04 ; 1.24]$

$0.36 \quad[-0.38 ; 1.10]$

$1.60 \quad[0.94 ; 2.26]$

$0.40 \quad[-0.33 ; 1.13]$

$0.90 \quad[0.36 ; 1.44]$

$1.11 \quad[-0.40 ; 2.62]$

$0.80 \quad[0.39 ; 1.21]$

$0.00 \quad[-0.60 ; 0.60]$

$1.21 \quad[0.52 ; 1.90]$

$0.38 \quad[-0.25 ; 1.01]$

$0.20 \quad[-0.26 ; 0.66]$

$1.20 \quad[0.69 ; 1.71]$

$1.35 \quad[0.78 ; 1.92]$

$1.00 \quad[0.44 ; 1.56]$

$1.00 \quad[0.65 ; 1.35]$

$0.10 \quad[-0.27 ; 0.47]$

$1.90 \quad[0.21 ; 3.59]$

$0.68[0.52 ; 0.84]$

$1017 \quad 733$

$21 \quad 22$

$142 \quad 19$

$28 \quad 28$

$63 \quad 63$

$12 \quad 16$

$56 \quad 28$

$29 \quad 27$

$125 \quad 19$

$30 \quad 30$

$34 \quad 34$

$76 \quad 76$

$33 \quad 33$

$50 \quad 50$

$8 \quad 8$

$\begin{array}{ll}7 & 7\end{array}$

$13 \quad 15$

727

475
$1.17 \quad[0.45 ; 1.89]$

$0.60 \quad[0.12 ; 1.08]$

$1.00 \quad[0.44 ; 1.56]$

$0.90 \quad[0.53 ; 1.27]$

$1.20 \quad[0.48 ; 1.93]$

$1.60 \quad[0.93 ; 2.27]$

$0.45 \quad[0.06 ; 0.84]$

$2.15 \quad[1.76 ; 2.54]$

$1.62 \quad[0.96 ; 2.28]$

$1.68 \quad[1.02 ; 2.34]$

$0.80 \quad[0.75 ; 0.85]$

$1.90 \quad[1.42 ; 2.38]$

$1.69 \quad[1.11 ; 2.27]$

$1.70 \quad[1.31 ; 2.09]$

$0.30 \quad[-0.01 ; 0.61]$

$2.12 \quad[1.22 ; 3.02]$

1.27 [ 0.98; 1.55 ]

Figure S1. Forest plot of cardiac output (CO) adjustments during normotensive pregnancy. CO is reported as mean difference with $95 \% \mathrm{Cl}$ in $\mathrm{L} \cdot \mathrm{min}^{-1}$ between pregnant women and non-pregnant reference group. 


\begin{tabular}{|c|c|c|c|c|c|}
\hline \multicolumn{6}{|l|}{ 22-28 weeks } \\
\hline Conrad 2019 & 20 & 22 & $\rightleftarrows$ & 1.39 & {$[0.64 ; 2.14]$} \\
\hline Meah 2019 & 13 & 14 & $\rightleftarrows$ & 1.40 & {$[0.89 ; 1.91]$} \\
\hline Mangos 2018 & 30 & 30 & 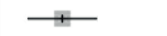 & 1.20 & {$[0.57 ; 1.83]$} \\
\hline Niemczyk 2018 & 32 & 35 & + & 1.25 & {$[1.16 ; 1.34]$} \\
\hline Nii 2018 & 12 & 15 & $\mp$ & 1.40 & {$[0.43 ; 2.37]$} \\
\hline lacobaeus 2017 & 49 & 31 & $\div$ & 0.90 & {$[0.45 ; 1.35]$} \\
\hline Sengupta 2017 & 30 & 20 & $\mp$ & 0.76 & {$[0.42 ; 1.10]$} \\
\hline Andreas 2016 & 59 & 19 & $\mp$ & 1.00 & {$[0.46 ; 1.54]$} \\
\hline Melchiorre 2016 & 207 & 98 & $\mp$ & 0.54 & {$[0.22 ; 0.86]$} \\
\hline Carpenter 2015 & 50 & 50 & $\mp$ & 1.50 & {$[1.06 ; 1.94]$} \\
\hline D'Silva 2014 & 28 & 28 & $\rightleftarrows$ & 1.40 & {$[0.84 ; 1.96]$} \\
\hline Mahendru 2014 & 54 & 54 & $\mp$ & 0.60 & {$[0.22 ; 0.98]$} \\
\hline Papadopoulou 2014 & 27 & 11 & 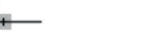 & 0.11 & {$[-0.58 ; 0.80]$} \\
\hline Vartun 2014 & 105 & 54 & $\mp$ & 1.48 & {$[1.09 ; 1.87]$} \\
\hline Estensen 2013 & 63 & 63 & $\mp$ & 1.20 & {$[0.85 ; 1.55]$} \\
\hline Savu 2012 & 49 & 31 & \# & 1.00 & {$[0.71 ; 1.29]$} \\
\hline Yosefy 2012 & 20 & 20 & $\mp$ & 0.53 & {$[-0.09 ; 1.15]$} \\
\hline Pandey 2010 & 19 & 22 & 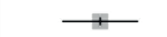 & 1.90 & {$[1.21 ; 2.59]$} \\
\hline Ogueh 2009 & 12 & 16 & $\mp$ & 1.46 & {$[0.53 ; 2.38]$} \\
\hline Valensise 2008 & 1119 & 1119 & $\mp$ & 1.51 & {$[1.42 ; 1.60]$} \\
\hline Bamfo 2007 & 104 & 19 & $\mp$ & 1.99 & {$[1.55 ; 2.43]$} \\
\hline Rang 2007 & 16 & 16 & $\mp$ & 0.90 & {$[0.13 ; 1.67]$} \\
\hline Desăi 2004 & 29 & 27 & 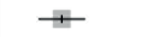 & 1.19 & {$[0.77 ; 1.61]$} \\
\hline Kametas 2004 & 125 & 18 & $\mp$ & 1.81 & {$[1.30 ; 2.32]$} \\
\hline Del Bene 2001 & 13 & 13 & $\mp$ & 1.20 & {$[-0.05 ; 2.45]$} \\
\hline Mesa 1999 & 35 & 8 & $\rightleftarrows$ & 1.00 & {$[0.32 ; 1.68]$} \\
\hline Clapp 1997 & 30 & 30 & $\mp$ & 2.03 & {$[1.29 ; 2.77]$} \\
\hline Gilson 1997 & 76 & 76 & + & 1.50 & {$[1.45 ; 1.55]$} \\
\hline Campos 1996 & 18 & 18 & 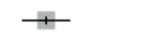 & 0.90 & {$[0.46 ; 1.34]$} \\
\hline Hennessy 1996 & 52 & 26 & $\mp$ & 0.80 & {$[0.39 ; 1.21]$} \\
\hline Capeless 1989 & 8 & 8 & $\mp$ & 1.50 & {$[1.15 ; 1.85]$} \\
\hline Mashini 1987 & 7 & 7 & $\mp$ & 1.30 & {$[0.87 ; 1.73]$} \\
\hline Airaksinen 1986 & 11 & 11 & $\longrightarrow$ & 2.60 & {$[1.14 ; 4.06]$} \\
\hline Rubler 1977 & 15 & 15 & $\mp-$ & 2.22 & {$[1.52: 2.92]$} \\
\hline Ueland 1969 & 11 & 11 & $\rightleftarrows$ & 1.30 & {$[0.76 ; 1.84]$} \\
\hline $\begin{array}{l}\text { Summary } \\
I^{2}=80 \%\end{array}$ & 2548 & 2055 & $\bullet$ & 1.23 & [ $1.12 ; 1.35]$ \\
\hline
\end{tabular}

Figure S1 (continued). Forest plot of cardiac output (CO) adjustments during normotensive pregnancy. CO is reported as mean difference with $95 \% \mathrm{Cl}$ in $\mathrm{L} \cdot \mathrm{min}^{-1}$ between pregnant women and non-pregnant reference group. 


\begin{tabular}{|c|c|c|}
\hline \multicolumn{3}{|l|}{ 29-35 weeks } \\
\hline Conrad 2019 & 20 & 22 \\
\hline McHugh 2019 & 46 & 20 \\
\hline Nii 2018 & 12 & 15 \\
\hline Yu 2018 & 30 & 30 \\
\hline Charkoudian 2017 & 23 & 23 \\
\hline Giannubilo 2017 & 50 & 50 \\
\hline lacobaeus 2017 & 46 & 31 \\
\hline Petersen 2017 & 10 & 10 \\
\hline Sengupta 2017 & 30 & 20 \\
\hline Andreas 2016 & 101 & 19 \\
\hline Carpenter 2015 & 50 & 50 \\
\hline D'Silva 2014 & 28 & 28 \\
\hline Ducas 2014 & 34 & 34 \\
\hline Papadopoulou 2014 & 27 & 11 \\
\hline Savu 2012 & 50 & 31 \\
\hline Heiskanen 2011 & 28 & 28 \\
\hline Pandey 2010 & 31 & 22 \\
\hline Rang 2008 & 28 & 28 \\
\hline Bamfo 2007 & 63 & 17 \\
\hline Rang 2007 & 16 & 16 \\
\hline Lof 2005 & 22 & 22 \\
\hline Desai 2004 & 61 & 27 \\
\hline Del Bene 2001 & 13 & 13 \\
\hline Borghi 2000 & 35 & 10 \\
\hline Mesa 1999 & 36 & 8 \\
\hline Clapp 1997 & 30 & 30 \\
\hline Geva 1997 & 34 & 34 \\
\hline Campos 1996 & 18 & 18 \\
\hline Hennessy 1996 & 26 & 26 \\
\hline Khodiguian 1996 & 25 & 8 \\
\hline Khodiguian 1996 & 8 & 8 \\
\hline Mone 1996 & 33 & 33 \\
\hline van Oppen 1996 & 50 & 50 \\
\hline Droste 1992 & 16 & 16 \\
\hline Airaksinen 1986 & 11 & 11 \\
\hline Larkin 1980 & 12 & 12 \\
\hline Ueland 1969 & 11 & 11 \\
\hline Summary & 1164 & 842 \\
\hline
\end{tabular}

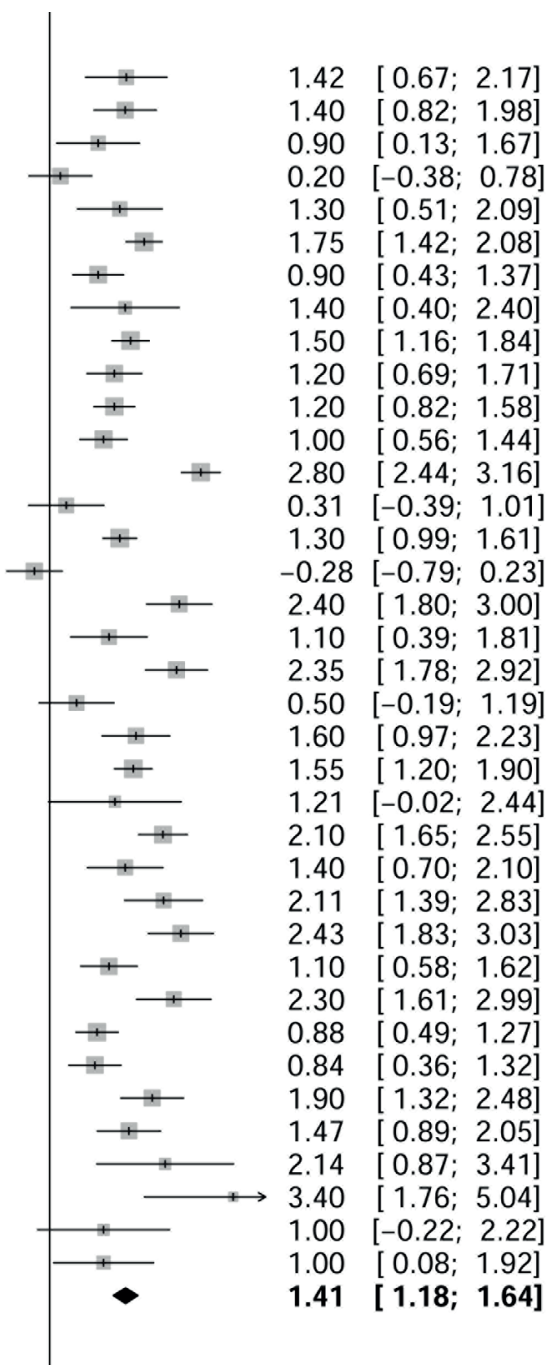

Figure S1 (continued). Forest plot of cardiac output (CO) adjustments during normotensive pregnancy. CO is reported as mean difference with $95 \% \mathrm{Cl}$ in $\mathrm{L} \cdot \mathrm{min}^{-1}$ between pregnant women and non-pregnant reference group. 


\section{6-41 weeks}

Niemczyk 2018

Andreas 2016

Melchiorre 2016

Mahendru 2014

Estensen 2013

Dennis 2012

Yosefy 2012

Ohashi 2010

Ogueh 2009

San-Frutos 2005

Desai 2004

Clapp 1997

Geva 1997

Gilson 1997

Campos 1996

Hennessy 1996

Mone 1996

van Oppen 1996

Mabie 1994

Mashini 1987

Rubler 1977

Ueland 1969

Summary

$I^{2}=91 \%$

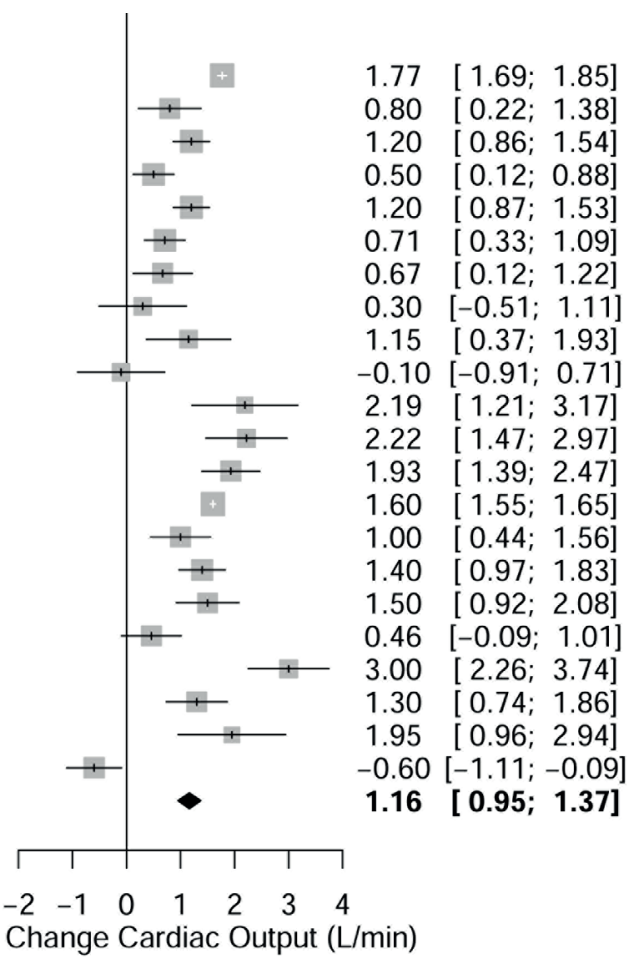

$1.77 \quad[1.69 ; 1.85]$

$0.80 \quad[0.22 ; 1.38]$

1.20 [0.86; 1.54$]$

$1.20 \quad[0.87 ; 1.53]$

$0.71 \quad[0.33 ; 1.09]$

$0.67 \quad[0.12 ; 1.22]$

$0.30 \quad[-0.51 ; 1.11]$

$1.15 \quad[0.37 ; 1.93]$

$-0.10[-0.91 ; 0.71]$

$2.19 \quad[1.21 ; 3.17]$

$2.22 \quad[1.47 ; 2.97]$

$1.93 \quad[1.39 ; 2.47]$

$1.55 ; 1.65$

$1.00 \quad[0.44 ; 1.56]$

$1.40 \quad[0.97 ; 1.83]$

$1.50 \quad[0.92 ; 2.08]$

$0.46 \quad[-0.09 ; 1.01]$

$3.00 \quad[2.26 ; 3.74]$

$1.30 \quad[0.74 ; 1.86]$

1.95 [0.96; 2.94]

$\mathbf{1 . 1 6}$ [ 0.95; 1.37]

Change Cardiac Output (L/min)
698

Figure S1 (continued). Forest plot of cardiac output (CO) adjustments during normotensive pregnancy. CO is reported as mean difference with $95 \% \mathrm{Cl}$ in $\mathrm{L} \cdot \mathrm{min}^{-1}$ between pregnant women and non-pregnant reference group. 
Study

Reference

Conrad 2019

McHugh 2019

Meah 2019

Mangos 2018

Niemczyk 2018

Nii 2018

Yu 2018

Charkoudian 2017

Giannubilo 2017

lacobaeus 2017

Petersen 2017

Sengupta 2017

Andreas 2016

Melchiorre 2016

Carpenter 2015

D'Silva 2014

Ducas 2014

Mahendru 2014

Papadopoulou 2014

Vartun 2014

Estensen 2013

Dennis 2012

Jarvis 2012

Savu 2012

Yosefy 2012

Heiskanen 2011

Hale 2010

Ohashi 2010

Pandey 2010

Ogueh 2009

Rang 2008

Valensise 2008

Bamfo 2007

Rang 2007

Lof 2005

San-Frutos 2005

Desai 2004

Kametas 2004

Del Bene 2001

Kametas 2001

Borghi 2000

Spaanderman 2000

Mesa 1999

Clapp 1997

Geva 1997

Gilson 1997

Campos 1996

Hennessy 1996

Khodiguian 1996

Mone 1996

van Oppen 1996

Mabie 1994

Droste 1992

Capeless 1989

Mashini 1987

Airaksinen 1986

Larkin 1980

Rubler 1977

Ueland 1969

Summary

$I^{2}=98 \%$
Mean $\quad 95 \% \mathrm{Cl}$

$4.86 \quad[4.42 ; 5.30]$

$4.90 \quad[4.42 ; 5.38]$

$3.40 \quad[3.14 ; 3.66]$

$5.60 \quad[5.17 ; 6.03]$

$4.46 \quad[4.43 ; 4.49]$

$4.30 \quad[3.95 ; 4.65]$

$6.00 \quad[5.61 ; 6.39]$

$5.90 \quad[5.41 ; 6.39]$

$5.03 \quad[4.78 ; 5.28]$

$3.40 \quad[2.98 ; 3.82]$

$4.70 \quad[4.19 ; 5.21]$

$3.33[3.00 ; 3.66]$

$4.70 \quad[4.25 ; 5.15]$

$5.60 \quad[5.38 ; 5.82]$

$5.70 \quad[5.40 ; 6.00]$

$6.00 \quad[5.61 ; 6.39]$

$3.50 \quad[3.23 ; 3.77]$

$5.60 \quad[5.33 ; 5.87]$

$4.94 \quad[4.29 ; 5.59]$

$5.12 \quad[4.83 ; 5.41]$

$4.80 \quad[4.55 ; 5.05]$

$3.40 \quad[3.07 ; 3.73]$

$2.44[2.14 ; 2.74]$

$4.30 \quad[4.16 ; 4.44]$

$4.14[3.78 ; 4.50]$

$5.70 \quad[5.35 ; 6.05]$

$4.80 \quad[4.37 ; 5.23]$

$5.60 \quad[5.17 ; 6.03]$

$4.90 \quad[4.47 ; 5.33]$

$5.28 \quad[4.82 ; 5.74]$

$6.00 \quad[5.48 ; 6.52]$

$5.10 \quad[5.04 ; 5.16]$

$4.60 \quad[4.30 ; 4.90]$

$5.20[4.71 ; 5.69]$

$4.80 \quad[4.42 ; 5.18]$

$7.17 \quad[6.76 ; 7.58]$

$4.75 \quad[4.49 ; 5.01]$

$5.08 \quad[4.60 ; 5.56]$

$5.64[4.65 ; 6.63]$

$4.80 \quad[4.49 ; 5.11]$

$5.80 \quad[5.49 ; 6.11]$

$5.20 \quad[4.86 ; 5.54]$

$4.60 \quad[4.05 ; 5.15]$

$4.69 \quad[4.22 ; 5.16]$

$5.42 \quad[5.09 ; 5.75]$

$4.20 \quad[4.18 ; 4.22]$

$3.40[3.03 ; 3.77]$

$4.70 \quad[4.39 ; 5.01]$

$3.30 \quad[3.02 ; 3.58]$

$4.70 \quad[4.32 ; 5.08]$

$5.91 \quad[5.54 ; 6.28]$

$5.70 \quad[5.33 ; 6.07]$

$6.27 \quad[5.50 ; 7.04]$

$4.20[3.92 ; 4.48]$

$4.20 \quad[3.98 ; 4.42]$

$5.00[4.00 ; 6.00]$

$4.40 \quad[3.72 ; 5.08]$

$3.93[3.66 ; 4.20]$

$5.10 \quad[4.69 ; 5.51]$

$4.82[4.68 ; 4.97]$

Figure S2. Forest plot of absolute cardiac output values in litres per minute with $95 \% \mathrm{Cl}$ in non-pregnant women and during normotensive pregnancy. 


\begin{tabular}{|c|c|c|c|}
\hline \multirow{2}{*}{\multicolumn{4}{|c|}{$<14$ weeks }} \\
\hline & & & \\
\hline Niemczyk 2018 & + & 5.24 & {$[5.12 ; 5.36]$} \\
\hline lacobaeus 2017 & $\mp$ & 4.20 & {$[4.06 ; 4.34]$} \\
\hline Petersen 2017 & $\rightleftarrows$ & 5.90 & {$[4.88 ; 6.92]$} \\
\hline Sengupta 2017 & + & 4.02 & {$[3.92 ; 4.12]$} \\
\hline Andreas 2016 & $=$ & 5.30 & {$[5.03 ; 5.57]$} \\
\hline Melchiorre 2016 & + & 5.70 & {$[5.50 ; 5.90]$} \\
\hline Carpenter 2015 & + & 7.10 & {$[6.77 ; 7.43]$} \\
\hline Mahendru 2014 & + & 5.80 & {$[5.48 ; 6.12]$} \\
\hline Papadopoulou 2014 & $\#$ & 4.41 & {$[4.07 ; 4.75]$} \\
\hline Jarvis 2012 & + & 2.74 & {$[2.41 ; 3.07]$} \\
\hline Savu 2012 & $\mp$ & 4.90 & {$[4.64 ; 5.16]$} \\
\hline Hale 2010 & + & 5.40 & {$[4.92 ; 5.88]$} \\
\hline Ogueh 2009 & $\mp$ & 5.64 & {$[5.07 ; 6.21]$} \\
\hline Rang 2008 & $\mp$ & 7.60 & {$[7.19 ; 8.01]$} \\
\hline Rang 2007 & $\mp$ & 5.60 & {$[5.06 ; 6.14]$} \\
\hline Lof 2005 & $\mp$ & 5.70 & {$[5.32 ; 6.08]$} \\
\hline Del Bene 2001 & $1-$ & 6.75 & {$[5.61 ; 7.89]$} \\
\hline Spaanderman 2000 & 풉 & 6.00 & {$[5.77 ; 6.23]$} \\
\hline Mesa 1999 & \pm & 4.60 & {$[4.37 ; 4.83]$} \\
\hline Clapp 1997 & $\mp$ & 5.90 & {$[5.39 ; 6.41]$} \\
\hline Geva 1997 & $\mp$ & 5.80 & {$[5.26 ; 6.34]$} \\
\hline Campos 1996 & $\mp$ & 3.60 & {$[3.32 ; 3.88]$} \\
\hline Mone 1996 & + & 5.90 & {$[5.56 ; 6.24]$} \\
\hline van Oppen 1996 & $\mp$ & 7.26 & {$[6.83 ; 7.69]$} \\
\hline Mabie 1994 & $\mp$ & 6.70 & {$[6.28 ; 7.12]$} \\
\hline Capeless 1989 & $\mp$ & 5.20 & {$[4.99 ; 5.41]$} \\
\hline Mashini 1987 & $\mp$ & 4.30 & {$[4.00 ; 4.60]$} \\
\hline Airaksinen 1986 & 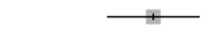 & 6.90 & {$[5.54 ; 8.26]$} \\
\hline $\begin{array}{l}\text { Summary } \\
I^{2}=98 \%\end{array}$ & $<$ & 5.48 & {$[5.11 ; 5.85]$} \\
\hline 15-21 weeks & & & \\
\hline Conrad 2019 & + & 6.03 & {$[5.47 ; 6.59]$} \\
\hline Andreas 2016 & + & 5.30 & {$[5.12 ; 5.48]$} \\
\hline D'Silva 2014 & + & 7.00 & {$[6.61 ; 7.39]$} \\
\hline Estensen 2013 & + & 5.70 & {$[5.43 ; 5.97]$} \\
\hline Ogueh 2009 & + & 6.49 & {$[5.92 ; 7.05]$} \\
\hline Rang 2008 & + & 7.60 & {$[7.18 ; 8.02]$} \\
\hline Desai 2004 & & 5.20 & {$[4.91 ; 5.49]$} \\
\hline Kametas 2001 & + & 6.95 & {$[6.72 ; 7.18]$} \\
\hline Clapp 1997 & + & 6.31 & {$[5.84 ; 6.78]$} \\
\hline Geva 1997 & + & 7.10 & {$[6.53 ; 7.67]$} \\
\hline Gilson 1997 & + & 5.00 & {$[4.96 ; 5.04]$} \\
\hline Mone 1996 & + & 6.60 & {$[6.29 ; 6.91]$} \\
\hline van Oppen 1996 & + & 7.60 & {$[7.15 ; 8.05]$} \\
\hline Capeless 1989 & + & 5.90 & {$[5.62 ; 6.18]$} \\
\hline Mashini 1987 & + & 4.50 & {$[4.28 ; 4.72]$} \\
\hline Rubler 1977 & $\longrightarrow$ & 6.05 & {$[5.19 ; 6.91]$} \\
\hline $\begin{array}{l}\text { Summary } \\
1^{2}=98 \%\end{array}$ & & 6.19 & {$[5.73 ; 6.66]$} \\
\hline 22-28 weeks & & & \\
\hline Conrad 2019 & $\mp$ & 6.25 & {$[5.64 ; 6.86]$} \\
\hline Meah 2019 & $\mp$ & 4.80 & {$[4.37 ; 5.23]$} \\
\hline Mangos 2018 & 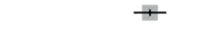 & 6.80 & {$[6.33 ; 7.27]$} \\
\hline Niemczyk 2018 & + & 5.71 & {$[5.63 ; 5.79]$} \\
\hline Nii 2018 & $\mp$ & 5.70 & {$[4.79 ; 6.61]$} \\
\hline lacobaeus 2017 & 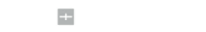 & 4.30 & {$[4.13 ; 4.47]$} \\
\hline Sengupta 2017 & 田 & 4.09 & {$[3.99 ; 4.19]$} \\
\hline Andreas 2016 & $\mp$ & 5.70 & {$[5.39 ; 6.01]$} \\
\hline Melchiorre 2016 & $\mp$ & 6.14 & {$[5.90 ; 6.38]$} \\
\hline Carpenter 2015 & $\mp$ & 7.20 & {$[6.87 ; 7.53]$} \\
\hline D'Silva 2014 & + & 7.40 & {$[7.01 ; 7.79]$} \\
\hline
\end{tabular}

Figure S2 (continued). Forest plot of absolute cardiac output values in litres per minute with $95 \% \mathrm{Cl}$ in non-pregnant women and during normotensive pregnancy. 


Mahendru 2014
Papadopoulou 2014 Vartun 2014
Estensen 2013
Savu 2012
Yosefy 2012
Pandey 2010
Ogueh 2009
Valensise 2008
Bamfo 2007
Rang 2007
Desai 2004
Kametas 2004
Del Bene 2001
Mesa 1999
Clapp 1997
Gilson 1997
Campos 1996
Hennessy 1996
Capeless 1989
Mashini 1987
Airaksinen 1986
Rubler 1977
Ueland 1969
Summary
I $^{2}=99 \%$

\section{9-35 weeks}

Conrad 2019

McHugh 2019

Nii 2018

Yu 2018

Charkoudian 2017

Giannubilo 2017

lacobaeus 2017

Petersen 2017

Sengupta 2017

Andreas 2016

Carpenter 2015

D'Silva 2014

Ducas 2014

Papadopoulou 2014

Savu 2012

Heiskanen 2011

Pandey 2010

Rang 2008

Bamfo 2007

Rang 2007

Lof 2005

Desai 2004

Del Bene 2001

Borghi 2000

Mesa 1999

Clapp 1997

Geva 1997

Campos 1996

Hennessy 1996

Khodiguian 1996

Khodiguian 1996

Mone 1996

van Oppen 1996

Droste 1992

Airaksinen 1986

Larkin 1980

Ueland 1969

Summary

$l^{2}=98 \%$

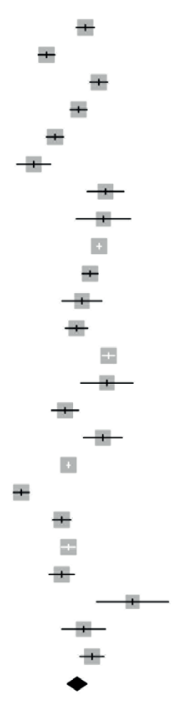

$6.20 \quad[5.93 ; 6.47]$

$5.05 \quad[4.81 ; 5.29]$

$6.60 \quad[6.34 ; 6.86]$

$6.00 \quad[5.75 ; 6.25]$

$5.30 \quad[5.05 ; 5.55]$

$4.67 \quad[4.17 ; 5.17]$

$6.80 \quad[6.26 ; 7.34]$

$6.74 \quad[5.93 ; 7.54]$

$6.61 \quad[6.55 ; 6.67]$

$6.34 \quad[6.11 ; 6.57]$

$6.10 \quad[5.51 ; 6.69]$

$5.94 \quad[5.61 ; 6.27]$

$6.89 \quad[6.71 ; 7.07]$

$6.84 \quad[6.07 ; 7.61]$

$5.60 \quad[5.20 ; 6.00]$

$6.72 \quad[6.15 ; 7.29]$

$5.70 \quad[5.66 ; 5.74]$

$4.30 \quad[4.07 ; 4.53]$

$5.50 \quad[5.23 ; 5.77]$

$5.70 \quad[5.49 ; 5.91]$

$5.50 \quad[5.13 ; 5.87]$

$7.60 \quad[6.54 ; 8.66]$

$6.15 \quad[5.51 ; 6.79]$

$6.40 \quad[6.05 ; 6.75]$

$5.95[5.67 ; 6.24]$

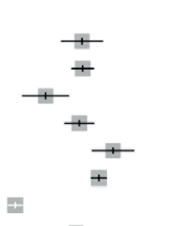

$6.28 \quad[5.67 ; 6.89]$

$6.30 \quad[5.98 ; 6.62]$

$5.20 \quad[4.52 ; 5.88]$

$6.20 \quad[5.77 ; 6.63]$

$7.20 \quad[6.59 ; 7.81]$

$6.78 \quad[6.56 ; 7.00]$

$4.30 \quad[4.10 ; 4.50]$

$6.10 \quad[5.24 ; 6.96]$

$4.83 \quad[4.73 ; 4.93]$

$5.90 \quad[5.67 ; 6.13]$

$6.90 \quad[6.67 ; 7.13]$

$7.00 \quad[6.80 ; 7.20]$

$6.30 \quad[6.06 ; 6.54]$

$5.25 \quad[5.00 ; 5.50]$

$5.60 \quad[5.32 ; 5.88]$

$5.42 \quad[5.05 ; 5.79]$

$7.30 \quad[6.88 ; 7.72]$

$7.10 \quad[6.62 ; 7.58]$

$7.31 \quad[7.01 ; 7.61]$

$5.70 \quad[5.21 ; 6.19]$

$6.40 \quad[5.90 ; 6.90]$

$6.30 \quad[6.07 ; 6.53]$

$6.85 \quad[6.13 ; 7.57]$

$7.90 \quad[7.57 ; 8.23]$

$6.00 \quad[5.58 ; 6.42]$

$6.80 \quad[6.25 ; 7.35]$

$7.85 \quad[7.35 ; 8.35]$

$4.50 \quad[4.13 ; 4.87]$

$7.00 \quad[6.38 ; 7.62]$

$4.18[3.91 ; 4.45]$

$4.14 \quad[3.75 ; 4.53]$

$6.60 \quad[6.16 ; 7.04]$

$7.38 \quad[6.93 ; 7.83]$

$8.41 \quad[7.41 ; 9.41]$

$8.40[7.10 ; 9.70]$

$5.40[4.38 ; 6.42]$

$6.10[5.27 ; 6.93]$

$6.28[5.91 ; 6.65]$

Figure S2 (continued). Forest plot of absolute cardiac output values in litres per minute with $95 \% \mathrm{Cl}$ in non-pregnant women and during normotensive pregnancy. 


\section{6-41 weeks}

Niemczyk 2018

Andreas 2016

Melchiorre 2016

Mahendru 2014

Estensen 2013

Dennis 2012

Yosefy 2012

Ohashi 2010

Ogueh 2009

San-Frutos 2005

Desai 2004

Clapp 1997

Geva 1997

Gilson 1997

Campos 1996

Hennessy 1996

Mone 1996

van Oppen 1996

Mabie 1994

Mashini 1987

Rubler 1977

Ueland 1969

Summary

$I^{2}=97 \%$
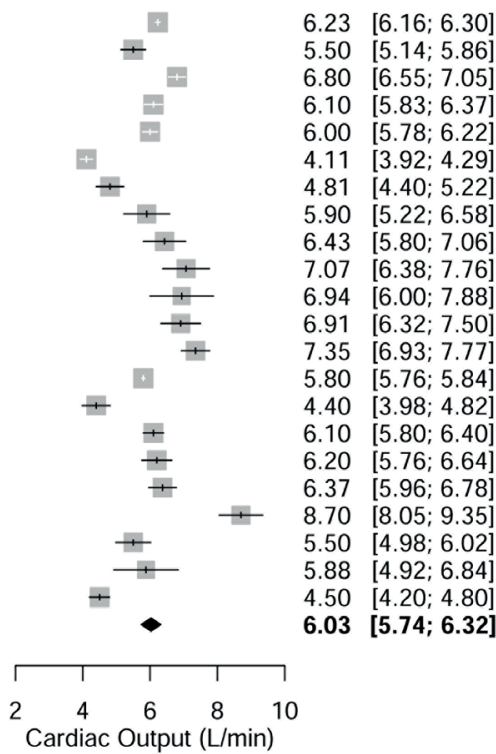

Figure S2 (continued). Forest plot of absolute cardiac output values in litres per minute with $95 \% \mathrm{Cl}$ in non-pregnant women and during normotensive pregnancy. 


\section{Study}

<14 weeks

Melchiorre 2016

Andreas 2016

Carpenter 2015

Mahendru 2014

Savu 2012

Jarvis 2012

Ogueh 2009

Rang 2008

Lof 2005

Simmons 2002

Del Bene 2001

Spaanderman 2000

Mesa 1999

Geva 1997

Clapp 1997

van Oppen 1996

Capeless 1989

Mashini 1987

Summary

$I^{2}=77 \%$

\section{5-21 weeks}

Andreas 2016

D'Silva 2014

Ogueh 2009

Rang 2008

Desai 2004

Gilson 1997

Geva 1997

Clapp 1997

van Oppen 1996

Capeless 1989

Mashini 1987

Summary

$I^{2}=75 \%$

\section{2-28 weeks}

Meah 2019

Mangos 2018

Melchiorre 2016

Andreas 2016

Carpenter 2015

Mahendru 2014

D'Silva 2014

Savu 2012

Pandey 2010

Ogueh 2009

Valensise 2008

Bamfo 2007

Kametas 2004

Desai 2004

Simmons 2002

Del Bene 2001

Mesa 1999

Gilson 1997

Clapp 1997

Capeless 1989

Rovinksy III 1965

Summary

$I^{2}=92 \%$
Sample size

Pregnant Reference

$\begin{array}{cc}109 & 98 \\ 69 & 19 \\ 50 & 50 \\ 54 & 54 \\ 46 & 31 \\ 11 & 11 \\ 21 & 13 \\ 81 & 28 \\ 21 & 22 \\ 44 & 44 \\ 13 & 13 \\ 48 & 12 \\ 36 & 8 \\ 34 & 34 \\ 30 & 30 \\ 50 & 50 \\ 8 & 8 \\ 7 & 7 \\ \mathbf{7 3 2} & \mathbf{5 3 2}\end{array}$

126

28

12

56

29

76

34

30

50

$\begin{array}{r}8 \\ 7 \\ \hline\end{array}$

456

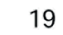

28

13

28

27

76

34

30

50

8
7

320

2167
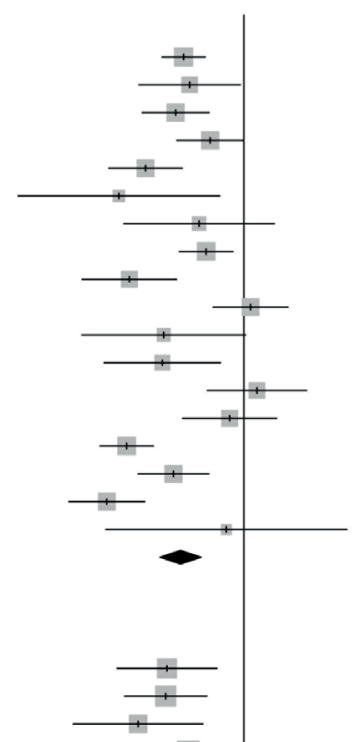

$-228[-376 ;-80]$

$-232[-354 ;-110]$

$-314[-506 ;-122]$

$-165[-242 ;-88]$

$-266[-371 ;-160]$

$-329[-347 ;-311]$

$-224[-311 ;-138]$

$-444[-529 ;-359]$

$-274[-379 ;-169]$

$-450[-560 ;-340]$

$-253[-534 ; 28]$

-293 [-348; -238]

$-532[-724 ;-340]$

$-230[-351 ;-109]$

-202 [-266; -138]

$-279[-445 ;-113]$

$-234[-330 ;-137]$

-230 [-308; -152]

$-283[-393 ;-173]$

-426 [-529; -323]

$-108 \quad[-234 ; 19]$

$-337[-572 ;-102]$

$-371[-390 ;-352]$

$-483[-633 ;-332]$

$-497[-627 ;-368]$

$-370[-480 ;-260]$

-139 [-246; -32]

$-329[-539 ;-119]$

-245 [-400; -90]

$-480[-497 ;-463]$

$-500[-580 ;-420]$

$-446[-560 ;-332]$

$-262[-358 ;-167]$

-331 [-383; -279]

Figure S3. Forest plot of total peripheral vascular resistance (TPVR) adjustments during normotensive pregnancy. TPVR is reported as mean difference with $95 \% \mathrm{Cl}$ in dyne $\cdot \mathrm{sec} \cdot \mathrm{cm}^{-5}$ between pregnant women and reference group. 
29-35 weeks

McHugh 2019

Giannubilo 2017

Andreas 2016

Carpenter 2015

Mahendru 2014

D'Silva 2014

Savu 2012

Pandey 2010

Rang 2008

Bamfo 2007

Lof 2005

Desai 2004

Simmons 2002

Del Bene 2001

Borghi 2000

Mesa 1999

Geva 1997

Clapp 1997

van Oppen 1996

Droste 1992

Mashini 1987

Larkin 1980

Rovinksy III 1965

Summary

$I^{2}=79 \%$

\section{6-41 weeks}

Melchiorre 2016

Andreas 2016

Dennis 2012

Ohashi 2010

Ogueh 2009

San-Frutos 2005

Desai 2004

Gilson 1997

Geva 1997

Clapp 1997

van Oppen 1996

Mashini 1987

Rovinksy III 1965

Summary

$l^{2}=95 \%$

$\begin{array}{rr}46 & 2 \\ 50 & 5 \\ 96 & 19 \\ 50 & 5 \\ 54 & 5 \\ 28 & 2 \\ 50 & 3 \\ 31 & 2 \\ 28 & 28 \\ 63 & 1 \\ 22 & 2 \\ 61 & 27 \\ 44 & 4 \\ 13 & 13 \\ 35 & 10 \\ 36 & 8 \\ 34 & 34 \\ 30 & 30 \\ 50 & 50 \\ 16 & 16 \\ 7 & 7 \\ 12 & 12 \\ 68 & 6 \\ \mathbf{9 2 4} & \mathbf{5 9}\end{array}$

20

50

19

54

28

31

22

28

17

22

27

44

13

10

34

30
50

16

7

12
6

598

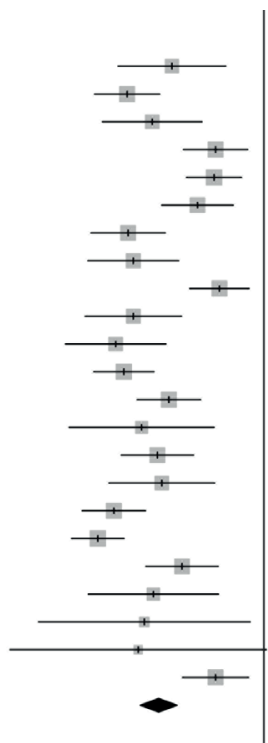

$-273[-433 ;-113]$

$-406[-503 ;-309]$

$-332[-479 ;-184]$

$-143[-239 ;-48]$

$-148[-230 ;-66]$

-197 [-303: -91]

$-403[-513 ;-293]$

$-388[-522 ;-253$

$-132[-220 ;-44]$

$-388[-531 ;-244]$

$-440[-589 ;-291]$

$-416[-505 ;-326]$

$-282[-376 ;-188]$

$-363[-578 ;-148]$

-316 [-423; -209]

$-303[-460 ;-146]$

$-446[-539 ;-352]$

$-493[-571 ;-415]$

$-243[-350 ;-136]$

$-328[-521 ;-135]$

$-355[-669 ;-41]$

$-373[-754 ; 7]$

$-144[-242 ;-45]$

-312 [-367; -258]

$-238[-308 ;-168]$

$-209[-372 ;-46]$

$-503[-726 ;-280]$

$70 \quad[-113 ; 253]$

$-295 \quad[-509 ;-81]$

$80 \quad[-44 ; 205]$

$-434[-568 ;-300]$

-415 [-433; -397]

$-300[-391 ;-209]$

$-482[-575 ;-389]$

$-57[-180 ; 66]$

-243 [-690; 203]

78 [ $23 ; 179]$

-226 [-340; -111]

408

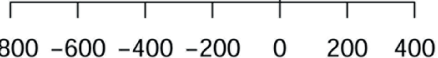

Change Total Peripheral Vascular Resistance (dyn $\cdot \mathrm{sec} \cdot \mathrm{cm}^{\wedge}-5$ )

Figure S3 (continued). Forest plot of total peripheral vascular resistance (TPVR) adjustments during normotensive pregnancy. TPVR is reported as mean difference with $95 \% \mathrm{Cl}$ in dyne $\cdot \mathrm{sec} \cdot \mathrm{cm}^{-5}$ between pregnant women and reference group. 


\begin{tabular}{|c|c|c|c|c|}
\hline Study & & & Mean & $95 \% \mathrm{Cl}$ \\
\hline \multicolumn{5}{|l|}{ Reference } \\
\hline McHugh 2019 & $\mp$ & & 1509 & {$[1372 ; 1646]$} \\
\hline Meah 2019 & & $\mp$ & 1979 & {$[1813 ; 2145]$} \\
\hline Mangos 2018 & $\mp$ & & 1211 & {$[1114 ; 1308]$} \\
\hline Giannubilo 2017 & $\mp$ & & 1384 & {$[1297 ; 1471]$} \\
\hline Andreas 2016 & $\mp$ & & 1453 & {$[1313 ; 1593]$} \\
\hline Melchiorre 2016 & $\mp$ & & 1238 & {$[1186 ; 1290]$} \\
\hline Carpenter 2015 & \# & & 1120 & {$[1035 ; 1205]$} \\
\hline D'Silva 2014 & $\mp$ & & 1143 & {$[1043 ; 1243]$} \\
\hline Mahendru 2014 & $\mp$ & & 1229 & {$[1167 ; 1291]$} \\
\hline Dennis 2012 & & $\mp$ & 2116 & {$[1916 ; 2316$} \\
\hline Jarvis 2012 & & $\rightarrow$ & 2543 & {$[2335 ; 2751$} \\
\hline Savu 2012 & $\mp$ & & 1602 & {$[1518 ; 1686$} \\
\hline Ohashi 2010 & $\mp$ & & 1137 & {$[1044 ; 1230]$} \\
\hline Pandey 2010 & $\mp$ & & 1320 & {$[1200 ; 1440]$} \\
\hline Ogueh 2009 & $\mp$ & & 1368 & {$[1199 ; 1537$} \\
\hline Valensise 2008 & 由 & & 1361 & {$[1345 ; 1377$} \\
\hline Rang 2008 & $\mp$ & & 809 & {$[739 ; 879]$} \\
\hline Bamfo 2007 & $\mp$ & & 1478 & {$[1332 ; 1624$} \\
\hline Ban & $\mp$ & & 1404 & {$[13$} \\
\hline Lof 2005 & $\mp$ & & 1530 & $3 ; 1647$ \\
\hline San-Frutos 2005 & $\mp$ & & 747 & {$[679 ; 816]$} \\
\hline Desai 2004 & $\#$ & & 1336 & {$[1254 ; 1418$} \\
\hline Kametas 2004 & $\mp$ & & 1579 & {$[1454 ; 1705$} \\
\hline Simmons 2002 & $\mp$ & & 1134 & {$[1058 ; 1210$} \\
\hline Del Bene 2001 & $\rightleftarrows$ & & 1275 & {$[1084 ; 1466$} \\
\hline Borghi 2000 & $\mp$ & & 1095 & {$[1011 ; 1179$} \\
\hline Spaanderman 2000 & $\mp$ & & 1434 & {$[1273 ; 1595$} \\
\hline Mesa 1999 & $\amalg$ & & 1446 & $; 1574$ \\
\hline Clapp 1997 & $\mp$ & & 1428 & {$[13$} \\
\hline 997 & $\Psi$ & & 1118 & 1191 \\
\hline Gilson 1997 & 由 & & 1356 & {$[1340 ; 1372$} \\
\hline van Oppen 1996 & $\mp$ & & 1175 & {$[1091 ; 125$} \\
\hline Droste 1992 & $\mp$ & & 1149 & {$[984 ; 1314$} \\
\hline Capeless 1989 & 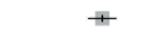 & & 1376 & {$[1277 ; 1475$} \\
\hline Mashini 1987 & $\mp$ & & 1572 & {$[1373 ; 1771$} \\
\hline Larkin 1980 & $\longrightarrow$ & & 1737 & {$[1442 ; 2032$} \\
\hline Rovinksy III 1965 & $\mp$ & & 1121 & {$[1026 ; 1216$} \\
\hline $\begin{array}{l}\text { Summary } \\
l^{2}=97 \%\end{array}$ & $\diamond$ & & 1358 & {$[1299 ; 141$} \\
\hline
\end{tabular}

Figure S4. Forest plot of absolute values with $95 \% \mathrm{Cl}$ of total peripheral vascular resistance in dyne $\cdot \mathrm{sec} \cdot \mathrm{cm}^{-5}$ in non-pregnant women and during normotensive pregnancy. 
<14 weeks

Melchiorre 2016

Andreas 2016

Carpenter 2015

Mahendru 2014

Savu 2012

Jarvis 2012

Ogueh 2009

Rang 2008

Lof 2005

Simmons 2002

Del Bene 2001

Spaanderman 2000

Mesa 1999

Geva 1997

Clapp 1997

van Oppen 1996

Capeless 1989

Mashini 1987

Summary

$I^{2}=98 \%$

\section{5-21 weeks}

Andreas 2016

D'Silva 2014

Ogueh 2009

Rang 2008

Desai 2004

Gilson 1997

Geva 1997

Clapp 1997

van Oppen 1996

Capeless 1989

Mashini 1987

Summary

$l^{2}=99 \%$

\section{2-28 weeks}

Meah 2019

Mangos 2018

Melchiorre 2016

Andreas 2016

Carpenter 2015

Mahendru 2014

D'Silva 2014

Savu 2012

Pandey 2010

Ogueh 2009

Valensise 2008

Bamfo 2007

Kametas 2004

Desai 2004

Simmons 2002

Del Bene 2001

Mesa 1999

Gilson 1997

Clapp 1997

Capeless 1989

Rovinksy III 1965

Summary

$l^{2}=98 \%$
1059 [1022; 1096]

1292 [1237; 1347]

917 [ 866; 969]

1129 [1051; 1207]

$1310 \quad[1240 ; 1380]$

$2172[1957 ; 2387]$

1235 [1088; 1382]

697 [660; 734]

1190 [1113; 1267]

1154 [1073; 1235]

1037 [ 888; 1186]

1192 [1129; 1255]

1485 [1411; 1559]

$1076 \quad[957 ; 1195]$

1080 [1027; 1133]

966 [ 903; 1029]

969 [916; 1022]

1520 [1223; 1817]

1178 [1070; 1286]

1225 [1177; 1273]

911 [840; 982]

1054 [ 961; 1147]

$644 \quad[614 ; 674]$

1070 [1004; 1137]

1027 [1018; 1036]

894 [ 848; 940]

984 [ 923; 1045]

$901 \quad$ [839; 963]

926 [ 879; 973]

1319 [1121; 1517]

988 [ 884; 1093]

1447 [1350; 1544]

$981 \quad[909 ; 1053]$

1036 [ 999; 1073]

1174 [1085; 1263]

886 [ 840; 932]

$999 \quad[951 ; 1047]$

860 [ 813; 907]

1176 [1116; 1236]

1213 [1174; 1251]

1031 [ 867; 1195]

$990 \quad[980 ; 1000]$

995 [959; 1032]

1082 [1052; 1111]

$966 \quad[893 ; 1039]$

995 [920; 1070]

946 [858; 1034]

1201 [1114; 1288]

876 [ 870; 882]

$928 \quad[873 ; 983]$

$930 \quad[873 ; 987]$

858 [ 847; 870]

1022 [ 979; 1064]

Figure S4 (continued). Forest plot of absolute values with $95 \% \mathrm{Cl}$ of total peripheral vascular resistance in dyne $\cdot \mathrm{sec} \cdot \mathrm{cm}^{-5}$ in non-pregnant women and during normotensive pregnancy. 


\section{9-35 weeks}

McHugh 2019

Giannubilo 2017

Andreas 2016

Carpenter 2015

Mahendru 2014

D'Silva 2014

Savu 2012

Pandey 2010

Rang 2008

Bamfo 2007

Lof 2005

Desai 2004

Simmons 2002

Del Bene 2001

Borghi 2000

Mesa 1999

Geva 1997

Clapp 1997

van Oppen 1996

Droste 1992

Mashini 1987

Larkin 1980

Rovinksy III 1965

Summary

$l^{2}=95 \%$

\section{6-41 weeks}

Melchiorre 2016

Andreas 2016

Dennis 2012

Ohashi 2010

Ogueh 2009

San-Frutos 2005

Desai 2004

Gilson 1997

Geva 1997

Clapp 1997

van Oppen 1996

Mashini 1987

Rovinksy III 1965

Summary

$l^{2}=98 \%$
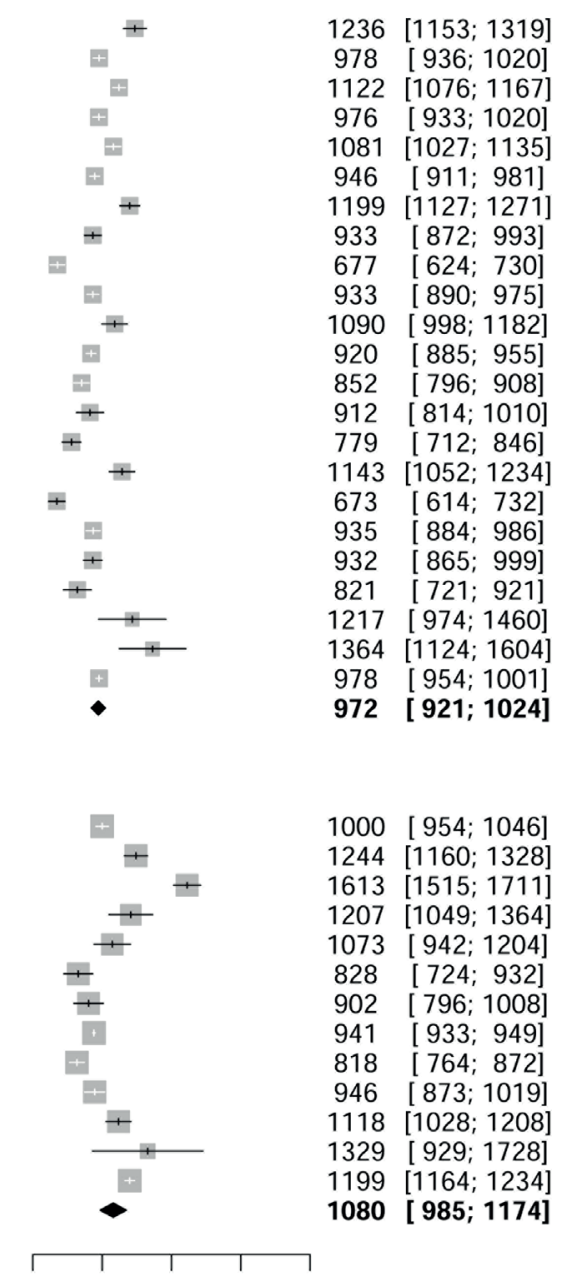

5001000150020002500

Total Peripheral Vascular Resistance (dyn. $\left.\mathrm{sec} \cdot \mathrm{cm}^{\wedge}-5\right)$

Figure S4 (continued). Forest plot of absolute values with $95 \% \mathrm{Cl}$ of total peripheral vascular resistance in dyne $\cdot \mathrm{sec} \cdot \mathrm{cm}^{-5}$ in non-pregnant women and during normotensive pregnancy. 
Study

$<14$ weeks

Conrad 2019

Petersen 2017

Sengupta 2017

lacobaeus 2017

Andreas 2016

Melchiorre 2016

Carpenter 2015

Mahendru 2014

Papadapoulou 2014

Jarvis 2012

Savu 2012

Hale 2010

Rang 2007

Lof 2005

Spaanderman 2000

Mesa 1999

Clapp 1997

Geva 1997

Mone 1996

van Oppen 1996

Capeless 1989

Mashini 1987

Airaksinen 1986

Summary

$I^{2}=63 \%$

\section{5-21 weeks}

Conrad 2019

Andreas 2016

D'Silva 2014

Estensen 2013

Desai 2004

Kametas 2001

Gilson 1997

Clapp 1997

Geva 1997

Mone 1996

van Oppen 1996

Capeless 1989

Mashini 1987

Rubler 1977

Summary

$I^{2}=83 \%$
Sample size

Pregnant Reference

$\begin{array}{rr}63 & 22 \\ 10 & 10 \\ 35 & 20 \\ 52 & 31 \\ 77 & 19 \\ 109 & 98 \\ 50 & 50 \\ 54 & 54 \\ 27 & 11 \\ 11 & 11 \\ 46 & 31 \\ 17 & 17 \\ 16 & 16 \\ 21 & 22 \\ 48 & 12 \\ 36 & 8 \\ 30 & 30 \\ 34 & 34 \\ 33 & 33 \\ 50 & 50 \\ 8 & 8 \\ 7 & 7 \\ 11 & 11 \\ \mathbf{8 4 5} & \mathbf{6 0 5}\end{array}$

$\begin{array}{rr}21 & 22 \\ 136 & 19 \\ 28 & 28 \\ 63 & 63 \\ 29 & 27 \\ 125 & 19 \\ 76 & 76 \\ 30 & 30 \\ 34 & 34 \\ 33 & 33 \\ 50 & 50 \\ 8 & 8 \\ 7 & 7 \\ 13 & 15 \\ \mathbf{6 5 3} & \mathbf{4 3 1}\end{array}$

MD $\quad 95 \% \mathrm{Cl}$

$5.3 \quad[-1.9 ; 12.5]$

$5.3 \quad[-7.6 ; 18.2]$

$9.3 \quad[5.2 ; 13.4]$

$6.0 \quad[1.6 ; 10.4]$

$5.0 \quad[-2.3 ; 12.3$

$-3.0 \quad[-7.7 ; 1.7]$

$8.9 \quad[2.9 ; 14.9]$

$-1.0 \quad[-6.8 ; 4.8]$

$-5.1 \quad[-14.1 ; 3.8]$

$3.0 \quad[-3.4 ; 9.4]$

$4.0 \quad[-0.8 ; 8.8]$

$8.5 \quad[-0.9 ; 17.9]$

$5.0 \quad[-4.4 ; 14.4]$

$11.0 \quad[4.4 ; 17.6]$

$4.5 \quad[-0.5 ; 9.5]$

$-6.0[-15.4 ; 3.4]$

$10.0 \quad[2.9 ; 17.1]$

$-2.7[-11.0 ; 5.6]$

$9.8 \quad[2.4 ; 17.2]$

$10.0 \quad[1.8 ; 18.2]$

$14.0 \quad[9.1 ; 18.9]$

$-7.7 \quad[-30.2 ; 14.8]$

$16.0 \quad[-6.2 ; 38.2]$

$5.1 \quad[\quad 2.7 ; 7.4]$

$7.0 \quad[-1.3 ; 15.3]$

$4.6 \quad[-2.6 ; 11.8]$

$12.5 \quad[\quad 5.1 ; 19.9]$

$8.0 \quad[2.9 ; 13.1]$

$2.3 \quad[-3.7 ; 8.3]$

$16.1 \quad[11.6 ; 20.6]$

$4.0 \quad[3.4 ; 4.6]$

$12.0 \quad[4.9 ; 19.1]$

$8.3 \quad[0.1 ; 16.5]$

$12.0 \quad[\quad 4.3 ; 19.7]$

$10.0 \quad[1.8 ; 18.2]$

$18.0 \quad[12.6 ; 23.4]$

$-4.2 \quad[-23.4 ; 15.0]$

$18.1 \quad[8.8 ; 27.4]$

$9.7 \quad[6.2 ; 13.2]$

Figure S5. Forest plot of stroke volume (SV) adjustments during normotensive pregnancy. SV is reported as mean difference with $95 \% \mathrm{Cl}$ in $\mathrm{mL}$ between pregnant women and reference group. 


\section{2-28 weeks}

Conrad 2019

Meah 2019

Nii 2018

lacobaeus 2017

Sengupta 2017

Melchiorre 2016

Andreas 2016

Carpenter 2015

Tso 2014

Vartun 2014

Mahendru 2014

Papadapoulou 2014

D'Silva 2014

Estensen 2013

Savu 2012

Pandey 2010

Valensise 2008

Rang 2007

Bamfo 2007

Desai 2004

Kametas 2004

Mesa 1999

Clapp 1997

Gilson 1997

Hennesy 1996

Capeless 1989

Airaksinen 1986

Rubler 1977

Ueland 1969

Rovinsky 1965

Summary

$l^{2}=83 \%$

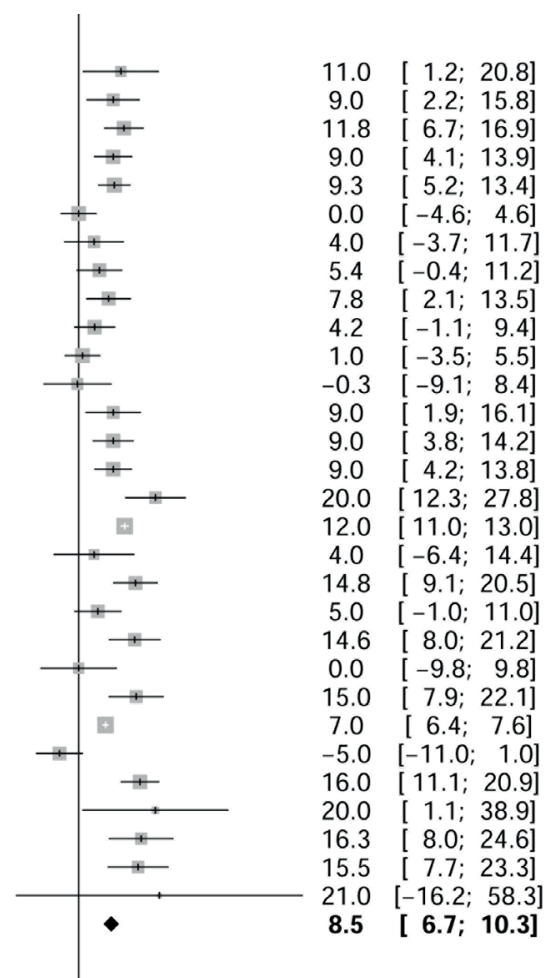

$9.0 \quad[2.2 ; 15.8]$

$11.8 \quad[6.7 ; 16.9]$

[ $4.1 ; 13.9]$

$4.0 \quad[-3.7 ; 11.7]$

$5.4 \quad[-0.4 ; 11.2$

$7.8 \quad[2.1 ; 13.5$

$4.2 \quad[-1.1 ; 9.4]$

$1.0[-3.5 ; 5.5]$

$-0.3 \quad[-9.1 ; 8.4]$

$9.0 \quad[1.9 ; 16.1]$

$9.0 \quad[3.8 ; 14.2]$

20.0 [12.3; 27.8$]$

$2.0 \quad[11.0 ; 13.0]$

$4.0 \quad[-6.4 ; 14.4]$

[9.1; 20.5]

$5.0 \quad[-1.0 ; 11.0]$

$\begin{array}{llr}4.6 & 8.0 ; & 21.2] \\ 0.0 & {[-9.8 ;} & 9.8]\end{array}$

$15.0 \quad[7.9 ; 22.1]$

$7.0 \quad[6.4 ; 7.6]$

$-5.0 \quad[-11.0 ; 1.0]$

$16.0 \quad[11.1 ; 20.9]$
$20.0 \quad[1.1 ; 38.9]$

16.3 [ $8.0 ; 24.6$

$15.5 \quad[7.7 ; 23.3]$

8.5 [ 6.7; 10.3]

Figure S5 (continued). Forest plot of stroke volume (SV) adjustments during normotensive pregnancy. SV is reported as mean difference with $95 \% \mathrm{Cl}$ in $\mathrm{mL}$ between pregnant women and reference group. 
29-35 weeks

Conrad 2019

McHugh 2019

Yu 2018

Nii 2018

Sengupta 2017

lacobaeus 2017

Petersen 2017

Andreas 2016

Carpenter 2015

Mahendru 2014

Ducas 2014

Tso 2014

Papadapoulou 2014

D'Silva 2014

Savu 2012

Heiskanen 2011

Pandey 2010

Rang 2007

Bamfo 2007

Lof 2005

Desai 2004

Mesa 1999

Geva 1997

Clapp 1997

Mone 1996

van Oppen 1996

Khodiguian 1996

Hennesy 1996

Khodiguian 1996

Droste 1992

Mashini 1987

Airaksinen 1986

Larkin 1980

Ueland 1969

Rovinsky 1965

Summary

$I^{2}=85 \%$

\section{6-41 weeks}

Melchiorre 2016

Andreas 2016

Estensen 2013

Dennis 2012

Ohashi 2010

San-Frutos 2005

Desai 2004

Gilson 1997

Geva 1997

Clapp 1997

Hennesy 1996

van Oppen 1996

Mone 1996

Mashini 1987

Rubler 1977

Ueland 1969

Rovinsky 1965

Summary

$l^{2}=89 \%$

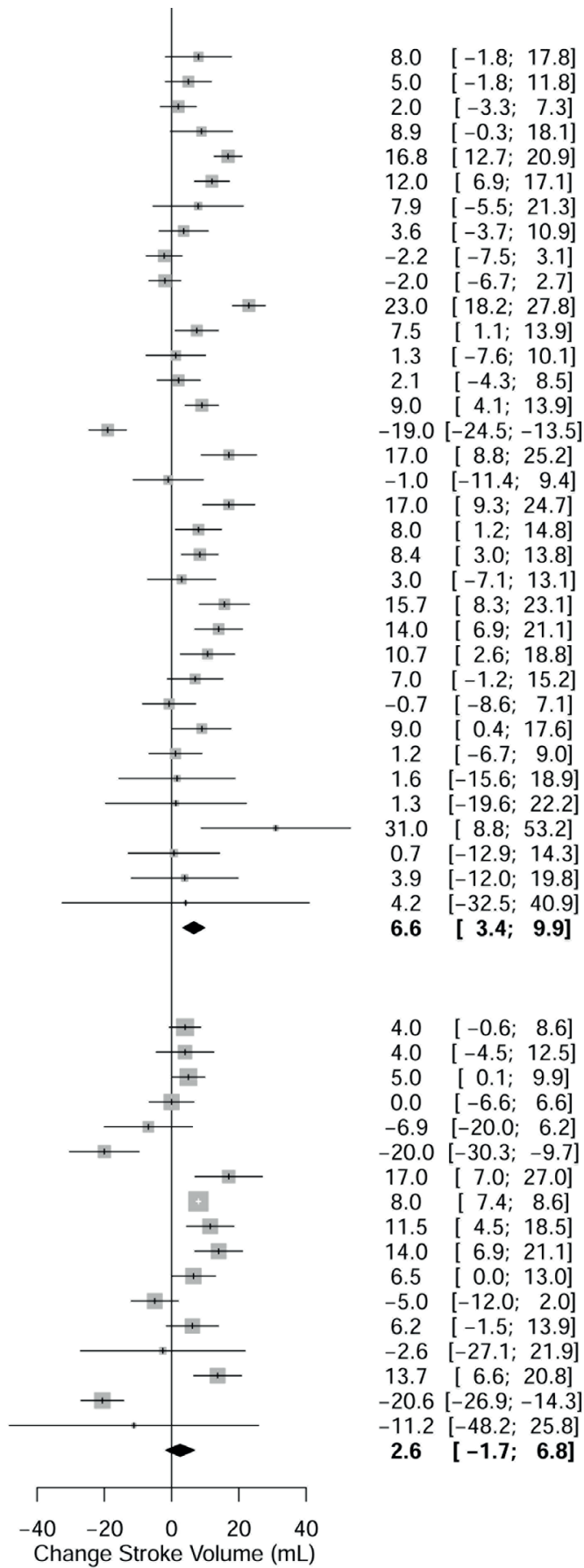

Figure S5 (continued). Forest plot of stroke volume (SV) adjustments during normotensive pregnancy. SV is reported as mean difference with $95 \% \mathrm{Cl}$ in $\mathrm{mL}$ between pregnant women and reference group. 
Study

Reference

Conrad 2019

McHugh 2019

Meah 2019

Nii 2018

Yu 2018

lacobaeus 2017

Petersen 2017

Sengupta 2017

Andreas 2016

Melchiorre 2016

Carpenter 2015

D'Silva 2014

Ducas 2014

Mahendru 2014

Papadapoulou 2014

Tso 2014

Vartun 2014

Estensen 2013

Dennis 2012

Jarvis 2012

Savu 2012

Heiskanen 2011

Hale 2010

Ohashi 2010

Pandey 2010

Valensise 2008

Bamfo 2007

Bamfo 2007

Rang 2007

Lof 2005

San-Frutos 2005

Desai 2004

Kametas 2004

Kametas 2001

Spaanderman 2000

Mesa 1999

Clapp 1997

Geva 1997

Gilson 1997

Hennesy 1996

Khodiguian 1996

Mone 1996

van Oppen 1996

Droste 1992

Capeless 1989

Mashini 1987

Airaksinen 1986

Larkin 1980

Rubler 1977

Ueland 1969

Rovinsky 1965

Summary

$l^{2}=97 \%$
Mean $\quad 95 \% \mathrm{Cl}$

$73.0 \quad[67.1 ; 78.9]$

$68.0 \quad[62.3 ; 73.7$

$69.0 \quad[64.7 ; 73.3]$

$62.2 \quad[57.2 ; 67.2]$

$74.0 \quad[70.1 ; 77.9]$

$46.0 \quad[42.5 ; 49.5]$

$72.4 \quad[64.0 ; 80.8]$

$44.5 \quad[40.5 ; 48.5]$

$62.0 \quad[55.3 ; 68.7]$

$79.0 \quad[75.3 ; 82.7]$

$78.5 \quad[74.5 ; 82.5]$

$77.0 \quad[72.5 ; 81.5]$

$62.0 \quad[58.0 ; 66.0]$

$79.0 \quad[75.8 ; 82.2]$

$59.7 \quad[51.4 ; 67.9]$

$56.2 \quad[51.5 ; 60.9]$

$79.8 \quad[75.8 ; 83.9]$

$70.0 \quad[66.3 ; 73.7]$

$53.0 \quad[48.6 ; 57.4]$

$38.0 \quad[34.5 ; 41.5]$

$62.0 \quad[58.1 ; 65.9]$

$85.0 \quad[81.1 ; 88.9]$

$66.4 \quad[59.4 ; 73.4]$

$83.3 \quad[75.6 ; 91.0]$

$72.8 \quad[67.0 ; 78.5]$

$71.0 \quad[70.3 ; 71.7]$

$72.8 \quad[66.2 ; 79.3$

$64.8 \quad[59.7 ; 69.9]$

$76.0 \quad[68.7 ; 83.3]$

$77.0 \quad[72.4 ; 81.6]$

$100.0[95.4 ; 104.6]$

$70.0 \quad[65.5 ; 74.5]$

$71.6 \quad[65.3 ; 78.0]$

$71.5 \quad[67.7 ; 75.3]$

$79.0 \quad[75.0 ; 83.0]$

$68.0 \quad[59.0 ; 77.0]$

$82.0 \quad[78.1 ; 85.9]$

$85.1 \quad[80.6 ; 89.6]$

$62.0 \quad[61.6 ; 62.4]$

$68.0 \quad[63.4 ; 72.6]$

$48.4 \quad[41.5 ; 55.2]$

$73.6 \quad[67.8 ; 79.4$

$75.0 \quad[69.2 ; 80.8]$

$94.2 \quad[83.5 ; 104.9]$

$65.0 \quad[61.5 ; 68.5]$

$66.2[48.7 ; 83.7]$

$78.0 \quad[63.2 ; 92.8$

$61.5 \quad[54.9 ; 68.1]$

$56.0 \quad[50.7 ; 61.3]$

$72.8 \quad[68.0 ; 77.6]$

$74.2[39.3 ; 109.1]$

$69.5[66.9 ; 72.2]$

Figure S6. Forest plot of absolute values with $95 \% \mathrm{Cl}$ of stroke volume in $\mathrm{mL}$ in non-pregnant women and during normotensive pregnancy. 
$<14$ weeks

Conrad 2019

Petersen 2017

Sengupta 2017

lacobaeus 2017

Andreas 2016

Melchiorre 2016

Carpenter 2015

Mahendru 2014

Papadapoulou 2014

Jarvis 2012

Savu 2012

Hale 2010

Rang 2007

Lof 2005

Spaanderman 2000

Mesa 1999

Clapp 1997

Geva 1997

Mone 1996

van Oppen 1996

Capeless 1989

Mashini 1987

Airaksinen 1986

Summary

$l^{2}=99 \%$

15-21 weeks

Conrad 2019

Andreas 2016

D'Silva 2014

Estensen 2013

Desai 2004

Kametas 2001

Gilson 1997

Clapp 1997

Geva 1997

Mone 1996

van Oppen 1996

Capeless 1989

Mashini 1987

Rubler 1977

Summary

$l^{2}=98 \%$
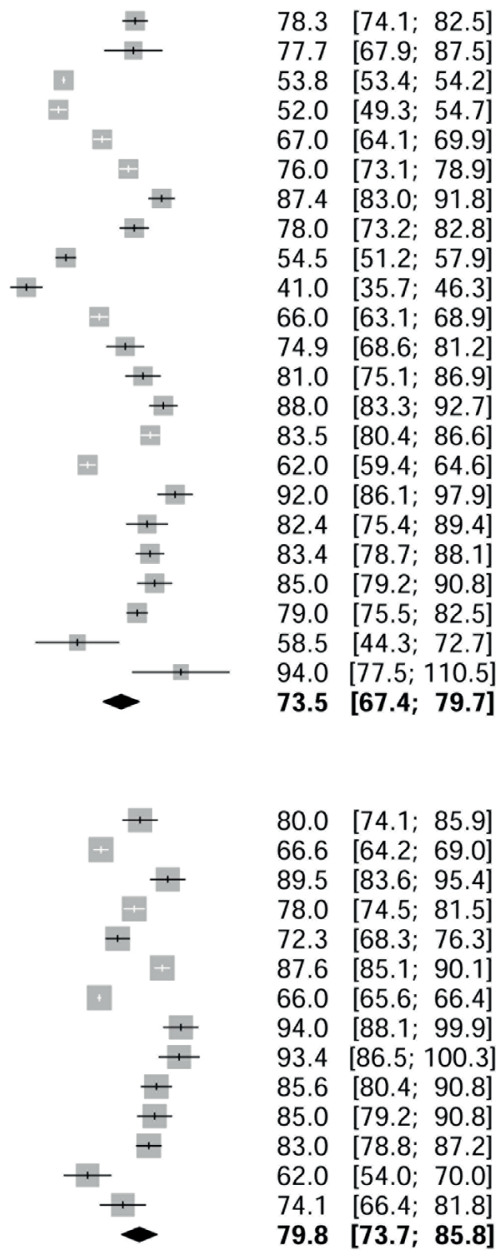

Figure S6 (continued). Forest plot of absolute values with $95 \% \mathrm{Cl}$ of stroke volume in $\mathrm{mL}$ in non-pregnant women and during normotensive pregnancy. 


\section{2-28 weeks}

Conrad 2019

Meah 2019

Nii 2018

lacobaeus 2017

Sengupta 2017

Melchiorre 2016

Andreas 2016

Carpenter 2015

Tso 2014

Vartun 2014

Mahendru 2014

Papadapoulou 2014

D'Silva 2014

Estensen 2013

Savu 2012

Pandey 2010

Valensise 2008

Rang 2007

Bamfo 2007

Desai 2004

Kametas 2004

Mesa 1999

Clapp 1997

Gilson 1997

Hennesy 1996

Capeless 1989

Airaksinen 1986

Rubler 1977

Ueland 1969

Rovinsky 1965

Summary

$l^{2}=99 \%$

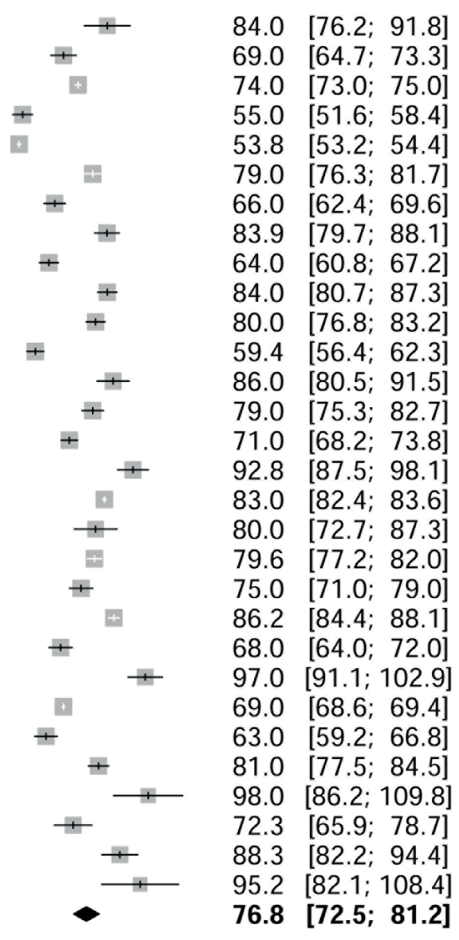

Figure S6 (continued). Forest plot of absolute values with $95 \% \mathrm{Cl}$ of stroke volume in $\mathrm{mL}$ in non-pregnant women and during normotensive pregnancy. 


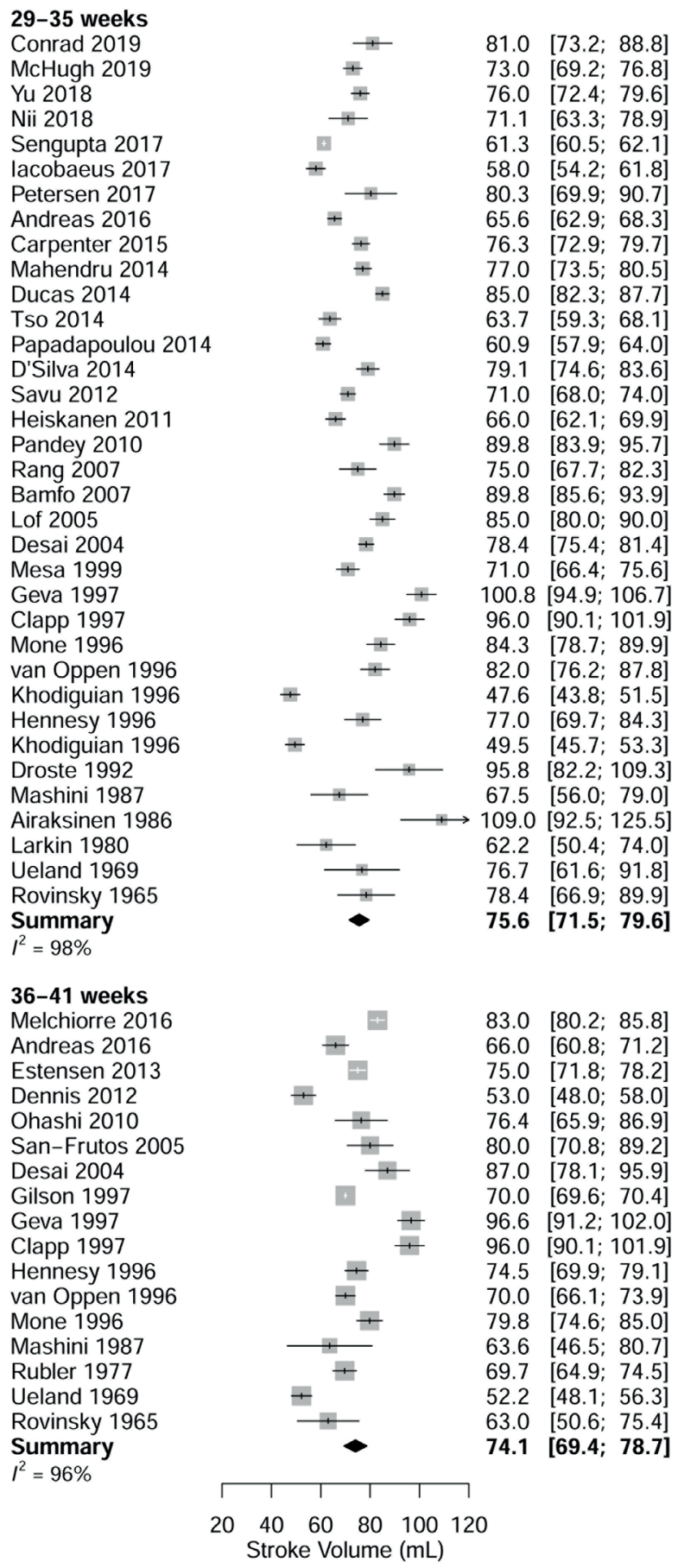

Figure $\mathbf{S 6}$ (continued). Forest plot of absolute values with $95 \% \mathrm{Cl}$ of stroke volume in $\mathrm{mL}$ in non-pregnant women and during normotensive pregnancy. 
Study

$<14$ weeks

Conrad 2019

Badrov 2019

Purdy 2018

Kolovetsiou 2018

Niemczyk 2018

Petersen 2017

Sengupta 2017

lacobaeus 2017

Martin 2017

Teli 2016

Andreas 2016

Melchiorre 2016

Carpenter 2015

Mahendru 2014

Papadopoulou 2014

Pandey 2014

Savu 2012

Hale 2010

Ogueh 2009

Rang 2007

Fok 2006

Mersich 2005

Lof 2005

Visontai 2002

Simmons 2002

Hasan 2002

Del Bene 2001

Spaanderman 2000

Mesa 1999

Dorup 1999

Speranza 1998

Geva 1997

Clapp 1997

Ahmad 1996

Mone 1996

van Oppen 1996

Vaha 1991

Capeless 1989

Thomsen 1988

Mashini 1987

Airaksinen 1986

Clapp 1985

Sorensen 1976

Burg 1974

Summary

$I^{2}=67 \%$

15-21 weeks

Conrad 2019

da Silva Correa 2019

Kolovetsiou 2018

Andreas 2016

Teli 2016

Cong 2015

D'Silva 2014

Estensen 2013

Ogueh 2009

Fok 2006

Mersich 2005

Desai 2004

Smith 2004

Pivarnik 2002

Hasan 2002
Sample size

Pregnant Reference

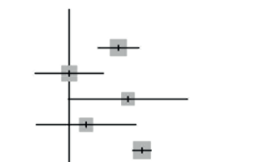

35
10

20

31

23

40

15

98

50

54
11

35

31

17
13

16

29

12

22
11

44

22

13

12

8
37

8

34

30

15

33

50

15

8
25

7

11

10

13

23
1087

1394

1087

$21 \quad 22$

$\begin{array}{ll}22 & 22 \\ 36 & 18\end{array}$

$\begin{array}{rr}36 & 18 \\ 149 & 15\end{array}$

$\begin{array}{ll}60 & 40 \\ 68 & 68\end{array}$

$28 \quad 28$

$63 \quad 63$

$12 \quad 13$

$34 \quad 29$

$\begin{array}{ll}12 & 12 \\ 29 & 27\end{array}$

$20 \quad 10$

$52 \quad 52$

22
MD $\quad 95 \% \mathrm{Cl}$

$6.7 \quad[3.9 ; 9.5]$

$0.0 \quad[-4.6 ; 4.6]$

$8.0[-0.1 ; 16.1]$

$2.3[-4.5 ; 9.1]$

9.9 [8.7; 11.1$]$

10.2 [3.3; 17.1]

$-0.2[-2.6 ; 2.2]$

$6.0 \quad[2.3 ; 9.7]$

$12.0[6.8 ; 17.2]$

$7.8 \quad[5.4 ; 10.2]$

$11.0[5.5 ; 16.5$

$5.0 \quad[2.3 ; 7.7]$

$8.0 \quad[4.1 ; 11.9]$

$3.0[-0.8 ; 6.8$

$4.5[-3.3 ; 12.3]$

$2.5[-4.4 ; 9.4$

$6.0 \quad[1.0 ; 11.0]$

$-1.8[-8.6 ; 5.0]$

$1.9 \quad[-6.0 ; 9.9]$

$3.0[-3.3 ; 9.3]$

$5.1 \quad[0.5 ; 9.7]$

$2.0 \quad[-3.8 ; 7.8]$

$3.0 \quad[-2.1 ; 8.1]$

$-1.0[-5.1 ; 3.1]$

$9.0 \quad[5.2 ; 12.8]$

$14.0[8.5 ; 19.5]$

$4.7[-6.7 ; 16.1]$

$4.0 \quad[0.6 ; 7.4]$

$6.0 \quad[0.9 ; 11.1]$

$9.0 \quad[1.1 ; 16.9]$

$9.5[0.5 ; 18.5]$

$7.8 \quad[2.7 ; 12.9]$

$7.0 \quad[2.6 ; 11.4]$

$4.0[-2.8 ; 10.8$

$8.0 \quad[3.4 ; 12.6]$

$7.0 \quad[2.7 ; 11.3]$

$5.7[-2.7 ; 14.1]$

$3.0[-0.5 ; 6.5]$

$8.0[4.9 ; 11.1]$

$8.6[-2.2 ; 19.4]$

$8.0 \quad[2.7 ; 13.3]$

$8.0 \quad[5.9 ; 10.1]$

$5.0[-3.0 ; 13.0]$

$5.0[-2.8 ; 12.8]$

$5.9[4.7 ; 7.0]$

$8.0 \quad[3.6 ; 12.4]$

$10.0[5.6 ; 14.4]$

$7.8 \quad[1.7 ; 13.9]$

$14.6[9.3 ; 19.9]$

$12.7[10.2 ; 15.2$

$2.3 \quad[-1.9 ; 6.5]$

$6.0 \quad[0.5 ; 11.5]$

$4.0 \quad[1.2 ; 6.8]$

$1.0 \quad[-6.9 ; 8.9]$

$10.5[5.6 ; 15.4$

$8.0 \quad[1.6 ; 14.4]$

$6.8 \quad[1.6 ; 12.0]$

$11.0 \quad[3.3 ; 18.7]$

$9.5 \quad[5.4 ; 13.6]$

$13.0[7.5 ; 18.5]$

Figure S7. Forest plot of heart rate (HR) adjustments during normotensive pregnancy. HR is reported as mean difference with $95 \% \mathrm{Cl}$ in beats per minute between pregnant women and reference group. 


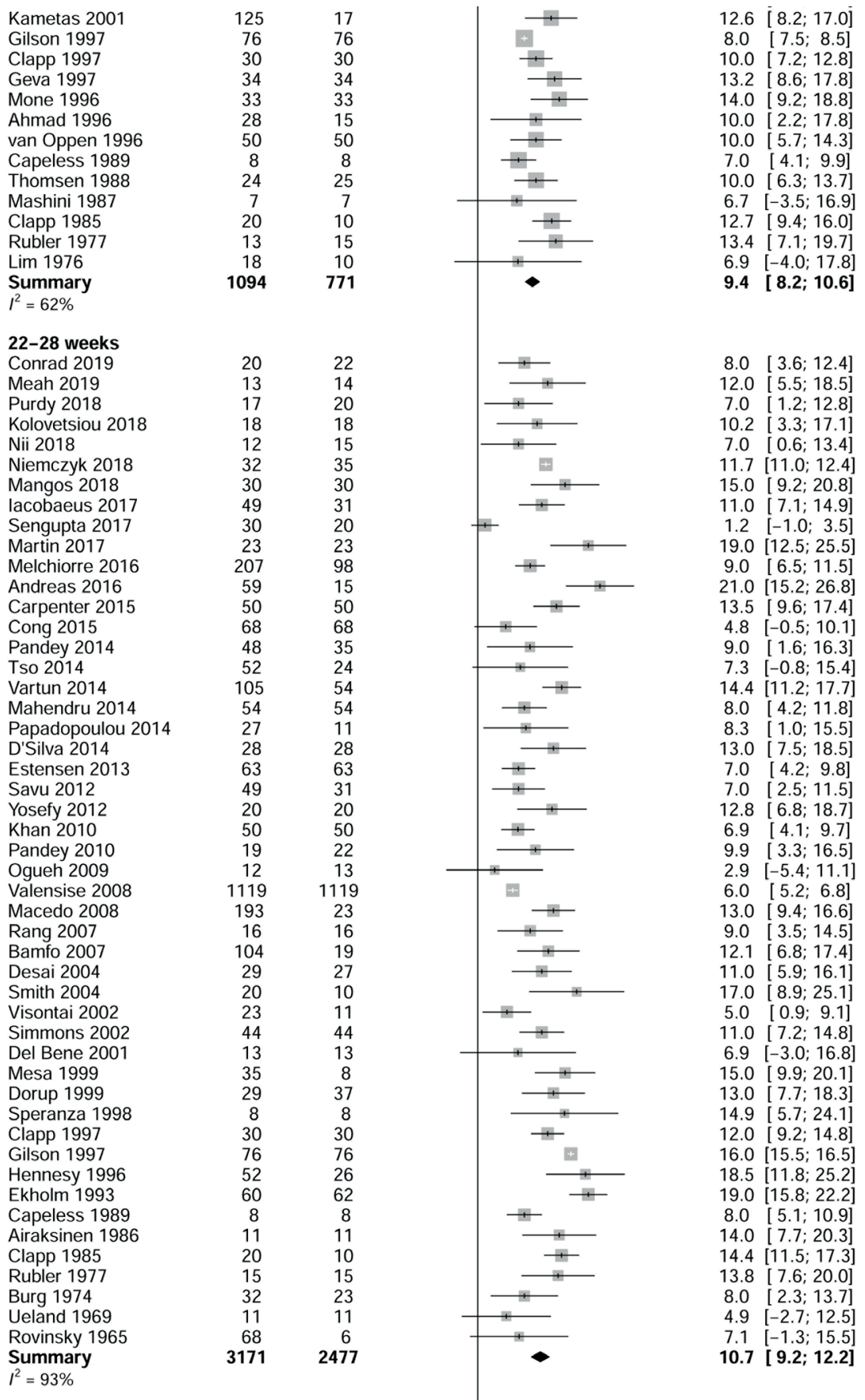

Figure S7 (continued). Forest plot of heart rate (HR) adjustments during normotensive pregnancy. HR is reported as mean difference with $95 \% \mathrm{Cl}$ in beats per minute between pregnant women and reference group. 
29-35 weeks

Conrad 2019

Badrov 2019

McHugh 2019

Kolovetsiou 2018

Purdy 2018

Yu 2018

Nii 2018

Kishan 2018

Sengupta 2017

Charkoudian 2017

lacobaeus 2017

Petersen 2017

Martin 2017

Andreas 2016

Teli 2016

Carpenter 2015

Mahendru 2014

Pandey 2014

Ducas 2014

Tso 2014

Karkkainen 2014

Papadopoulou 2014

D'Silva 2014

Yuan 2013

Savu 2012

Wykretowic 2011

Heiskanen 2011

Khan 2010

Pandey 2010

Rang 2007

Bamfo 2007

Tihtonen 2006

Fok 2006

Lof 2005

Mersich 2005

Desai 2004

Smith 2004

Hasan 2002

Pivarnik 2002

Visontai 2002

Simmons 2002

Del Bene 2001

Greenwood 2001

Borghi 2000

Mesa 1999

Dorup 1999

Speranza 1998

Lewinsky 1998

Geva 1997

Clapp 1997

Mone 1996

van Oppen 1996

Khodiguian 1996

Khodiguian 1996

Hennesy 1996

Ahmad 1996

Droste 1992

Sadaniantz 1992

Thomsen 1988

Mashini 1987

Airaksinen 1986

Clapp 1985

Larkin 1980

Lim 1976

Burg 1974

Ueland 1969

Rovinsky 1965

Summary

$1^{2}=72 \%$

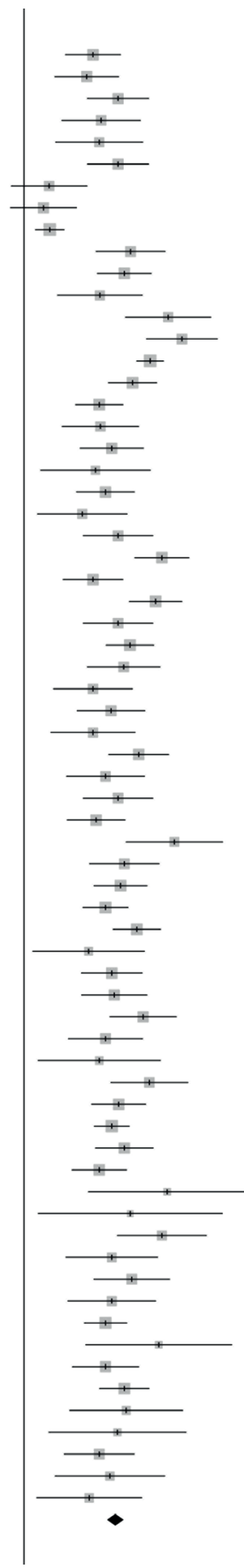

$11.0 \quad[6.6 ; 15.4]$

$10.0[4.9 ; 15.1]$

$15.0[10.1 ; 19.9$

12.3 [ 6.0; 18.6]

$12.0[5.1 ; 18.9]$

$15.0[10.1 ; 19.9]$

$4.0[-2.0 ; 10.0]$

$3.1[-2.2 ; 8.3]$

$4.1 \quad[1.8 ; 6.4]$

$17.0[11.5 ; 22.5$

$16.0[11.7 ; 20.3$

$12.1[5.3 ; 18.9]$

$23.0[16.2 ; 29.8$

25.2 [19.6; 30.8]

20.1 [18.0; 22.2]

$17.3[13.5 ; 21.2]$

12.0 [ $8.2 ; 15.8]$

$12.2[6.1 ; 18.3]$

14.0 [9.0; 19.0

$11.4[2.7 ; 20.1]$

$13.0[8.4 ; 17.6$

$9.3[2.1 ; 16.4]$

$15.0[9.5 ; 20.5$

$22.0[17.7 ; 26.3]$

$11.0[6.2 ; 15.8]$

$21.0[16.8 ; 25.2]$

$15.0[9.5 ; 20.5]$

$16.9[13.1 ; 20.7]$

$15.9[10.1 ; 21.7$

$11.0[4.7 ; 17.3]$

$13.9[8.5 ; 19.3$

$11.0[4.3 ; 17.7]$

$18.3[13.5 ; 23.1]$

$13.0[6.8 ; 19.2]$

$15.0[9.5 ; 20.5]$

$11.5[6.9 ; 16.1]$

$24.0[16.3 ; 31.7$

$16.0[10.5 ; 21.5]$

15.4 [11.2; 19.6

$13.0[9.4 ; 16.6]$

18.0 [14.2; 21.8 ]

$10.3[1.4 ; 19.2]$

$14.0[9.2 ; 18.8]$

$14.4 \quad[9.2 ; 19.6]$

$19.0[13.7 ; 24.3$ ]

$13.0[7.1 ; 18.9]$

12.0 [2.2: 21.8$]$

$20.0[13.9 ; 26.1]$

$15.1[10.8 ; 19.4$

$14.0[11.2 ; 16.8]$

$16.0[11.4 ; 20.6]$

$12.0[7.7 ; 16.3]$

$22.8[10.3 ; 35.4]$

$17.0[2.3 ; 31.6]$

$22.0[14.9 ; 29.1]$

$14.0[6.7 ; 21.3]$

$17.2[11.2 ; 23.2]$

14.0 [ 7.0; 21.0]

$13.0[9.6 ; 16.4$

$21.5[9.9 ; 33.1]$

$13.0[7.7 ; 18.3]$

$16.0[12.1 ; 19.9$

16.3 [ $7.3 ; 25.3]$

14.9 [ $4.0 ; 25.8$

$12.0[6.4 ; 17.6]$

13.7 [ 5.0; 22.4$]$

10.4 [ $2.0 ; 18.8]$

$14.6[13.4 ; 15.8]$

Figure S7 (continued). Forest plot of heart rate (HR) adjustments during normotensive pregnancy. HR is reported as mean difference with $95 \% \mathrm{Cl}$ in beats per minute between pregnant women and reference group. 
36-41 weeks

Niemczyk 2018

Kolovetsiou 2018

Melchiorre 2016

Andreas 2016

Cong 2015

Estensen 2013

Dennis 2012

Yosefy 2012

Ohashi 2010

Ogueh 2009

Chamchad 2007

San-Frutos 2005

Kaaja 2004

Dyer 2004

Desai 2004

Hasan 2002

Miyake 2002

Lechmanova 2002

Speranza 1998

Gilson 1997

Geva 1997

Hennesy 1996

van Oppen 1996

Mone 1996

Eneroth-Grimfors 1994

Vaha 1991

Mashini 1987

Hart 1986

Clapp 1985

Rubler 1977

Sorensen 1976

Ueland 1969

Rovinsky 1965

Summary

$I^{2}=53 \%$

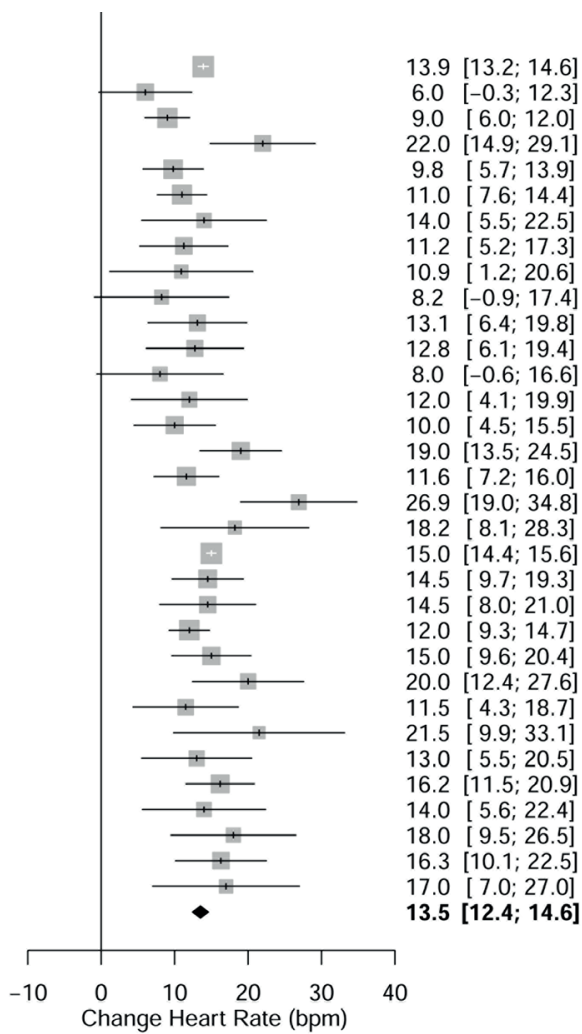

Figure S7 (continued). Forest plot of heart rate (HR) adjustments during normotensive pregnancy. HR is reported as mean difference with $95 \% \mathrm{Cl}$ in beats per minute between pregnant women and reference group. 
Study

Reference

Badrov 2019

Conrad 2019

da Silva Correa 2019

McHugh 2019

Meah 2019

Kishan 2018

Kolovetsiou 2018

Mangos 2018

Niemczyk 2018

Nii 2018

Purdy 2018

Yu 2018

Charkoudian 2017

lacobaeus 2017

Martin 2017

Petersen 2017

Sengupta 2017

Andreas 2016

Melchiorre 2016

Teli 2016

Carpenter 2015

Cong 2015

D'Silva 2014

Ducas 2014

Karkkainen 2014

Mahendru 2014

Pandey 2014

Papadopoulou 2014

Tso 2014

Vartun 2014

Estensen 2013

Yuan 2013

Dennis 2012

Savu 2012

Yosefy 2012

Heiskanen 2011

Wykretowic 2011

Hale 2010

Khan 2010

Ohashi 2010

Pandey 2010

Ogueh 2009

Rang 2008

Macedo 2008

Valensise 2008

Bamfo 2007

Bamfo 2007

Chamchad 2007

Rang 2007

Fok 2006

Tihtonen 2006

Lof 2005

Mersich 2005

San-Frutos 2005

Desai 2004

Dyer 2004

Kaaja 2004

Kametas 2004
Mean $\quad 95 \% \mathrm{Cl}$

$67.0 \quad[63.4 ; 70.6$

$67.0 \quad[65.0 ; 69.0]$

$69.0 \quad[65.7 ; 72.3]$

$72.0 \quad[68.1 ; 75.9]$

$69.0 \quad[65.2 ; 72.8]$

$75.1 \quad[70.7 ; 79.5$

$72.2 \quad[66.9 ; 77.5]$

$67.0 \quad[63.1 ; 70.9]$

$68.1 \quad[67.6 ; 68.6]$

$69.0 \quad[64.4 ; 73.6]$

$72.0 \quad[67.6 ; 76.4]$

$68.0 \quad[65.1 ; 70.9]$

$67.0 \quad[63.3 ; 70.7]$

$61.0 \quad[57.8 ; 64.2]$

$61.0 \quad[57.3 ; 64.7]$

$64.8 \quad[61.5 ; 68.1]$

$74.7 \quad[73.0 ; 76.4$

$67.0 \quad[61.9 ; 72.1]$

$70.0 \quad[67.9 ; 72.1]$

$75.6 \quad[74.3 ; 76.9]$

$73.6 \quad[70.9 ; 76.3$

$80.3 \quad[76.9 ; 83.7]$

$75.0 \quad[71.1 ; 78.9$

$60.0 \quad[56.0 ; 64.0]$

$69.0 \quad[65.6 ; 72.4$

$68.0 \quad[65.3 ; 70.7]$

$68.7 \quad[64.1 ; 73.3]$

$77.2 \quad[70.6 ; 83.8$

$79.3 \quad[72.1 ; 86.5]$

$66.7 \quad[64.3 ; 69.0$

$69.0 \quad[67.0 ; 71.0]$

$72.0 \quad[67.7 ; 76.3]$

$64.0 \quad[56.1 ; 71.9]$

$69.0 \quad[65.1 ; 72.9]$

$71.8 \quad[68.2 ; 75.5]$

$68.0[64.1 ; 71.9]$

$68.0 \quad[65.7 ; 70.3]$

$73.2[67.8 ; 78.6]$

$72.9 \quad[72.5 ; 73.3]$

$67.9 \quad[61.3 ; 74.5]$

$72.7 \quad[68.8 ; 76.6$

$72.7 \quad[65.8 ; 79.6]$

$70.3 \quad[64.0 ; 76.6]$

$64.0 \quad[60.7 ; 67.3]$

$74.0 \quad[73.5 ; 74.5]$

$67.7 \quad[62.9 ; 72.6]$

$68.2 \quad[64.9 ; 71.5]$

$75.0 \quad[70.5 ; 79.5]$

$67.0 \quad[63.1 ; 70.9]$

$68.6 \quad[65.2 ; 72.0]$

$69.0 \quad[63.9 ; 74.1]$

$62.0 \quad[57.8 ; 66.2]$

$77.0 \quad[73.1 ; 80.9]$

$71.3 \quad[65.8 ; 76.8]$

$69.0 \quad[64.9 ; 73.1]$

$70.3 \quad[65.2 ; 75.4]$

$63.8 \quad[56.4 ; 71.2]$

71.2 [67.6; 74.8]

Figure S8. Forest plot of absolute values with $95 \% \mathrm{Cl}$ of heart rate in beats per minute in non-pregnant women and during normotensive pregnancy. 


\begin{tabular}{|c|c|c|c|c|}
\hline Smith 2004 & $\rightarrow$ & 69.0 & {$[62.2 ;$} & 75.8] \\
\hline Hasan 2002 & $\mp$ & 71.0 & {$[67.1 ;$} & 74.9] \\
\hline Lechmanova 2002 & $\mp$ & 75.2 & {$[69.9 ;$} & 80.5] \\
\hline Miyake 2002 & $\mp$ & 71.0 & {$[67.1 ;$} & $74.9]$ \\
\hline Pivarnik 2002 & $\Psi$ & 75.4 & {$[72.0 ;$} & 78.8] \\
\hline Simmons 2002 & $\mp$ & 67.0 & {$[64.6 ;$} & 69.4] \\
\hline Visontai 2002 & $\mp$ & 83.0 & {$[80.0 ;$} & 86.0] \\
\hline Del Bene 2001 & $\mp$ & 76.9 & {$[69.2 ;$} & 84.6] \\
\hline Greenwood 2001 & + & 68.0 & {$[64.7 ;$} & 71.3] \\
\hline Kametas 2001 & $\mp$ & 67.2 & {$[63.3 ;$} & 71.1] \\
\hline Borghi 2000 & $\mp$ & 70.1 & {$[66.4$} & 73.8] \\
\hline Spaanderman 2000 & $\mp$ & 66.0 & {$[63.2 ;$} & 68.8] \\
\hline Dorup 1999 & $\mp$ & 66.0 & {$[62.5$} & 69.5] \\
\hline Mesa 1999 & $\mp$ & 68.0 & {$[63.8 ;$} & 72.2] \\
\hline Lewinsky 1998 & $\mp$ & 65.0 & {$[60.3 ;$} & 69.7 \\
\hline Speranza 1998 & $\mp$ & 69.5 & {$[62.8 ;$} & 76.2] \\
\hline Clapp 1997 & $\mp$ & 57.0 & {$[55.0 ;$} & 59.0] \\
\hline Geva 1997 & $\mp$ & 63.8 & {$[61.1 ;$} & $66.5]$ \\
\hline Gilson 1997 & 田 & 67.0 & {$[66.6 ;$} & 67.4] \\
\hline Ahmad 1996 & $\mp$ & 80.0 & {$[73.9 ;$} & 86.1 \\
\hline Hennesy 1996 & $\mp$ & 69.0 & [63.6; & 74.4] \\
\hline Khodiguian 1996 & $\mp$ & 67.5 & {$[56.4 ;$} & 78.5 \\
\hline Mone 1996 & + & 64.0 & {$[60.9 ;$} & 67.1] \\
\hline van Oppen 1996 & $\mp$ & 80.0 & {$[78.1 ;$} & 81.9] \\
\hline Eneroth-Grimfors 1994 & $\mp$ & 65.0 & {$[58.8 ;$} & 71.2 \\
\hline Ekholm 1993 & $\mp$ & 64.0 & {$[61.8 ;$} & 66.2 \\
\hline Droste 1992 & $\Psi$ & 66.6 & {$[62.3 ;$} & 70.9 \\
\hline Sadaniantz 1992 & $\mp$ & 70.0 & {$[64.1 ;$} & 75.9 \\
\hline Vaha 1991 & $\mp$ & 71.8 & {$[65.6 ;$} & 78.0] \\
\hline Capeless 1989 & $\mp$ & 65.0 & {$[62.9 ;$} & 67.1] \\
\hline Thomsen 1988 & $\mp$ & 72.0 & {$[69.6 ;$} & 74.4 \\
\hline Mashini 1987 & —- & 66.4 & {$[57.4 ;$} & 75.4 \\
\hline Airaksinen 1986 & $\mp$ & 64.0 & {$[59.3$} & 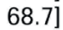 \\
\hline Hart 1986 & $\mp$ & 67.0 & {$[63.0 ;$} & 71.0] \\
\hline Clapp 1985 & w & 57.8 & {$[56.1 ;$} & 59.5 \\
\hline Rubler 1977 & $\mp$ & 71.1 & {$[66.6 ;$} & 75. \\
\hline Lim 1976 & 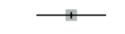 & 75.3 & {$[64.9 ;$} & 85.7 \\
\hline Sorensen 1976 & $\mp$ & 68.0 & {$[60.9 ;$} & 75.1 \\
\hline Burg 1974 & $\mp$ & 72.0 & {$[67.7 ;$} & 76.3 \\
\hline Ueland 1969 & $\mp$ & 69.5 & {$[65.1 ;$} & 73.9 \\
\hline Rovinsky 1965 & $\mp$ & 81.0 & {$[72.8 ;$} & 89.2 \\
\hline Summary & + & 69.4 & [68.5; & 70.3 \\
\hline$l^{2}=94 \%$ & & & & \\
\hline \multicolumn{5}{|l|}{$<14$ weeks } \\
\hline Conrad 2019 & $\mp$ & 73.7 & {$[71.7 ;$} & 75.7 \\
\hline Badrov 2019 & $\mp$ & 67.0 & {$[64.1 ;$} & 69. \\
\hline Purdy 2018 & $\mp$ & 80.0 & {$[73.2 ;$} & 86. \\
\hline Kolovetsiou 2018 & + & 74.5 & {$[70.3 ;$} & 78. \\
\hline Niemczyk 2018 & + & 78.0 & {$[76.9 ;$} & 79. \\
\hline Petersen 2017 & $\mp$ & 75.0 & {$[68.9 ;$} & 81. \\
\hline Sengupta 2017 & \pm & 74.5 & {$[72.9 ;$} & 76. \\
\hline lacobaeus 2017 & $\Psi$ & 67.0 & {$[65.1 ;$} & 68. \\
\hline Martin 2017 & + & 73.0 & {$[69.3$} & 76. \\
\hline Teli 2016 & \pm & 83.4 & [81.3; & 85. \\
\hline Andreas 2016 & + & 78.0 & {$[75.9 ;$} & 80. \\
\hline Melchiorre 2016 & + & 75.0 & {$[73.2 ;$} & 76. \\
\hline Carpenter 2015 & + & 81.6 & [78.8; & 84. \\
\hline Mahendru 2014 & $\mp$ & 71.0 & {$[68.3 ;$} & 73.7 \\
\hline Papadopoulou 2014 & + & 81.7 & {$[77.6 ;$} & 85.8 \\
\hline Pandey 2014 & $\mp$ & 71.2 & {$[66.1 ;$} & 76.3 \\
\hline
\end{tabular}

Figure S8 (continued). Forest plot of absolute values with $95 \% \mathrm{Cl}$ of heart rate in beats per minute in nonpregnant women and during normotensive pregnancy. 


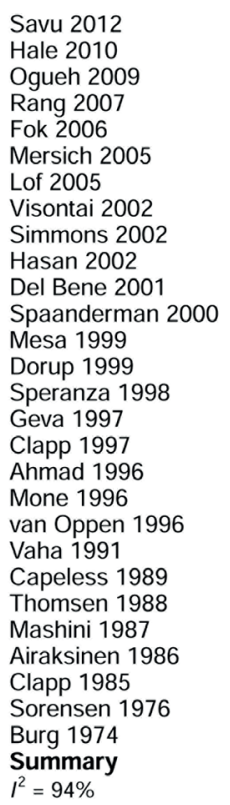

15-21 weeks

Conrad 2019

da Silva Correa 2019

Kolovetsiou 2018

Andreas 2016

Teli 2016

Cong 2015

D'Silva 2014

Estensen 2013

Ogueh 2009

Fok 2006

Mersich 2005

Desai 2004

Smith 2004

Pivarnik 2002

Hasan 2002

Kametas 2001

Gilson 1997

Clapp 1997

Geva 1997

Mone 1996

Ahmad 1996

van Oppen 1996

Capeless 1989

Thomsen 1988

Mashini 1987

Clapp 1985

Rubler 1977

Lim 1976

Summary

$I^{2}=96 \%$
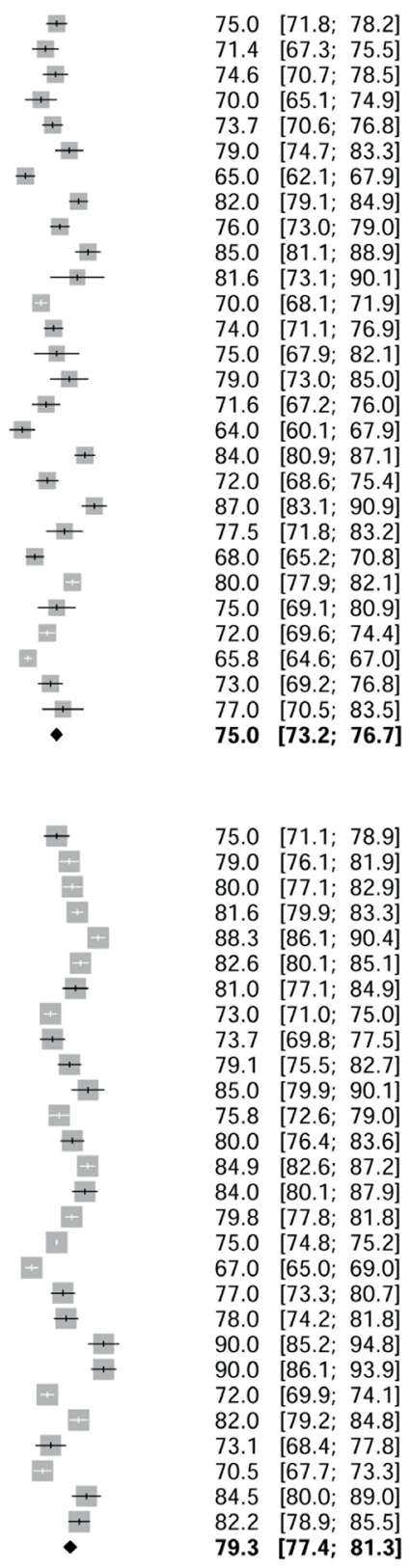

Figure S8 (continued). Forest plot of absolute values with $95 \% \mathrm{Cl}$ of heart rate in beats per minute in nonpregnant women and during normotensive pregnancy. 


\begin{tabular}{|c|c|c|c|}
\hline 29-35 weeks & & & \\
\hline Conrad 2019 & $\mp$ & 78.0 & {$[74.1 ; 81.9]$} \\
\hline Badrov 2019 & $\mp$ & 77.0 & {$[73.4 ; 80.6]$} \\
\hline McHugh 2019 & $\mp$ & 87.0 & {$[84.1 ; 89.9]$} \\
\hline Kolovetsiou 2018 & $\mp$ & 84.5 & {$[81.2 ; 87.8]$} \\
\hline Purdy 2018 & $\mp$ & 84.0 & {$[78.6 ; 89.4]$} \\
\hline Yu 2018 & $\mp$ & 83.0 & {$[79.1 ; 86.9]$} \\
\hline Nii 2018 & $\mp$ & 73.0 & {$[69.0 ; 77.0]$} \\
\hline Kishan 2018 & $\mp$ & 78.2 & {$[75.3 ; 81.1]$} \\
\hline Sengupta 2017 & ت\# & 78.8 & {$[77.3 ; 80.3]$} \\
\hline Charkoudian 2017 & $\mp$ & 84.0 & {$[79.9 ; 88.1]$} \\
\hline lacobaeus 2017 & $\mp$ & 77.0 & {$[74.1 ; 79.9]$} \\
\hline Petersen 2017 & $\mp$ & 76.9 & {$[71.0 ; 82.8]$} \\
\hline Martin 2017 & $\mp$ & 84.0 & {$[78.3 ; 89.7]$} \\
\hline Andreas 2016 & $\mp$ & 92.2 & {$[89.7 ; 94.7]$} \\
\hline Teli 2016 & تt & 95.7 & {$[94.0 ; 97.4]$} \\
\hline Carpenter 2015 & $\mp$ & 90.9 & {$[88.2 ; 93.6]$} \\
\hline Mahendru 2014 & $\mp$ & 80.0 & {$[77.3 ; 82.7]$} \\
\hline Pandey 2014 & $\mp$ & 80.9 & {$[76.9 ; 84.9]$} \\
\hline Ducas 2014 & $\mp$ & 74.0 & {$[71.0 ; 77.0]$} \\
\hline Tso 2014 & $\mp$ & 90.7 & {$[85.8 ; 95.6]$} \\
\hline Karkkainen 2014 & $\mp$ & 82.0 & {$[78.9 ; 85.1]$} \\
\hline Papadopoulou 2014 & $\mp$ & 86.5 & {$[83.7 ; 89.3]$} \\
\hline D'Silva 2014 & $\rightleftarrows$ & 90.0 & {$[86.1 ; 93.9]$} \\
\hline Yuan 2013 & (1) & 94.0 & {$[93.7 ; 94.3]$} \\
\hline Savu 2012 & $\mp$ & 80.0 & {$[77.2 ; 82.8]$} \\
\hline Wykretowic 2011 & $\mp$ & 89.0 & {$[85.5 ; 92.5]$} \\
\hline Heiskanen 2011 & $\mp$ & 83.0 & {$[79.1 ; 86.9]$} \\
\hline Khan 2010 & $\mp$ & 89.8 & {$[86.0 ; 93.6]$} \\
\hline Pandey 2010 & $\mp$ & 88.6 & {$[84.3 ; 92.9]$} \\
\hline Rang 2007 & $\mp$ & 78.0 & {$[73.1 ; 82.9]$} \\
\hline Bamfo 2007 & $\mp$ & 82.6 & {$[79.7 ; 85.6]$} \\
\hline Tihtonen 2006 & + & 80.0 & {$[75.6 ; 84.4]$} \\
\hline Fok 2006 & + & 86.9 & {$[83.6 ; 90.2]$} \\
\hline Lof 2005 & $\mp$ & 75.0 & {$[70.4 ; 79.6]$} \\
\hline Mersich 2005 & \# & 92.0 & {$[88.1 ; 95.9]$} \\
\hline Desai 2004 & 푤 & 80.5 & {$[78.5 ; 82.5]$} \\
\hline Smith 2004 & $\mp$ & 93.0 & {$[89.5 ; 96.5]$} \\
\hline Hasan 2002 & $\mp$ & 87.0 & {$[83.1 ; 90.9]$} \\
\hline Pivarnik 2002 & $\mp$ & 90.8 & {$[88.3 ; 93.3]$} \\
\hline Visontai 2002 & 폴 & 96.0 & {$[94.0 ; 98.0]$} \\
\hline Simmons 2002 & \# & 85.0 & {$[82.0 ; 88.0]$} \\
\hline Del Bene 2001 & $\mp$ & 87.2 & {$[82.7 ; 91.7]$} \\
\hline Greenwood 2001 & $\mp$ & 82.0 & {$[78.5 ; 85.5]$} \\
\hline Borghi 2000 & $\mp$ & 84.5 & {$[80.9 ; 88.1]$} \\
\hline Mesa 1999 & $\mp$ & 87.0 & {$[83.7 ; 90.3]$} \\
\hline Dorup 1999 & $\mp$ & 79.0 & {$[74.3 ; 83.7]$} \\
\hline Speranza 1998 & $\mp$ & 81.5 & {$[74.4 ; 88.6]$} \\
\hline Lewinsky 1998 & $\mp$ & 85.0 & {$[81.1 ; 88.9]$} \\
\hline Geva 1997 & $\mp$ & 78.9 & {$[75.5 ; 82.3]$} \\
\hline Clapp 1997 & F & 71.0 & {$[69.0 ; 73.0]$} \\
\hline Mone 1996 & $\mp$ & 80.0 & {$[76.6 ; 83.4]$} \\
\hline van Oppen 1996 & $\mp$ & 92.0 & {$[88.1 ; 95.9]$} \\
\hline Khodiguian 1996 & $\mp$ & 90.3 & {$[84.3 ; 96.3]$} \\
\hline Khodiguian 1996 & $\longrightarrow$ & 84.4 & {$[74.7 ; 94.1]$} \\
\hline Hennesy 1996 & 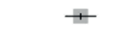 & 91.0 & {$[86.4 ; 95.6]$} \\
\hline Ahmad 1996 & $\mp$ & 94.0 & {$[89.9 ; 98.1]$} \\
\hline Droste 1992 & 廿 & 83.8 & {$[79.5 ; 88.1]$} \\
\hline Sadaniantz 1992 & $\mp$ & 84.0 & {$[80.3 ; 87.7]$} \\
\hline Thomsen 1988 & $\mp$ & 85.0 & {$[82.6 ; 87.4]$} \\
\hline Mashini 1987 & $\mp$ & 87.9 & {$[80.6 ; 95.2]$} \\
\hline
\end{tabular}

Figure S8 (continued). Forest plot of absolute values with $95 \% \mathrm{Cl}$ of heart rate in beats per minute in nonpregnant women and during normotensive pregnancy. 


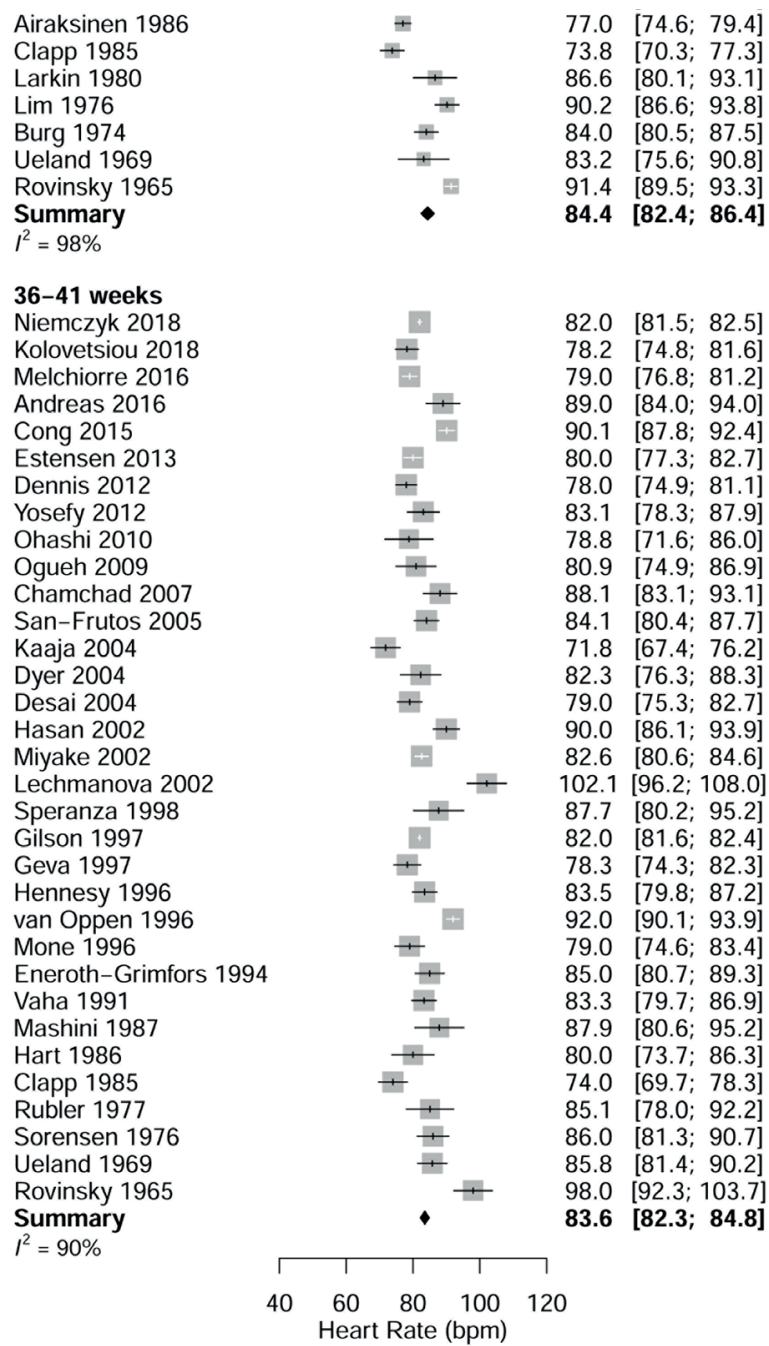

Figure $\mathbf{S} 8$ (continued). Forest plot of absolute values with $95 \% \mathrm{Cl}$ of heart rate in beats per minute in nonpregnant women and during normotensive pregnancy. 


\begin{tabular}{|c|c|c|c|c|c|c|}
\hline Study & $\begin{array}{r}\text { San } \\
\text { Pregna }\end{array}$ & ize & & & MD & $95 \% \mathrm{Cl}$ \\
\hline \multicolumn{7}{|l|}{$<14$ weeks } \\
\hline Hale 2010 & 3 & 3 & - & 1 & 0.40 & {$[-1.05 ; 1.85]$} \\
\hline Rang 2008 & 15 & 5 & & $\ldots$ & 2.10 & {$[0.52 ; 3.68]$} \\
\hline Rang 2008 & 15 & 5 & & - & 1.30 & {$[0.37 ; 2.23]$} \\
\hline $\begin{array}{l}\text { Summary } \\
I^{2}=18 \%\end{array}$ & 33 & 13 & & & 1.25 & {$[0.45 ; 2.04]$} \\
\hline \multicolumn{7}{|l|}{ 15-21 weeks } \\
\hline Rang 2008 & 10 & 5 & & 1 & 1.85 & {$[0.21 ; 3.49]$} \\
\hline Rang 2008 & 10 & 5 & & 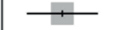 & 1.80 & {$[0.76 ; 2.84]$} \\
\hline $\begin{array}{l}\text { Summary } \\
I^{2}=0 \%\end{array}$ & 20 & 10 & & & 1.81 & {$[0.93 ; 2.69]$} \\
\hline \multicolumn{7}{|l|}{ 22-28 weeks } \\
\hline Valensise 2008 & 75 & 75 & $\mp$ & & -0.54 & {$[-0.89 ;-0.19]$} \\
\hline Valensise 2008 & 32 & 32 & & $\div$ & 3.21 & {$[2.49 ; 3.93]$} \\
\hline Borghi 2000 & 40 & 10 & & 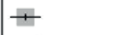 & 0.70 & {$[0.26 ; 1.14]$} \\
\hline $\begin{array}{l}\text { Summary } \\
I^{2}=98 \%\end{array}$ & 147 & 117 & & & 1.10 & {$[-0.72 ; 2.91]$} \\
\hline \multicolumn{7}{|l|}{ 29-35 weeks } \\
\hline Yu 2018 & 25 & 25 & & $t$ & 0.00 & {$[-0.42 ; 0.42]$} \\
\hline Yu 2018 & 27 & 27 & & \pm & 0.10 & {$[-0.41 ; 0.61]$} \\
\hline Giannubilo 2017 & 48 & 50 & & $\mp$ & 0.67 & {$[0.27 ; 1.07]$} \\
\hline Dennis 2012 & 19 & 20 & & $\mp$ & 1.45 & {$[0.73 ; 2.16]$} \\
\hline Heiskanen 2011 & 28 & 28 & & $\mp$ & 0.58 & {$[0.01 ; 1.15]$} \\
\hline Rang 2008 & 5 & 5 & & 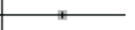 & 1.80 & {$[-0.06 ; 3.66]$} \\
\hline Rang 2008 & 5 & 5 & & $x$ & 1.40 & {$[-0.21 ; 3.01]$} \\
\hline $\begin{array}{l}\text { Summary } \\
I^{2}=67 \%\end{array}$ & 157 & 160 & & $<$ & 0.62 & {$[0.19 ; 1.04]$} \\
\hline \multicolumn{7}{|l|}{ 36-41 weeks } \\
\hline Dennis 2012 & 21 & 20 & & + & 1.34 & {$[0.63 ; 2.04]$} \\
\hline Ohashi 2010 & 10 & 10 & & + & 1.00 & {$[0.39 ; 1.61]$} \\
\hline \multirow{3}{*}{$\begin{array}{l}\text { Summary } \\
I^{2}=0 \%\end{array}$} & 31 & 30 & & $<$ & 1.15 & {$[0.68 ; 1.61]$} \\
\hline & & & & ᄀ & & \\
\hline & & & & 2 & & \\
\hline
\end{tabular}

Figure S9. Forest plot of cardiac output (CO) adjustments during hypertensive pregnancy. CO is reported as mean difference with $95 \% \mathrm{Cl}$ between pregnant women and reference group in litres per minute. 
Study

\section{Reference}

Yu 2018

Yu 2018

Giannubilo 2017

Dennis 2012

Heiskanen 2011

Hale 2010

Ohashi 2010

Rang 2008

Rang 2008

Valensise 2008

Valensise 2008

Borghi 2000

Summary

$I^{2}=94 \%$

$<14$ weeks

Hale 2010

Rang 2008

Rang 2008

Summary

$l^{2}=94 \%$

15-21 weeks

Rang 2008

Rang 2008

Summary

$l^{2}=61 \%$

\section{2-28 weeks}

Valensise 2008

Valensise 2008

Borghi 2000

Summary

$I^{2}=99 \%$

\section{9-35 weeks}

Yu 2018

Yu 2018

Giannubilo 2017

Dennis 2012

Heiskanen 2011

Rang 2008

Rang 2008

Summary

$I^{2}=85 \%$

\section{6-41 weeks}

Dennis 2012

Ohashi 2010

Summary

$l^{2}=96 \%$
Mean $\quad 95 \% \mathrm{Cl}$

$5.60 \quad[5.26 ; 5.94]$

$5.50 \quad[5.23 ; 5.77]$

5.03 [4.78; 5.28]

$3.40 \quad[3.07 ; 3.73$

$5.91 \quad[5.50 ; 6.32]$

$3.90 \quad[2.99 ; 4.81]$

$5.60 \quad[5.17 ; 6.03$

$6.60 \quad[5.37 ; 7.83]$

$5.60 \quad[4.81 ; 6.39]$

$5.03 \quad[4.79 ; 5.27$

$5.75 \quad[5.40 ; 6.10]$

$5.80 \quad[5.49 ; 6.11]$

$5.29[4.86 ; 5.72]$

$4.30 \quad[3.17 ; 5.43]$

$8.70 \quad[7.70 ; 9.70]$

$6.90 \quad[6.41 ; 7.39]$

$6.66[4.66 ; 8.65]$

8.45 [7.37; 9.53]

$7.40 \quad[6.72 ; 8.08]$

$7.84[6.82 ; 8.85]$

$4.49 \quad[4.24 ; 4.74]$

$8.96 \quad[8.33 ; 9.59]$

$6.50 \quad[6.19 ; 6.81]$

$6.63[4.51 ; 8.75]$

$5.50 \quad[5.19 ; 5.81]$

$5.70 \quad[5.32 ; 6.08]$

$5.70 \quad[5.39 ; 6.01]$

$4.85 \quad[4.21 ; 5.48]$

$6.49 \quad[6.10 ; 6.88]$

$8.40 \quad[7.00 ; 9.80]$

$7.00 \quad[5.60 ; 8.40]$

$5.97[5.49 ; 6.45]$

$4.74 \quad[4.11 ; 5.36]$

$6.60 \quad[6.17 ; 7.03]$

$5.68[3.86 ; 7.51]$

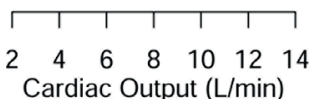

Cardiac Output (L/min)

Figure S10. Forest plot of absolute values $(95 \% \mathrm{Cl})$ of cardiac output in non-pregnant women and during hypertensive pregnancy. 
Study

$<14$ weeks

Rang 2008

Rang 2008

Summary

$1^{2}=0 \%$

15-21 weeks

Rang 2008

Rang 2008

Summary

$1^{2}=0 \%$

22-28 weeks

Valensise 2008

Valensise 2008

Borghi 2000

Summary

$I^{2}=98 \%$

29-35 weeks

Giannubilo 2017

Dennis 2012

Rang 2008

Rang 2008

Summary

$1^{2}=78 \%$

36-41 weeks

Dennis 2012

Ohashi 2010

Summary

$I^{2}=80 \%$
Sample size

Pregnant Reference

$\begin{array}{rr}15 & 5 \\ 15 & 5 \\ \mathbf{3 0} & \mathbf{1 0}\end{array}$

\section{5}

10

$\begin{array}{ll}10 & 5 \\ 10 & 5\end{array}$

$20 \quad 10$

$\begin{array}{rr} & \\ \mathbf{7 5} & 75 \\ 32 & 32 \\ 40 & 10 \\ \mathbf{1 4 7} & \mathbf{1 1 7}\end{array}$

$\begin{array}{cr}48 & 50 \\ 19 & 20 \\ 5 & 5 \\ 4 & 5 \\ \mathbf{7 6} & \mathbf{8 0}\end{array}$

$76 \quad 80$

$21 \quad 20$

$10 \quad 10$

$31 \quad 30$
MD $\quad 95 \% \mathrm{Cl}$

$-125 \quad[-257 ; 77]$

$-38 \quad[-206 ; 130]$

-92 [-195; 12]

-140 [-256; -24]

-111 [-290; 68]

$-131[-229 ;-34]$

147 [ 61; 233]

$-518[-646 ;-390]$

225 [ 105; 345]

$-47[-468 ; 373]$

203 [ 94; 312]

$-56 \quad[-445 ; 333$

$-116[-251 ; 19]$

$26[-241 ; 293]$

27 [-172; 226]

$-140[-437 ; 157]$

233 [ 91; 375]

$70 \quad[-292 ; 433]$

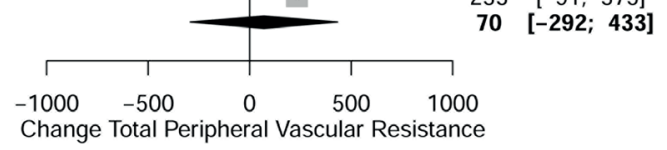

Figure S11. Forest plot of total peripheral vascular resistance (TPVR) adjustments during hypertensive pregnancy. TPVR is reported as mean difference with $95 \% \mathrm{Cl}$ between pregnant women and reference group in dyne $\cdot \mathrm{sec} \cdot \mathrm{Cm}^{-5}$. 
Study

Reference

Giannubilo 2017

Dennis 2012

Ohashi 2010

Valensise 2008

Valensise 2008

Rang 2008

Rang 2008

Borghi 2000

Summary

$I^{2}=97 \%$

<14 weeks

Rang 2008

Rang 2008

Summary

$l^{2}=85 \%$

\section{5-21 weeks}

Rang 2008

Rang 2008

Summary

$I^{2}=65 \%$

\section{2-28 weeks}

Valensise 2008

Valensise 2008

Borghi 2000

Summary

$I^{2}=99 \%$

\section{9-35 weeks}

Giannubilo 2017

Dennis 2012

Rang 2008

Rang 2008

Summary

$l^{2}=99 \%$

\section{6-41 weeks}

Dennis 2012

Ohashi 2010

Summary

$I^{2}=96 \%$

\section{Mean $\quad 95 \% \mathrm{Cl}$}

1384 [1297; 1471]

2116 [1916; 2316]

1137 [1044; 1230$]$

1458 [1393; 1523]

$1257[1161 ; 1353]$

$767 \quad[675 ; 859]$

$846 \quad[700 ; 992]$

$1095[1011 ; 1179]$

1251 [1040; 1461]

642 [ 547; 737]

$808 \quad[725 ; 891]$

727 [ 564; 889]

627 [556; 698]

$735 \quad[631 ; 839]$

674 [ 569; 779]

$1605[1549 ; 1661]$

$739 \quad[654 ; 824]$

$1320[1234 ; 1406]$

$1222[711 ; 1732]$

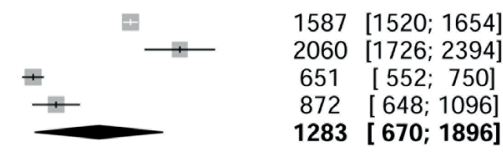

$1976 \quad[1757 ; 2195]$

$1370[1262 ; 1477]$

$1665[1071 ; 2259]$

$500 \quad 1500 \quad 2500$

Total Peripheral Vascular Resistance (dyn. $\mathrm{sec} \cdot \mathrm{cm}^{\wedge}-5$ )

Figure S12. Forest plot of absolute values $(95 \% \mathrm{Cl})$ of total peripheral vascular resistance in non-pregnant women and during hypertensive pregnancy. 
Study

$<14$ weeks

Hale 2010

Summary

not applicable

22-28 weeks

Valensise 2008

Valensise 2008

Summary

$l^{2}=99 \%$

29-35 weeks

Yu 2018

Yu 2018

Dennis 2012

Heiskanen 2011

Summary

$l^{2}=0 \%$

36-41 weeks

Dennis 2012

Ohashi 2010

Summary

$l^{2}=71 \%$
Sample size

Pregnant Reference

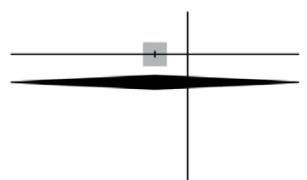

$\begin{array}{rr}75 & 75 \\ 32 & 32 \\ \mathbf{1 0 7} & \mathbf{1 0 7}\end{array}$

32
107

107

$25 \quad 25$

$27 \quad 27$

$19 \quad 20$

$28 \quad 28$

$99 \quad 100$

28
100

$\begin{array}{ll}21 & 20 \\ 10 & 10\end{array}$

$31 \quad 30$

30
MD $\quad 95 \% \mathrm{Cl}$

$-6.3[-34.0 ; 21.4]$

$-6.3[-34.0 ; 21.4]$

$-7.0[-11.0 ;-3.0]$

$28.0[20.7 ; 35.3]$

10.4 [-23.9; 44.7]

$0.0 \quad[-6.1 ; 6.1]$

$2.0[-3.6 ; 7.6]$

$7.0 \quad[-0.7 ; 14.7]$

$0.0 \quad[-7.1 ; 7.1]$

$1.9[-1.3 ; 5.1]$

$5.0 \quad[-1.7 ; 11.7]$

$-5.6[-14.5 ; 3.3]$

$0.1[-10.2 ; 10.5]$

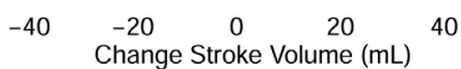

Figure S13. Forest plot of stroke volume (SV) adjustments during hypertensive pregnancy. SV is reported as mean difference with $95 \% \mathrm{Cl}$ between pregnant women and reference group in $\mathrm{mL}$. 
Study

Reference

Yu 2018

Yu 2018

Dennis 2012

Heiskanen 2011

Ohashi 2010

Hale 2010

Valensise 2008

Valensise 2008

Summary

$l^{2}=95 \%$

<14 weeks

Hale 2010

Summary

not applicable

22-28 weeks

Valensise 2008

Valensise 2008

Summary

$l^{2}=99 \%$

\section{9-35 weeks}

Yu 2018

Yu 2018

Dennis 2012

Heiskanen 2011

Summary

$l^{2}=91 \%$

\section{6-41 weeks}

Dennis 2012

Ohashi 2010

Summary

$I^{2}=97 \%$
Mean $\quad 95 \% \mathrm{Cl}$

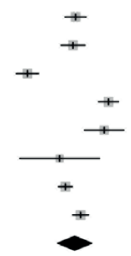

$72.0 \quad[67.9 ; 76.1]$

$71.0 \quad[66.3 ; 75.7]$

$53.0 \quad[48.6 ; 57.4]$

$85.0 \quad[81.1 ; 88.9]$

83.3 [75.6; 91.0]

$65.7 \quad[50.0 ; 81.4]$

$68.0 \quad[65.3 ; 70.7]$

$74.0 \quad[70.9 ; 77.1]$

71.7 [65.0; 78.3]

$59.4 \quad[36.7 ; 82.1]$

59.4 [36.7; 82.1]
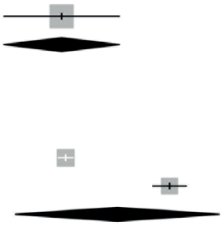

$61.0 \quad[58.1 ; 63.9]$

$102.0[95.4 ; 108.6]$

$81.4[41.2 ; 121.6]$

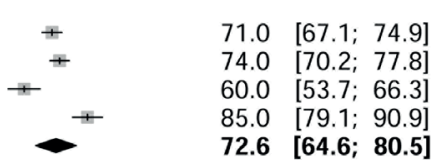

$72.6[64.6 ; 80.5]$

$58.0 \quad[52.9 ; 63.1]$

$77.7 \quad[73.2 ; 82.2]$

67.9 [48.6; 87.2]

\section{卜 1 1 1 1 \\ $20 \quad 40 \quad 60 \quad 80 \quad 100120$}

Stroke Volume $(\mathrm{mL})$

Figure S14. Forest plot of absolute values $(95 \% \mathrm{Cl})$ of stroke volume in non-pregnant women and during hypertensive pregnancy. 


\section{Study}

$<14$ weeks

Badrov 2019

Hale 2010

Summary

$I^{2}=78 \%$

\section{2-28 weeks}

Valensise 2008

Valensise 2008

Borghi 2000

Lim 1976

Summary

$l^{2}=88 \%$

\section{9-35 weeks}

Badrov 2019

Yu 2018

Yu 2018

Cong 2015

Cong 2015

Dennis 2012

Heiskanen 2011

Tihtonen 2006

Hasan 2002

Miyake 2002

Lewinsky 1998

Ahmad 1996

Eneroth-Grimfors 1994

Lim 1976

Summary

$I^{2}=75 \%$

36-41 weeks

Dennis 2012

Ohashi 2010

Kaaja 2004

Summary

$l^{2}=0 \%$
Sample size

Pregnant Reference

$\begin{array}{cr}8 & 8 \\ 3 & 3 \\ 11 & 11 \\ & \\ & \\ 75 & 75 \\ 32 & 32 \\ 40 & 10 \\ 5 & 10 \\ 152 & 127\end{array}$

$\begin{array}{rr}8 & 8 \\ 25 & 25 \\ 27 & 27 \\ 36 & 30 \\ 34 & 30 \\ 19 & 20 \\ 28 & 28 \\ 20 & 29 \\ 11 & 22 \\ 17 & 34 \\ 15 & 11 \\ 16 & 15 \\ 10 & 10 \\ 13 & 10 \\ \mathbf{2 7 9} & \mathbf{2 9 9}\end{array}$

$\begin{array}{rr}21 & 20 \\ 10 & 10 \\ 11 & 8 \\ \mathbf{4 2} & \mathbf{3 8}\end{array}$

8

11

8

25

30

30

20

28

29

34

11

15

10

299

38

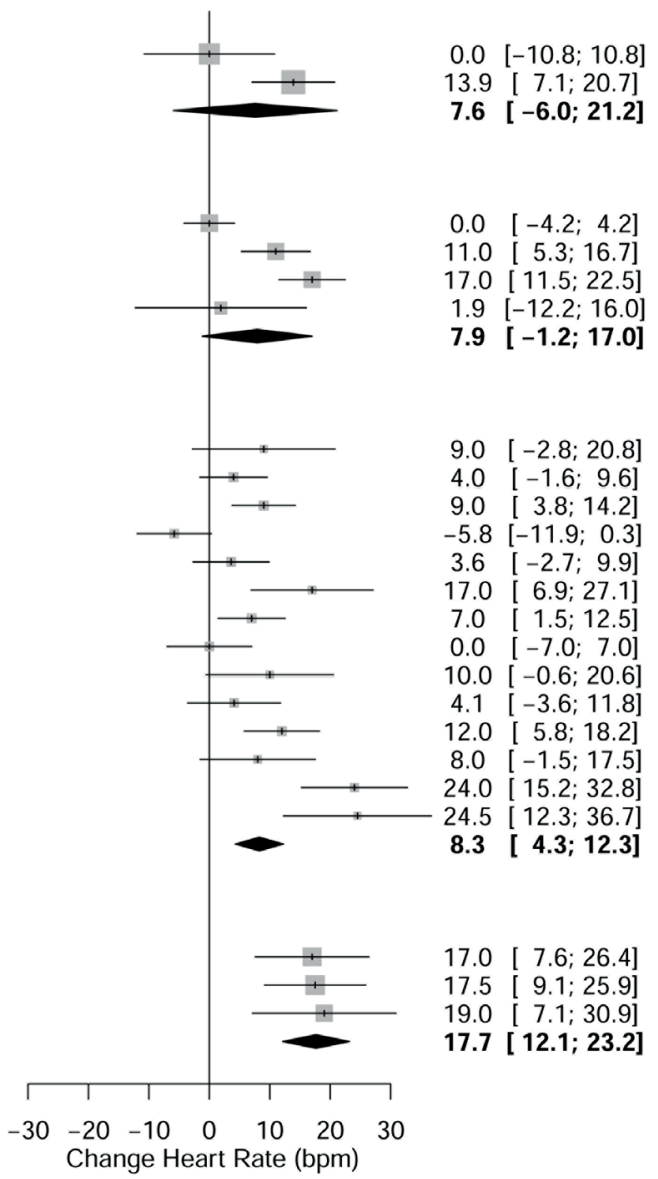

Figure S15. Forest plot of heart rate (HR) adjustments during hypertensive pregnancy. HR is reported as mean difference with $95 \% \mathrm{Cl}$ between pregnant women and reference group in bpm. 
Study

Reference

Badrov 2019

Yu 2018

Yu 2018

Cong 2015

Dennis 2012

Heiskanen 2011

Hale 2010

Ohashi 2010

Valensise 2008

Valensise 2008

Tihtonen 2006

Kaaja 2004

Hasan 2002

Miyake 2002

Borghi 2000

Lewinsky 1998

Ahmad 1996

Eneroth-Grimfors 1994

Lim 1976

Summary

$I^{2}=96 \%$

$<14$ weeks

Badrov 2019

Hale 2010

Summary

$I^{2}=0 \%$

\section{2-28 weeks}

Valensise 2008

Valensise 2008

Borghi 2000

Lim 1976

Summary

$I^{2}=91 \%$

\section{9-35 weeks}

Badrov 2019

Yu 2018

Yu 2018

Cong 2015

Cong 2015

Dennis 2012

Heiskanen 2011

Tihtonen 2006

Hasan 2002

Miyake 2002

Lewinsky 1998

Ahmad 1996

Eneroth-Grimfors 1994

Lim 1976

Summary

$l^{2}=86 \%$

\section{6-41 weeks}

Dennis 2012

Ohashi 2010

Kaaja 2004

Summary

$I^{2}=0 \%$

$I^{2}=97 \%$
Mean $\quad 95 \% \mathrm{Cl}$

$71.0 \quad[63.4 ; 78.6]$

$69.0 \quad[66.4 ; 71.6]$

$71.0 \quad[67.5 ; 74.5]$

$81.1 \quad[76.0 ; 86.2]$

$64.0 \quad[56.1 ; 71.9]$

$70.0 \quad[66.1 ; 73.9]$

$59.9 \quad[59.2 ; 60.6]$

67.9 [61.3; 74.5]

$75.0 \quad[72.3 ; 77.7]$

$78.0 \quad[74.5 ; 81.5]$

$69.0 \quad[63.9 ; 74.1]$

$63.8 \quad[56.4 ; 71.2]$

$71.0 \quad[67.1 ; 74.9]$

$71.0 \quad[67.1 ; 74.9]$

$70.1 \quad[66.4 ; 73.8]$

$65.0 \quad[60.3 ; 69.7]$

$80.0 \quad[73.9 ; 86.1]$

$65.0 \quad[58.8 ; 71.2]$

$75.3 \quad[64.9 ; 85.7]$

70.4 [66.5; 74.2]

$71.0 \quad[63.4 ; 78.6]$

$73.8 \quad[67.0 ; 80.6]$

$72.6[67.5 ; 77.6]$
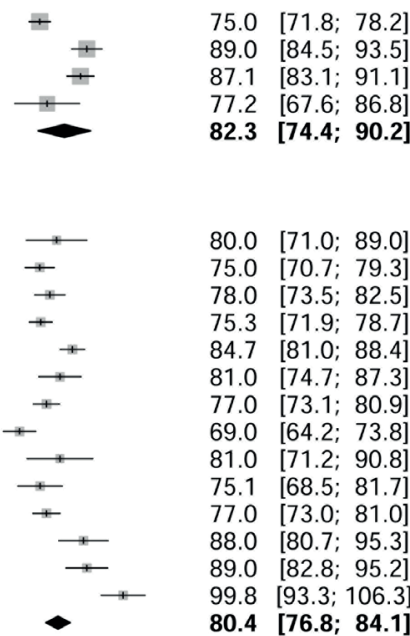

$80.0 \quad[71.0 ; 89.0]$

$75.0 \quad[70.7 ; 79.3$

$78.0 \quad[73.5 ; 82.5]$

$75.3 \quad[71.9 ; 78.7]$

84.7 [81.0; 88.4]

$81.0 \quad[74.7 ; 87.3]$

$77.0 \quad[73.1 ; 80.9]$

$69.0 \quad[64.2 ; 73.8]$

$81.0 \quad[71.2 ; 90.8]$

$75.1 \quad[68.5 ; 81.7]$

$77.0 \quad[73.0 ; 81.0]$

$88.0 \quad[80.7 ; 95.3]$

$89.0 \quad[82.8 ; 95.2]$

$99.8[93.3 ; 106.3]$

80.4 [76.8; 84.1]

$81.0 \quad[75.9 ; 86.1]$

85.4 [80.2; 90.6]

$82.8 \quad[73.5 ; 92.1]$

$83.1[79.7 ; 86.5]$

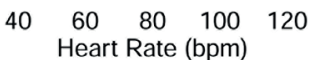

Figure S16. Forest plot of absolute values $(95 \% \mathrm{Cl})$ of heart rate in non-pregnant women and during hypertensive pregnancy. 

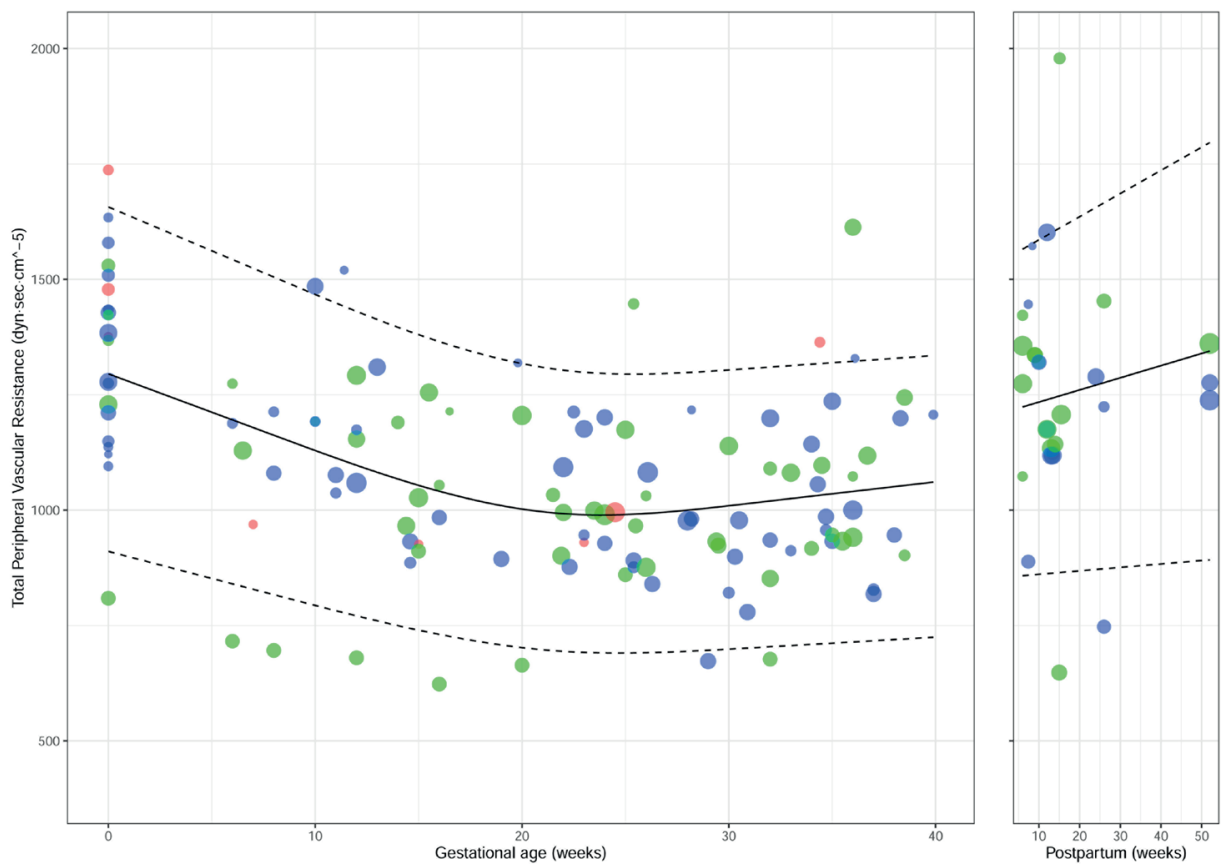

Figure S17. Reference curve of total peripheral vascular resistance during pregnancy and in the postpartum period, with mean (solid line), and $5^{\text {th }}$ and $95^{\text {th }}$ percentiles (dashed lines) weighted by study sample size. Size of individual plots indicates sample size of point estimate and their colour indicates quality assigned to the study: red, low quality; green, moderate quality; blue, high quality. Studies with multiple measurements during pregnancy are per measurement plotted. 

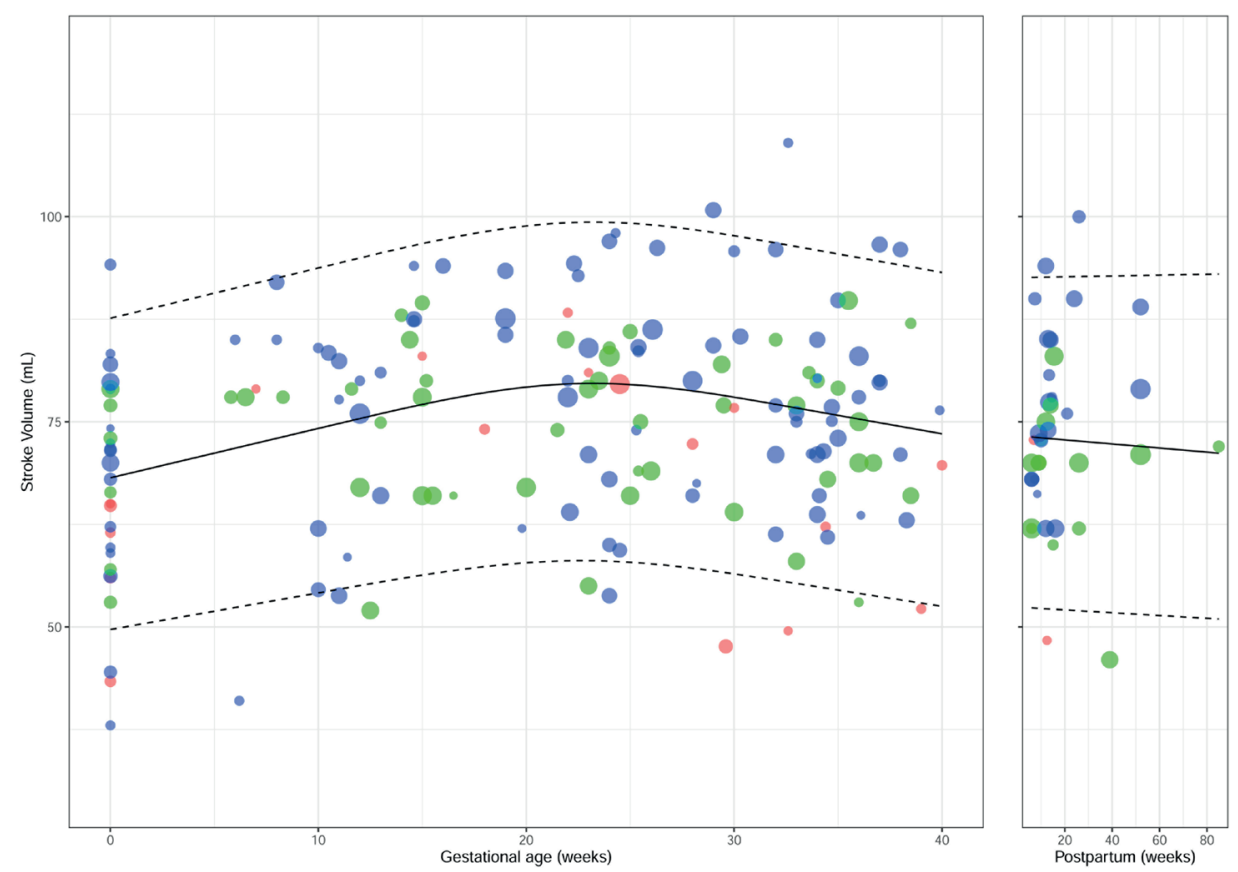

Figure S18. Reference curve of stroke volume during pregnancy and in the postpartum period, with mean (solid line), and $5^{\text {th }}$ and $95^{\text {th }}$ percentiles (dashed lines) weighted by study sample size. Size of individual plots indicates sample size of point estimate and their colour indicates quality assigned to the study: red, low quality; green, moderate quality; blue, high quality. Studies with multiple measurements during pregnancy are per measurement plotted. 

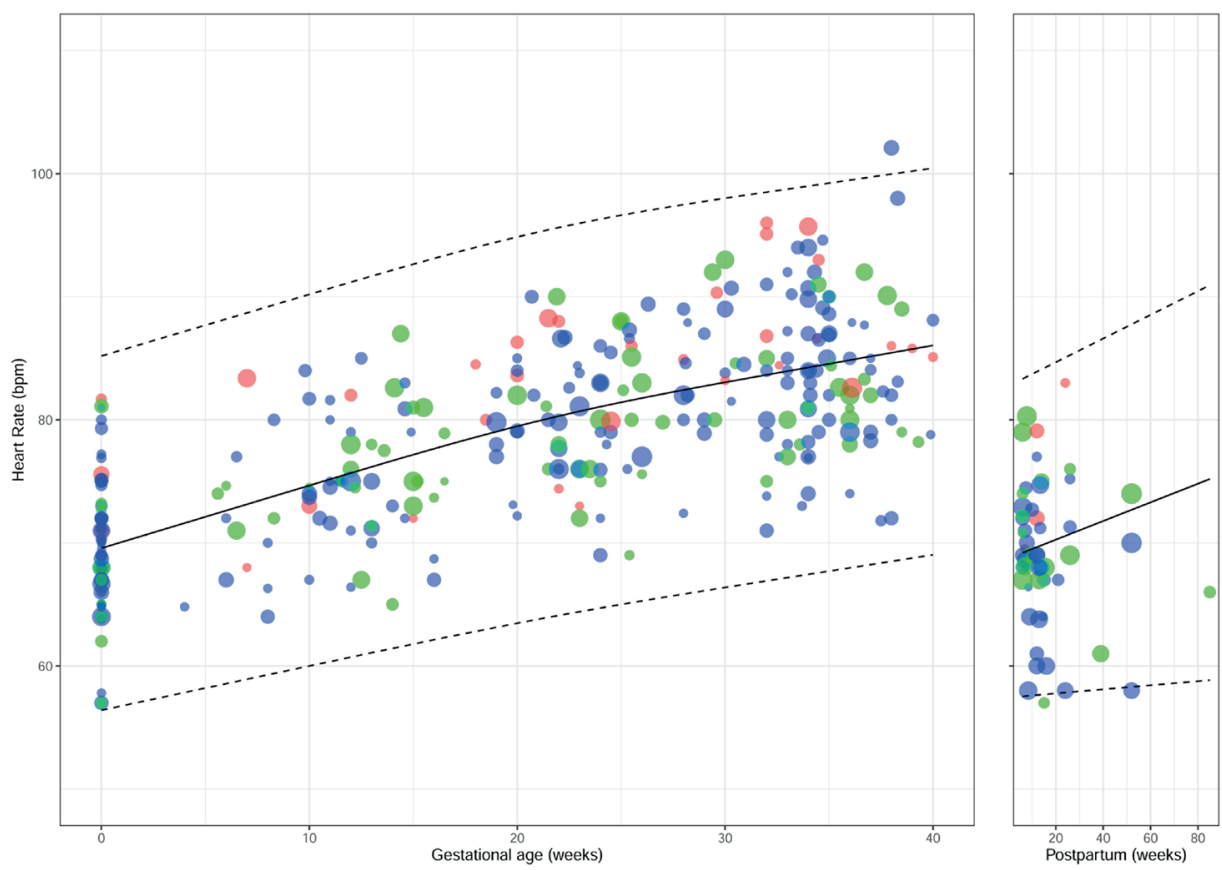

Figure S19. Reference curve of heart rate during pregnancy and in the postpartum period, with mean (solid line), and $5^{\text {th }}$ and $95^{\text {th }}$ percentiles (dashed lines) weighted by study sample size. Size of individual plots indicates sample size of point estimate and their colour indicates quality assigned to the study: red, low quality; green, moderate quality; blue, high quality. Studies with multiple measurements during pregnancy are per measurement plotted. 


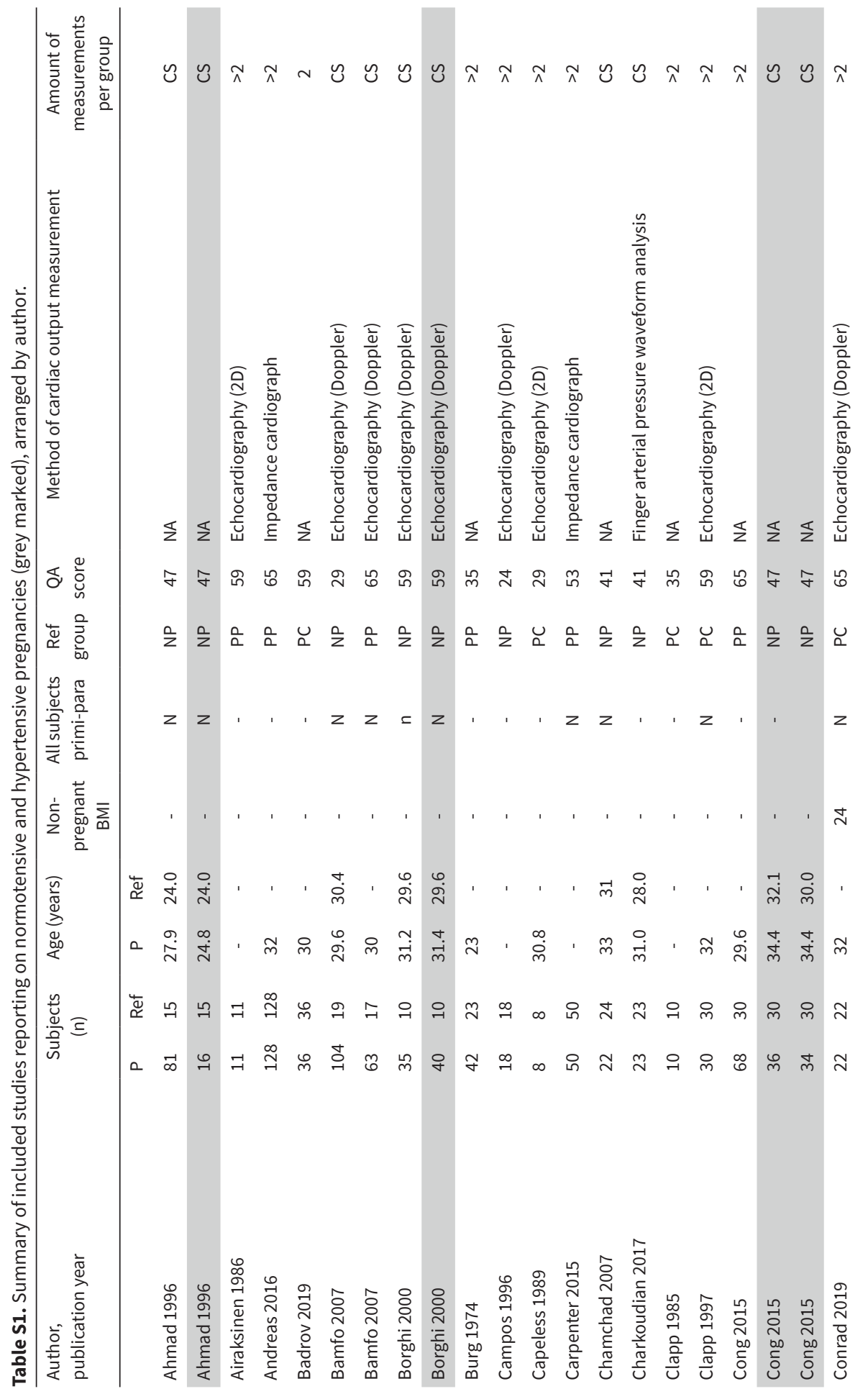




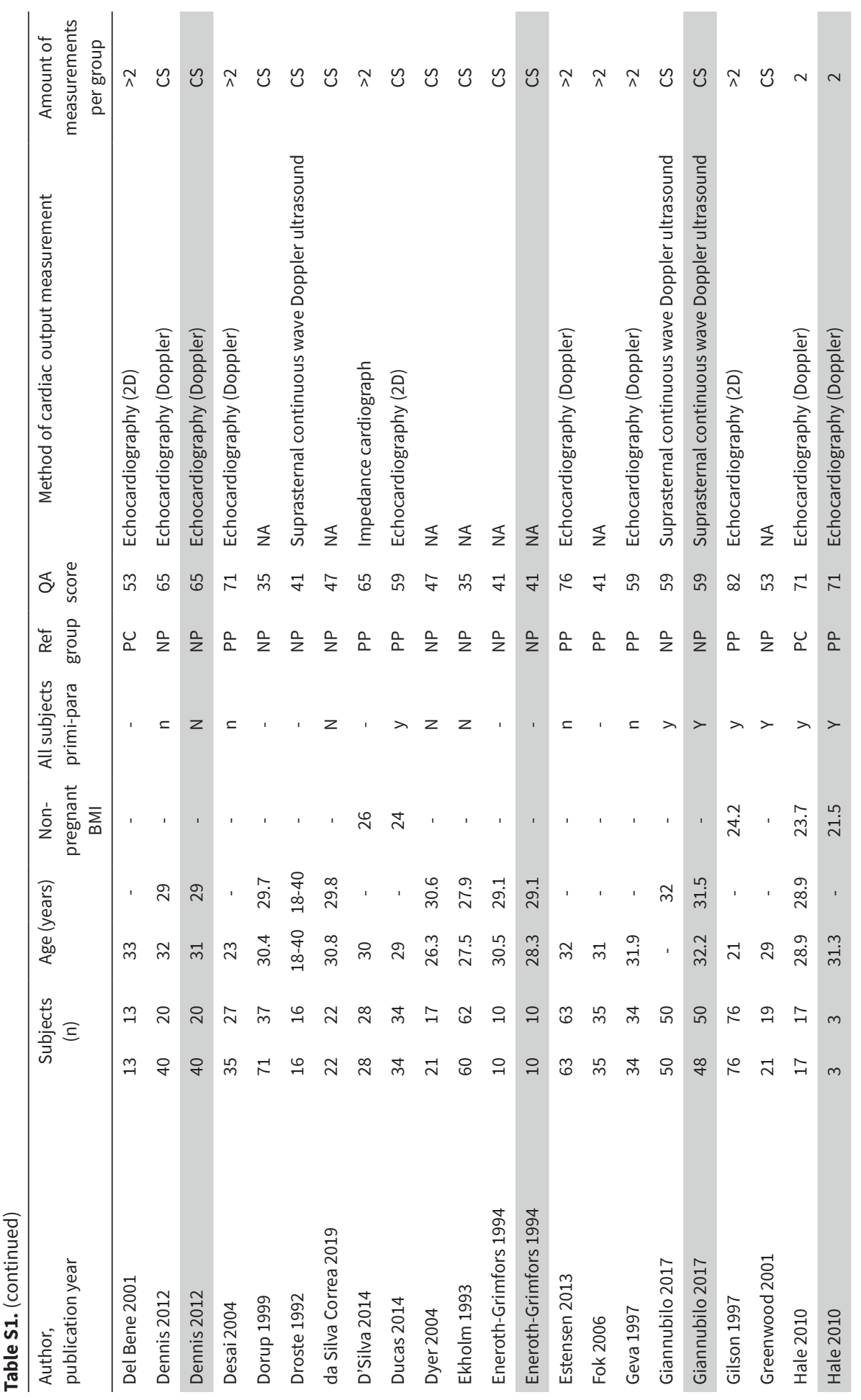




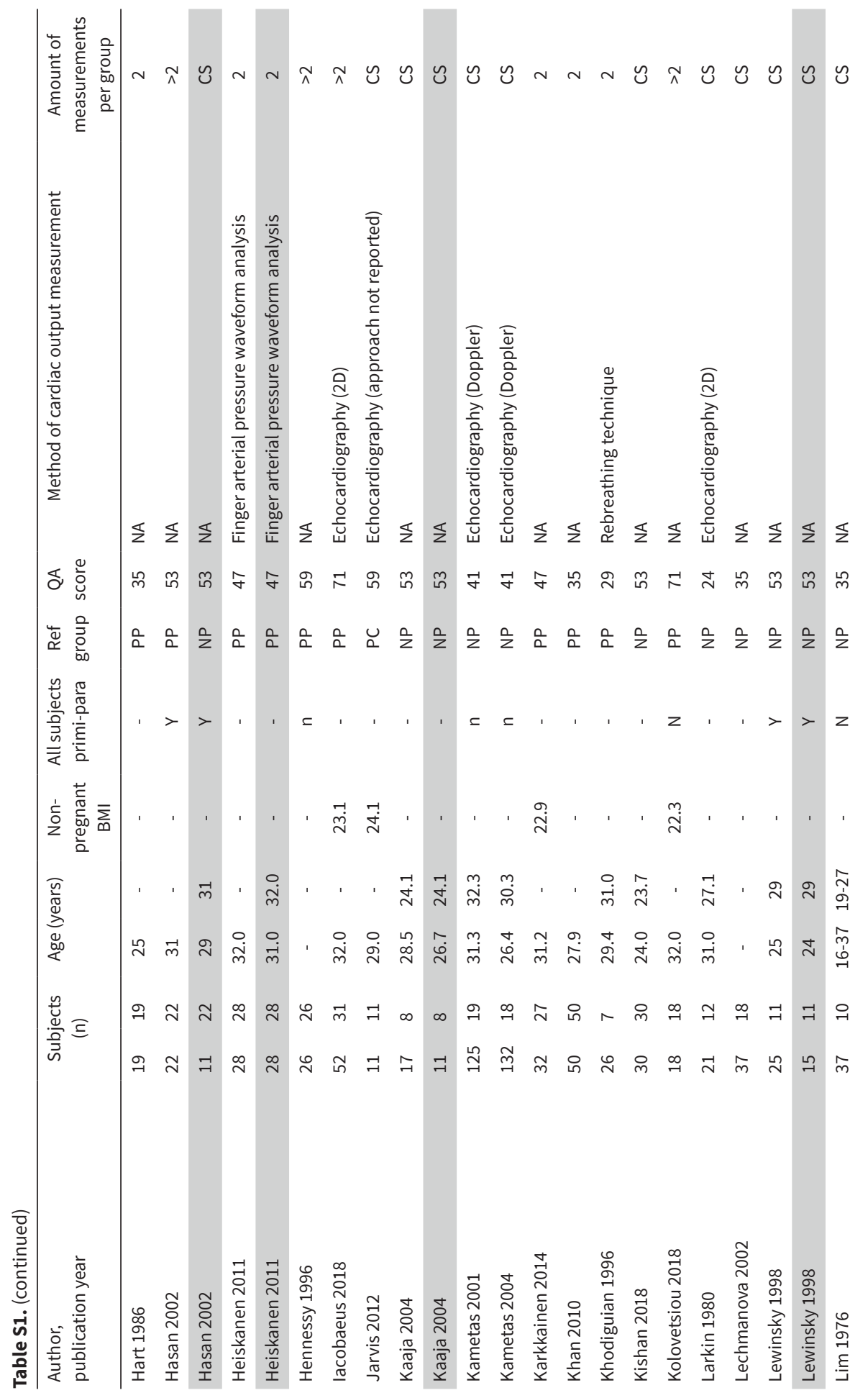




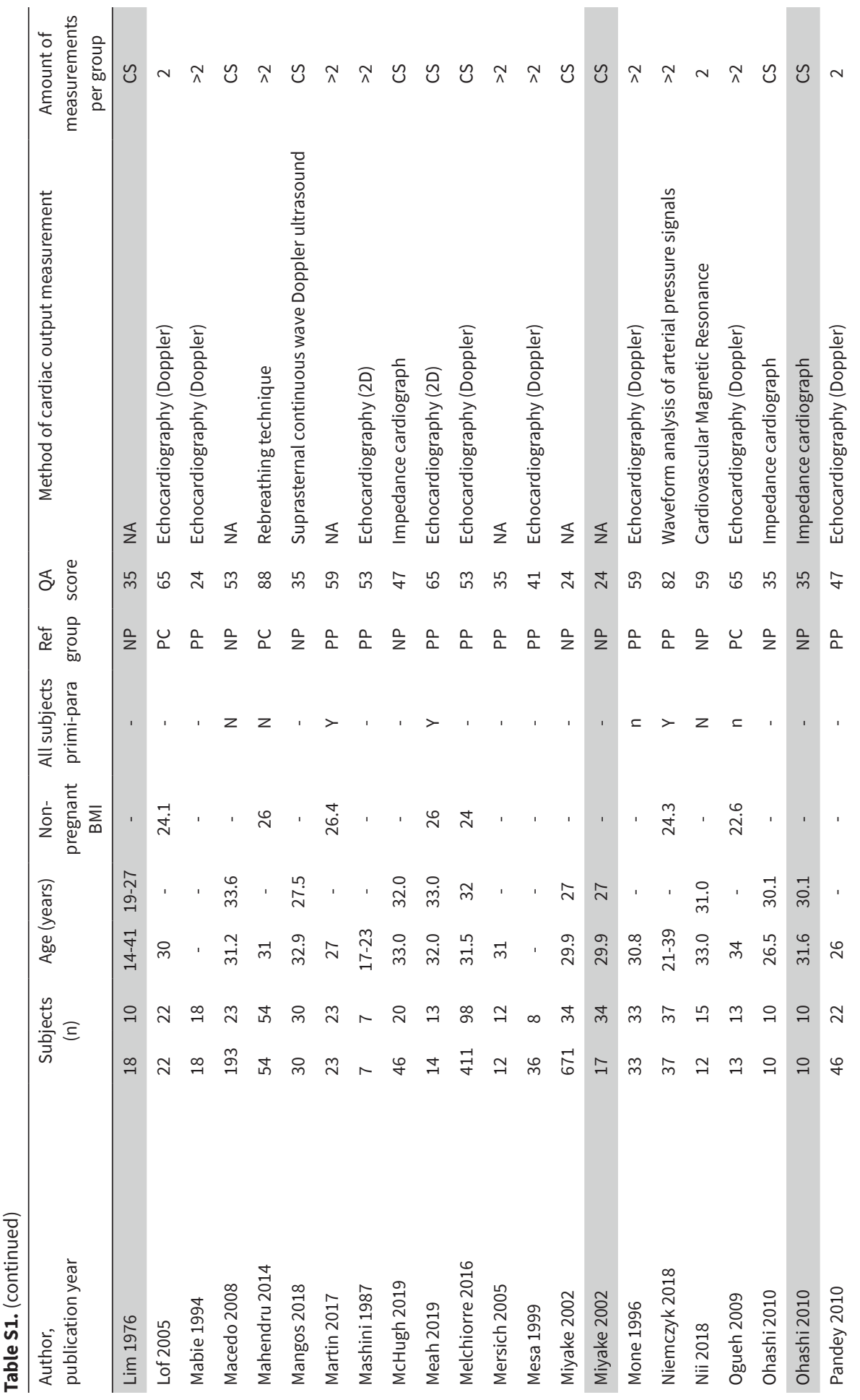




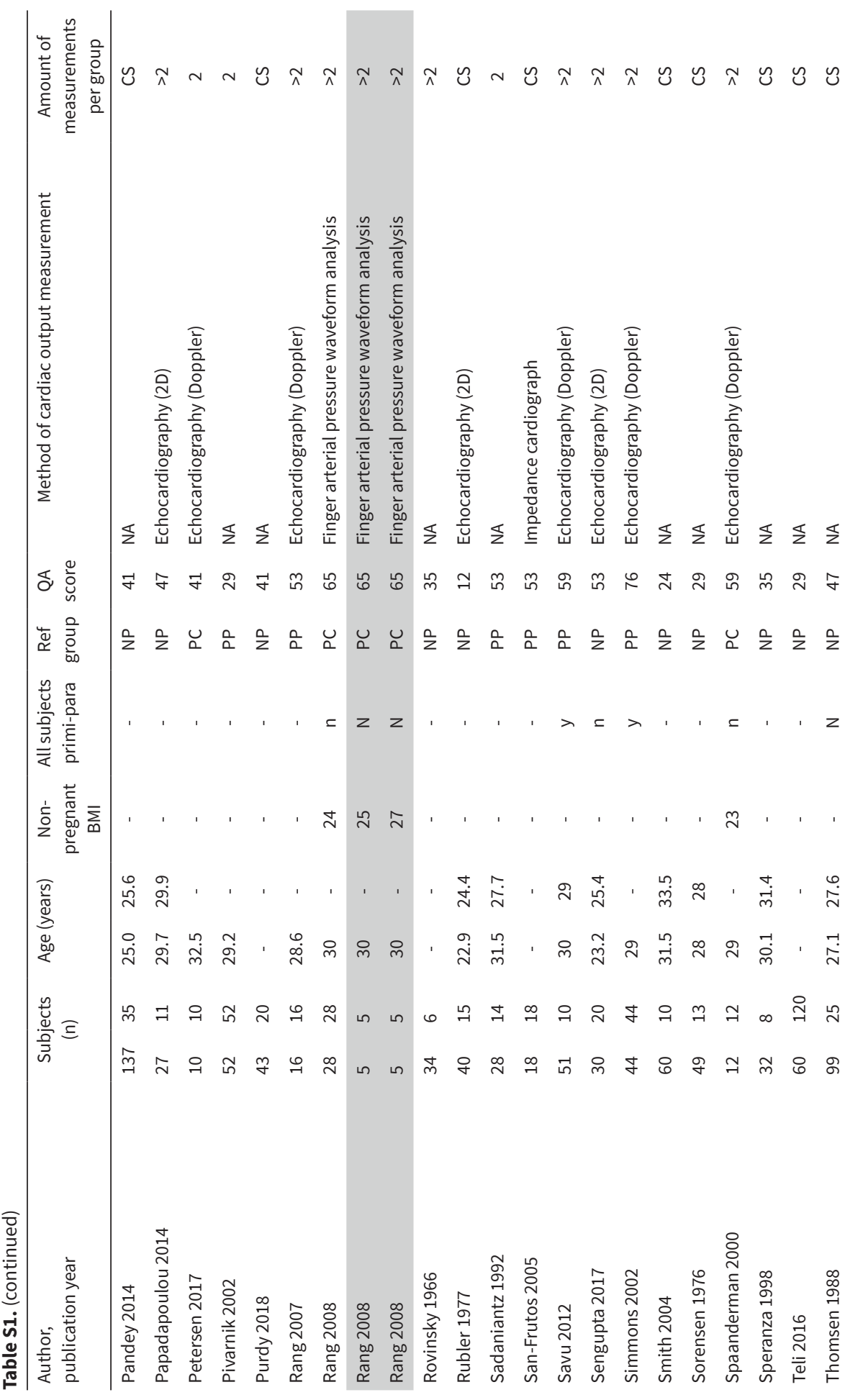




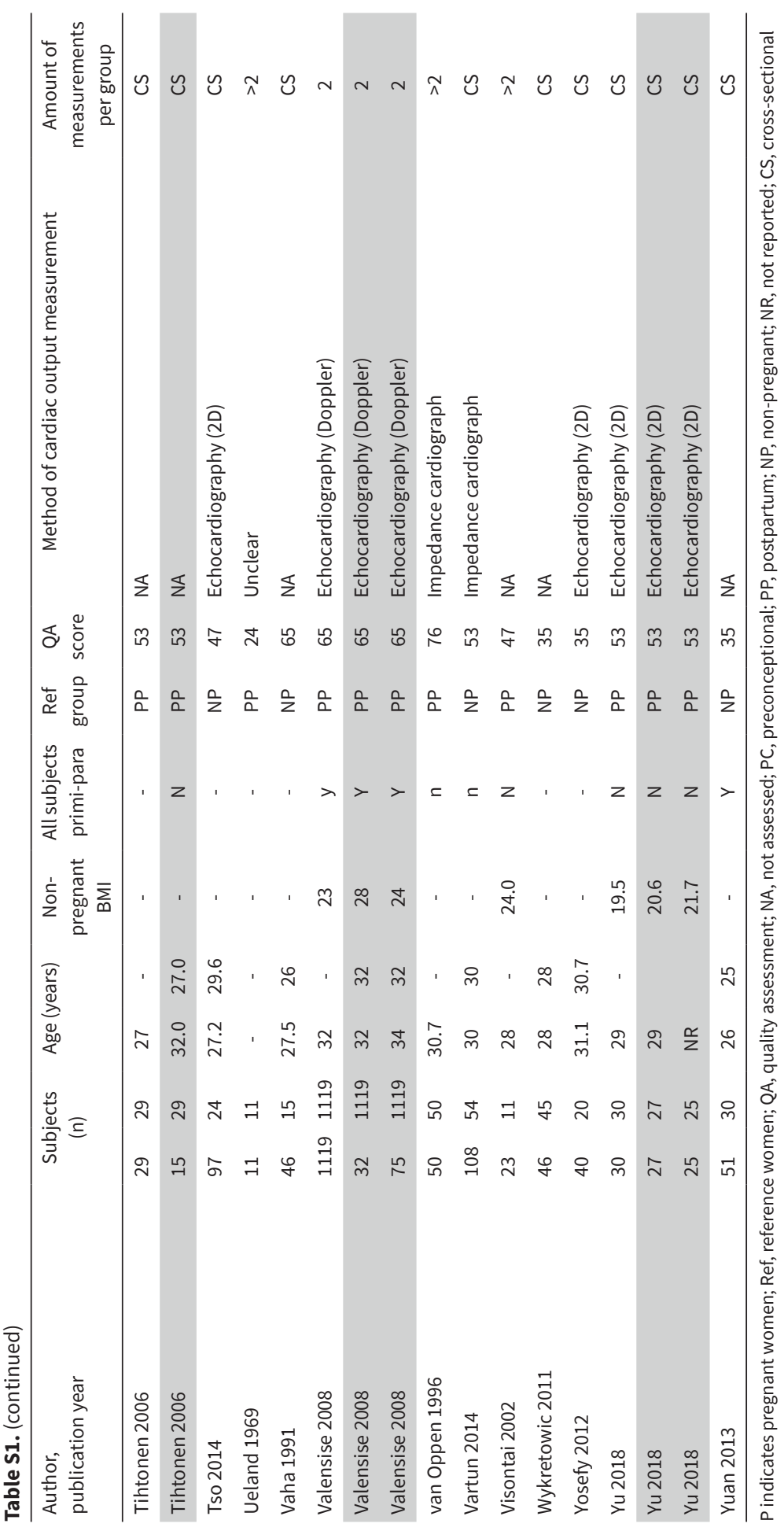


Table S2. Used criteria to define hypertensive pregnancies

Author,
publication year Definition of hypertensive pregnancy

These patients developed hypertension and proteinuria in the third trimester of their pregnancy but were normotensive and aproteinuric on their initial visits. Hypertension was defined as two consecutive measurements of blood pressure of $>140 / 90 \mathrm{mmHg}$ or rise of

Ahmad $1996>15 \mathrm{mmHg}$ in diastolic blood pressure or $>30 \mathrm{mmHg}$ in systolic blood pressure above the baseline in the first trimester of pregnancy. Urinary protein was estimated initially by urine dipstick examination and later confirmed by biochemical analysis. Significant proteinuria was defined as detection of $>300 \mathrm{mg} / \mathrm{L}(2+)$ protein in two random samples of urine.

The diagnosis of preeclampsia was based on the concomitant presence after 20 weeks' gestation of hypertension (diastolic blood pressure $>90 \mathrm{mmHg}$ on two occasions 4 hours

Borghi 2000 apart), proteinuria ( $\geq 300 \mathrm{mg} / 24 \mathrm{~h}$, one dipstick measurement $\geq 2+$, or two dipstick measurements $\geq 1+$ at a specified interval for blood pressure measurements), and peripheral oedema.

Preeclampsia was identified according to the criteria of the international society for the

Cong 2015 study of hypertension in pregnancy. Women with pregnancy induced hypertension were excluded.

Dennis 2012 Hypertension and one or more deranged maternal organ systems and/or uterofoetal compromise.

Eneroth-Grimfors 1994

Preeclampsia: blood pressure $\geq 140 / 90 \mathrm{mmHg}$ and proteinuria $\geq 300 \mathrm{mg} / 24 \mathrm{~h}$ or dipstick $\geq 1+$

According to the International Society for the Study of Hypertension in Pregnancy,

Giannubilo 2017 preeclampsia was defined as a blood pressure of at least $140 / 90 \mathrm{mmHg}$, on two occasions 4-6 $\mathrm{h}$ apart, after week 20 of gestation in previously normotensive women, accompanied by proteinuria $\geq 300 \mathrm{mg} / 24 \mathrm{~h}$.

A total of 3 women developed complicated hypertension during pregnancy; 2 had classically defined preeclampsia with 24-hour urine collections demonstrating proteinuria

Hale 2010 $>300 \mathrm{mg} / \mathrm{dL}$ and blood pressure $>140 / 90 \mathrm{mmHg}$ and the third woman had new onset third trimester, elevated blood pressure $>140 / 90 \mathrm{mmHg}$, elevated liver enzymes, elevated uric acid concentration ( $>5 \mathrm{mg} / \mathrm{dL}$ ) and foetal growth restriction with iatrogenic delivery at 37 weeks.

Preeclampsia was defined as follows: new hypertension (diastolic pressure consistently Hasan 2002 greater than $90 \mathrm{mmHg}$, with previous lower values) and new proteinuria ( $>300 \mathrm{mg} / 24 \mathrm{~h}$ ) in the absence of urinary tract infection; both remitting sometime after delivery.

Gestational hypertension was defined as a systolic blood pressure level $\geq 140 \mathrm{mmHg}$ or Heiskanen 2011 a diastolic blood pressure level $\geq 90 \mathrm{mmHg}$ after 20 weeks of pregnancy in women with previously normal blood pressure and with or without proteinuria.

Preeclampsia was defined by a blood pressure of greater than $140 / 90 \mathrm{mmHg}$ on at least

Kaaja 2004 two occasions after 20 weeks' gestation, and proteinuria of $\geq 0.3 \mathrm{~g} / 24 \mathrm{~h}$ or $\geq 1+$ on dipstick. Women with severe preeclampsia were excluded.

Lewinsky 1998

All had blood pressure values exceeding 140/90 mmHg on two occasions at least $6 \mathrm{~h}$ apart and proteinuria exceeding $300 \mathrm{mg}$ per day.

$\operatorname{Lim} 1976$ Hypertension was defined as a mean brachial arterial blood pressure of $100 \mathrm{mmHg}$ (equivalent to $130 \mathrm{mmHg}$ systolic pressure and $85 \mathrm{mmHg}$ diastolic pressure) or more.

Only women with severe preeclampsia were included, defined as de novo hypertension

Miyake 2002 more than $160 / 100 \mathrm{mmHg}$ after gestational week 20 with proteinuria (>300 $\mathrm{mg} / \mathrm{dl}$ ) in a spot urine. 
Table S2. (continued)

\begin{tabular}{|c|c|}
\hline $\begin{array}{l}\text { Author, } \\
\text { publication year }\end{array}$ & Definition of hypertensive pregnancy \\
\hline Ohashi 2010 & $\begin{array}{l}\text { Preeclampsia was defined by The American College of Obstetricians and Gynecologists } \\
\text { criteria as newly diagnosed systolic blood pressure of at least } 140 \mathrm{mmHg} \text { or diastolic blood } \\
\text { pressure of } 90 \mathrm{mmHg} \text { on at least } 2 \text { occasions; the measurements had to be taken at least } \\
4 \text { hours but not more than } 7 \text { days apart. }\end{array}$ \\
\hline Rang 2008 & $\begin{array}{l}\text { Gestational hypertension was defined by an SBP higher than } 140 \mathrm{mmHg} \text { or a DBP } \\
\text { higher than } 90 \mathrm{mmHg} \text {, measured at least twice with an interval of more than } 6 \text { hours } \\
\text { after } 20 \text { weeks' gestational age in women with normal blood pressure before } 20 \text { weeks. } \\
\text { Preeclampsia was defined by gestational hypertension with proteinuria more than } 0.3 \mathrm{mg} \\
\text { per } 24 \text { hours, according to the International Society for the Study of Hypertension in } \\
\text { Pregnancy recommendation. }\end{array}$ \\
\hline Tihtonen 2006 & $\begin{array}{l}\text { Preeclampsia was diagnosed if blood pressure was constantly higher than 140/90 mmHg } \\
\text { and if consistent proteinuria of more than } 300 \mathrm{mg} / \text { day was present. }\end{array}$ \\
\hline Valensise 2008 & $\begin{array}{l}\text { The criteria of the International Society for the Study of Hypertension in Pregnancy were } \\
\text { used to define preeclampsia. Preeclampsia was diagnosed if a previously normotensive } \\
\text { woman had } 2 \text { consecutive ( } 4 \text { hours apart) diastolic blood pressure measurements of } \\
\geq 90 \mathrm{mmHg} \text { after the 20th week of gestation, and proteinuria >300 mg in a } 24 \text {-hour urine } \\
\text { specimen. }\end{array}$ \\
\hline Yu 2018 & $\begin{array}{l}\text { Gestational hypertension was defined as blood pressure } \geq 140 / 90 \mathrm{mmHg} \text { occurring } \\
\text { for the first-time during pregnancy and no proteinuria. Preeclampsia was considered } \\
\geq 140 \mathrm{mmHg} \text { systolic blood pressure or } \geq 90 \mathrm{mmHg} \text { diastolic blood pressure with proteinuria } \\
\text { (>300 mg/24h) after } 20 \text { weeks of gestation in a previously normotensive woman. }\end{array}$ \\
\hline
\end{tabular}


Table S3. Overview of the quality assessment

\begin{tabular}{|c|c|c|}
\hline Domain & Item & $\begin{array}{l}\text { Percentage } \\
\text { studies with } \\
\text { positive score }\end{array}$ \\
\hline \multirow{7}{*}{$\begin{array}{l}\text { Adequate } \\
\text { description of } \\
\text { participants' } \\
\text { characteristics }\end{array}$} & Parity or gravidity & 53 \\
\hline & Health or comorbidities of participants & 79 \\
\hline & Clear reporting of gestational age & 88 \\
\hline & Ethnicity & 22 \\
\hline & Height & 40 \\
\hline & Non-pregnant weight and/or body mass index & 43 \\
\hline & Use of medication or supplements & 56 \\
\hline \multirow{2}{*}{$\begin{array}{l}\text { Study } \\
\text { Participation }\end{array}$} & Adequate description of participant recruitment & 61 \\
\hline & Adequate description of in- and exclusion criteria & 61 \\
\hline \multirow[b]{2}{*}{ Study Attrition } & Reasons for loss to follow-up/drop-out are provided & 30 \\
\hline & $\begin{array}{l}\text { Adequate description of participants lost to follow-up and differences } \\
\text { between participants who completed and drop-outs }\end{array}$ & 4 \\
\hline \multirow{2}{*}{$\begin{array}{l}\text { Variable } \\
\text { Measurements }\end{array}$} & $\begin{array}{l}\text { Method of measurement is adequately valid and reliable. Amount of } \\
\text { measurements, mean or median and position are mentioned }\end{array}$ & 67 \\
\hline & $\begin{array}{l}\text { Methods and setting are the same for all participants and throughout } \\
\text { follow up }\end{array}$ & 88 \\
\hline Data Reporting & Time frame of measurements (gestational age) is reported as mean & 43 \\
\hline \multirow{3}{*}{ Study Design } & Study used a longitudinal study design & 52 \\
\hline & Multiple longitudinal measurements during pregnancy of the variable & 39 \\
\hline & Reference value was a pre-pregnant measurement of the variable & 13 \\
\hline
\end{tabular}






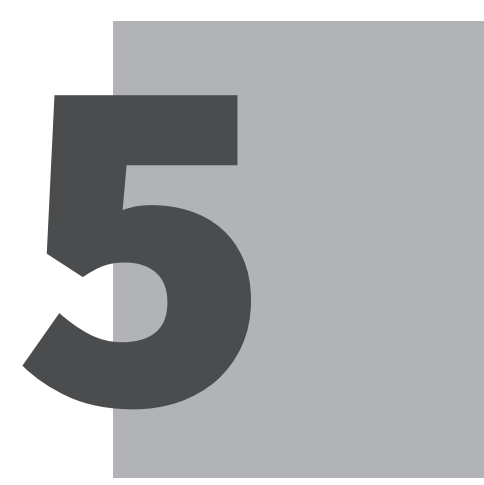

\title{
STUDY PROTOCOL FOR THE RANDOMIZED CONTROLLED EVA (EARLY VASCULAR ADJUSTMENTS) TRIAL: TAILORED TREATMENT OF MILD HYPERTENSION IN PREGNANCY TO PREVENT SEVERE HYPERTENSION AND PREECLAMPSIA
}

\author{
Eva Mulder \\ Chahinda Ghossein-Doha \\ Evine Appelman \\ Sander van Kuijk \\ Luc Smits \\ Rogier van der Zanden \\ Joris van Drongelen \\ Marc Spaanderman
}




\section{ABSTRACT}

Background: In contrast to severe gestational hypertension, it is questioned whether antihypertensive medication for mild to moderate gestational hypertension prevents adverse maternal and offspring outcomes. Hypertensive drugs halve the risk of severe hypertension, but do not seem to prevent progression to preeclampsia or reduce the risk of complications in offspring. In fact, beta-blockers, a first line therapy option, are suspected to impair foetal growth. Disappointing effects of antihypertensive medication can be anticipated when the pharmacological mode of action does not match the underlying haemodynamic imbalance. Hypertension may result from 1) high cardiac output, low vascular resistance state, in which beta-blockade is expected to be most effective, or 2) low cardiac output, high vascular resistance state where dihydropyridine calcium channel blockers or central-acting alpha agonists might be the best corrective medication. In the latter, beta-blockade might be maternally ineffective and even contribute to impaired foetal growth by keeping cardiac output low. We propose a randomized controlled trial to determine whether correcting the haemodynamic imbalance in women with mild to moderate hypertension reduces the development of severe hypertension and/or preeclampsia more than non-pharmacological treatment does, without alleged negative effects on foetal growth.

Methods: Women diagnosed with mild to moderate hypertension without proteinuria or signs of other organ damage before 37 weeks of pregnancy are invited to participate in this randomized controlled trial. Women randomized to the intervention group will be prescribed tailored antihypertensive medication, using a simple diagnostic and treatment algorithm based on the mean arterial pressure/heart rate ratio, which serves as an easy-to-determine proxy for maternal circulatory state. Women randomized to the control group will receive non-pharmacological standard care according to national and international guidelines. In total, 208 women will be randomized in a 1:1 ratio. The primary outcome is progression to severe hypertension and preeclampsia and the secondary outcomes are adverse maternal and neonatal outcomes.

Discussion: This trial will provide evidence of whether tailoring treatment of mild to moderate gestational hypertension to the individual haemodynamic profile prevents maternal disease progression.

Trial registration number: clinicaltrials.gov, NCT02531490, registered on 24 August 2015

Keywords: Gestational hypertension, pregnancy, preeclampsia, haemodynamic profile, tailored treatment, antihypertensive drugs 


\section{INTRODUCTION}

Preeclampsia is a leading cause of maternal and perinatal morbidity and mortality in the Western world. ${ }^{1}$ In most cases of preeclampsia-related maternal death, blood pressure is not adequately controlled. ${ }^{2,3}$ For its well-established maternal benefits, it is generally accepted to treat blood pressure when it reaches the threshold of severe hypertension (systolic or diastolic blood pressure $\geq 160$ or $\geq 110 \mathrm{mmHg}$, respectively). ${ }^{4}$ In contrast, effectiveness of antihypertensive medication in mild to moderate hypertension is subject of debate and medication is not uniformly initiated because of different effects on maternal disease progression and alleged poorer foetal outcomes. ${ }^{5,6}$ In mild to moderate hypertension, the use of any antihypertensive drugs halves the risk of developing severe hypertension (relative risk of $0.49 ; 95 \% \mathrm{Cl} 0.40-0.60$ ), but does not prevent progression to preeclampsia (relative risk of $0.93 ; 95 \% \mathrm{Cl} 0.80-1.08$ ), or reduce the risk of offspring complications (relative risk for small-for-gestation-age neonate, $0.97 ; 95 \% \mathrm{Cl} 0.80-1.17$, relative risk for stillbirth, $1.14 ; 95 \% \mathrm{Cl} 0.60-2.17$ and relative risk for neonatal death, 0.79 ; $95 \% \mathrm{Cl} 0.14-4.34) .{ }^{6}$ On the other hand, sub-grouped by class of drugs, beta-blockers seemed to reduce the development of preeclampsia (OR $0.73 ; 95 \% \mathrm{Cl} 0.57-0.94$ ) but may increase the chance of the neonate being small-for-gestational-age (OR $1.38 ; 95 \% \mathrm{CI}$ 0.99-1.92), while calcium antagonists seemed to increase the chance of preeclampsia (OR $1.40 ; 95 \% \mathrm{Cl} 1.06-1.86$ ), but have no effect on foetal growth (OR $0.84 ; 95 \% \mathrm{Cl} 0.60-1.16$ ). ${ }^{6}$ As a consequence of these inconsistent findings when pooling all antihypertensives irrespective of mode of action, international guidelines recommend initiating medication of choice only in severe hypertension or repeated moderate gestational hypertension. ${ }^{7,8}$

A drawback in studies investigating treatment of mild to moderate gestational hypertension is that they do not consider the maternal circulatory state or the circulatory response to the blood pressure lowering drug. Instead, most reported treatments involve stepwise use of compound drug classes, based on the physician's experience; in this treatment approach, chosen medications are only changed if severe side effects are observed or if increasing dosages do not achieve the target blood pressure. This trialand-error approach may not only delay the time interval to effective circulatory control, but may also negatively affect foetal wellbeing that may prelude to preterm birth.

Antihypertensive drugs lower blood pressure via different mechanisms. Blood pressure is regulated within narrow boundaries by beat-to-beat baroreceptor-mediated alteration of cardiac output and vascular resistance. Blood pressure only changes when these two determinants are unable to compensate deteriorations; therefore, elevated blood pressure can be lowered by reducing cardiac output or vascular resistance or both. Betablockers, central-acting alpha agonists, and calcium antagonists are commonly used to 
lower blood pressure during pregnancy. Selective beta-blockers lower elevated blood pressure predominantly by lowering the heart rate $(\mathrm{HR})$ and reducing contractility, resulting in reduced cardiac output. Beta-blockers with additional a-adrenergic receptor blockade activity, like labetalol, concurrently reduce peripheral resistance. ${ }^{9,10}$ Centralacting alpha receptor agonists, like methyldopa, lower blood pressure by altering central sympathetic activity. Cardiac output levels do not change, suggesting a balance between reduced afterload, venous return, and negative chronotropic and inotropic effects of sympathetic inhibition. ${ }^{11,12}$ Dihydropyridine calcium channel blockers, like nifedipine, are relatively vasoselective. They inhibit calcium ions from entering the calcium channels of vascular smooth muscle, so blood pressure is mainly lowered by reducing arterial tone and with it, peripheral vascular resistance. Secondary to vasodilation, the sympathetic nervous system is activated resulting in increased levels of norepinephrine, higher HR and ultimately increased cardiac output. ${ }^{13-15}$

\section{Haemodynamic parameters in gestational hypertension}

The haemodynamic profile of gestational hypertension differs between individuals. On the one hand, gestational hypertension can originate from hyperdynamic circulation characterized by high cardiac output and low vascular resistance; this profile is often accompanied by late onset preeclampsia and normal foetal growth (Figure 1). On the other hand, a hypertensive profile with high vascular resistance is associated with early onset maternal complications and impaired foetal growth. ${ }^{16-19}$ In the clinical phase of preeclampsia, most women exhibit a high-resistance profile with either low cardiac output (in $58 \%$ of women) or normal cardiac output (in $36 \%$ of women). ${ }^{20}$ Altered pre-pregnant haemodynamic phenotypes, inadequate cardiovascular adaptation to pregnancy, or crossover from hyperdynamic circulation to the more unfavourable hypertensive circulation with high vascular resistance as a consequence of endothelial derangement and loss of intravascular fluid, might underlie the divergent haemodynamic profiles. ${ }^{21,22}$ These heterogeneous circulatory profiles may explain the variable results of trials on antihypertensive therapy in mild to moderate hypertension during pregnancy. Beta-blockers are thought to be suitable for treating hyperdynamic hypertension, but reducing cardiac output may be detrimental in hypertensive women with high vascular resistance who already have low-cardiac-output. These women may instead benefit from vasodilation by dihydropyridine calcium channel blockers, or from central-acting alpha agonists that reduce peripheral resistance.

\section{Tailored treatment of hypertension}

In non-pregnant individuals with uncontrolled hypertension, haemodynamically tailored antihypertensive treatment almost doubled the chance of reaching the target blood pressure within three months of initiating or adjusting the therapy compared 
with conventional standard treatment based on the specialist's preference. ${ }^{23,24}$ During pregnancy, with respect to underlying haemodynamic profile, adequate blood pressure response to beta-blockage can be predicted by the mean arterial pressure (MAP), HR, and (if available) stroke volume index. ${ }^{25}$ About $20-25 \%$ of gestational hypertensive women were refractory to labetalol and needed additional vasodilatory therapy. In these women, cardiac output was lowest and vascular resistance was highest before treatment. The highest response rate to labetalol primarily relates to alteration of HR and peripheral vascular resistance, and consequently blood pressure, but not stroke volume. This suggests that a simple algorithm weighing blood pressure and HR may grossly indicate the underlying haemodynamic profile. Therefore, it may be better to view antihypertensive drugs as adjusters of the haemodynamic state rather than as reducers of blood pressure. ${ }^{26}$ If we do not take the maternal haemodynamic profile and the pharmacological mode of action of the drug into account, generic antihypertensive treatment will continue to result in disappointing, ineffective or even paradoxical outcomes for at least part of treated mothers and their offspring. To address this problem, we propose a randomized trial to compare tailored antihypertensive treatment based on the maternal circulatory profile with generally practiced active surveillance of hypertension in pregnant women with mild to moderate hypertension.
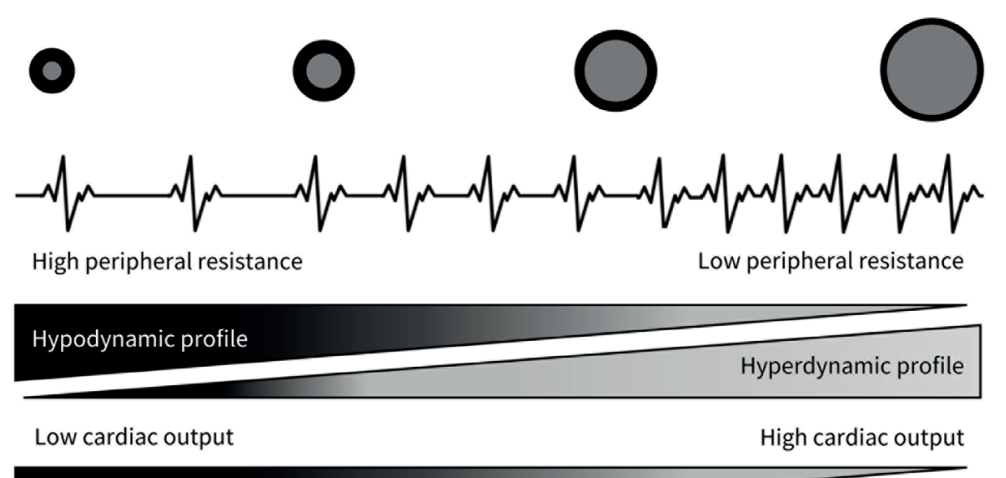

Calcium antagonist / alpha agonist

Beta blocker

\section{Early onset preeclampsia}

Late onset preeclampsia

Impaired foetal growth

Normal foetal growth

Figure 1. Haemodynamic profiles in mild hypertension, associated complications and anticipated effect of antihypertensive treatment. 


\section{METHODS}

\section{Aim}

The aim of this study is to determine whether haemodynamically tailored antihypertensive therapy in pregnant women with mild to moderate hypertension reduces the incidence of severe hypertension and preeclampsia and improves offspring outcome compared with standard care.

\section{Objectives}

Our primary objective is to determine whether haemodynamically tailored treatment of mild to moderate hypertension reduces disease progression to severe hypertension and preeclampsia compared with standard care. Our secondary objectives are to assess the effects of this treatment approach on maternal and offspring outcomes, including concomitant HELLP syndrome and eclampsia, gestational age at delivery, and neonatal birthweight and centile.

\section{Trial design and setting}

The Early Vascular Adjustments (EVA) trial is a randomized controlled open-label superiority trial, with two parallel groups (intervention and control). Progression to severe hypertension or preeclampsia is the primary endpoint. A schematic overview of patient enrolment and follow-up, and the SPIRIT timetable for the study are presented in Figures 2 and 3. Participants will be randomized 1:1 to the intervention or control group using premade, non-opaque sealed envelopes, in two blocks of 104 participants to achieve equal sample sizes in the end. Generalizability of the findings will be assessed in a third group of women who do not consent to randomization, but agree to follow-up of their pregnancy outcomes. In this group, women will receive standard care, meaning that their physician will discuss treatment with them, and decide which medication to prescribe. Participants will be recruited from the outpatient clinic and department of obstetrics in Maastricht University Medical Centre, which is both a secondary and tertiary referring hospital. During every routine pregnancy check-up, blood pressure is measured. Women with mild to moderate hypertension (defined as systolic blood pressure measures $\geq 140$ and $<160 \mathrm{mmHg}$ and/or diastolic blood pressure $\geq 90$ and $<110 \mathrm{mmHg}$ ) without symptoms or signs of preeclampsia will be given the study patient information form, and follow-up on blood pressure is planned at least 4 hours later and within a few days. Eligible women who give consent will be randomized to the intervention or control group, after which they will continue regular pregnancy check-ups with blood pressure measurements; additional laboratory analysis will be performed when indicated. After 37 weeks' gestation, induction of labour will be recommended to all participants, as this is associated with improved maternal outcome. ${ }^{27}$ Study endpoints are an unevent- 
ful pregnancy and 6-week postpartum period, or diagnosis of severe hypertension or preeclampsia. In the latter case, participants will receive standard care, which usually means hospitalization and intensifying or initializing antihypertensive medication for the intervention group and control group, respectively.

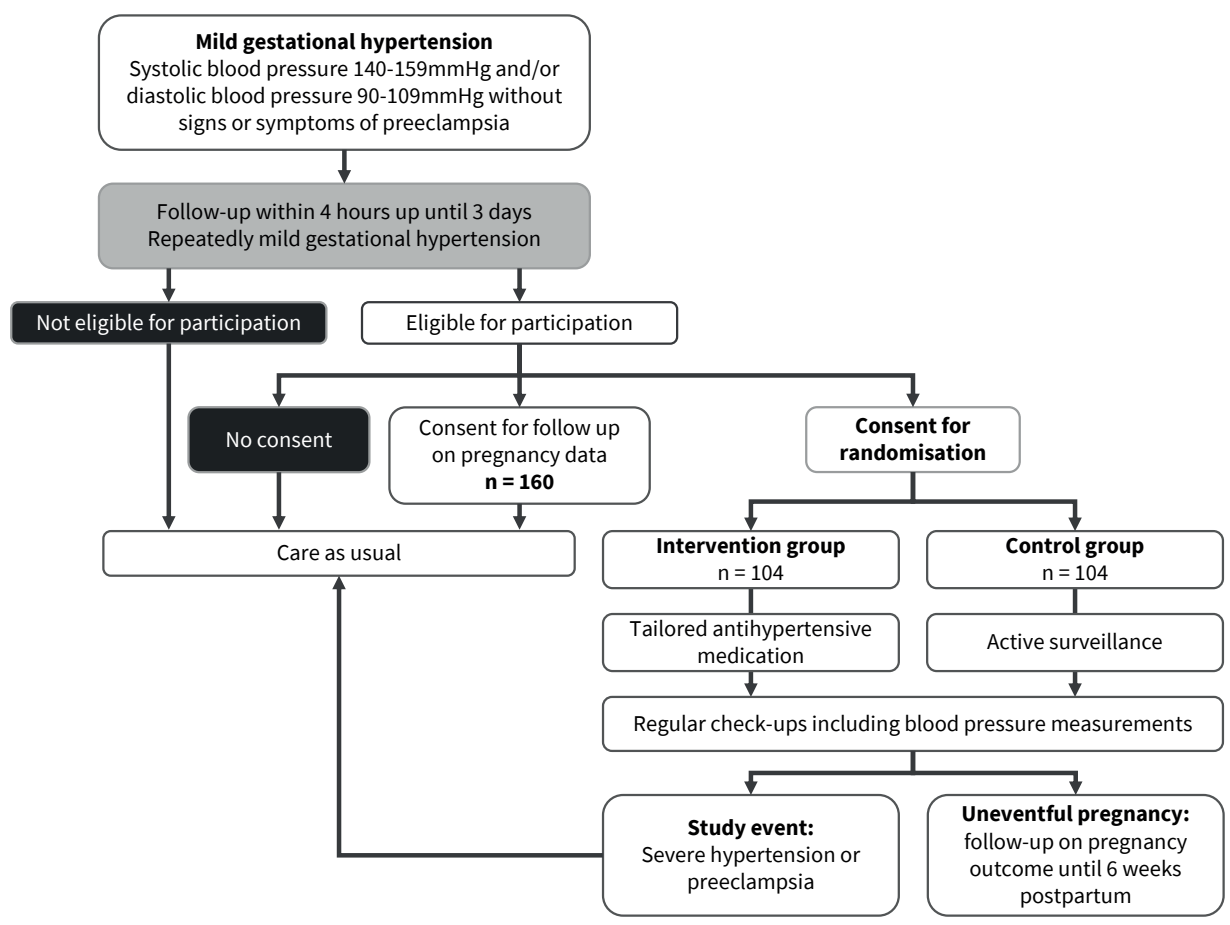

Figure 2. Schedule of enrolment, intervention, and assessments.

\section{Eligibility criteria}

Women must provide written informed consent before any study procedure occurs.

\section{Inclusion criteria}

Patients eligible for the trial must meet the following criteria at randomization:

- Age $\geq 18$ years;

- Living foetus before 37 weeks' gestation;

- Diagnosed with mild gestational hypertension (systolic blood pressure 140-159 $\mathrm{mmHg}$ and/or diastolic blood pressure 90-109 $\mathrm{mmHg}$, measured twice with at least 4 hours in between). 


\section{Exclusion criteria}

- Severe hypertension (systolic blood pressure $\geq 160 \mathrm{mmHg}$ and/or diastolic blood pressure $\geq 110 \mathrm{mmHg}$ );

- Diagnosed with preeclampsia, HELLP syndrome, or eclampsia;

- Taking antihypertensive drugs;

- Intending to terminate the pregnancy;

- Foetus has a major anomaly or chromosomal abnormality;

- Not able to comprehend the study outline;

- Contraindication for one of the possible prescribed antihypertensive medications.

\section{Interventions}

Eligible patients who consent to participate will be randomized to receive tailored antihypertensive medication (intervention group) or standard care (control group). The antihypertensive medications we plan to administer to participants in the intervention group can be safely prescribed to pregnant women. ${ }^{6}$ Total peripheral vascular resistance (calculated as: $80 \times$ MAP / cardiac output) indicates whether the hypertension is cardiacor vascular-driven. In a healthy pregnancy, total peripheral vascular resistance drops from approximately 1300 to 1000 dyne.s $/ \mathrm{cm}^{5}$ during the second and third trimester. ${ }^{28,29}$ Considering a standard deviation (SD) of 150 dyne.s $/ \mathrm{cm}^{5}$, the upper limit of healthy dilated total peripheral vascular resistance is 1300 dyne.s $/ \mathrm{cm}^{5}$. Women can be considered vasoconstricted when gestational vascular resistance exceeds 1300 dyne.s $/ \mathrm{cm}^{5}$ and vasodilated when vascular resistance is below 1300 dyne.s $/ \mathrm{cm}^{5}$. To avoid the need for an additional tool to assess cardiac output (stroke volume $\times \mathrm{HR}$ ), the MAP/HR ratio is used as a proxy for the haemodynamic profile. The MAP/HR ratio differs from total peripheral vascular resistance assessment in that it does not account for stroke volume. During healthy pregnancy, the mean \pm SD stroke volume is $75 \pm 10 \mathrm{ml}$. In the estimation of which proportion of women can be assumed to be vasoconstricted or vasodilated using the $\mathrm{MAP} / \mathrm{HR}$ ratio, we can estimate the range in which total peripheral vascular resistance must be by taking the mean \pm 2 SD stroke volume. When the MAP/HR ratio exceeds 1.4 , more than $95 \%$ of all women must be considered vasoconstrictive. Contrary, when the MAP/HR ratio is 1.1 or less, more than $50 \%$ of women are likely to have a vasodilated circulation (Figure 4). In the absence of empirical data that support the determination of cut-off values, we assumed a likelihood of more than $95 \%$ vasoconstrictive and relatively hypodynamic, corresponding a MAP/HR ratio 1.4 as reference value for considering vasodilating medication, and opposite, a likelihood of more than $50 \%$ of women to be vasodilated and hyperdynamic, corresponding MAP/HR ratio of 1.1 as a reference value for considering HR-lowering and with it, cardiac output-lowering medication. In the latter case, a beta-blocker with dual alpha- and beta-adrenergic receptor antagonism will account for the potential overlap in profiles. Thus, we will administer labetalol in 


\begin{tabular}{|c|c|c|c|c|c|c|c|}
\hline \multirow[b]{4}{*}{ TIMEPOINT } & \multicolumn{6}{|c|}{ STUDY PERIOD } & \multirow{4}{*}{$\begin{array}{c}\text { Close-out } \\
\begin{array}{c}6 \text { weeks } \\
\text { postpartum }\end{array} \\
t_{p p}\end{array}$} \\
\hline & \multirow{3}{*}{$\begin{array}{c}\text { Enrolment } \\
-t_{1}\end{array}$} & \multirow{3}{*}{$\begin{array}{c}\text { Allocation } \\
0\end{array}$} & \multicolumn{4}{|c|}{ Post-allocation } & \\
\hline & & & \multicolumn{3}{|c|}{ Antenatal check-ups } & \multirow[b]{2}{*}{$t_{d}$} & \\
\hline & & & $t_{1}$ & $t_{2}$ & $t_{\ldots}$ & & \\
\hline \multicolumn{8}{|l|}{ ENROLMENT: } \\
\hline Eligibility screen & $X$ & & & & & & \\
\hline \multirow{2}{*}{$\begin{array}{c}\text { Informed consent } \\
\text { Randomization }\end{array}$} & $\mathrm{x}$ & & & & & & \\
\hline & $x$ & & & & & & \\
\hline Allocation & & $x$ & & & & & \\
\hline \multicolumn{8}{|l|}{ INTERVENTIONS: } \\
\hline Tailored medication & & & $\mathrm{X}$ & $x$ & $\mathrm{X}$ & $x$ & \\
\hline Care as usual & & & $x$ & $x$ & $x$ & $x$ & \\
\hline \multicolumn{8}{|l|}{ ASSESSMENTS: } \\
\hline Blood pressure & $X$ & $x$ & $\mathrm{X}$ & $\mathrm{X}$ & $\mathrm{X}$ & $\mathrm{X}$ & $x$ \\
\hline Heart rate & $X$ & $x$ & $x$ & $x$ & $x$ & $x$ & $x$ \\
\hline Subjective symptoms & & & $\mathrm{x}$ & $\mathrm{X}$ & $x$ & & $x$ \\
\hline $\begin{array}{r}\text { Medication adherence } \\
\text { (intervention group) }\end{array}$ & & & $\mathrm{X}$ & $x$ & $X$ & & \\
\hline $\begin{array}{r}\text { Side-effects } \\
\text { (intervention qroup) }\end{array}$ & & & $\mathrm{X}$ & $\mathrm{X}$ & $X$ & & \\
\hline Laboratory tests & & & Xii & Xii & Xii & Xii & Xii \\
\hline $\begin{array}{r}\text { Delivery related } \\
\text { variables }\end{array}$ & & & & & & $X$ & \\
\hline Offspring outcomes & & & & & & $\mathrm{x}$ & \\
\hline $\begin{array}{r}\text { Adverse maternal } \\
\text { outcomes }\end{array}$ & & & & & & & $\mathrm{X}$ \\
\hline $\begin{array}{r}\text { Adverse neonatal } \\
\text { outcomes }\end{array}$ & & & & & & & $\mathrm{X}$ \\
\hline
\end{tabular}

$t_{d}$ : at delivery; $t_{p p}: 6$ weeks postpartum; Xii: assessed if indicated

Figure 3. SPIRIT timetable of the study

the intervention group when hyperdynamic hypertension is assumed (MAP/HR ratio $\leq 1.1$ ), and slow-release nifedipine when hypodynamic hypertension is assumed (MAP/ $\mathrm{HR}$ ratio $\geq 1.4$ ). Women with normodynamic hypertension will be identified by a MAP/ 
HR ratio between 1.1 and 1.4 and will be prescribed methyldopa (Figure 5). Treatment will be increased if the targeted blood pressure of $<130 / 80 \mathrm{mmHg}$ (MAP $97 \mathrm{mmHg}$ ) is not achieved. ${ }^{7,30}$ The maximum dosages for blood pressure control are $800 \mathrm{mg}$ three times daily for labetalol, $30 \mathrm{mg}$ three times daily for slow release nifedipine and 1000 $\mathrm{mg}$ three times daily for methyldopa. If the maximum dosage has been administered and the MAP/HR ratio does not indicate another medication class, the blood pressure will be accepted. Moreover, in the unlikely event that blood pressure measurements fall below $95 / 50 \mathrm{mmHg}$, the treatment regime will be reduced and the last added medication step will be stopped. In case of intolerable side effects, the medication class will be switched; methyldopa will substitute labetalol or nifedipine, and nifedipine will substitute methyldopa when the MAP/HR ratio is $\geq 1.3$ and labetalol when the MAP/HR ratio is $<1.3$. Antihypertensive drugs will be provided by the local pharmacy. Since this is an open-label study, the participant, researcher, and physician will know the type and dosage of the prescribed medication. Adherence to the treatment and side effects of the medication in the intervention group will be discussed and recorded during each scheduled check-up.

vasodilatated vasoconstricted

MAP/HR ratio

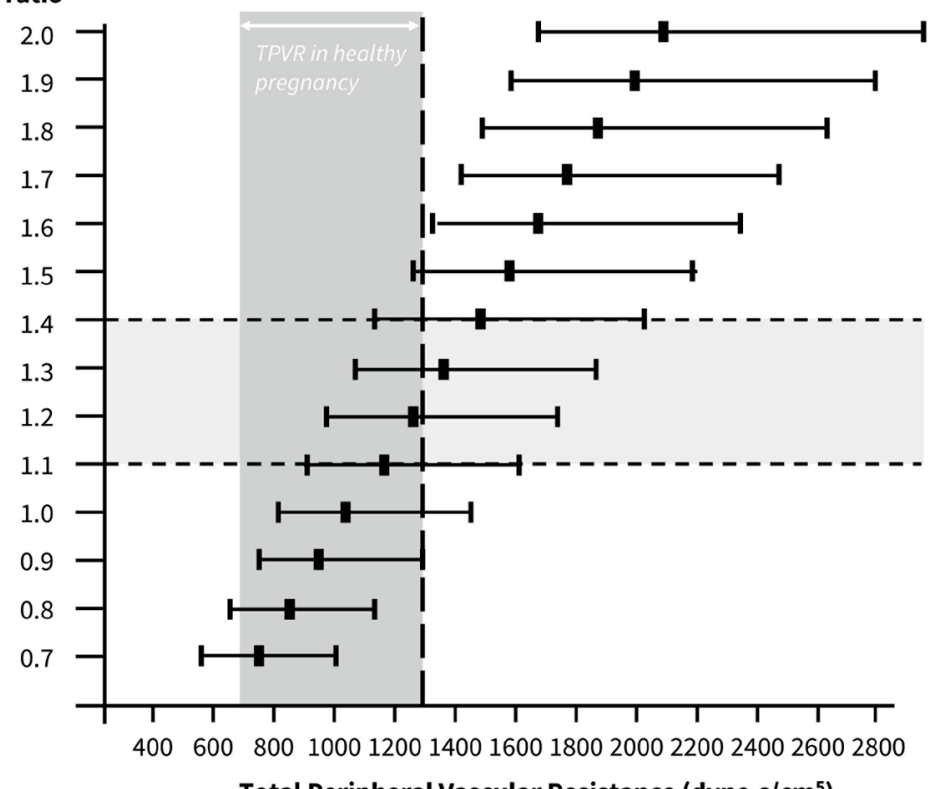

Total Peripheral Vascular Resistance (dyne.s/cm ${ }^{5}$ )

Figure 4. Assessment of underlying haemodynamic profile by MAP/HR ratio and the likelihood of vasoconstricted low output, or vasodilated high output hypertension. 


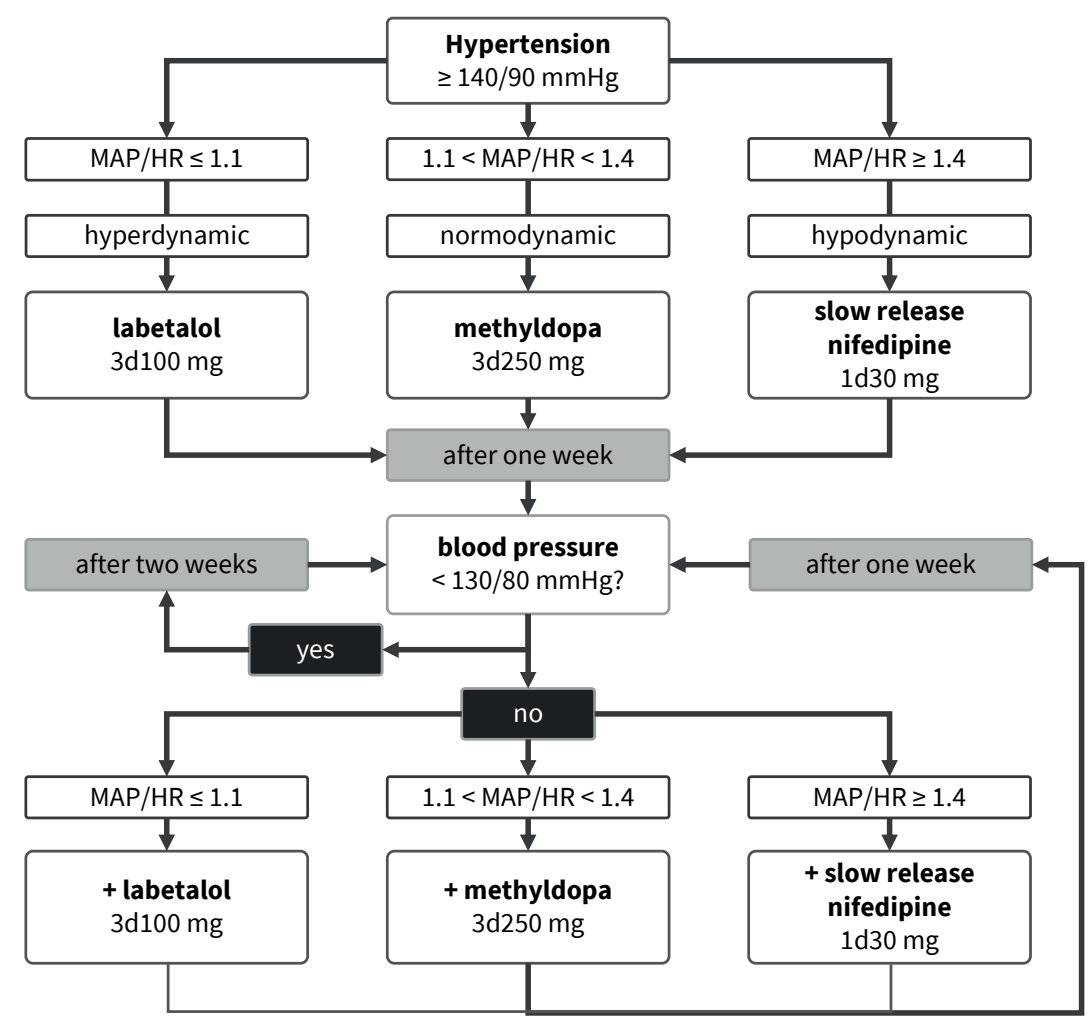

Figure 5. Tailored antihypertensive treatment strategy in the intervention group.

\section{Example 1:}

A 34-year-old woman, eligible for participation is randomized for the intervention group. Her blood pressure is $145 / 80$ (102) $\mathrm{mmHg}$, with a HR of 60bpm (MAP/HR ratio 1.7) and therefore she is prescribed slow release nifedipine $30 \mathrm{mg}$ once a day, and at follow-up her blood pressure is $135 / 74$ (94) $\mathrm{mmHg}$, HR of $72 \mathrm{bpm}$ (MAP/HR ratio 1.3). Therefore, methyldopa $250 \mathrm{mg} 3$ times daily is added. One week later her blood pressure is 118/74 (89) $\mathrm{mmHg}, \mathrm{HR}$ of $74 \mathrm{bpm}$ (MAP/HR ratio 1.2 ), which is below (additional) treatment threshold, and adequate blood pressure control is reached. Check-ups are continued every two weeks.

\section{Example 2:}

A 23-year-old woman eligible for participation is randomized for the intervention group. Her blood pressure is $155 / 91$ (112) $\mathrm{mmHg}$, and her HR is $94 \mathrm{bpm}$ (MAP/HR ratio 1.2). She is prescribed methyldopa $250 \mathrm{mg}$ three times daily. At the follow-up visit, her blood pressure measures 141/85 (104) mmHg, HR is 101bpm (MAP/HR ratio 1.0). As she did not achieve target blood pressure, labetalol 100mg 3 times daily is added. One week later, 
blood pressure is $125 / 75$ (92) $\mathrm{mmHg}, 92 \mathrm{bpm}$ (MAP/HR ratio 1.0) and adequate blood pressure control is reached. Check-up are continued every two weeks.

\section{Outcome measures}

Primary study endpoints:

1) Severe hypertension, defined as a systolic blood pressure $\geq 160 \mathrm{mmHg}$ and/or a diastolic blood pressure $\geq 110 \mathrm{mmHg}{ }^{31}$

2) Preeclampsia defined as hypertension and one or more of the following new-onset conditions:

- Proteinuria (spot urine protein/creatinine $\geq 30 \mathrm{~g} / \mathrm{mol}$ or $\geq 300 \mathrm{mg} / 24 \mathrm{~h}$ );

- Renal insufficiency (creatinine levels $\geq 90 \mu \mathrm{mol} / \mathrm{L}$ );

- Liver involvement (elevated transaminases at least twice the upper limit of normal $(\geq 70 \mathrm{U} / \mathrm{I})$;

- Neurological complications (hyperreflexia when accompanied by clonus and/or severe headaches, persistent visual scotomata, altered mental status, eclampsia);

- Haematological complications (thrombocytopenia defined as platelet count below $150^{\star} 10^{9} / \mathrm{L}$, disseminated intravascular coagulation, haemolysis). ${ }^{31}$

\section{Secondary and other study parameters}

Maternal outcomes: side effects of medication, required level of care, serious maternal complications (maternal death, HELLP syndrome defined as the combination of thrombocytopenia, elevated transaminases and haemolysis, stroke, blindness, uncontrolled hypertension, respiratory failure, myocardial ischaemia/infarction, renal failure, hepatic haematoma and/or rupture, coagulopathy), birth-related variables, and placental abruption.

Neonatal outcomes: miscarriage, gestational age at delivery, birthweight and centile, Apgar score at 1 and 5 minutes after birth, use of antenatal corticosteroids and surfactant, adverse perinatal outcomes (miscarriage, stillbirth, neonatal mortality, and serious morbidity including neonatal sepsis, central nervous system morbidity and necrotizing enterocolitis), required level of care, and duration of care.

\section{Data collection}

Data will be recorded in predesigned case record forms. Data on pregnancy and neonatal outcomes will be collected from the hospital maternity records. Additional neonatal outcomes will be collected from the discharge summary when neonates are admitted to the neonatal care department. 


\section{Sample size / power calculation}

Severe hypertension and preeclampsia develop respectively in $20 \%$ and $15-25 \%$ of women initially diagnosed with mild to moderate gestational hypertension. ${ }^{6,32}$ As severe hypertension and preeclampsia require comparable in-hospital treatment, we consider an $15 \%$ reduced incidence of both as clinically relevant. We calculated the sample size based on a progression level of $10 \%$ in the intervention group and a progression level of $25 \%$ in the control group. For a desired power of $80 \%$ and a two-tailed alpha level of 0.05 , we need to recruit 99 women per group. Considering an anticipated dropout rate of $5 \%$, we will recruit 208 women for randomization. We expect to include approximately 160 women who do not consent for randomization but agree to follow-up of their pregnancy outcomes. In this observational cohort, we will evaluate general obstetrical care for mild to moderate hypertension, patient characteristics, and patient outcomes comparable to the randomized population.

\section{Planned statistical analysis}

The effectiveness of haemodynamically tailored treatment of mild to moderate gestational hypertension will be evaluated based on the intention-to-treat principle. Descriptive statistics will be used to compare baseline characteristics between study groups. The primary analysis will be an $\mathrm{X}^{2}$ test, or Fisher's exact test in groups with less than five cases, to compare the incidence of severe hypertension and preeclampsia in the intervention group and the control group. We planned to conduct a per protocol sub-analysis in with women with at least $80 \%$ of their medication intake assessed by self-report at each pregnancy check-up. Secondary outcomes will be assessed by using $\mathrm{X}^{2}$, Fisher's exact test, Mann-Whitney $\mathrm{U}$ or $\mathrm{T}$ test as appropriate. For both primary and secondary outcomes, crude and adjusted odds ratio's will be calculated (control group will be considerate as reference) and adjustments will be made for gestational age at recruitment. Separate analyses will be conducted to evaluate whether or not optimal blood pressure control was reached, if the type of medication and dosage affected the outcomes, which haemodynamic profiles were most prevalent, and if the initial haemodynamic profile affected the outcome, and to explore the effect of BMI, parity and age on the haemodynamic profile and response to medication.

\section{DISCUSSION}

Mild to moderate hypertension is a common complication during pregnancy, leading to increased maternal and foetal mortality and morbidity when it progresses to severe hypertension, preeclampsia and associated sequela. Previous studies show paradoxical maternal and foetal outcomes when a general, stepwise antihypertensive medica- 
tion strategy is used. Previous studies on treating gestational hypertension have not considered the maternal circulatory profile and pharmaceutical mode of action of the prescribed medication, and the contemplated response to the medication class, while hypertensive pregnant women exhibit distinct circulatory profiles. This trial will investigate whether haemodynamically tailored treatment of mild to moderate gestational hypertension prevents progression to severe hypertension and preeclampsia without paradoxical maternal and offspring outcomes as observed in traditional non-tailored stepwise treatment approaches. We will tailor antihypertensive treatment to participants' individual haemodynamic profiles using a simple diagnostic and treatment algorithm that includes the MAP and HR values. Directly measuring cardiac function might determine the underlying haemodynamic profile more precisely, but these methods (such as echocardiography) are labour-intensive and require expertise. Our designed algorithm represents a pragmatic approach to choosing appropriate antihypertensive drugs and can be easily implemented since both parameters are readily available in daily clinical practice. 


\section{REFERENCES}

1. Kuklina EV, Ayala C and Callaghan WM. Hypertensive disorders and severe obstetric morbidity in the United States. Obstet Gynecol 2009; 113: 1299-1306.

2. Schutte JM, Schuitemaker NW, van Roosmalen J, Steegers EA and Dutch Maternal Mortality C. Substandard care in maternal mortality due to hypertensive disease in pregnancy in the Netherlands. BJOG 2008; 115: 732-736.

3. Judy $A E$, McCain CL, Lawton ES, Morton $\mathrm{CH}$, Main EK and Druzin ML. Systolic Hypertension, Preeclampsia-Related Mortality, and Stroke in California. Obstet Gynecol 2019; 133: 1151-1159.

4. Duley L, Meher S and Jones L. Drugs for treatment of very high blood pressure during pregnancy. Cochrane Database Syst Rev 2013: CD001449.

5. von Dadelszen $P$ and Magee LA. Fall in mean arterial pressure and fetal growth restriction in pregnancy hypertension: an updated metaregression analysis. J Obstet Gynaecol Can 2002; 24: 941-945.

6. Abalos E, Duley L and Steyn DW. Antihypertensive drug therapy for mild to moderate hypertension during pregnancy. Cochrane Database Syst Rev 2014: CD002252.

7. National Institute for Health and Clinical Excellence Hypertension in pregnancy: the management of hypertensive disorders of pregnancy NICE clinical guideline 107, August 2010.

8. ACOG Practice Bulletin No. 202: Gestational Hypertension and Preeclampsia. Obstet Gynecol 2019; 133: e1-e25.

9. Messerli FH and Grossman E. beta-Blockers in hypertension: is carvedilol different? $A m$ J Cardiol 2004; 93: 7B-12B.

10. Bakris G. An in-depth analysis of vasodilation in the management of hypertension: focus on adrenergic blockade. J Cardiovasc Pharmacol 2009; 53: 379-387.
11. Chrysant SG, Frohlich ED, Adamopoulos PN, Stein PD, Whitcomb WH, Allen EW, et al. Pathophysiologic significance of "stress" or relative polycythemia in essential hypertension. Am J Cardiol 1976; 37: 1069-1072.

12. Safar ME, London GM, Levenson JA, Kheder MA, Aboras NE and Simon AC. Effect of alpha-methyldopa on cardiac output in hypertension. Clin Pharmacol Ther 1979; 25: 266-272

13. Grossman E and Messerli FH. Effect of calcium antagonists on plasma norepinephrine levels, heart rate, and blood pressure. Am J Cardiol 1997; 80: 1453-1458.

14. Vetrovec GW. Hemodynamic and electrophysiologic effects of first- and secondgeneration calcium antagonists. $\mathrm{Am} \mathrm{J}$ Cardiol 1994; 73: 34A-38A.

15. Borow KM, Neumann A, Lang RM, Ehler $D$, Valentine-Bates B, Wolff A, et al. Noninvasive assessment of the direct action of oral nifedipine and nicardipine on left ventricular contractile state in patients with systemic hypertension: importance of reflex sympathetic responses. J Am Coll Cardiol 1993; 21: 939-949.

16. Valensise $\mathrm{H}$, Vasapollo B, Novelli GP, Pasqualetti P, Galante A and Arduini D. Maternal total vascular resistance and concentric geometry: a key to identify uncomplicated gestational hypertension. BJOG 2006; 113: 1044-1052.

17. Valensise $H$, Vasapollo B, Gagliardi $G$ and Novelli GP. Early and late preeclampsia: two different maternal hemodynamic states in the latent phase of the disease. Hypertension 2008; 52: 873-880.

18. Melchiorre K, Sutherland G, Sharma R, Nanni M and Thilaganathan B. Midgestational maternal cardiovascular profile in preterm and term pre-eclampsia: a prospective study. BJOG 2013; 120: 496504. 
19. Stott D, Nzelu O, Nicolaides KH and Kametas NA. Maternal hemodynamics in normal pregnancy and in pregnancy affected by pre-eclampsia. Ultrasound Obstet Gynecol 2018; 52: 359-364.

20. Mei S, Gu H, Wang Q, Zhang S and Zeng Y. Pre-eclampsia outcomes in different hemodynamic models. J Obstet Gynaecol Res 2008; 34: 179-188.

21. Foo FL, Mahendru AA, Masini G, Fraser A, Cacciatore S, Maclntyre DA, et al. Association Between Prepregnancy Cardiovascular Function and Subsequent Preeclampsia or Fetal Growth Restriction. Hypertension 2018; 72: 442-450.

22. Bosio PM, McKenna PJ, Conroy R and O'Herlihy C. Maternal central hemodynamics in hypertensive disorders of pregnancy. Obstet Gynecol 1999; 94: 978-984.

23. Taler SJ, Textor SC and Augustine JE. Resistant hypertension: comparing hemodynamic management to specialist care. Hypertension 2002; 39: 982-988.

24. Smith RD, Levy P, Ferrario $\mathrm{CM}$ and Consideration of Noninvasive Hemodynamic Monitoring to Target Reduction of Blood Pressure Levels Study G. Value of noninvasive hemodynamics to achieve blood pressure control in hypertensive subjects. Hypertension 2006; 47: 771-777.

25. Stott D, Bolten M, Paraschiv D, Papastefanou I, Chambers JB and Kametas NA. Longitudinal hemodynamics in acute phase of treatment with labetalol in hypertensive pregnant women to predict need for vasodilatory therapy. Ultrasound Obstet Gynecol 2017; 49: 85-94.
26. Stott $D$, Bolten $M$, Salman $M$, Paraschiv $D$, Douiri A and Kametas NA. A prediction model for the response to oral labetalol for the treatment of antenatal hypertension. $J$ Hum Hypertens 2017; 31: 126-131.

27. Koopmans CM, Bijlenga D, Groen $\mathrm{H}$, Vijgen SM, Aarnoudse JG, Bekedam DJ, et al. Induction of labour versus expectant monitoring for gestational hypertension or mild pre-eclampsia after 36 weeks' gestation (HYPITAT): a multicentre, open-label randomised controlled trial. Lancet 2009; 374: 979-988.

28. Desai DK, Moodley J and Naidoo DP. Echocardiographic assessment of cardiovascular hemodynamics in normal pregnancy. Obstet Gynecol 2004; 104: 20-29.

29. Mahendru AA, Everett TR, Wilkinson IB, Lees CC and McEniery CM. A longitudinal study of maternal cardiovascular function from preconception to the postpartum period. J Hypertens 2014; 32: 849-856.

30. Magee LA, Singer J, von Dadelszen $P$ and Group CS. Less-tight versus tight control of hypertension in pregnancy. N Engl J Med 2015; 372: 2367-2368.

31. Tranquilli AL, Dekker G, Magee L, Roberts J, Sibai BM, Steyn W, et al. The classification, diagnosis and management of the hypertensive disorders of pregnancy: A revised statement from the ISSHP. Pregnancy Hypertens 2014; 4: 97-104.

32. Saudan P, Brown MA, Buddle ML and Jones $M$. Does gestational hypertension become pre-eclampsia? Br J Obstet Gynaecol 1998; 105: 1177-1184. 




\title{
PREVENTING RECURRENT PREECLAMPSIA BY TAILORED TREATMENT OF NON- PHYSIOLOGICAL HEMODYNAMIC ADJUSTMENTS TO PREGNANCY
}

\author{
Eva G. Mulder \\ Chahinda Ghossein-Doha \\ Ella Cauffman \\ Veronica A. Lopes van Balen \\ Veronique M.M.M. Schiffer \\ Robert-Jan Alers \\ Jolien Oben \\ Luc Smits \\ Sander M.J. van Kuijk \\ Marc E.A. Spaanderman
}




\section{ABSTRACT}

Preeclampsia is often preceded by abnormal hemodynamic changes with heterogeneous patterns in the first half of pregnancy. We assessed the effect of timely tailored correction of non-physiological hemodynamic changes on preventing preeclampsia in a high-risk population. Primiparous women with a history of preeclampsia were invited to participate in a longitudinal program in their next pregnancy, including repeated hemodynamic assessments at 12-, 16-, 20- and 30-weeks' gestation additional to regular pregnancy check-ups. When at least 2 of the hemodynamic variables were not within physiological reference values, the hemodynamic imbalance between cardiac output and peripheral vascular resistance was counteracted with either labetalol, methyldopa, or nifedipine using a simple treatment algorithm. Normogram-guided women $(n=157)$ were matched to 157 women receiving care as usual (power $80 \%, \alpha=0.05$ ).

Risk of recurrent preeclampsia was analysed with logistic regression adjusted for daily low-dose aspirin or calcium supplementation. Hemodynamic changes were considered non-physiological in $90 \%$ of women in the normogram-guided group. Twelve percent of these women developed recurrent preeclampsia compared with $22 \%$ in the care-asusual group (adjusted odds ratio, 0.47 [95\% Cl, 0.25-0.88]). There were no differences between groups in gestational age at delivery $\left(38^{1}\right.$ and $38^{2}$ weeks in the normogram-guided and care-as-usual groups, respectively) and neonatal birthweight (3148 and $3180 \mathrm{~g}$ in the normogram-guided and care-as-usual groups, respectively). Tailored circulatory normalization of non-physiological hemodynamic changes during pregnancy halves the risk of recurrent preeclampsia, without disadvantageous effects on offspring outcome. This simple and innovative treatment strategy may also be beneficial to other women at increased risk for preeclampsia in pregnancy.

Keywords: Pregnancy; Hemodynamics; Physiology; Preeclampsia; Hypertension, Pregnancy-Induced; Foetal Development 


\section{INTRODUCTION}

Healthy pregnancy is normally accompanied by major changes in hemodynamic parameters that benefit the uteroplacental circulation. The first-trimester drop in vascular resistance triggers several compensatory mechanisms, resulting in increased plasma volume and cardiac output, to maintain adequate blood pressure and perfusion. ${ }^{1,2}$ Women destined to develop gestational hypertensive complications exhibit nonphysiological hemodynamic changes with heterogeneous patterns, long before overt clinical disease..$^{3-8}$ The heterogeneous abnormal patterns are prominently shown in the differences between late-onset preeclampsia ( $\geq 34$ weeks of gestation), early-onset preeclampsia ( $<34$ weeks of gestation), and whether there is concomitant impaired foetal growth. Late-onset preeclampsia, typically with normal foetal growth, is preceded by exaggerated early-pregnancy rise in cardiac output, whereas early-onset preeclampsia with foetal growth restriction is mostly headed by shallow first-trimester rise in cardiac output and absent drop in peripheral vascular resistance..$^{3-8}$

There is increasing evidence that in hypertensive pregnant women, improved blood pressure control is achieved when the choice for antihypertensive drug is based on correction of the underlying hemodynamic imbalance between cardiac output and peripheral vascular resistance. ${ }^{9-12}$ Following this line of reasoning, normalization of non-physiological hemodynamic changes in early pregnancy with counteracting medication may impede the circulatory processes that contribute to the development of preeclampsia. The aim of this study was to evaluate the effect of circulatory modification of abnormal hemodynamic changes to pregnancy before the onset of hypertension on preventing recurrent preeclampsia.

\section{METHODS}

The data that support the findings of this study are available from the principal investigator (M.E.A.S., marc.spaanderman@mumc.nl) upon reasonable request. This study was registered in https://www.clinicaltrials.gov (unique identifier NCT04216706). The hospital medical ethical committee of the Maastricht University Medical Centre approved the study protocol (METC azM/UM 14-4-118). Informed consent related to the use of clinically acquired data for scientific analysis was obtained, as is customary in the Maastricht University Medical Centre. From 1996 onwards, a nonpregnant cardiovascular and metabolic risk factor assessment was offered to women with a history of preeclampsia. This clinical service was accessible to all women in the country, and $\approx 65 \%$ of women were referred by physicians from other hospitals, who mainly referred women 
with severe complications. Women were scheduled for the assessment at at least 4, but preferably 6 months postpartum.

\section{Nonpregnant assessment}

Assessment of cardiovascular and metabolic risk factors was performed in standardized environmental conditions in the morning after an overnight fast. Clinical data on obstetric history, medical history, and use of medication were collected from medical files, discharge letters, and by direct patient enquiry. Haemoglobin level, plasma fibronectin, glucose, insulin, and lipid-spectrum levels were obtained from fasting blood samples. Urine was collected in the 24 hours preceding the measurements and assayed for albumin, creatinine, and total protein. Arterial blood pressure and mean arterial pressure were measured in sitting position by a semiautomatic oscillometric device (Dinamap Vital Signs Monitor 1846; Critikon, Tampa, FL) at a 3-minute interval with a cuff size appropriate for arm circumference. The median value of 11 measurements was used to detail blood pressure. Transthoracic echocardiography was performed according to the American Society of Echocardiography guidelines using a commercially available phased-array echocardiographic Doppler system (iE33 system with S5-1 or X5-1 transducers; Philips Medical Systems, Best, the Netherlands). ${ }^{13}$ All images were acquired in left lateral position, and recorded as ECG-gated digital loops and stored for off-line analysis. Outflow tract diameter and velocity time integrals were measured at the level of the aortic annulus. Heart rate was calculated by measuring the time interval between 2 consecutive $\mathrm{R}$ peaks on the ECG. Cardiac output was calculated using the formula: $\pi$ (outflow tract diameter $/ 2)^{2} \times$ velocity time integral $\times$ heart rate, and total peripheral vascular resistance (TPVR) was calculated using the formula mean arterial pressure $\times 80 /$ cardiac output.

\section{Structured cardiovascular program during pregnancy}

From 2013 onwards, all women admitted to the nonpregnant assessment were invited to participate in a follow-up program during their subsequent pregnancy. Women and partners could decide for themselves whether they wanted to participate, irrespective of insurance as maternity care is covered by the compulsory basic health care insurance in the Netherlands. The sole aim of the program was to evaluate hemodynamic changes at several moments during pregnancy and to adjust abnormal adaptation with tailored medication. The program took place at 12-, 16-, 20- and 30-week gestational age, and it was additive to regular pregnancy check-ups. All other clinical decisions regarding patient management were at the discretion of the referring physician. Content of additional pregnancy assessments was similar to the nonpregnant assessment and included fasting blood samples, blood pressure measurements and echocardiography and in addition, Doppler flow measurements of the uterine arteries according to ISUOG guidelines of the International Society of Ultrasound in Obstetrics \& Gynecology. ${ }^{14}$ 


\section{Assessment of Adaptation and Treatment Scheme}

Treatment decisions at the four evaluations during pregnancy were made in a 2-step strategy. The first step was to diagnose hemodynamic non-physiological gestational adjustments. The second step was to choose the appropriate treatment in case of non-physiological hemodynamic adjustments. At each following evaluation, the hemodynamic profile was reassessed and tailored medication was initiated or added accordingly, whenever applicable.

\section{Step 1, diagnosis}

Adequacy of hemodynamic adjustments was evaluated based on 7 parameters: (1) cardiac output, (2) TPVR, (3) blood pressure, (4) haemoglobin concentration (as a proxy for plasma volume expansion ${ }^{15}$ ), (5) plasma fibronectin (as biochemical proxy for endothelial shear), (6) mean pulsatility index of uterine arteries, and (7) the presence of diastolic notching (the latter two as proxy for downstream spiral artery remodelling). Absolute physiologic values appropriate for gestational-age (graphed in Figure S1 in the Data Supplement) were weighted together with individual changes at each gestational age moment relative to individuals' nonpregnant values. ${ }^{5,16-20}$ Non-physiological adjustment was diagnosed when at least 2 of the parameters were outside the gestational age-normalized physiological range (Figure S2).

\section{Step 2, treatment}

Type of medication was chosen to balance circulatory function towards physiologic values and guided on TPVR and heart rate normalized to gestational age interval. The used algorithm (depicted in Figure S3) was as follows:

-A dual $\alpha$ - and $\beta$-adrenergic receptor blocker (labetalol, starting dose, $100 \mathrm{mg}$ TID) was initiated when heart rate was extreme high (higher than the $90^{\text {th }}$ percentile, ie, $>$ p90) in combination with an intermediate-to-low TPVR $(<p 50)$, or when TPVR was extreme low $(<p 10)$ in combination with an intermediate-to-high heart rate $(>p 50)$.

-A vasodilating agent, that is, a dihydropyridine calcium channel blocker (slow-release nifedipine; starting dose, $30 \mathrm{mg}$ QD), was initiated when heart rate was extremely low $(<\mathrm{p} 10)$ in combination with an intermediate-to-high TPVR (>p50), or when TPVR was extremely high (>p90) in combination with an intermediate-to-low heart rate (<p50). In general, a calcium channel blocker was only initiated in women already using a centrally acting sympatholytic agent as increased TPVR in early pregnancy may also originate from exaggerated sympathetic response.

-A centrally acting sympatholytic agent (methyldopa, starting dose, $250 \mathrm{mg}$ TID) was indicated when both heart rate and TPVR were equally high, without deviating to the extreme sites. We considered blood pressure too low to initiate medication when it 
was below the physiological reference values. In case of increased TPVR with abnormal uterine artery waveforms at 30 weeks requiring calcium antagonist treatment, women were hospitalized for 1 day for additional foetal monitoring.

\section{Primary and secondary outcome measures}

The primary outcome was the occurrence of recurrent preeclampsia, defined as newonset hypertension with blood pressure $\geq 140 / 90 \mathrm{mmHg}$ at 2 repeated measurements along with de novo proteinuria ( $\geq 0.3 \mathrm{~g} / 24 \mathrm{~h}$ or $\geq 2+$ on dipstick analysis) or other maternal organ dysfunction (ie, renal insufficiency, liver involvement, neurological complications or haematological complications) after 20 weeks of gestation in previously normotensive women or superimposed on chronic hypertension. ${ }^{21}$ Secondary outcomes were associated maternal and offspring complications (occurrence of haemolysis, elevated liver enzymes, and low platelets [HELLP] syndrome, eclampsia, placental abruption, and stillbirth), gestational age at the onset of complications, gestational age at delivery, and neonatal outcomes (birthweight and centile). ${ }^{22}$ Complications are defined in the Data Supplement. Data on pregnancy outcomes were obtained from medical files and via regular patient enquiry following the nonpregnant assessment.

\section{Statistical analysis}

Women voluntarily participating in the additive program during their second pregnancy (normogram guided group) were matched, based on the year of delivery, to women attending the nonpregnant assessment but not participating in the additive program and who thus received only regular antenatal care in their second pregnancy (care-as-usual group). Logistic regression analyses were used to determine the difference between groups in incidence of dichotomous outcomes. Adjustments were made for daily low-dose aspirin and calcium supplementation, because we anticipated an increased use of these preventive measures in the normogram-guided group owing to limited employment in regular antenatal care in absence of recommendation in national guidelines. ${ }^{23}$ The intervention effect was quantified as odds ratios with corresponding $95 \% \mathrm{Cls}$. The Kaplan-Meier estimate was used to compute preeclampsia-free pregnancy prolongation, right censored for women who delivered. The log-rank test was used to test for equality of the survival function between the normogramguided and care-as-usual groups. The least needed sample size was estimated a priori based on an expected prevalence of recurrent preeclampsia of $24 \%$ in the care-as-usual group. ${ }^{23}$ Halving the recurrence rate would need 157 women per group to evaluate the effectiveness of this program with a desired power of $80 \%$ and a 2 -tailed a level of 0.05 . Outcomes were evaluated by both intention-to-treat and per protocol analyses. In the latter, all women in the normogram-guided group not able to attend all 4 assessments during pregnancy, or women noncompliant to advised medication were excluded. Statistical analyses were performed using R, version 3.6.1 and IBM SPSS Statistics, version 24 . 


\section{RESULTS}

A total of 314 women attending the nonpregnant assessment between 2005 and 2018 with known subsequent pregnancy outcome were selected, of which half formed the normogramguided group (Figure 1). Women referred from the Maastricht University Medical Centre participated more often in the normogram-guided group than in the care-as-usual group. Obstetric outcomes of the first pregnancy and findings at the nonpregnant assessment are presented in Table 1. Besides a slightly lower prepregnant cardiac output and higher TPVR in the normogramguided group, there were no differences between the two groups with respect to the severity of complications in the first pregnancy and prevalence of nonpregnant cardiovascular and metabolic risk factors. In the second pregnancy, daily low-dose aspirin and calcium supplementation were taken more often in the normogram-guided group ( $97 \%$ and $96 \%$ respectively) compared with the care-as-usual group ( $73 \%$ and $45 \%$, respectively) (both $\mathrm{P}<0.001)$.

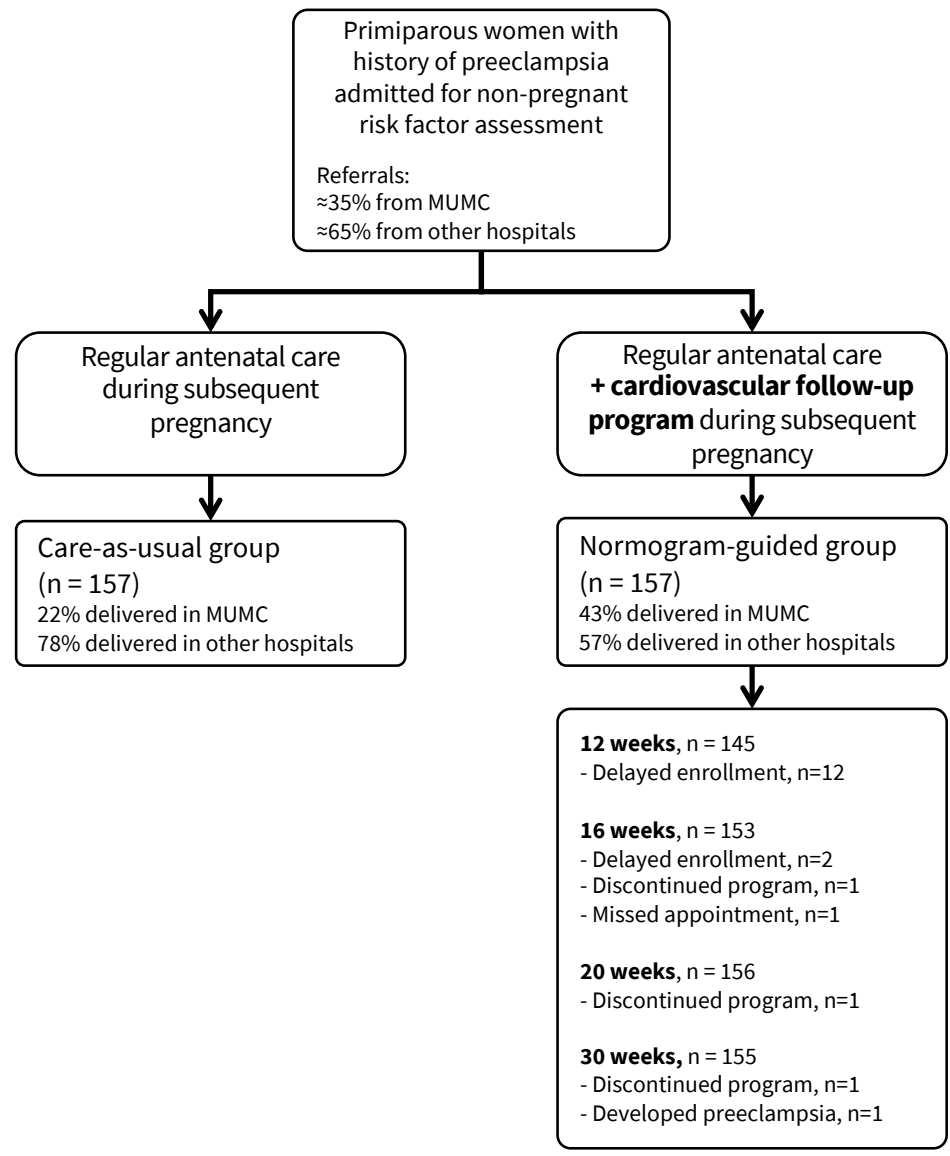

Figure 1. Flow diagram showing enrolment of women.

MUMC indicates Maastricht University Medical Centre 
Table 1. Obstetric history and cardiovascular and metabolic characteristics during nonpregnant assessment in women receiving normogram-guided care and care as usual in their next pregnancy.

\begin{tabular}{|c|c|c|c|}
\hline $\begin{array}{l}\text { Obstetric history and characteristics } \\
\text { at assessment }\end{array}$ & $\begin{array}{l}\text { Normogram-guided care } \\
\qquad(n=157)\end{array}$ & $\begin{array}{l}\text { Care-as-usual } \\
\quad(n=157)\end{array}$ & P-value \\
\hline \multicolumn{4}{|l|}{ First pregnancy } \\
\hline Maternal age, y & $29.6(3.8)$ & $29.3(3.6)$ & 0.62 \\
\hline Gestational age at delivery & $34^{3}\left[30^{5}-37^{0}\right]$ & $34^{3}\left[31^{5}-37^{0}\right]$ & 0.94 \\
\hline Gestational age at diagnosis & $33^{0}\left[29^{1}-36^{0}\right]$ & $33^{0}\left[28^{6}-36^{0}\right]$ & 0.97 \\
\hline Early-onset preeclampsia & $88 / 157(56 \%)$ & $91 / 156(58 \%)$ & 0.68 \\
\hline Superimposed preeclampsia & $5 / 157(3 \%)$ & $9 / 157(6 \%)$ & 0.27 \\
\hline HELLP syndrome & $105 / 157(67 \%)$ & $105 / 157(67 \%)$ & 1.00 \\
\hline Eclampsia & $9 / 157(6 \%)$ & $8 / 157(5 \%)$ & 0.80 \\
\hline Birthweight, g & $1968[1248-2691]$ & 2035 [1302-2608] & 0.86 \\
\hline Birthweight centile & $20[9-47]$ & $25[9-47]$ & 0.57 \\
\hline Multifetal pregnancy & $3 / 157(2 \%)$ & $2 / 157(1 \%)$ & 1.00 \\
\hline Small-for-gestational-age neonate & $42 / 157(27 \%)$ & $40 / 157(26 \%)$ & 0.80 \\
\hline Placental abruption & $3 / 157(2 \%)$ & $6 / 157(4 \%)$ & 0.50 \\
\hline Offspring demise & $12 / 157(8 \%)$ & $13 / 157(8 \%)$ & 0.84 \\
\hline Stillbirth & $6 / 157(4 \%)$ & $11 / 157(7 \%)$ & 0.21 \\
\hline Infant mortality & $6 / 157(4 \%)$ & $2 / 157(1 \%)$ & 0.17 \\
\hline Time to assessment, mo. & $9[6-19]$ & $9[6-14]$ & 0.29 \\
\hline Body mass index, $\mathrm{kg} / \mathrm{m}^{2}$ & $24.3[21.8-27.6]$ & $24.0[21.8-27.0]$ & 0.58 \\
\hline Metabolic syndrome* & $14 / 156(9 \%)$ & $14 / 154(9 \%)$ & 0.97 \\
\hline Hyperinsulinemia & $65 / 157(41 \%)$ & $60 / 157(38 \%)$ & 0.56 \\
\hline Obesity & $24 / 157(15 \%)$ & $17 / 157(11 \%)$ & 0.24 \\
\hline Dyslipidaemia & $28 / 157(18 \%)$ & $25 / 157(16 \%)$ & 0.65 \\
\hline Hypertension & $26 / 157(17 \%)$ & $26 / 157(17 \%)$ & 1.00 \\
\hline Albuminuria/proteinuria & $26 / 156(17 \%)$ & $29 / 154(19 \%)$ & 0.62 \\
\hline Systolic blood pressure, $\mathrm{mmHg}$ & $113[108-121]$ & $113[107-120]$ & 0.35 \\
\hline Diastolic blood pressure, $\mathrm{mmHg}$ & $72[67-77]$ & $71[66-74]$ & 0.11 \\
\hline Mean arterial pressure, $\mathrm{mmHg}$ & $87[82-94]$ & $87[81-91]$ & 0.26 \\
\hline Cardiac output, L/min & $4.7[4.1-5.5]$ & $5.0[4.5-5.7]$ & 0.04 \\
\hline TPVR, dyne $\cdot \mathrm{sec} \cdot \mathrm{cm}^{-5}$ & $1478[1263-1687]$ & $1364[1225-1596]$ & 0.01 \\
\hline Haemoglobin, $\mathrm{mmol} / \mathrm{L}$ & $8.3[8.0-8.7]$ & $8.3[8.0-8.6]$ & 0.74 \\
\hline Plasma fibronectin, $\mathrm{mg} / \mathrm{L}$ & $300[263-343]$ & 303 [262-364] & 0.50 \\
\hline
\end{tabular}

Data are presented as mean (SD), median [interquartile range] or number/valid measurements (percentage in group). BMI indicates body mass index; HELLP, haemolysis, elevated liver enzymes, and low platelets; TPVR, total peripheral vascular resistance; WHO, World Health Organization

*Metabolic syndrome based on the WHO criteria as follows: the presence of hyperinsulinemia (fasting insulin $\geq 9.2 \mathrm{mU} / \mathrm{L}$, fasting blood glucose $\geq 6.1 \mathrm{mmol} / \mathrm{L}$, or Homeostasis Model Assessment for insulin resistance $>2.2$ ), along with two or more of the following: 1) obesity $\left(\mathrm{BMI} \geq 30 \mathrm{~kg} / \mathrm{m}^{2}\right) ; 2$ ) dyslipidaemia (triglycerides $>1.69 \mathrm{mmol} / \mathrm{L}$ or $\mathrm{HDL}<0.9 \mathrm{mmol} / \mathrm{L}$ ); 3) hypertension (systolic blood pressure $\geq 140 \mathrm{mmHg}$, or diastolic blood pressure $\geq 90 \mathrm{mmHg}$, or antihypertensive medication use); 4) albuminuria ( $\geq 2.5 \mathrm{~g} / \mathrm{mol}$ creatinine) or proteinuria ( $\geq 0.30 \mathrm{~g} / 24 \mathrm{~h})$. 
In the normogram-guided group, 142 women (90\%) attended all 4 pregnancy assessments. The main reason for missing an assessment was because of delayed enrolment, resulting in, respectively, 145 and 153 women attending the 12- and 16-week assessment. In addition, one woman decided to refrain from further assessments when early hemodynamic adjustments were considered adequate, and one woman unintendedly missed her 16-week appointment. One woman did not attend the last assessment because she delivered preterm due to preeclampsia.

Parameters measured during the assessments before and during pregnancy of women in the normogram-guided group, and specific medication recommendations are presented in Table S1. Twenty-four women were on antihypertensive medication before their first assessment. In 142 women (90\%), hemodynamic adjustments at $\geq 1$ attended assessment were outside the physiologic range, resulting in medication advice. Fifteen women decided to refrain from treatment as they did not want to take antihypertensive medication when being normotensive. Nineteen women (13\%) experienced side effects resulting in dose reduction of medication. Blood pressure trajectories based on number of times inadequate adjustments to pregnancy (ranging from 0 to 4) are presented in Table 2, showing that antihypertensive medication prescribed on circulatory-guided arguments did not result in lower blood pressure levels. The risk for recurrent preeclampsia increased substantially with number of assessments with hemodynamic functioning outside physiological ranges (odds ratio per assessment adjusted for number of attended assessments, 2.52 [95\% Cl, 1.43-4.44]).

Table 2. Association between number of gestational check-ups with inadequate adjustments to pregnancy, concurrent blood pressure, and recurrent preeclampsia in the normogram-guided group.

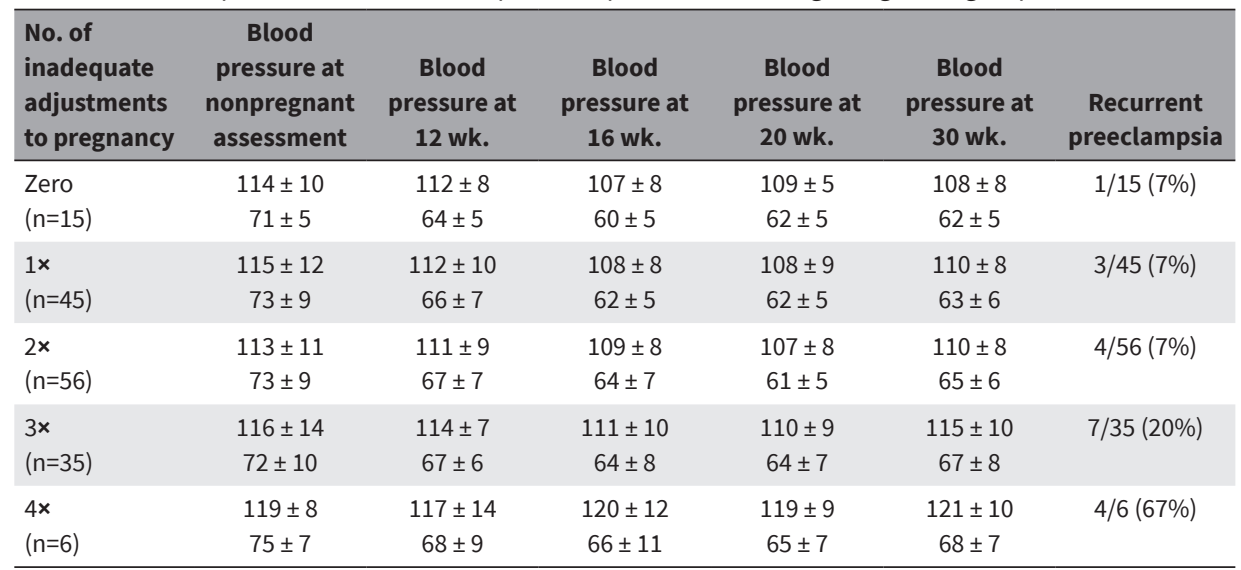


Obstetric outcomes of the second pregnancy are presented in Table 3. In the normogramguided group, significantly less women developed recurrent preeclampsia compared with the care-as-usual group ( $12 \%$ versus $22 \%$, respectively) with an adjusted odds ratio of 0.47 (95\% Cl, 0.25-0.88) (Table 4). Also, the HELLP syndrome developed in less women in the normogram-guided group compared with the care-as-usual group (1\% versus $6 \%$, respectively; adjusted odds ratio 0.11 [95\% Cl, 0.01-0.86]). Gestational age at delivery and offspring outcomes did not differ between groups. The Kaplan-Meier survival curves of the normogram-guided and care-as-usual groups illustrate the proportion of women with an ongoing pregnancy without preeclampsia from 24-week gestational age to delivery (Figure 2). Event-free survival was better for women in the normogram-guided group than in the care-as-usual group, with borderline significance (log-rank test statistic $\mathrm{P}=0.05)$.

Table 3. Outcome of subsequent pregnancy in the normogram-guided and care-as-usual group.

\begin{tabular}{|c|c|c|c|}
\hline Outcome & $\begin{array}{l}\text { Normogram-guided group } \\
\qquad(\mathrm{n}=157)\end{array}$ & $\begin{array}{l}\text { Care-as-usual group } \\
\qquad(n=157)\end{array}$ & P-value \\
\hline Maternal age, y & $32.8(3.7)$ & $32.8(3.7)$ & 0.82 \\
\hline GA at delivery & $38^{1}\left[37^{2}-39^{1}\right]$ & $38^{2}\left[37^{3}-39^{5}\right]$ & 0.43 \\
\hline Preterm birth & $19 / 157(12 \%)$ & $24 / 157(15 \%)$ & 0.51 \\
\hline \multicolumn{4}{|c|}{ Maternal complications } \\
\hline Preeclampsia & $19 / 157(12 \%)$ & $34 / 157(22 \%)$ & 0.03 \\
\hline HELLP syndrome & $1 / 157(1 \%)$ & $10 / 157(6 \%)$ & 0.01 \\
\hline Eclampsia & $0 / 157$ & $1 / 157(1 \%)$ & 1.00 \\
\hline \multicolumn{4}{|l|}{ Offspring outcomes } \\
\hline Birthweight, g & 3148 [2711-3483] & 3170 [2831-3506] & 0.52 \\
\hline Birthweight centile & 38 [17-67] & $41[22-67]$ & 0.36 \\
\hline SGA neonate & $17 / 157(11 \%)$ & $22 / 157(14 \%)$ & 0.49 \\
\hline Placental abruption & $0 / 157$ & $1 / 157(1 \%)$ & 1.00 \\
\hline Stillbirth & $0 / 157$ & $0 / 157$ & NA \\
\hline Infant mortality & $1 / 157(1 \%)$ & $2 / 157(1 \%)$ & 1.00 \\
\hline
\end{tabular}

Preeclamptic second pregnancies Normogram-guided group $(n=19) \quad$ Care-as-usual group $(n=34)$

\begin{tabular}{llll} 
GA at onset of preeclampsia & $36^{1}\left[34^{6}-36^{6}\right]$ & $35^{0}\left[32^{1}-37^{2}\right]$ & 0.66 \\
GA at delivery & $37^{0}\left[36^{4}-37^{3}\right]$ & $37^{0}\left[35^{5}-38^{0}\right]$ & 1.00 \\
\hline
\end{tabular}

Data are presented as mean (SD), median [interquartile range] or number per group (percentage). GA indicates gestational age; HELLP, haemolysis, elevated liver enzymes, and low platelets; NA, not applicable; SGA, small-for-gestational-age 
Table 4. Odds ratios for preeclampsia and HELLP-syndrome between normogram-guided care as compared to care-as-usual during the second pregnancy.

\begin{tabular}{|c|c|c|c|c|}
\hline Obstetric outcome & Odds ratio $(95 \% \mathrm{Cl})$ & $P$ value & Adjusted odds ratio $(95 \% \mathrm{CI})^{\star}$ & $P$ value \\
\hline \multicolumn{5}{|c|}{ Intention-to-treat analysis $(n=314)$} \\
\hline Recurrent preeclampsia & $0.50(0.27-0.92)$ & 0.03 & $0.47(0.25-0.88)$ & 0.02 \\
\hline HELLP syndrome & $0.09(0.01-0.75)$ & 0.03 & $0.11(0.01-0.86)$ & 0.04 \\
\hline \multicolumn{5}{|c|}{ Per-protocol analysis $(n=287)$} \\
\hline Recurrent preeclampsia & $0.44(0.23-0.86)$ & 0.02 & $0.43(0.22-0.84)$ & 0.01 \\
\hline HELLP syndrome & $0.11(0.14-0.90)$ & 0.04 & $0.13(0.02-1.06)$ & 0.06 \\
\hline
\end{tabular}

${ }^{*}$ Corrected for daily low-dose aspirin or calcium supplementation

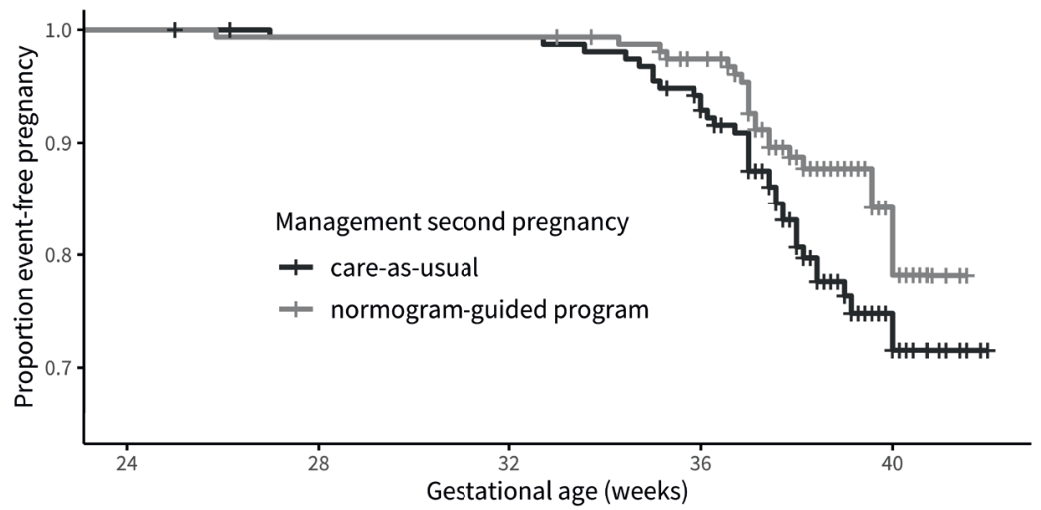

Figure 2. Kaplan-Meier survival curve showing ongoing pregnancies until delivery (right censored) without developing recurrent preeclampsia in the normogram-guided and care-as-usual groups (log-rank test statistic $\mathrm{P}=0.05)$.

\section{DISCUSSION}

Physiologic normogram-guided care halves the risk of recurrent preeclampsia. Individualized pharmacological modulation of nonphysiological circulatory adjustments in pregnancy seems an effective strategy to prevent preeclampsia in a high-risk population, without disadvantageous effects on offspring outcome.

The unfavourable, heterogeneous patterns of hemodynamic changes preceding preeclampsia develop through different trajectories. These trajectories may originate in abnormal prepregnant hemodynamic capacity, deviant adjustments to pregnancy, or a crossover from high-output, low-vascular resistance to low-output, high-vascular resistance circulation. The latter is thought to result from endothelial derangement and loss of intravascular fluid. 5, 7,24 In the normogram-guided group, antihypertensive medication was chosen to correct the leading hemodynamic imbalance before the onset of 
hypertension. This modulation is expected to impede pathologic processes contributing to the development of preeclampsia. ${ }^{25}$ In healthy functioning circulations, spontaneous fluctuations in blood pressure are autonomically counterbalanced by baroreceptormediated changes in heart rate and vascular tone to keep blood pressure stable around each individual's blood pressure set point. ${ }^{26}$ As a result, alterations in cardiac output and TPVR both contribute to maintain stable blood pressure. Consistent rise or fall in blood pressure within one person throughout gestation, therefore, indicates failure of these response mechanisms to compensate for the pregnancy-induced drop in TPVR. As such, rising blood pressure is a late signal in the system biology toward hypertensive complications in pregnancy. When adjusting nonphysiological hemodynamic functioning before the onset of hypertension, compensational responses in heart rate, stroke volume and TPVR are activated to maintain stable blood pressure as we also observed in our normogram-guided population.

The medications used in the current treatment strategy are commonly prescribed in pregnancy. Labetalol is a dual acting $\alpha$ - and $\beta$-receptor blocker. It lowers elevated blood pressure by lowering heart rate and contractility and concurrent $a$-receptor blockade-induced reduction in TPVR, although the $\beta$-blocking activity might be lower in pregnancy. ${ }^{27,} 28$ Lowering exaggerated cardiac output that is beyond physiological boundaries may decrease endothelial shear and overperfusion of the placental intervillous space, the latter affecting healthy placental development and with it, foetal growth. ${ }^{25,29,30}$ Methyldopa-a dopamine receptor agonist- is a centrally acting sympatholytic agent that modestly reduces vascular resistance and slightly increases cardiac output. $^{31,32}$ Nifedipine-a dihydropyridine calcium channel blocker-inhibits calcium ions from entering vascular smooth muscle cells and strongly reduces arterial vascular tone and TPVR. Secondary to arterial vasodilation, the sympathetic nervous system is activated resulting in increased levels of norepinephrine, higher heart rate, and ultimately increased cardiac output. ${ }^{33,34}$

In normotensive women, in general, centrally acting sympatholytic agents and calcium antagonists are thought to support the uterine perfusion by reducing systemic and uterine bed vascular resistance. ${ }^{35-37}$ The different modes of action of these compounds are pivotal in correcting the underlying non-physiological alterations that may jeopardize individuals and offspring health throughout gestation.

Absolute birthweight, birthweight centile, and incidence of small-for-gestational-age infants were similar in both groups. This is an important finding given the common conventional concerns that lowering blood pressure with antihypertensive medication negatively associates with neonatal birthweight. Beta-blockers are thought to negatively 
affect foetal growth by attenuating perfusion of the placental intervillous space. ${ }^{38-40}$ However, our approach was different on two aspects compared to previous studies. Timing of treatment, before the rise of blood pressure, may have allowed the maternal cardiovascular system to compensate changes induced by medication without having an effect on blood pressure. Also, it may be that the unfavourable effects of treatment on foetal growth could be avoided by using $\beta$-blockers only in women with an appropriateto-high output effectuated by high heart rate. Moreover, previous hemodynamically guided antihypertensive treatment with additional vasodilators in women with lower cardiac output also did not result in increased prevalence of growth restriction. ${ }^{12}$ Normalization of preconceptional and early-pregnancy circulatory function might favour placentation, but a large trial is needed to evaluate the effects on foetal growth. ${ }^{5}$

\section{Strengths and limitations}

The novelty of this treatment strategy lies in approaching the heterogenic syndrome preeclampsia by categorizing the underlying nonphysiological circulatory function to individualize treatment before blood pressure rises. The magnitude of the clinical effect along with large group size yielding to substantial statistical power supports a fundamental change in treatment paradigm for future studies. Besides strengths, there are also some shortcomings that need to be addressed. First, the vast majority of women in our study population were of Northern-European ancestry, which may affect generalizability to other ethnicities. On the other hand, the intervention is based on individuals' hemodynamic profile instead of ethnic groups' averages. Second, the study design reflects the effectiveness in clinical practice, but a placebo effect of the normogramguided program, possibly enhancing the sense of control and reducing stress and anxiety affecting development of preeclampsia, cannot be ruled out. ${ }^{41}$ Third, as this study is not randomized, it is prone to self-selection (healthy user) bias, but the effect on the outcomes is anticipated to be small, considering that the prevalence of prepregnant cardiometabolic risk factors in both groups were comparable. The latter two issues are both to overcome with a randomized placebo-controlled trial. ${ }^{42}$ An alternative, possibly more feasible approach would be a randomized open-label approach, in which women receive normogram-guided-care or care as usual. The only difference with this study would then be the randomization upfront. Lastly, the physiologic normograms used to weigh changes in pregnancy result from relatively small studies, and larger samples or comprehensive meta-analyses on variables used should result in more robust reference values. Ideally, locally derived reference values specific for measurement method should be used. 


\section{Perspectives}

Physiological normogram-guided care and tailored pharmacological intervention directed to correct underlying hemodynamic imbalances during pregnancy halves the risk of recurrent preeclampsia, without unfavourable effects on offspring outcome. This treatment strategy is likely to be beneficial to all women at high risk of preeclampsia. The proposed treatment strategy does not introduce novel medication but uses 3 drugs being used for decades in obstetric healthcare. The clinically relevant decrease in the occurrence of preeclampsia along with the reassuring offspring effects may facilitate implementation of this simple diagnosis and treatment paradigm into large multicentre clinical trials and clinical practice. The increasing global interest of obstetric centres in serially monitoring circulatory function along with the availability of easy operable devices that assess cardiac output facilitates implementation in general practice. On the one hand, generic preventive measures as low-dose aspirin and calcium can be advised in high-risk women, and on the other hand, tailored nongeneric preventive strategies with modulation of maladaptive hemodynamic functions can be pursued. A randomized controlled trial to evaluate the treatment strategy is an appropriate next step to confirm these promising findings. 


\section{REFERENCES}

1. de Haas S, Ghossein-Doha C, van Kuijk SM, van Drongelen $\mathrm{J}$ and Spaanderman ME. Physiologic adaptation of plasma volume during pregnancy: a systematic review and meta-analysis. Ultrasound Obstet Gynecol 2017; 49(2): 177-187.

2. Meah VL, Cockcroft JR, Backx K, Shave $\mathrm{R}$ and Stohr EJ. Cardiac output and related haemodynamics during pregnancy: a series of meta-analyses. Heart 2016; 102: 518-526.

3. Valensise H, Vasapollo B, Gagliardi G and Novelli GP. Early and late preeclampsia: two different maternal hemodynamic states in the latent phase of the disease. Hypertension 2008; 52: 873-880.

4. Easterling TR, Benedetti TJ, Schmucker BC and Millard SP. Maternal hemodynamics in normal and preeclamptic pregnancies: a longitudinal study. Obstet Gynecol 1990; 76: 1061-1069.

5. Rang S, van Montfrans GA and Wolf H. Serial hemodynamic measurement in normal pregnancy, preeclampsia, and intrauterine growth restriction. Am J Obstet Gynecol 2008; 198: 519 e511-519.

6. Mahendru AA, Foo FL, McEniery CM, Everett TR, Wilkinson IB and Lees CC. Change in maternal cardiac output from preconception to mid-pregnancy is associated with birth weight in healthy pregnancies. Ultrasound Obstet Gynecol 2017; 49: 78-84.

7. Foo FL, Mahendru AA, Masini G, Fraser A, Cacciatore S, Maclntyre DA, et al. Association Between Prepregnancy Cardiovascular Function and Subsequent Preeclampsia or Fetal Growth Restriction. Hypertension 2018; 72: 442-450.

8. Khaw A, Kametas NA, Turan OM, Bamfo JE and Nicolaides $\mathrm{KH}$. Maternal cardiac function and uterine artery Doppler at 11-14 weeks in the prediction of pre-eclampsia in nulliparous women. BJOG 2008; 115: 369-376.
9. Easterling TR, Benedetti TJ, Schmucker BC and Carlson KL. Antihypertensive therapy in pregnancy directed by noninvasive hemodynamic monitoring. Am J Perinatol 1989; 6: 86-89.

10. Easterling TR. Pharmacological management of hypertension in pregnancy. Semin Perinatol 2014; 38: 487-495.

11. Stott D, Papastefanou I, Paraschiv D, Clark $\mathrm{K}$ and Kametas NA. Serial hemodynamic monitoring to guide treatment of maternal hypertension leads to reduction in severe hypertension. Ultrasound Obstet Gynecol 2017; 49: 95-103.

12. Chaffin DG and Webb DG. Outcomes of pregnancies at risk for hypertensive complications managed using impedance cardiography. Am J Perinatol 2009; 26: 717721.

13. Mitchell C, Rahko PS, Blauwet LA, Canaday B, Finstuen JA, Foster MC, et al. Guidelines for Performing a Comprehensive Transthoracic Echocardiographic Examination in Adults: Recommendations from the American Society of Echocardiography. $J$ Am Soc Echocardiogr 2018

14. Bhide A AG, Bilardo CM, Brezinka C, Cafici D, Hernandez-Andrade E, Kalache K, Kingdom J, Kiserud T, Lee W, Lees C, Leung KY, Malinger G, Mari G, Prefumo F, Sepulveda W and Trudinger B. ISUOG Practice Guidelines: use of Doppler ultrasonography in obstetrics. Ultrasound Obstet Gynecol 2013; 41: 233-239.

15. Whittaker PG, Macphail S and Lind T. Serial hematologic changes and pregnancy outcome. Obstet Gynecol 1996; 88: 33-39.

16. Chapman AB, Abraham WT, Zamudio S, Coffin C, Merouani A, Young D, et al. Temporal relationships between hormonal and hemodynamic changes in early human pregnancy. Kidney Int 1998; 54: 2056-2063.

17. Ochsenbein-Kolble N, Roos M, Gasser T, Huch R, Huch A and Zimmermann R. 
Cross sectional study of automated blood pressure measurements throughout pregnancy. BJOG 2004; 111: 319-325.

18. van Buul EJ, Steegers EA, Jongsma HW, Eskes TK, Thomas CM and Hein PR. Haematological and biochemical profile of uncomplicated pregnancy in nulliparous women; a longitudinal study. Neth J Med 1995; 46: 73-85.

19. Paarlberg KM, de Jong CL, van Geijn HP, van Kamp GJ, Heinen AG and Dekker GA. Total plasma fibronectin as a marker of pregnancy-induced hypertensive disorders: a longitudinal study. Obstet Gynecol 1998; 91: 383-388.

20. Gomez O, Figueras F, Fernandez S, Bennasar M, Martinez JM, Puerto B, et al. Reference ranges for uterine artery mean pulsatility index at 11-41 weeks of gestation. Ultrasound Obstet Gynecol 2008; 32: 128-132.

21. Tranquilli AL, Dekker G, Magee L, Roberts J, Sibai BM, Steyn W, et al. The classification, diagnosis and management of the hypertensive disorders of pregnancy: A revised statement from the ISSHP. Pregnancy Hypertens 2014; 4: 97-104.

22. Kloosterman GJ. [Intrauterine growth and intrauterine growth curves]. Maandschr Kindergeneeskd 1969; 37: 209-225.

23. Mulder EG, Ghossein-Doha C, Froeling M, van Kuijk SMJ and Spaanderman MEA. Recurrence rates of preeclampsia over the past 20 years in women assessed for non-pregnant cardiovascular risk factors. Pregnancy Hypertens 2018; 14: 150-155.

24. Bosio PM, McKenna PJ, Conroy R and O'Herlihy C. Maternal central hemodynamics in hypertensive disorders of pregnancy. Obstet Gynecol 1999; 94: 978-984.

25. Easterling TR, Brateng D, Schmucker B, Brown $Z$ and Millard SP. Prevention of preeclampsia: a randomized trial of atenolol in hyperdynamic patients before onset of hypertension. Obstet Gynecol 1999; 93: 725-733.
26. Laitinen T, Hartikainen J, Niskanen L, Geelen $\mathrm{G}$ and Lansimies E. Sympathovagal balance is major determinant of shortterm blood pressure variability in healthy subjects. Am J Physiol 1999; 276: H12451252.

27. Bakris G. An in-depth analysis of vasodilation in the management of hypertension: focus on adrenergic blockade. J Cardiovasc Pharmacol 2009; 53: 379-387.

28. Carvalho TM, Cavalli Rde C, Cunha SP, de Baraldi CO, Marques MP, Antunes NJ, et al. Influence of gestational diabetes mellitus on the stereoselective kinetic disposition and metabolism of labetalol in hypertensive patients. Eur J Clin Pharmacol 2011; 67: 55-61.

29. Burton GJ and Jauniaux E. Placental oxidative stress: from miscarriage to preeclampsia. J Soc Gynecol Investig 2004; 11: 342-352.

30. Tun WM, Yap CH, Saw SN, James JL and Clark AR. Differences in placental capillary shear stress in fetal growth restriction may affect endothelial cell function and vascular network formation. Sci Rep 2019; 9: 9876.

31. Chrysant SG, Frohlich ED, Adamopoulos PN, Stein PD, Whitcomb WH, Allen EW, et al. Pathophysiologic significance of "stress" or relative polycythemia in essential hypertension. Am J Cardiol 1976; 37: 1069-1072.

32. Safar ME, London GM, Levenson JA, Kheder MA, Aboras NE and Simon AC. Effect of alpha-methyldopa on cardiac output in hypertension. Clin Pharmacol Ther 1979; 25: 266-272.

33. Grossman E and Messerli FH. Effect of calcium antagonists on plasma norepinephrine levels, heart rate, and blood pressure. Am J Cardiol 1997; 80: 1453-1458.

34. Vetrovec GW. Hemodynamic and electrophysiologic effects of first- and secondgeneration calcium antagonists. $A m \mathrm{~J}$ Cardiol 1994; 73: 34A-38A. 
35. Vasapollo B, Novelli GP, Gagliardi G, Tiralongo GM, Pisani I, Manfellotto D, et al. Medical treatment of early-onset mild gestational hypertension reduces total peripheral vascular resistance and influences maternal and fetal complications. Ultrasound Obstet Gynecol 2012; 40: 325331.

36. Cornette J, Duvekot JJ, Roos-Hesselink JW, Hop WC and Steegers EA. Maternal and fetal haemodynamic effects of nifedipine in normotensive pregnant women. BJOG 2011; 118: 510-540.

37. Rothberger S, Carr D, Brateng D, Hebert M and Easterling TR. Pharmacodynamics of clonidine therapy in pregnancy: a heterogeneous maternal response impacts fetal growth. Am J Hypertens 2010; 23: 12341240.

38. Giannubilo SR, Bezzeccheri V, Cecchi S, Landi B, Battistoni GI, Vitali P, et al. Nifedipine versus labetalol in the treatment of hypertensive disorders of pregnancy. Arch Gynecol Obstet 2012; 286: 637-642.
39. von Dadelszen $P$ and Magee LA. Fall in mean arterial pressure and fetal growth restriction in pregnancy hypertension: an updated metaregression analysis. J Obstet Gynaecol Can 2002; 24: 941-945.

40. Magee LA, Group CS, von Dadelszen P, Singer J, Lee T, Rey E, et al. Do labetalol and methyldopa have different effects on pregnancy outcome? Analysis of data from the Control of Hypertension In Pregnancy Study (CHIPS) trial. BJOG 2016; 123: 11431151.

41. Zhang S, Ding Z, Liu H, Chen Z, Wu J, Zhang $Y$, et al. Association between mental stress and gestational hypertension/preeclampsia: a meta-analysis. Obstet Gynecol Surv 2013; 68: 825-834.

42. Fanaroff AC, Califf RM, Harrington RA, Granger CB, McMurray JJV, Patel MR, et al. Randomized Trials Versus Common Sense and Clinical Observation: JACC Review Topic of the Week. J Am Coll Cardiol 2020; 76: 580-589. 


\section{DATA SUPPLEMENT}

\section{Supplemental text - used definitions}

- A subsequent pregnancy was defined as an ongoing pregnancy beyond 24 weeks with known maternal and foetal outcome.

- Preeclampsia was defined as new-onset hypertension with systolic blood pressure $\geq 140 \mathrm{mmHg}$ and/or diastolic blood pressure $\geq 90 \mathrm{mmHg}$ at two repeated measurements along with de novo proteinuria ( $\geq 0.3 \mathrm{~g} / 24 \mathrm{~h}$ or $\geq 2+$ on dipstick analysis) or other maternal organ dysfunction (i.e. renal insufficiency, liver involvement, neurological complications or haematological complications) after 20 weeks of gestation in previously normotensive women, or superimposed on chronic hypertension. ${ }^{1}$ We considered normotensive women on normogram-guided antihypertensive medication with de-novo persistent proteinuria also as preeclamptic.

- Early-onset preeclampsia was defined as diagnosis before 34 weeks' gestation.

- HELLP syndrome was defined as LDH $\geq 600 \mathrm{IU} / \mathrm{L}$, AST or ALT levels elevated more than twice the upper limit of normal and platelet count $<100 \times 10^{9} / \mathrm{L}$.

- Eclampsia was defined as the occurrence of new onset seizures.

- Small for gestational age infancy was defined as neonatal birthweight below the $10^{\text {th }}$ percentile of the national birthweight charts. ${ }^{2}$ 

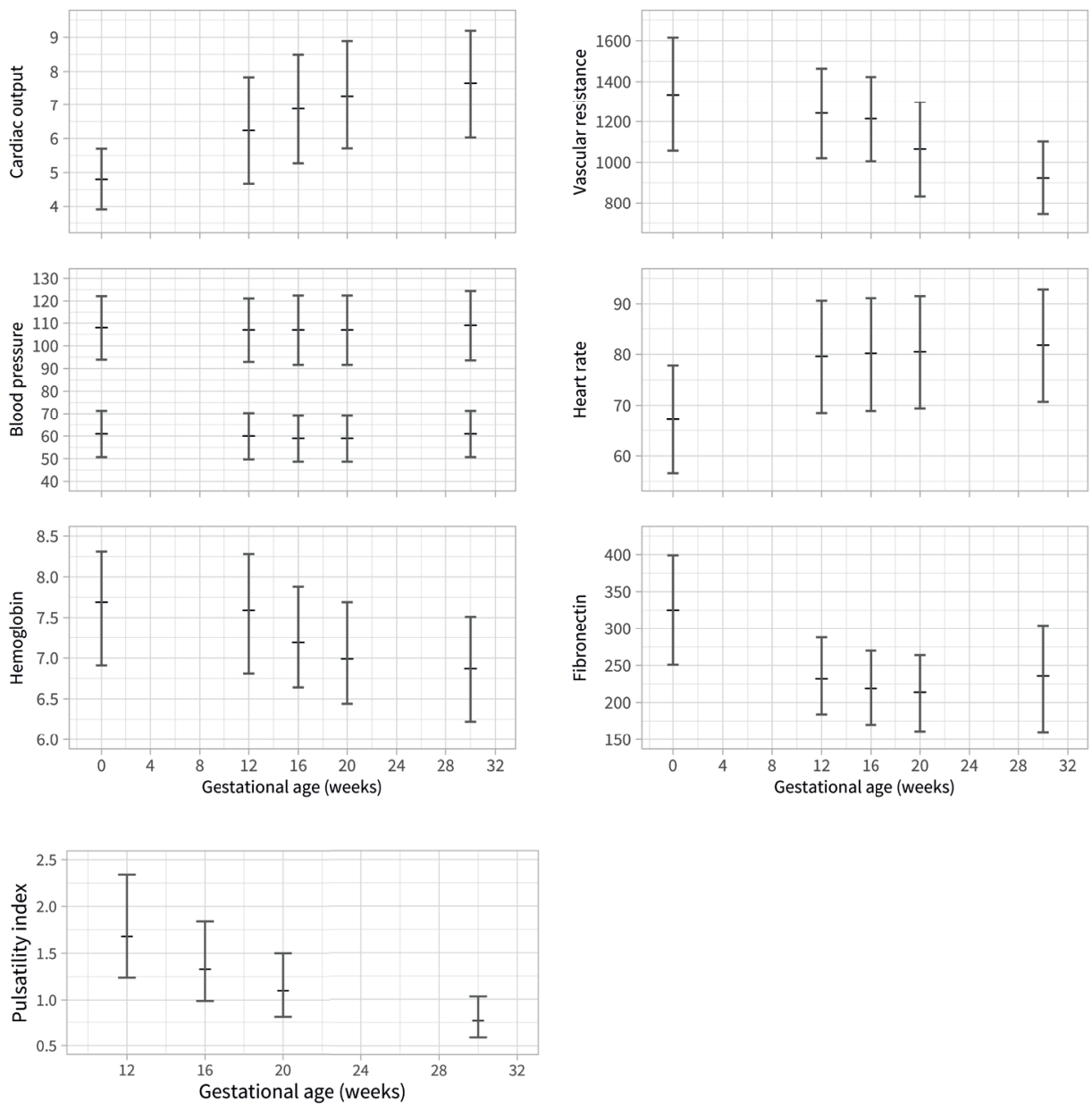

Figure S1. Reference curves of parameters over the course of pregnancy with the $10^{\text {th }}, 50^{\text {th }}$ and $90^{\text {th }}$ centiles as (error) bars. 


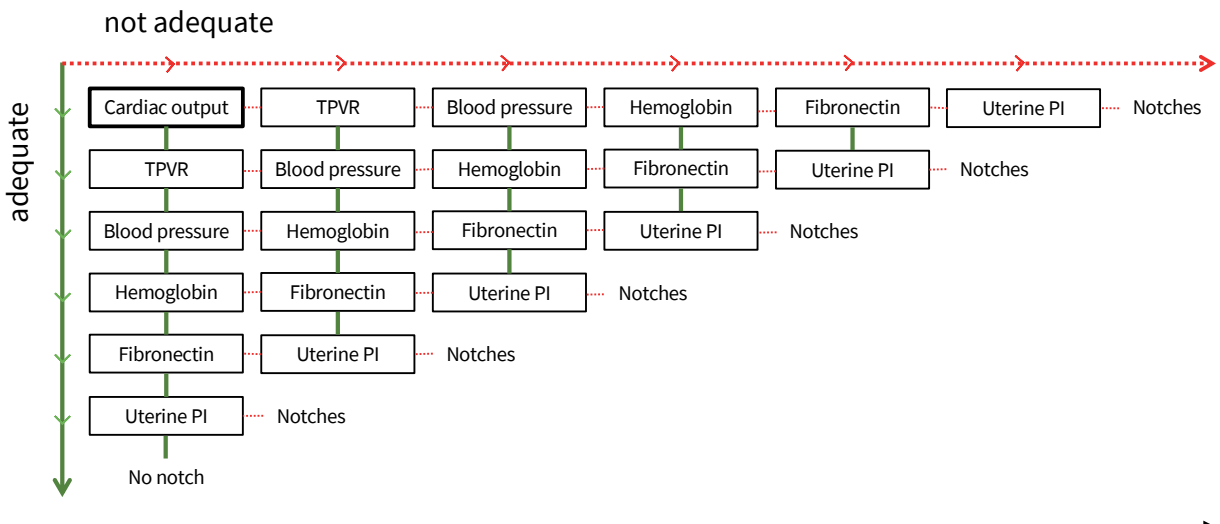

Medication not recommended

Medication recommended

Figure S2. Assessment of maternal hemodynamic adaptation to pregnancy based on 7 parameters.

Adequate adaptation of parameters (starting with cardiac output) leads to downward shifts, and inadequate adaptation leads to rightwards shifts in the scheme. Medication is recommended when adaptation of two or more parameters are outside the gestational-age-normalized physiological range. TPVR indicates total peripheral vascular resistance; PI, pulsatility index.

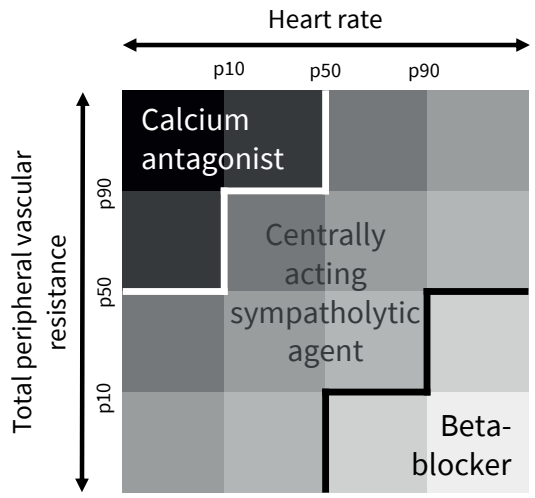

Figure S3. Treatment scheme for tailored medication

The treatment scheme was based on three different underlying hemodynamic response profiles:

- A hypodynamic hemodynamic profile characterized by a low cardiac output, effectuated by a low heart rate, and high peripheral vascular resistance, in which Nifedipine was the preferred medication.

- A hyperdynamic hemodynamic profile characterized by a high cardiac output, effectuated by a high heart rate, and low peripheral vascular resistance, in which Labetalol was the preferred medication.

- A mixed hemodynamic profile characterized by an equal cardiac output and peripheral vascular resistance, without one of those (or both) deviating explicitly to the extreme sides, suggesting mixed sympathetic response for which methyldopa was the preferred medication.

A calcium antagonist was initiated when total peripheral vascular resistance was extreme high (above the $90^{\text {th }}$ percentile [ $>\mathrm{p} 90])$ in combination with an intermediate to low heart rate $(<\mathrm{p} 50)$, or when heart rate was extreme low $(<\mathrm{p} 10)$ in combination with an intermediate to high total peripheral resistance $(>p 50)$. A betablocker was initiated when heart rate was extreme high ( $>\mathrm{p} 90)$ in combination with an intermediate to low $(<\mathrm{p} 50)$ total peripheral vascular resistance, or when total peripheral vascular resistance was extreme low $(<\mathrm{p} 10)$ in combination with an intermediate to high heart rate $(>\mathrm{p} 50)$. A centrally acting sympatholytic agent was indicated when both heart rate and total peripheral resistance were equally high. 
Table S1. Hemodynamic parameters of the normogram-guided group at non-pregnant assessment and at the assessments during the second pregnancy in women with and without recurrent preeclampsia.

\begin{tabular}{|c|c|c|c|c|}
\hline Characteristics & Total & $\begin{array}{l}\text { Non-recurrent } \\
\text { preeclampsia }\end{array}$ & $\begin{array}{l}\text { Recurrent } \\
\text { preeclampsia }\end{array}$ & P-value \\
\hline Non-pregnant assessment & $\mathrm{n}=157$ & $\mathrm{n}=138$ & $\mathrm{n}=19$ & \\
\hline Systolic blood pressure, $\mathrm{mmHg}$ & 113 [108-121] & $113[108-120]$ & 121 [110-129] & 0.08 \\
\hline Diastolic blood pressure, $\mathrm{mmHg}$ & $72[67-77]$ & $72[67-77]$ & $72[68-80]$ & 0.70 \\
\hline Mean arterial pressure, $\mathrm{mmHg}$ & $87[82-94]$ & 87 [82-93] & 89 [86-97] & 0.17 \\
\hline Cardiac output, L/min & $4.7[4.1-5.5]$ & $4.7[4.1-5.8]$ & $4.6[4.2-5.4]$ & 0.97 \\
\hline TPVR, dyne $\cdot \mathrm{sec} \cdot \mathrm{cm}^{-5}$ & $1478[1263-1687]$ & 1472 [1255-1695] & $1515[1376-1631]$ & 0.44 \\
\hline Haemoglobin, mmol/L & $8.3[8.0-8.7]$ & $8.3[8.0-8.7]$ & $8.2[8.0-8.7]$ & 0.70 \\
\hline Plasma fibronectin, $\mathrm{mg} / \mathrm{L}$ & 300 [263-343] & 301 [263-343] & 299 [269-337] & 0.76 \\
\hline 12 weeks assessment & $\mathrm{n}=145$ & $\mathrm{n}=128$ & $\mathrm{n}=17$ & \\
\hline Systolic blood pressure, $\mathrm{mmHg}$ & $113[106-118]$ & $112[106-118]$ & $115[110-120]$ & 0.17 \\
\hline Diastolic blood pressure, $\mathrm{mmHg}$ & $67[62-71]$ & $67[62-71]$ & $66[60-73]$ & 0.96 \\
\hline Mean arterial pressure, $\mathrm{mmHg}$ & $84[78-89]$ & $84[78-89]$ & 85 [81-91] & 0.47 \\
\hline Cardiac output, L/min & $5.4[4.9-6.3]$ & $5.4[4.8-6.3]$ & $5.4[4.9-6.4]$ & 0.90 \\
\hline TPVR, dyne $\cdot \mathrm{sec} \cdot \mathrm{cm}^{-5}$ & $1231[1073-1401]$ & 1234 [1064-1408] & $1230[1106-1367]$ & 1.00 \\
\hline Haemoglobin, mmol/L & $7.8[7.5-8.2]$ & $7.8[7.5-8.2]$ & $8.0[7.6-8.2]$ & 0.54 \\
\hline Plasma fibronectin, $\mathrm{mg} / \mathrm{L}$ & 307 [266-361] & $308[268-361]$ & 304 [260-363] & 0.91 \\
\hline Mean PI uterine arteries & $1.72[1.21-2.16]$ & $1.72[1.22-2.16]$ & $1.75[1.02-2.14]$ & 0.68 \\
\hline Suboptimal adjustments & $110 / 145(76 \%)$ & $96 / 128(75 \%)$ & $14 / 17(82 \%)$ & 0.76 \\
\hline Start Labetalol & $17 / 110(15 \%)$ & $13 / 96(14 \%)$ & $4 / 14(29 \%)$ & \\
\hline Methyldopa & $85 / 110(77 \%)$ & $76 / 96(79 \%)$ & $9 / 14(64 \%)$ & \\
\hline or add Nifedipine ${ }^{\star}$ & $8 / 110(7 \%)$ & $7 / 96(7 \%)$ & $1 / 14(7 \%)$ & \\
\hline 16 weeks assessment & $n=153$ & $n=134$ & $\mathrm{n}=19$ & \\
\hline Systolic blood pressure, $\mathrm{mmHg}$ & 109 [103-115] & $108[102-114]$ & $115[109-121]$ & $<0.01$ \\
\hline Diastolic blood pressure, $\mathrm{mmHg}$ & $62[58-68]$ & $62[58-67]$ & $65[58-72]$ & 0.21 \\
\hline Mean arterial pressure, $\mathrm{mmHg}$ & $80[76-85]$ & $79[76-84]$ & 86 [79-90] & $<0.01$ \\
\hline Cardiac output, L/min & $5.7[5.1-6.6]$ & $5.8[5.0-6.7]$ & $5.5[5.3-6.0]$ & 0.60 \\
\hline TPVR, dyne $\cdot \mathrm{sec} \cdot \mathrm{cm}^{-5}$ & $1120[996-1246]$ & $1108[981-1241]$ & 1181 [1109-1322] & 0.03 \\
\hline Haemoglobin, mmol/L & $7.5[7.3-7.9]$ & $7.5[7.3-7.9]$ & $7.7[7.3-8.1]$ & 0.28 \\
\hline Plasma fibronectin, mg/L & 306 [258-360] & 306 [258-359] & 324 [256-369] & 0.67 \\
\hline Mean PI uterine arteries & $1.29[1.02-1.62]$ & $1.24[1.02-1.58]$ & $1.46[0.96-2.06]$ & 0.22 \\
\hline Suboptimal adjustments & $70 / 153(46 \%)$ & $57 / 134(43 \%)$ & $13 / 19(68 \%)$ & 0.03 \\
\hline Start or add Labetalol & $11 / 70(16 \%)$ & $9 / 57(16 \%)$ & $2 / 13(15 \%)$ & \\
\hline Methyldopa & $49 / 70(70 \%)$ & $40 / 57(70 \%)$ & $9 / 13(69 \%)$ & \\
\hline Nifedipine & $10 / 70(14 \%)$ & $8 / 57(14 \%)$ & $2 / 13(15 \%)$ & \\
\hline 20 weeks assessment & $n=156$ & $\mathrm{n}=137$ & $\mathrm{n}=19$ & \\
\hline Systolic blood pressure, $\mathrm{mmHg}$ & $108[103-114]$ & $107[102-113]$ & $114[111-119]$ & $<0.01$ \\
\hline Diastolic blood pressure, $\mathrm{mmHg}$ & $62[58-66]$ & $62[58-65]$ & $64[58-70]$ & 0.15 \\
\hline
\end{tabular}


Table S1. (continued)

\begin{tabular}{|c|c|c|c|c|}
\hline Characteristics & Total & $\begin{array}{l}\text { Non-recurrent } \\
\text { preeclampsia }\end{array}$ & $\begin{array}{l}\text { Recurrent } \\
\text { preeclampsia }\end{array}$ & P-value \\
\hline Mean arterial pressure, $\mathrm{mmHg}$ & $80[75-83]$ & $79[75-82]$ & $83[79-90]$ & 0.01 \\
\hline Cardiac output, L/min & $5.8[5.3-6.8]$ & $5.8[5.3-6.9]$ & $5.8[5.1-6.3]$ & 0.52 \\
\hline TPVR, dyne $\cdot \mathrm{sec} \cdot \mathrm{cm}^{-5}$ & $1090[947-1219]$ & $1080[937-1215]$ & 1103 [1022-1253] & 0.17 \\
\hline Haemoglobin, mmol/L & $7.3[7.1-7.6]$ & $7.3[7.0-7.6]$ & $7.4[7.2-7.8]$ & 0.59 \\
\hline Plasma fibronectin, $\mathrm{mg} / \mathrm{L}$ & 287 [252-344] & $286[252-342]$ & 305 [248-357] & 0.07 \\
\hline Mean PI uterine arteries & $1.06[0.84-1.41]$ & $1.05[0.84-1.32]$ & $1.54[0.83-1.81]$ & 0.08 \\
\hline Suboptimal adjustments & $51 / 156(33 \%)$ & $41 / 137(30 \%)$ & $10 / 19(53 \%)$ & 0.05 \\
\hline Start or add Labetalol & $11 / 51(22 \%)$ & $10 / 41(24 \%)$ & $1 / 10(10 \%)$ & \\
\hline Methyldopa & $35 / 51(65 \%)$ & $29 / 41(71 \%)$ & $6 / 10(60 \%)$ & \\
\hline Nifedipine & $5 / 51(10 \%)$ & $2 / 41(5 \%)$ & $3 / 10(30 \%)$ & \\
\hline 30 weeks assessment & $n=155$ & $n=137$ & $\mathrm{n}=18$ & \\
\hline Systolic blood pressure, $\mathrm{mmHg}$ & $110[104-117]$ & $110[104-116]$ & $121[113-129]$ & $<0.01$ \\
\hline Diastolic blood pressure, $\mathrm{mmHg}$ & $64[60-69]$ & $63[60-68]$ & $67[64-75]$ & $<0.01$ \\
\hline Mean arterial pressure, $\mathrm{mmHg}$ & $81[77-86]$ & $81[77-86]$ & 89 [82-95] & $<0.01$ \\
\hline Cardiac output, L/min & $5.9[5.3-6.5]$ & $5.9[5.3-6.6]$ & $5.9[5.4-6.2]$ & 0.59 \\
\hline TPVR, dyne $\cdot \mathrm{sec} \cdot \mathrm{cm}^{-5}$ & 1120 [967-1252] & 1110 [959-1224] & 1220 [1124-1395] & 0.01 \\
\hline Haemoglobin, mmol/L & $7.1[6.7-7.4]$ & $7.1[6.7-7.5]$ & $7.2[6.8-7.4]$ & 0.47 \\
\hline Plasma fibronectin, $\mathrm{mg} / \mathrm{L}$ & 312 [261-370] & $308[258-357]$ & 371 [311-489] & $<0.01$ \\
\hline Mean PI uterine arteries & $0.82[0.68-0.94]$ & $0.80[0.68-0.93]$ & $0.94[0.72-1.51]$ & 0.05 \\
\hline Suboptimal adjustments & $55 / 155(35 \%)$ & $44 / 137(32 \%)$ & $11 / 18(61 \%)$ & 0.02 \\
\hline Start or add Labetalol & $25 / 55(45 \%)$ & $20 / 44(45 \%)$ & $5 / 11(45 \%)$ & \\
\hline Methyldopa & $26 / 55(47 \%)$ & $21 / 44(48 \%)$ & $5 / 11(45 \%)$ & \\
\hline Nifedipine & $4 / 55(7 \%)$ & $3 / 44(7 \%)$ & $1 / 11(9 \%)$ & \\
\hline
\end{tabular}

*In general, nifedipine was only initiated in women already using a centrally acting sympatholytic agent.

Data are presented as median [interquartile range] or number/valid measurements (percentage in group).

TPVR indicates total peripheral vascular resistance; PI, pulsatility index 




\title{
ACCURACY AND PRECISION OF USCOM VERSUS TRANSTHORACIC ECHOCARDIOGRAPHY BEFORE AND DURING PREGNANCY.
}

\author{
Eva G. Mulder \\ Shumalla Basit \\ Jolien Oben \\ Sander M.J. van Kuijk \\ Chahinda Ghossein-Doha \\ Marc E.A. Spaanderman
}

Pregnancy Hypertens. 2019 July;17:138-143. doi: 10.1016/j.preghy.2019.04.003. 


\section{ABSTRACT}

Objective: Monitoring hemodynamic status throughout pregnancy may help in identifying women with maladaptation predisposing to hypertensive complications. The Ultrasonic Cardiac Output Monitor (USCOM) is an easy-to-operate device for measuring cardiac output (CO) quickly. Our aim was to assess agreement between USCOM and transthoracic echocardiography (TTE) in: 1) non-pregnant women to correct for possible sources of discrepancy; 2) women longitudinally over the course of the pregnancy.

Study design: High-risk women admitted for cardiovascular risk factor evaluation before pregnancy and multiple times during pregnancy, were included. CO was measured by TTE directly followed by USCOM measurements.

Main outcome measures: Bias, limits of agreement (LOA) and percentage error between the two methods by Bland-Altman analysis.

Results: Despite comparable non-pregnant CO levels (4.6 L/min), LOA and percentage error between the two methods improved moderately by optimizing the measurements using only the highest quality USCOM recordings in 132 non-pregnant women (percentage error of 39\% and 30\%, respectively). During pregnancy, in total 83, 106, 96 and 77 measurements were evaluated at respectively 12-, 16-, 20- and 30-weeks' gestational age. Mean CO in USCOM was about $0.6 \mathrm{~L} / \mathrm{min}$ higher compared to TTE in all trimesters; percentage error ranged from $35 \%$ to $45 \%$. Linear mixed model analysis showed no association between bias and moment of measurement.

Conclusion: Agreement between USCOM and TTE in pregnancy was outside our a priori determined level of acceptability and therefore absolute values of USCOM and TTE cannot be used interchangeably. Future research should focus on the agreement of USCOM and TTE in clinical decision-making.

Keywords: Cardiac output, Hemodynamics, Echocardiography, Heart, Pregnancy, Measurement techniques comparison 


\section{INTRODUCTION}

During pregnancy, the maternal cardiovascular system undergoes major changes, including increases in blood volume, stroke volume (SV) and heart rate (HR), and an accompanying increase in cardiac output (CO). ${ }^{1-3}$ During pregnancy, hypertensive complications and foetal growth restriction are often preceded by deviant hemodynamic adaptation. ${ }^{4}$ Women who develop gestational hypertension often have a higher CO accompanied by low peripheral vascular resistance early in pregnancy, while in earlyonset preeclampsia, low first trimester $\mathrm{CO}$ and elevated peripheral vascular resistance is seen. ${ }^{5-8}$ In the case of impaired foetal growth, a limited initial increase in maternal CO parallel to a restricted fall in peripheral resistance is often observed. ${ }^{9,10}$ Therefore, determining hemodynamic status early in pregnancy may be helpful in identifying women at risk for complications. ${ }^{11,12}$ It may improve our intervention and prevention possibilities, thereby reducing the high maternal and foetal morbidity and mortality of hypertensive disorders and impaired foetal growth. ${ }^{13}$ Moreover, classifying maternal hemodynamic parameters when gestational hypertensive complications occur may indicate corrective measures, directed to a more tailored choice in antihypertensive medication. ${ }^{14,15}$

The gold standard for CO measurement is the pulmonary artery catheter method. However, the invasiveness of the procedure and associated risks of injury and infection make longitudinal and outpatient use impossible. Transthoracic echocardiography (TTE) is a non-invasive alternative that has been widely used in regular practice. In pregnant populations, TTE can be used as a reference method for the validation of $\mathrm{CO}$ measuring techniques. ${ }^{16}$ Although many specialized centres optimised their accessibility to TTE, it is still not standardly available in all obstetrics departments. Moreover, this method is labour-intensive, expertise-dependent and results are not readily available. The Ultrasonic Cardiac Output Monitor (USCOM) is a non-invasive method using continuous wave Doppler ultrasound to determine CO. No additional costs are incurred after purchase, and the device is compact and portable, making it possible to measure $\mathrm{CO}$ at the bedside with results immediately available. The skills required to perform measurements with USCOM are quickly acquired when compared to TTE.

Previous studies have shown poor agreement between USCOM and TTE in non-pregnant and postpartum individuals. ${ }^{17,18}$ In the study by Nguyen et al., increased discrepancy between the two methods could have been introduced by including both adults and children. ${ }^{17}$ Estimated valve area based on height, as is applied in the USCOM device, could be a contributing source of error. For $\mathrm{CO}$ monitoring purposes, it might be profitable to measure valve diameter once by TTE, and use it for subsequent efficient USCOM follow-up measurements. ${ }^{19}$ 
Two studies have cross-sectionally determined the accuracy of USCOM compared with TTE in pregnant women. ${ }^{18,20}$ Both studies report higher $\mathrm{CO}$ values when measured by USCOM, and only in the third trimester, agreement between the two methods was close to the proposed level for clinical acceptability when comparing CO monitors. ${ }^{21}$ The cross-sectional study design did not allow to check whether the difference in readings of two methods is consistent when measured multiple times during pregnancy.

In this study, we aimed to quantify the accuracy and precision of TTE and USCOM for measuring $\mathrm{CO}$ in: 1) non-pregnant women to correct for possible sources of discrepancy; and 2) pregnant women over the course of pregnancy, measured longitudinally at defined time points of gestational age.

\section{METHODS}

The hospital medical ethical committee of the Maastricht University Medical Centre (MUMC) approved the study protocol (MEC azM/UM 14-4-118). Individually informed consent related to the use of clinically acquired data for scientific analysis was obtained, as is customary in the MUMC. Participants were recruited from a standard monitoring programme that has been running since 2014 at the Department of Obstetrics. In this ongoing programme, high-risk non-pregnant women structurally undergo cardiovascular measurements in a single assessment, and again during their subsequent pregnancy around 12, 16, 20 and 30 weeks ( \pm 1 week) of gestational age. High risk is defined as having pre-existent hypertension, diabetes mellitus, an auto-immune disease or a previous pregnancy complicated by hypertension, preeclampsia, HELLP syndrome, eclampsia and/or related foetal complications, including delivery of a small for gestational age (SGA) neonate, stillbirth or placental abruption. The aim of the preconception assessment is to determine underlying disorders and risk factors that contribute to the development of pregnancy complications and cardiovascular disease, and to advise on preventive measures. The aim of the assessments during pregnancy is to monitor cardiovascular adaptation to pregnancy and to adjust maladaptation with medication in order to the reduce risk of complications. Data on obstetric outcomes of pregnancies were obtained from medical files after delivery. The effect of pharmaceutical correction of maladaptation as intervention was not the scope of this study. Women with congenital or acquired heart valve disease were excluded from the analysis.

Measurements of hemodynamic parameters were performed in one morning session and USCOM measurements parallel to TTE measurements were introduced in the period July 2015 through to December 2017. Arterial blood pressure was measured in 
sitting position on the left arm at a 3-minute interval by a semiautomatic oscillometric device (Dinamap Vital Signs Monitor 1846; Critikon, Tampa, FL). The median value of 11 measurements was reported. TTE was performed in all women, directly followed by USCOM measurements in triplicate. These examinations were performed by a single experienced cardiac sonographer (J.O.) to assure accuracy and consistency, and to avoid inter-observer variation.

TTE was performed according to the American Society of Echocardiography guidelines using a commercially available phased-array echocardiographic Doppler system (iE33 system with S5-1 or X5-1 transducers, Philips Medical Systems, Best, the Netherlands). ${ }^{22}$ As per recommendations, all images were acquired in left lateral position, after $10 \mathrm{~min}$ utes of rest to ensure stable hemodynamic variables and timed at the end of expiration. Images were recorded as ECG-gated digital loops and stored for offline analysis. Data on hemodynamic parameters were collected and analysed offline using specific software (Xcelera, Philips, Best, the Netherlands) after completing all measurements. Outflow tract diameter (OTD) and velocity time integrals (VTI) were measured at the level of the aortic annulus. HR was calculated by measuring the time interval between two consecutive R peaks on the ECG. SV was calculated using the following formula: $\mathrm{SV}=\pi(\mathrm{OTD} / 2)^{2 \star} \mathrm{VTI}$; three VTI traces were used to determine SV. CO was calculated as $\mathrm{CO}=\mathrm{HR}^{\star} \mathrm{SV}$. TTE measurements with low image quality were excluded for the analysis. To determine reproducibility, images on CO were acquired in duplicate for 24 women, with a few minutes rest in left lateral position in between.

USCOM (Ultrasonic Cardiac Output Monitor, USCOM Ltd, Sydney, Australia) measurements were performed standardized in supine position. Hemodynamic parameters were determined by placing the 3.3-MHz transducer in the suprasternal notch directing caudally towards the aortic valve where blood flow through the valve can be measured. According to the manufacturer's instructions, the systolic Doppler profile was optimized through small angulations of the probe in order to achieve the highest velocity and greatest spectral intensity with a clear systolic beginning and end, full systolic timing, and sharp peaks. All measurements were displayed and analysed in the flow trace modus, including all VTI complexes displayed on the screen. Singular flows that were traced inadequately were deselected offline. All measurements with USCOM were individually scored by a single researcher (S.B.), blinded to the TTE measurements, using the Fremantle criteria, a 6-point score system to assess the quality of images. ${ }^{23}$ The first collected image per subject with a Fremantle score of $\geq 4$ was included in the analysis. To determine reproducibility, multiple measurements of women with a Fremantle score of $\geq 4$ were analysed. Overall, the first twenty examinations whereof aim was to gain assessment competence were excluded from analysis, as proposed by Dey et al. ${ }^{23}$ 


\section{Statistical analyses}

In both groups of women, agreement between USCOM and TTE was determined by using the Bland-Altman method, as it measures the extent of deviation from the line of complete agreement between the two methods. ${ }^{24}$ The Bland-Altman graph was constructed by plotting the difference of USCOM and TTE values for each subject against the average of both measurements. Moreover, for $\mathrm{CO}$ and each component that defines $\mathrm{CO}$-including SV, OTD, VTI and HR- mean difference (bias), precision (SD of mean difference), limits of agreement (LOA, bias $\pm 1.96 \mathrm{SD})$ and the percentage of error $\left(100{ }^{*} 1.96 \mathrm{SD} /\right.$ mean value) were determined. As suggested by Critchley et al., a threshold of $<30 \%$ for percentage error was defined as acceptable. ${ }^{21}$ In order to detect potential proportional bias (i.e. the mean difference related to the magnitude of measurement), the difference of the two methods was regressed on the average of the two methods.

In non-pregnant women, we repeated the analysis with only high-quality USCOM measurements (Fremantle score $>5$ ), and incorporated the measured OTD in the USCOM formula for $\mathrm{CO}$ to assess whether better agreement was obtained by minimizing the influence of an estimated OTD. For the longitudinal data of the pregnant women, a linear mixed-effects regression analysis was performed to assess the association between the average difference in $\mathrm{CO}$ measured by the two methods and the moment of measurement. The linear mixed-effects regression accounts for the clustering of multiple measures within each patient (i.e., the longitudinal measurements). Reliability of both TTE and USCOM was assessed by scatterplots and by calculating the intra-class correlation coefficient for repeated measurements. IBM SPSS version 21.0 was used for calculations and statistical analysis.

\section{RESULTS}

\section{Non-pregnant participants}

A total of 172 eligible non-pregnant women were enrolled in this study. Eight participants $(4.7 \%)$ were excluded from analysis due to inadequate TTE measurements and 32 women (18.6\%) due to poor USCOM image quality (Fremantle score <4). Consequently, data from 132 non-pregnant participants were suitable for analysis. Baseline characteristics of non-pregnant women are presented in Table 1. Figure 1 shows the Bland-Altman plot for $\mathrm{CO}$ in the non-pregnant group. We observed no systematic bias (mean difference $=0.0$ ), and the LOA were -1.8 to $1.8 \mathrm{~L} / \mathrm{min}$. However, the percentage error was 39\%. No proportional bias was detected in the group of non-pregnant women. Replacing the estimated OTD by the measured OTD in USCOM calculations for CO, a bias (LOA) of -0.3 (-1.9 to 1.3 ) L/min was found with a lower percentage error of $36 \%$. In a sub- 
group consisting only of participants with a Fremantle score $\geq 5$ ( $n=103)$, a bias (LOA) of 0.1 (-1.5 to 1.7$) \mathrm{L} / \mathrm{min}$ was seen. Participants with a Fremantle score of $6(n=52)$ showed a bias (LOA) of 0.2 (-1.2 to 1.6) L/min. Percentage error for image qualities scoring $\geq 5$ and 6 were respectively $34 \%$ and $30 \%$ (Table 2 ).

Table 1. Baseline characteristics of non-pregnant women and obstetric outcomes of pregnant women.

\begin{tabular}{|c|c|}
\hline & $\begin{array}{l}\text { Non-pregnant women } \\
n=132\end{array}$ \\
\hline Age, y & $39(9.3)$ \\
\hline Height, cm & $168(7)$ \\
\hline Weight, kg & $73(12)$ \\
\hline Parity & $2[1]$ \\
\hline Systolic blood pressure, mmHg & $114(12)$ \\
\hline Diastolic blood pressure, $\mathrm{mmHg}$ & $71(8)$ \\
\hline \multirow[t]{2}{*}{ Mean arterial pressure, $\mathrm{mmHg}$} & $88(9)$ \\
\hline & $\begin{array}{l}\text { Pregnant women } \\
n=139\end{array}$ \\
\hline Gestational age at delivery, w & $38^{2}[13]$ \\
\hline Preterm birth <37 w, n (\%) & $15(11)$ \\
\hline Birthweight & 3095 [749] \\
\hline Birth percentile & $35[47]$ \\
\hline SGA neonate, $\mathrm{n}(\%)$ & $19(14)$ \\
\hline Preeclampsia, n (\%) & $10(7)$ \\
\hline Stillbirth, n (\%) & $2(1)$ \\
\hline Neonatal death, n (\%) & $1(1)$ \\
\hline
\end{tabular}

Data are presented as mean (standard deviation) or as median [interquartile range].

W indicates weeks; $y$, years; cm, centimetres; kg, kilogrammes; SGA, small-for-gestational-age.

Table 2. Agreement of CO between USCOM and TTE in non-pregnant women, with proceedings to optimize measurements

\begin{tabular}{llllll}
\hline & & $\begin{array}{l}\text { All measurements } \\
\mathbf{n = 1 3 2}\end{array}$ & $\begin{array}{l}\text { Measured OTD } \\
\mathbf{n = 1 3 2}\end{array}$ & $\begin{array}{l}\text { Fremantle } \\
\text { score } \mathbf{5} \\
\mathbf{n = 1 0 3}\end{array}$ & $\begin{array}{l}\text { Fremantle } \\
\text { score =6 } \\
\mathbf{n = 5 2}\end{array}$ \\
\hline CO & USCOM & $4.6(0.9)$ & $4.3(1.0)$ & $4.7(0.9)$ & $4.7(0.8)$ \\
\hline (L/min) & TTE & $4.6(0.9)$ & $4.6(0.9)$ & $4.6(0.9)$ & $4.6(0.9)$ \\
& Bias & 0.0 & -0.3 & 0.1 & 0.2 \\
& Precision & 0.9 & 0.8 & 0.8 & 0.7 \\
& Limits of agreement & -1.8 to 1.8 & -1.9 to 1.3 & -1.5 to 1.7 & -1.2 to 1.6 \\
\hline & Percentage error & $39 \%$ & $36 \%$ & $34 \%$ & $30 \%$ \\
\hline
\end{tabular}

Data are presented as mean (standard deviation).

OTD indicates outflow tract diameter; CO, cardiac output; USCOM, Ultrasonic Cardiac Output Monitor; TTE, transthoracic echocardiography. 


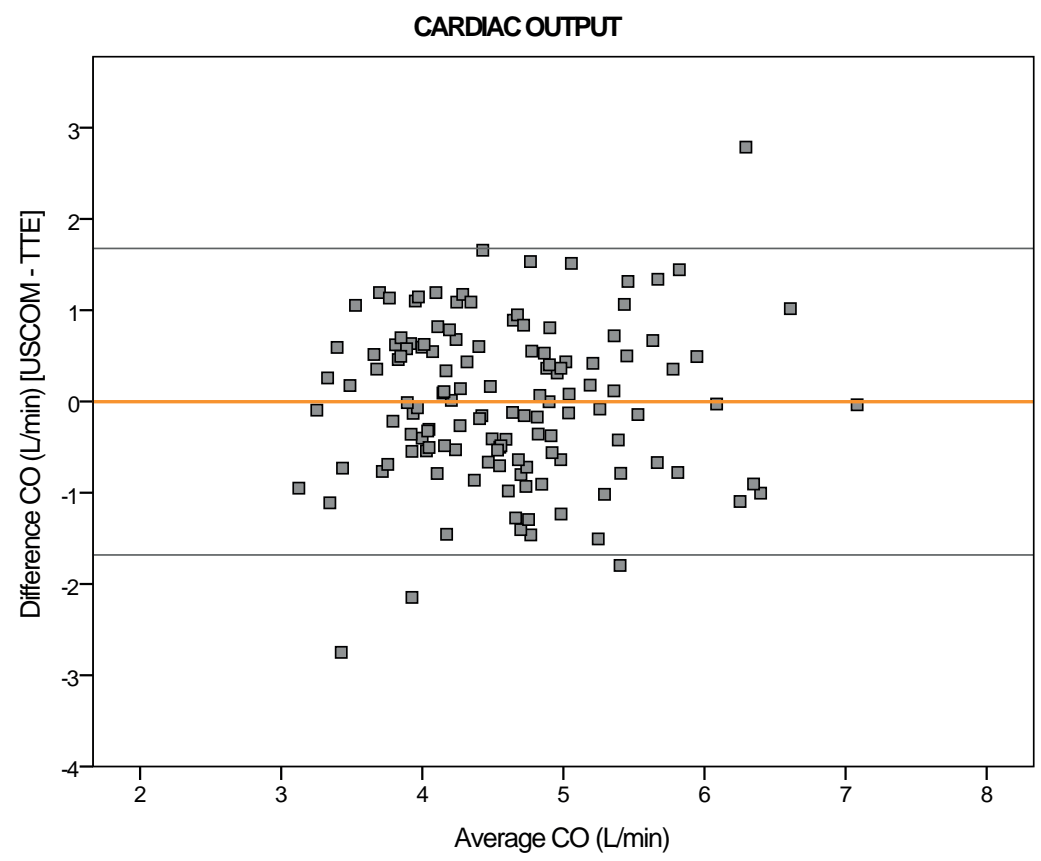

Figure 1. Bland-Altman plot presenting agreement between USCOM and echocardiography (TTE) for cardiac output (CO) in non-pregnant women. The centred line (yellow) presents bias between two methods, and upper and lower lines (blue) indicate the limits of agreement.

\section{Pregnant participants}

139 pregnant women were included, of whom 20 (14\%) were measured once, 27 (19\%) were measured twice, 54 (39\%) were measured three times, and 38 (27\%) were measured four times during pregnancy. The number of pregnant women measured at 12 , 16, 20 and 30 weeks of gestational age was respectively 87, 111, 104 and 86. Obstetric outcomes of pregnant women are presented in Table 1. Women who developed complications during pregnancy were included in the analysis. In all four gestational age groups, one woman was excluded due to poor image quality obtained by TTE. Additionally, due to poor USCOM quality (Fremantle scores <4), we excluded three women $(3.4 \%)$ at 12 weeks of gestation, five women (4.5\%) at 16 weeks of gestation, seven women $(6.7 \%)$ at 20 weeks of gestation, and eight women (9.3\%) at 30 weeks of gestation. There was no difference in the number of poor USCOM quality measurements between groups at different gestational ages $(P=0.356)$. For the comparison between USCOM and TTE, we analysed respectively $83,105,96$, and 77 women at the gestational age of $12,16,20$ and 30 weeks. 
(A) Bland-Altman plot in pregnant women at 12 weeks of gestational age.

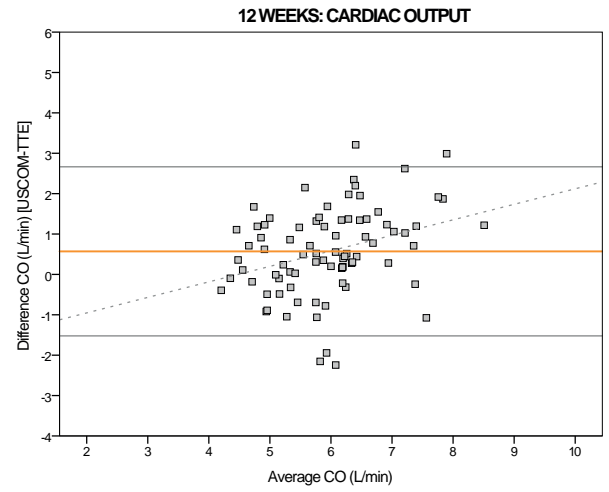

(C) Bland-Altman plot in pregnant women at 20 weeks of gestational age.

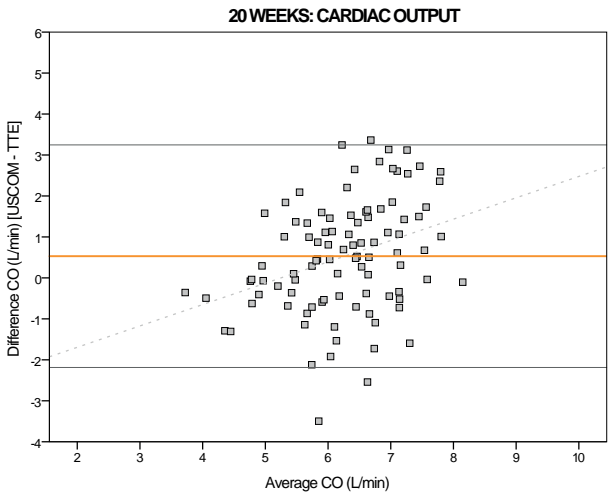

(B) Bland-Altman plot in pregnant women at 16 weeks of gestational age.

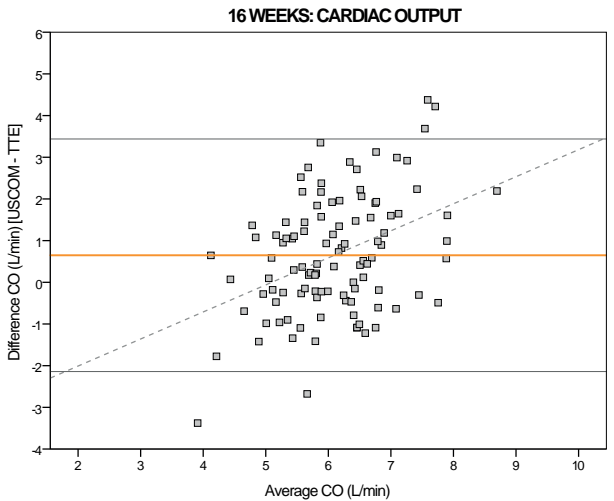

(D) Bland-Altman plot in pregnant women at 30 weeks of gestational age.

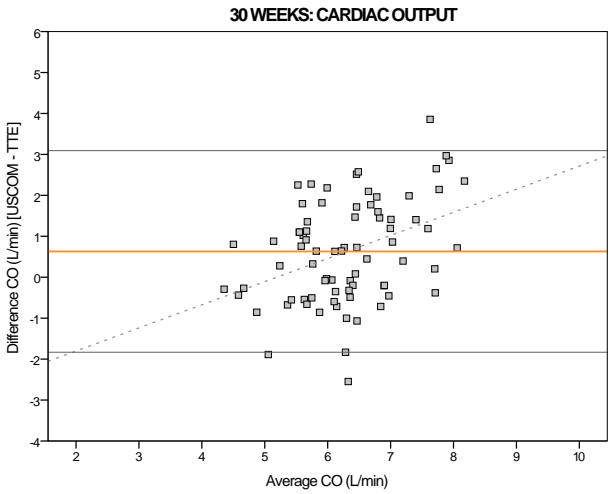

Figure 2 (A-D). Bland-Altman plots presenting agreement between USCOM and transthoracic echocardiography (TTE) for cardiac output (CO) in pregnant women over the course of pregnancy. The centred line (yellow) presents bias between two methods, and upper and lower lines (blue) indicate the limits of agreement. The dotted lines indicate significant proportional bias.

Bland-Altman plots for CO measured at 12, 16, 20 and 30 weeks of gestational age are shown in Figure 2. Results on bias, LOA and percentage error of the variables are presented in Table 3. During pregnancy, CO measured by USCOM was at about $0.6 \mathrm{~L} /$ min higher compared to $\mathrm{CO}$ measurement by TTE. Percentage error of $\mathrm{CO}$ varied between $35 \%$ and $45 \%$, being lowest at 12 weeks of pregnancy, and highest at 16 weeks of pregnancy. Regression analysis showed proportional bias at all gestational age groups, indicating a tendency for USCOM to overestimate higher $\mathrm{CO}$ values and underestimate lower $\mathrm{CO}$ values.

This table is supplemented with mean values and Bland-Altman analysis for variables that determine CO, namely SV, HR, OTD and VTI. Bland-Altman analysis of SV shows 
Table 3. Agreement between USCOM and TTE of cardiac output, and variables that determine cardiac output during pregnancy

\begin{tabular}{|c|c|c|c|c|c|}
\hline & & $\begin{array}{l}12 \text { weeks } \\
n=83\end{array}$ & $\begin{array}{l}16 \text { weeks } \\
n=105\end{array}$ & $\begin{array}{l}20 \text { weeks } \\
n=96\end{array}$ & $\begin{array}{l}30 \text { weeks } \\
n=77\end{array}$ \\
\hline & GA age at measurement & $12^{3}[5]$ & $16^{3}[5]$ & $20^{1}[4]$ & $30^{1}[4]$ \\
\hline & Height, cm & $166(6)$ & $166(6)$ & $167(6)$ & $167(6)$ \\
\hline & Weight, kg & $72(14)$ & $73(14)$ & $75(13)$ & $79(14)$ \\
\hline $\mathrm{CO}$ & USCOM & $6.2(1.2)$ & $6.4(1.3)$ & $6.5(1.3)$ & $6.6(1.3)$ \\
\hline \multirow[t]{5}{*}{ (L/min) } & TTE & $5.7(0.9)$ & $5.8(0.9)$ & $6.0(0.9)$ & $6.0(0.9)$ \\
\hline & Bias & 0.6 & 0.6 & 0.5 & 0.6 \\
\hline & Precision & 1.1 & 1.4 & 1.4 & 1.3 \\
\hline & Limits of agreement & -1.5 to 2.7 & -2.2 to 3.4 & -2.2 to 3.2 & -1.8 to 3.1 \\
\hline & Percentage error & $35 \%$ & $45 \%$ & $43 \%$ & $39 \%$ \\
\hline SV & USCOM & $85(15)$ & $88(17)$ & $89(17)$ & $84(15)$ \\
\hline \multirow[t]{5}{*}{ (ml) } & TTE & $75(10)$ & $77(12)$ & $79(12)$ & $72(11)$ \\
\hline & Bias & 9 & 11 & 10 & 11 \\
\hline & Precision & 15 & 18 & 18 & 15 \\
\hline & Limits of agreement & -21 to 39 & -24 to 46 & -25 to 45 & -19 to 41 \\
\hline & Percentage error & $37 \%$ & $43 \%$ & $42 \%$ & $39 \%$ \\
\hline HR & USCOM & $74(10)$ & $73(9)$ & $74(9)$ & $80(9)$ \\
\hline \multirow[t]{5}{*}{ (bpm) } & TTE & $76(11)$ & $75(9)$ & $77(11)$ & $83(10)$ \\
\hline & Bias & -2 & -2 & -3 & -4 \\
\hline & Precision & 7 & 6 & 6 & 6 \\
\hline & Limits of agreement & -15 to 11 & -14 to 10 & -16 to 10 & -15 to 8 \\
\hline & Percentage error & $17 \%$ & $17 \%$ & $17 \%$ & $14 \%$ \\
\hline OTD & USCOM & $1.91(0.06)$ & $1.91(0.06)$ & $1.92(0.06)$ & $1.92(0.06)$ \\
\hline \multirow[t]{5}{*}{$(\mathrm{cm})$} & TTE & $1.90(0.12)$ & $1.90(0.11)$ & $1.91(0.11)$ & $1.93(0.13)$ \\
\hline & Bias & 0.02 & 0.02 & 0.00 & -0.02 \\
\hline & Precision & 0.12 & 0.11 & 0.11 & 0.13 \\
\hline & Limits of agreement & -0.22 to 0.25 & -0.20 to 0.24 & -0.21 to 0.21 & -0.27 to 0.24 \\
\hline & Percentage error & $12 \%$ & $11 \%$ & $11 \%$ & $13 \%$ \\
\hline VTI & USCOM & $29.6(4.7)$ & $30.6(5.4)$ & $30.7(5.4)$ & $28.9(4.9)$ \\
\hline \multirow[t]{5}{*}{$(\mathrm{cm})$} & TTE & $26.7(3.3)$ & $27.5(4.0)$ & $27.8(4.4)$ & $24.9(3.5)$ \\
\hline & Bias & 2.9 & 3.1 & 2.9 & 4.1 \\
\hline & Precision & 4.0 & 5.1 & 5.6 & 4.5 \\
\hline & Limits of agreement & -4.9 to 10.7 & -6.9 to 13.1 & -8.0 to 13.8 & -4.8 to 12.9 \\
\hline & Percentage error & $28 \%$ & $35 \%$ & $37 \%$ & $33 \%$ \\
\hline
\end{tabular}

Data are presented as mean (standard deviation) or as median [interquartile range]. USCOM indicates Ultrasonic Cardiac Output Monitor; TTE, transthoracic echocardiography; GA, gestational age; y, years; cm, centimetres; kg, kilogrammes; $\mathrm{CO}$, cardiac output; L/min, litres per minute; SV, stroke volume; $\mathrm{ml}$, millilitres; HR, heart rate; bpm, beats per minute; OTD, outflow tract diameter; VTI, velocity time integral 
similar results as compared to $\mathrm{CO}$, with an overestimation when measured with USCOM, and lowest percentage error found early in pregnancy. HR measured with USCOM was on average lower compared to TTE. Linear mixed-effects regression showed no evidence of an association between the difference in $\mathrm{CO}$ by the two methods and moment of measurement $(P=0.874)$.

\section{Method characteristics}

TTE measurements in duplicate showed an intra-class correlation coefficient of 0.86 (95\% Cl 0.71-0.94; $P<0.001)$ and 0.93 (95\% Cl 0.90-0.95; $P<0.001)$ for USCOM.

\section{DISCUSSION}

The aim of this study was to assess accuracy and precision of CO measured with USCOM and TTE before and during pregnancy. Optimizing measurements in non-pregnant women only moderately improved agreement between the methods. Therefore, only unrefined data of pregnant women were used in further analysis. Bland-Altman analyses revealed similar results of bias in pregnant women over the course of the pregnancy, being $0.6 \mathrm{~L} / \mathrm{min}$ higher when measured with USCOM, however, percentage error in all trimesters was higher than clinical acceptability of $30 \%$.

First, we determined whether agreement between the two methods could be improved by optimizing measurements in the non-pregnant population. Estimated OTD based on height by USCOM was replaced by measured OTD by TTE, which could be useful for monitoring purposes. This procedure barely improved percentage error, and precision decreased slightly. Therefore, we would not recommend this procedure to optimize agreement. Similar results of only small improvements in agreement when estimated OTD was replaced was found in a study comparing USCOM with Cardiac Magnetic Resonance and in a study comparing USCOM with thermodilution. ${ }^{19,} 25$ Selecting only high-quality USCOM images (Fremantle score $=6$ ) improved percentage error up to $30 \%$, reaching approximately the clinical level of acceptability. Since only 52 of the 132 measurements (40\%) had this Fremantle score, in clinical practice, this restriction is not feasible.

Percentages of error in pregnant women in our study varied between 35\% and 45\%, which is higher compared to McNamara et al. (percentage of error 33\%) and Vinayagam et al. (percentage of error between $29 \%$ and $38 \%$ ). ${ }^{18,20}$ This might be explained by difference in measurement position. McNamara et al. performed both measurements in left lateral position, while women in our study were shifted from left lateral (TTE) to supine 
position (USCOM), in compliance with manufacturer's instructions. The difference in position in itself and shifting may have induced changes in $\mathrm{CO}$, especially in the third trimester, when the enlarged uterus may compress the inferior vena cava and affect cardiac preload, filling and SV. ${ }^{26}$ Another explanation for the difference in percentage error could be the higher mean CO measured in women by Vinayagam et al. Percentage error is calculated by dividing precision by mean $\mathrm{CO}$, and lower percentages of error could be expected in high CO states. This difference was most pronounced in advanced gestation. All determinants of CO (i.e. SV calculated from VTI and OTD, and HR) had some degree of disagreement. In contrast to McNamara et al. the percentage error of SV was comparable to the percentage error of $\mathrm{CO}$, and we would not recommend assessing this as an independent variable. ${ }^{20}$

This is the first study reporting the difference between TTE and USCOM measurements longitudinally during pregnancy. For valid measures of $\mathrm{CO}$ during pregnancy, it is important that bias is independent from the moment of measurement during pregnancy. We found no evidence that the bias in $\mathrm{CO}$ increases or decreases over the course of pregnancy, taking repeated measurement within individuals into account.

Insight in hemodynamic status early in pregnancy may be helpful in identifying women with deviant adaptation to pregnancy, who are at risk for hypertensive complications and/or growth restriction. ${ }^{10,11}$ Also, information on maternal hemodynamic parameters when hypertensive problems arise may result in a tailored choice of antihypertensive medication. ${ }^{14,15}$ A "point-of-care" device, such as USCOM, should be efficient, cheap and easy to operate. USCOM is portable and results are immediately readable. We showed good intra-observer correlations for USCOM measurements, and good inter-observer correlations have been reported previously. ${ }^{27}$ However, utility in clinical practice greatly depends on useful results, and acceptable quality measurements. In USCOM, only $80 \%$ of the images were of a good quality in the non-pregnant women in our population, which is a significant limitation of the measure. This study showed that exact values of USCOM and TTE cannot be used interchangeably. Biological fluctuations in CO that result from respiration and baroreceptor-mediated cardiac responses might have moderately contributed to the discrepancy between the two methods. Even though measurements with TTE were timed at the end of expiration, a deviation of $20 \%$ of the averaged CO during a complete respiratory cycle cannot be ruled out. ${ }^{28}$ USCOM measurements were not timed within the respiratory cycle. Previous research has shown that repeated CO measurements with thermodilution randomly at different phases of the respiratory cycle substantially affected variation (range of $1.50 \mathrm{~L} / \mathrm{min}$ ) compared with timed repeated measurements (range of $0.47 \mathrm{~L} / \mathrm{min}$ at end-exhalation). ${ }^{29}$ 
Compared to TTE, CO in USCOM is based on more heartbeats and velocity time integral complexes, averaging hemodynamic fluctuations. Ideally, when comparing methods, CO should be measured during a similar period, using many more, but at least a comparable amount of cardiac cycles to enable a more accurate comparison. Lastly, as extensively explained by Cecconi et al., fulfilling the $30 \%$ criteria of clinical acceptability greatly depends on the precision of the reference technique, which appeared to be moderate for TTE. ${ }^{30}$ With a lower precision of the reference measurement, it is more difficult to reach the limit of clinical acceptability for a newly introduced method.

The main strength of our study is the comparison of a new method with a reference method in non-pregnant women, and a broad range of gestational ages in the same women. The possible self-induced biological CO fluctuation through a change in the assessment position was a limitation of our study, as were the untimed USCOM measurements in the respiratory cycle. Moreover, our high-risk population is more likely to have deviant hemodynamic adaptation to pregnancy. Due to the present proportional bias, indicating that $\mathrm{CO}$ is underestimated by USCOM in low $\mathrm{CO}$ values, and overestimated in high CO values, agreement might be more acceptable within the normal range of $\mathrm{CO}$. However, especially women with deviant adaptation to pregnancy might benefit from CO determination, and a method that replaces echocardiography should be able to accurately identify both a limited as well as a marked increase in CO. We would therefore not recommend to study agreement of these methods solely in a low-risk population. Taken the proportional bias into account, USCOM provides a rough estimate of CO (low, moderate, high), only allowing to identify women at higher risk of complications.

\section{CONCLUSION}

Agreement between USCOM and TTE in pregnancy was outside our a priori determined level of acceptability and absolute values of TTE and USCOM should not be used interchangeably. Optimizing USCOM measurements resulted only in limited improvement in agreement between the two methods. Future research should focus on the clinical consequences and decision-making of the measured $\mathrm{CO}$ for the separate techniques. 


\section{REFERENCES}

1. Ouzounian JG and Elkayam U. Physiologic changes during normal pregnancy and delivery. Cardiol Clin 2012; 30: 317-329.

2. Meah VL, Cockcroft JR, Backx K, Shave $\mathrm{R}$ and Stohr EJ. Cardiac output and related haemodynamics during pregnancy: a series of meta-analyses. Heart 2016; 102: 518-526.

3. de Haas S, Ghossein-Doha C, van Kuijk SM, van Drongelen $J$ and Spaanderman ME. Physiological adaptation of maternal plasma volume during pregnancy: a systematic review and meta-analysis. Ultrasound Obstet Gynecol 2017; 49: 177-187.

4. Easterling TR, Benedetti TJ, Schmucker BC and Millard SP. Maternal hemodynamics in normal and preeclamptic pregnancies: a longitudinal study. Obstet Gynecol 1990; 76: 1061-1069.

5. Bosio PM, McKenna PJ, Conroy R and O'Herlihy C. Maternal central hemodynamics in hypertensive disorders of pregnancy. Obstet Gynecol 1999; 94: 978-984.

6. Valensise H, Vasapollo B, Gagliardi G and Novelli GP. Early and late preeclampsia: two different maternal hemodynamic states in the latent phase of the disease. Hypertension 2008; 52: 873-880.

7. Giannubilo SR, Pasculli A, Tidu E, Biagini A, Boscarato $V$ and Ciavattini A. Relationship between maternal hemodynamics and plasma natriuretic peptide concentrations during pregnancy complicated by preeclampsia and fetal growth restriction. J Perinatol 2017; 37: 484-487.

8. Melchiorre K, Sutherland G, Sharma R, Nanni M and Thilaganathan B. Midgestational maternal cardiovascular profile in preterm and term pre-eclampsia: a prospective study. BJOG 2013; 120: 496504.

9. Khaw A, Kametas NA, Turan OM, Bamfo JE and Nicolaides KH. Maternal cardiac function and uterine artery Doppler at 11-14 weeks in the prediction of pre-eclampsia in nulliparous women. BJOG 2008; 115: 369-376.

10. Tiralongo GM, Lo Presti D, Pisani I, Gagliardi G, Scala RL, Novelli GP, et al. Assessment of total vascular resistance and total body water in normotensive women during the first trimester of pregnancy. A key for the prevention of preeclampsia. Pregnancy Hypertens 2015; 5: 193-197.

11. Easterling TR, Brateng D, Schmucker B, Brown Z and Millard SP. Prevention of preeclampsia: a randomized trial of atenolol in hyperdynamic patients before onset of hypertension. Obstet Gynecol 1999; 93: 725-733.

12. Ferrazzi E, Stampalija T, Monasta L, Di Martino D, Vonck $S$ and Gyselaers W. Maternal hemodynamics: a method to classify hypertensive disorders of pregnancy. Am J Obstet Gynecol 2018; 218: 124 e121-124 e111.

13. Abalos E, Cuesta C, Grosso AL, Chou D and Say L. Global and regional estimates of preeclampsia and eclampsia: a systematic review. Eur J Obstet Gynecol Reprod Biol 2013; 170: 1-7.

14. Valensise H, Vasapollo B, Novelli GP, Pasqualetti P, Galante A and Arduini D. Maternal total vascular resistance and concentric geometry: a key to identify uncomplicated gestational hypertension. BJOG 2006; 113: 1044-1052.

15. Lees $C$ and Ferrazzi E. Relevance of Haemodynamics in Treating Pre-eclampsia. Curr Hypertens Rep 2017; 19: 76.

16. Cornette J, Laker S, Jeffery B, Lombaard $\mathrm{H}$, Alberts A, Rizopoulos D, et al. Validation of maternal cardiac output assessed by transthoracic echocardiography against pulmonary artery catheterization in severely ill pregnant women: prospective comparative study and systematic review. Ultrasound Obstet Gynecol 2017; 49: 25-31. 
17. Nguyen HB, Banta DP, Stewart G, Kim $\mathrm{T}$, Bansal R, Anholm J, et al. Cardiac index measurements by transcutaneous Doppler ultrasound and transthoracic echocardiography in adult and pediatric emergency patients. J Clin Monit Comput 2010; 24: 237-247.

18. Vinayagam D, Patey $\mathrm{O}$, Thilaganathan $\mathrm{B}$ and Khalil A. Cardiac output assessment in pregnancy: comparison of two automated monitors with echocardiography. Ultrasound Obstet Gynecol 2017; 49: 32-38.

19. Van den Oever HL, Murphy EJ and ChristieTaylor GA. USCOM (Ultrasonic Cardiac Output Monitors) lacks agreement with thermodilution cardiac output and transoesophageal echocardiography valve measurements. Anaesth Intensive Care 2007; 35: 903-910.

20. McNamara H, Barclay $\mathrm{P}$ and Sharma V. Accuracy and precision of the ultrasound cardiac output monitor (USCOM 1A) in pregnancy: comparison with three-dimensional transthoracic echocardiography. $\mathrm{Br}$ J Anaesth 2014; 113: 669-676.

21. Critchley LA and Critchley JA. A metaanalysis of studies using bias and precision statistics to compare cardiac output measurement techniques. J Clin Monit Comput 1999; 15: 85-91.

22. Mitchell C, Rahko PS, Blauwet LA, Canaday $B$, Finstuen JA, Foster MC, et al. Guidelines for Performing a Comprehensive Transthoracic Echocardiographic Examination in Adults: Recommendations from the American Society of Echocardiography. J Am Soc Echocardiogr 2018

23. Dey I and Sprivulis P. Emergency physicians can reliably assess emergency department patient cardiac output using the USCOM continuous wave Doppler cardiac output monitor. Emerg Med Australas 2005; 17: 193-199.
24. Bland JM and Altman DG. Statistical methods for assessing agreement between two methods of clinical measurement. Lancet 1986; 1: 307-310.

25. Trinkmann F, Doesch C, Papavassiliu T, Weissmann J, Haghi D, Gruettner J, et al. A novel noninvasive ultrasonic cardiac output monitor: comparison with cardiac magnetic resonance. Clin Cardiol 2010; 33: E8-14.

26. Clark SL, Cotton DB, Pivarnik JM, Lee W, Hankins GD, Benedetti TJ, et al. Position change and central hemodynamic profile during normal third-trimester pregnancy and post partum. Am J Obstet Gynecol 1991; 164: 883-887.

27. Kager CC, Dekker GA and Stam MC. Measurement of cardiac output in normal pregnancy by a non-invasive two-dimensional independent Doppler device. Aust $N$ Z J Obstet Gynaecol 2009; 49: 142-144.

28. Jansen JR, Schreuder JJ, Settels JJ, Kloek JJ and Versprille A. An adequate strategy for the thermodilution technique in patients during mechanical ventilation. Intensive Care Med 1990; 16: 422-425.

29. Stevens JH, Raffin TA, Mihm FG, Rosenthal $\mathrm{MH}$ and Stetz CW. Thermodilution cardiac output measurement. Effects of the respiratory cycle on its reproducibility. JAMA 1985; 253: 2240-2242.

30. Cecconi M, Rhodes A, Poloniecki J, Della Rocca G and Grounds RM. Benchto-bedside review: the importance of the precision of the reference technique in method comparison studies--with specific reference to the measurement of cardiac output. Crit Care 2009; 13: 201. 



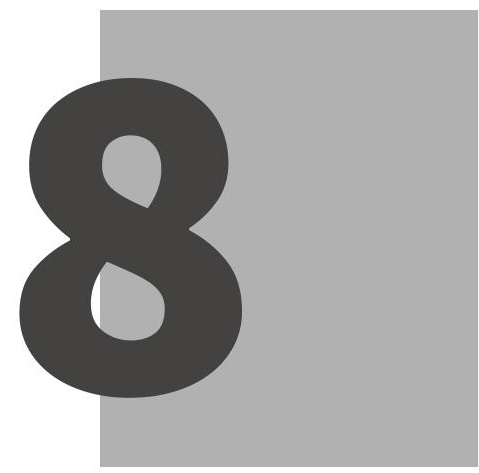

General discussion 

The syndrome of preeclampsia complicates 3-5\% of all pregnancies. In the short term, it is a leading cause of maternal and neonatal mortality and morbidity in the Western world. Remotely, preeclampsia associates with early development of cardiovascular and metabolic diseases in affected women and their offspring. In favour of women's and offspring's health, preventing preeclampsia and managing its postpartum sequalae are of great importance. In-depth insight in pathogenetic processes that contribute to the development of this gestational complication might provide clues for personalized preventive measures and targeted treatment.

Vascular complications in pregnancy are preceded by different cardiovascular stages. A prepregnant risk status predisposes to abnormal cardiovascular adjustments to pregnancy, that are followed by an increasing loss in maternal and placental reserve capacity, sympathetic system dominated maintenance of blood pressure, ultimately leading to preeclampsia. This thesis focusses on pre-pregnancy hemodynamic performance and the subsequent adjustments to pregnancy, and its crucial role in the development of hypertension and preeclampsia. Heterogeneous patterns of deviant hemodynamic adjustments are associated with hypertensive complications of pregnancy. However, even in high-risk women, hemodynamic assessment in addition to blood pressure measurements throughout gestation are not routinely performed. This might be due to the absence of physiologic reference values over the course of pregnancy, the lack of clinical evidence of effectiveness of hemodynamic-guided treatment in women at risk and the lack of optimal measurement methods for this purpose. Elucidations on these limiting factors are explored in this thesis. The first chapters underscore the necessity of preventive measures by presenting the postpartum consequences of preeclampsia and the limited improvement of recurrent rates over the last two decades.

\section{Results of preventing recurrent preeclampsia in the past two decades}

Incidences of recurrent preeclampsia range from 7 to $80 \%$, depending on studied populations., ${ }^{3,4}$ The risk of recurrent preeclampsia relates to severity of complications in the first pregnancy and underlying maternal cardiovascular and cardiometabolic risk factors..$^{4-7}$ In contrast to our expectations, we did not find a decreased incidence of recurrent preeclampsia and related maternal complications in the past two decades, even though, in contrast to older guidelines, current guidelines advocate preventive use of aspirin and calcium. In population-based studies, such a finding might be explained by the consistent rise in prevalence of maternal constitutional risk factors for preeclampsia and advanced maternal age. ${ }^{8,9}$ In our study, we were able to adjust for the presence of pre-pregnancy underlying cardiovascular and cardiometabolic risk factors and gestational preventive measures, because all women underwent a risk factor assessment at comparable time after their first complicated pregnancy and in all women the use 
of above mentioned preventive measures were evaluated. Later onset of preeclampsia could be another measure reflecting improved health care, which was additionally evaluated in our study, but the gestational age at onset of recurrent disease did not change over the past two decades. Also, trends of earlier elective delivery may have masked an even higher incidence of preeclampsia that could have developed in case pregnancy was prolonged. ${ }^{10}$ The HYPITAT trial showed advantages of labour induction at 37 weeks of gestational age, instead of watchful waiting in pregnancies complicated by hypertension. ${ }^{11}$ As this study ran in about a quarter of all hospitals in the Netherlands, induction of labour in case of hypertension at term was rapidly implemented throughout the country in the last decade.

A population-based study in Norway between 1973 and 2012 showed a reduction of recurrent early preterm preeclampsia from 1993 onwards, attributed to the introduction of prophylaxis with daily low-dose aspirin during the subsequent pregnancy. ${ }^{12}$ This was only advised to women with a history of early-onset preeclampsia. As a consequence, women with a history of late preterm and term preeclampsia were neither advised to take preventive medication nor showed a reduction in recurrence rate. Nowadays, the advantageous effect of timely instituted daily low-dose aspirin on preeclampsia is evidenced, regardless of the risk level of women, although the number needed to treat for one woman to benefit is high (>60 in the overall population). ${ }^{13}$ Another generic beneficial preventive measure during pregnancy, calcium supplementation, reduces the risk of preeclampsia, but the effect varies with dietary calcium intake. ${ }^{14}$ In the consultation after the non-pregnant risk factor assessment, all women in our study were advised to take daily low-dose aspirin and calcium supplementation during their subsequent pregnancy. Preventive measures had effect, but even when correcting for these factors, this did not affect the general recurrence rate. The low adherence was remarkable: only $60 \%$ and $28 \%$ of women in our study reported to have taken aspirin and calcium, respectively. Similar limited aspirin usage in a high-risk population was noticed in the early 2000s across the United Kingdom. ${ }^{15}$ It might be that physicians who provided perinatal care during the next pregnancy were reserved in prescribing this measure in absence of recommendations in national guidelines, especially in women with a history of late-onset preeclampsia. Future rates of incident and recurrent preeclampsia could be improved by incorporating general preventive measures in the national guidelines, not limited to selected highest risk populations.

\section{Maternal adjustments during pregnancy}

Healthy pregnancy is accompanied by major hemodynamic changes that later benefit and preserve sufficient uteroplacental circulation. A drop in systemic vascular resistance during the first trimester triggers several compensatory mechanisms to maintain 
blood pressure, amongst an increase in plasma volume and cardiac output. ${ }^{16,17}$ One of our aims was to provide detailed insight into the magnitude and moment of healthy hemodynamic changes during normotensive pregnancies, and to construct reference curves of hemodynamic parameters for normotensive gestation by performing a systematic review and meta-analysis. Our results showed that during normotensive pregnancies, cardiac output started to increase from the first trimester onwards, reaching its maximum in the early third trimester. In parallel, total peripheral vascular resistance substantially decreased in the first trimester, and reached its minimum between 22 and 28 weeks of gestation after which it slightly increased until term. The initial increase in cardiac output in normotensive pregnancy results from an increase in both heart rate and stroke volume. ${ }^{17,18}$ Nonetheless, we observed that heart rate steadily increased over de course of pregnancy, while the rise in stroke volume attenuated in the second half of the pregnancy, and at term, stroke volume was no longer different from nonpregnant women. This may be the resultant of several factors. First, preload might be hampered because the enlarged uterus compresses the inferior vena cava at the end of pregnancy. ${ }^{19,20}$ Second, a higher heart rate decreases the diastolic period, which may impair filling of the left ventricle. ${ }^{21}$ Third, cardiac remodelling during pregnancy may reduce compliance of the extensively stretched sarcomeres, which could reduce stroke volume. $^{22}$ The latter is only valid when end-diastolic filling is substantially increased.

The specific mechanisms and vasodilators contributing to the reduction in vascular resistance are not yet completely unravelled. There appears to be a role for the secretory products of the corpus luteum, amongst progesterone, oestrogen and relaxin, as functionally supported by similar cardiovascular changes to take place in the luteal phase of the menstrual cycle, and cardiovascular changes that are attenuated in in vitro fertilization pregnancies without a corpus luteum. ${ }^{23,24}$ This hormonal environment is paralleled by a first trimester rise in arterial compliance along with decreased general vascular tone, followed by decreased vascular responsiveness to vasoconstrictors (especially angiotensin II and norepinephrine), increased sensitivity to vasodilatory substances, and the functional opening of maternal protective regulatory micro-circulatory and placental arterio-venous shunts. ${ }^{25-28}$ The resulting first trimester relative circulatory underfill is counterbalanced by activation of the renin-angiotensin-aldosterone system, which stimulates renal volume retention that expands plasma volume, supporting a rise in stroke volume and therewith cardiac output. ${ }^{23,29}$ Plasma volume expansion leads to dilutional anaemia, which additionally may reduce total peripheral vascular resistance by reducing blood viscosity. ${ }^{30,31}$ Marked sympathetic activation in favour of elevated inotropy and chronotropy may be a compensatory mechanism to maintain blood pressure at pre-pregnancy levels, although resetting of baroreceptor sensitivity and reduction of 
neurovascular transduction in pregnancy blunts the effect of sympathetic regulation on arterial blood pressure. ${ }^{32-35}$

The compensatory central hemodynamic mechanisms of healthy pregnancy seem to be compromised in gestational hypertensive diseases. In our meta-analysis, we observed that, on top of a higher prepregnant cardiac output, the initial increase in cardiac output to be greater in later developing hypertensive complications than the increase observed in normotensive evolving pregnancies. The excessive rise predominantly originates from an increased heart rate rather than stroke volume, because the latter did not significantly change compared to non-pregnant values. Also, total peripheral vascular resistance did not substantially decrease in any trimester in women who eventually developed hypertensive complications. Despite these aggregated findings, previous longitudinal studies have shown that heterogeneous deviant hemodynamic changes precede hypertensive complications. Late-onset preeclampsia, typically with normal foetal growth, is headed by an exaggerated early-rise in cardiac output, whereas earlyonset preeclampsia with foetal growth restriction is mostly preceded by shallow first-trimester increase in cardiac output and absent drop in peripheral vascular resistance. ${ }^{36-40}$ Because the system-biological pathways to complications are so divergent, combining measurements of women at different pathophysiologic time points results in the wide confidence intervals of hemodynamic parameters found in hypertensive pregnancies. It is likely that women with late-onset preeclampsia were overrepresented, because it develops much more frequently than early-onset preeclampsia. In addition, women with early-onset preeclampsia and concomitant foetal growth restriction are likely to deliver preterm, thus their measurements at term are not available. Unfortunately, subgroup analyses on gestational hypertension, early-onset and late-onset preeclampsia was not possible because of combined groups, and inconsistent definitions among the studies included in our meta-analysis.

In healthy functioning circulations, spontaneous fluctuations in blood pressure are autonomically counterbalanced by short-term baroreceptor-mediated changes in heart rate and vascular tone to keep blood pressure stable around each individual's blood pressure set point. ${ }^{41}$ Long-term regulation of blood pressure involves hormonal and renal mechanisms, affecting systemic vascular resistance and blood volume, which influences cardiac output. As a result, alterations in cardiac output and total peripheral vascular resistance both contribute to maintain stable blood pressure. Consistent rise or fall in blood pressure within one person throughout gestation indicates failure of response mechanisms to compensate for the pregnancy-induced drop in total peripheral vascular resistance. As such, rising blood pressure is a rather late circulatory signal in the system biology toward hypertensive complications in pregnancy. Normalization of 
non-physiological hemodynamic adjustments in early pregnancy with counteracting medication may impede the circulatory processes that contribute to the development of preeclampsia. Lowering exaggerated cardiac output that is beyond physiological boundaries may decrease endothelial shear and damage by overperfusion to the placental intervillous space. ${ }^{42,43}$ Centrally acting sympatholytic agents and calcium antagonists may support uterine perfusion by reducing uterine bed vascular resistance, while beta-blockers may reduce the detrimental effect of overperfusion. ${ }^{44,45}$ We showed that, in a high-risk population, modification of abnormal hemodynamic adjustments halves the risk of recurrent preeclampsia and reduces the risk of HELLP syndrome about $90 \%$, without disadvantageous effects on offspring outcome.

\section{Towards appropriate and early treatment of elevated blood pressure}

Current management of elevated blood pressure in pregnant women is less tight compared with non-pregnant individuals. First, blood pressure thresholds to define hypertension and to advice pharmacological treatment in pregnant women are higher compared with non-pregnant individuals. Second, the choice of pregnancy-compatible antihypertensive agent is often guided by physicians' experience and regional stepwise treatment protocols. On the contrary, in non-pregnant individuals, choice of antihypertensive drug depends on presence of cardiovascular risk factors, comorbidities and ancestry, of which the latter associates with distinct circulatory profiles. ${ }^{46,47}$ Changing treatment paradigms of elevated blood pressure during pregnancy may improve obstetric outcomes.

Gestational hypertension can originate from hyperdynamic circulation characterized by high cardiac output and low vascular resistance ('cardiac hypertension'), a hypodynamic circulation characterized by low cardiac output and high vascular resistance ('vascular hypertension'), or a mixed hemodynamic circulation. Beta-blockers, central-acting alpha agonists, and calcium antagonists are commonly administered during pregnancy because of their safety profile. Each of this drug class is considered to lower high blood pressure via different mechanisms by reducing cardiac output or vascular resistance. Selective beta-blockers lower high blood pressure primarily by reducing cardiac output, while beta-blockers with additional a-adrenergic receptor blockade activity concurrently reduce peripheral resistance. ${ }^{48,49}$ Central-acting alpha agonists lower elevated blood pressure by altering central sympathetic activity. Cardiac output levels before and after start treatment do not change, suggesting a balance between reduced afterload, venous return, and negative chronotropic and inotropic effects of sympathetic inhibition. ${ }^{50,51}$ Dihydropyridine calcium channel blockers inhibit calcium ions from entering the calcium channels of vascular smooth muscle, so elevated blood pressure is mainly lowered by reducing arterial tone and with it, vascular resistance. ${ }^{52,53}$ Along these lines 
of reasoning, beta-blockers are thought to be suitable for treating 'cardiac' hypertension, but could be detrimental in 'vascular' hypertensive women. These women may instead benefit from vasodilation by dihydropyridine calcium channel blockers, or from central-acting alpha agonists that reduce peripheral resistance.

Pharmacological treatment is recommended for severe hypertension to prevent cerebrovascular haemorrhage, liver or kidney failure: serious but very rare adverse events. ${ }^{54}$ Therefore, an extensive meta-analysis on pharmacological treatment of mild to moderate hypertension was underpowered to assess these compliations. ${ }^{55}$ The current rationale for pharmacological treatment of mild to moderate hypertension is to prevent or delay progression to severe hypertension and preeclampsia. Medication is not recommended and uniformly initiated due to different effects on maternal disease progression and alleged poorer foetal outcomes, mainly related to foetal growth. ${ }^{56,57}$ Despite divergent pharmacological mode of action of the various anti-hypertensive drugs used in obstetric hypertensive disease, most studies on which this recommendation is based, did not consider the maternal circulatory state or the circulatory response to the antihypertensive drug.

Our latest systematic review and meta-analysis on arterial blood pressure adjustments during pregnancy showed that virtually all blood pressure levels during normotensive pregnancy are $<130 / 80 \mathrm{mmHg} .{ }^{58}$ Lowering thresholds to define hypertension, even when not pharmacologically treated, may result in improved risk perception and awareness. This could contribute to increased surveillance with appropriate risk counselling and additional screening tests for related complications when indicated. Women may be earlier and specifically pointed out to pay attention to preeclampsia-related symptoms, that necessitates contact with their perinatal health care provider. On the other hand, earlier treatment with tailored antihypertensive medication based on mode of action and underlying maternal circulatory profile might improve obstetric outcomes. Another argument in favour of early pharmacological treatment is the possibility to attenuate unfavourable cardiac remodelling. During healthy pregnancy, the maternal heart undergoes reversible morphological alterations to meet the increased cardiac demand. ${ }^{21,22}$ In hypertensive pregnancy, these alterations tend more towards unfavourable structural changes associated with diastolic dysfunction, that may persist after gestation. Deviant adjustments of the heart may be hampered by early treatment of elevated blood pressure. Blood-pressure lowering medication, especially when directed at the hemodynamic imbalance, may temper geometric changes and myocardial damage. ${ }^{59}$

The Control of Hypertension in Pregnancy Study (CHIPS) trial randomized almost 1000 hypertensive pregnant women to tight control (target diastolic blood pressure of 
$85 \mathrm{mmHg}$ ) or less tight control (target diastolic blood pressure of $100 \mathrm{mmHg}$ ) of blood pressure. ${ }^{60}$ Tight control reduced progression to severe hypertension, which was, in a secondary analysis, evaluated as an outcome worthy of avoidance, because it associates with more adverse maternal and perinatal outcomes, independent of the effects of preeclampsia. ${ }^{61}$ The currently ongoing Chronic Hypertension and Pregnancy (CHAP) trial intends to evaluate whether a targeted blood pressure of $<140 / 90 \mathrm{mmHg}$ compared to treatment of severe hypertension $(\geq 160 / 105 \mathrm{mmHg}$ ) in women with chronic hypertension results in less adverse perinatal outcomes (ClinicalTrials.gov unique identifier: NCT02299414). In both studies, Labetalol is recommended as a first line agent, but other antihypertensive medications treatment schemes are also accepted. In about threequarters of women with mild to moderate hypertension, betablockers are likely to be the appropriate class of antihypertensive drugs, as their hypertension is of hyperdynamic 'cardiac' origin. However, about a quarter of women develops hypodynamic 'vascular' hypertension, and they require (additional) vasodilator therapy to achieve blood pressure control. ${ }^{62,63}$ Women with high peripheral resistance who respond adequately are less likely to develop severe complications. ${ }^{44}$ Monitoring of response, with repeated hemodynamic evaluation is necessary to detect a crossover from a hyperdynamic to hypodynamic circulation, which is a sign of circulatory decompensation. ${ }^{64,65}$ In the clinical phase of preeclampsia, most women exhibit a high-resistance profile with either low cardiac output (in 58\% of women) or normal cardiac output (in $36 \%$ of women). ${ }^{66}$

\section{Monitoring hemodynamic parameters}

Implementation of central hemodynamic assessment in pregnancy is challenged by the limited possibility to measure hemodynamic parameters efficiently and accurately. In the recent years, minimally- and non-invasive techniques to measure cardiac output are developed, and these are increasingly in use, also in the obstetric population in an outpatient setting. ${ }^{67}$ Some specialized centres have accessibility to transthoracic echocardiography, but this is not standardly available in all obstetrics departments. Echocardiography is labour-intensive, expertise-dependent and results are not readily accessible, unlike diverse other point-of-care methods. With the Ultrasonic Cardiac Output Monitor (USCOM), cardiac output is measured efficiently, and skills to perform measurements are quickly acquired. In pregnant populations, transthoracic echocardiography can be used as a reference method for the validation of cardiac output measuring techniques. ${ }^{68}$ Therefore, we executed a validation study to compare echocardiography with the USCOM in non-pregnant, and pregnant women over the course of their pregnancy. The found percentage of error, a measure to define agreement between the two methods, was outside our predetermined level of acceptability, indicating that cardiac output values of echocardiography and USCOM should not be used interchangeably, and one method cannot be mixed with the other. Two other validation studies showed similar 
results with borderline deviant percentages of error over the course of pregnancy. ${ }^{69,70}$ In all studies, cardiac output in pregnancy measured by the USCOM was higher than cardiac output measured by echocardiography, with a surplus that ranged between 0.5 and $1.1 \mathrm{~L} / \mathrm{min}$. The meta-regression on cardiac output measurement method in our systematic review and meta-analysis also indicated a trend of higher measured cardiac output with suprasternal aortic Doppler velocimetry methods compared with the other techniques $(p=0.09)$.

The conclusion that absolute cardiac output values are not interchangeable does not inevitably mean that the USCOM is unsuitable to use. It merely denotes that a single method should be used to monitor hemodynamic adjustments. Cardiac output is subject to transient biological fluctuations that result from respiration and baroreceptor-mediated compensations. A single estimate might deviate up to $20 \%$ from the averaged cardiac output during a complete respiratory cycle. ${ }^{71}$ Repeated cardiac output measurements randomly at different phases of the respiratory cycle substantially affected variation (range of $1.50 \mathrm{~L} / \mathrm{min}$ ) compared to timed repeated measurements (range of $0.47 \mathrm{~L} / \mathrm{min}$ at end-exhalation). ${ }^{72}$ Compared with echocardiography, cardiac output measurement by the USCOM is based on more heartbeats and velocity time integral complexes, averaging those hemodynamic fluctuations.

In any case, absolute values should be evaluated with device-specific reference ranges, and reference values for the USCOM during pregnancy are available. ${ }^{73}$ Another direct application is to determine the difference in cardiac output during pregnancy relative to the non-pregnant value. In our systematic review and meta-analysis on central hemodynamic adjustments during pregnancy, the primary outcome was the mean difference between the non-pregnant and pregnant values determined per gestational age interval. These values can be used to assess an individual's adjustments, provided that the prepregnant value is present. Finally, clinical consequences of the cardiac output values for the separate techniques were not evaluated, because these parameters are not standardly used in obstetrics. Future research on the use of hemodynamic parameters in obstetric clinical practice could reveal similar clinical consequences between measurement techniques.

\section{FUTURE PERSPECTIVES}

\section{Hemodynamics and foetal growth}

Hypertensive gestational disorders and impaired foetal growth are related complications, that share common pathophysiological mechanisms, including deviant 
hemodynamic functioning during pregnancy. In uncomplicated pregnancies, the early increase in cardiac output and reduction in peripheral vascular resistance correlates with foetal growth and birthweight of the neonate. ${ }^{74}$ Women who give birth to a smallfor-gestational-age neonate have a decreased cardiac output and an increased vascular resistance throughout pregnancy, and differences are more pronounced in severely growth restricted neonates. ${ }^{75,76}$ Administration of vasodilators and plasma volume expanders in women with early-onset preeclampsia and foetal growth restriction changed maternal hemodynamic parameters, supported pregnancy prolongation and improved neonatal birthweight. ${ }^{77}$ However, medication was not started until preeclampsia and growth restriction were diagnosed. Another multicentre trial, that currently evaluates the vasodilating effect of an organic nitrate on foetal growth restriction, antedates the complication by including women with impaired uterine artery Doppler at mid gestation. ${ }^{78}$ We showed that very early modification of hemodynamic parameters helps to prevent maternal gestational vascular complications and may possibly benefit first and second trimester placental development and function. This raises the prospect of early modification therapy to also optimize foetal growth, but pharmacologically lowering of high blood pressure, especially by betablockers, is previously negatively associated with neonatal birthweight. ${ }^{56}$ On the other hand, personalized early circulatory restoration of deviant adjustments prior to gestational hypertension allows the maternal cardiovascular system to compensate changes induced by medication while keeping blood pressure stabile. The potential beneficial effect of an intervention with early hemodynamic modification when the placenta is still developing on foetal growth needs to be evaluated in future trials.

\section{Impact on reproductive choice}

Experiencing a preeclamptic pregnancy influences couples' decision-making about future family planning. ${ }^{79-81} \mathrm{~A}$ first pregnancy complicated by preeclampsia results in lower rates of subsequent pregnancies compared to women without preeclampsia, although not in case of perinatal death. ${ }^{82,83}$ Reasons for not achieving a subsequent pregnancy are fear of recurrent disease and preterm delivery. ${ }^{83}$ However, general estimates of recurrent complications might not match the risk and impact perceived by a parental couple. Counselling with individualized risk estimates might be useful to aid women and their partners to make confident choices regarding their reproductive future. Several prediction models have yet been developed for preeclampsia, incorporating maternal characteristics, uterine ultrasound appearances and serum biomarkers, but many models can only be used during pregnancy. ${ }^{84}$ Therefore, there is urgent need for prediction models that are applicable before pregnancy. Besides obstetric characteristics of the first complicated pregnancy, these models could include maternal cardiovascular and cardiometabolic risk factors that are related to the risk of recurrent 
disease. ${ }^{4-6}$ Many of those risk factors that have predictable capacity are modifiable with lifestyle changes. With specific insight in one's own situation, women may strive to optimize their cardiovascular and cardiometabolic status before trying to conceive again, and to improve cardiovascular risk factors to prevent long-term cardiovascular diseases. Potential reduction in risk of recurrence of pregnancy complications is found to be an important motivator for women to change their lifestyle. ${ }^{85}$ Although there are no intervention trials of prepregnant lifestyle modification on subsequent pregnancy outcomes, a positive effect of adopting a healthy life style is very likely. A higher preconception physical activity level is associated with a risk reduction of preeclampsia, and weight loss between pregnancies, even in women with a normal BMI, reduces the risk for recurrent preeclampsia. ${ }^{86,87}$ Formerly preeclamptic women who ran through an intensive 12 weeks aerobic training program achieved substantial improvement of their cardiovascular and metabolic risk factors. ${ }^{88,89}$ Future research should reveal what the effect is of such a training program on subsequent pregnancy outcomes.

\section{Conclusion}

Healthy pregnancy is accompanied by major changes in hemodynamic parameters, such as an increase in cardiac output and a drop in peripheral vascular resistance, from the first trimester on. Hemodynamic changes in women who eventually develop hypertensive complications are substantially different over the course of pregnancy. Therefore, serial monitoring and weighing actual performance against developed normograms helps to identify women with deviant adjustments who are at risk for hypertensive complications. This allows timely initiation of generic preventive measures, including daily low-dose aspirin and calcium supplementation during pregnancy, and tailored non-generic preventive strategies with pharmacological modulation of the hemodynamic imbalance. Such an innovative strategy halves the risk of recurrent preeclampsia in high-risk women, and reduces the risk on HELLP syndrome by $90 \%$. Also, information on maternal hemodynamic parameters when hypertensive problems arise results in a substantiated choice of antihypertensive medication, based on pharmacological mode of action and anticipated hemodynamic response instead of the current stepwise approach to pharmacological therapy. Tailored prescription of antihypertensives in mild to moderate gestation hypertension may prevent disease evolvement to severe hypertension and preeclampsia, without adverse effect on foetal outcomes. The potential use of maternal hemodynamic parameters in pregnancy, and the availability of monitors that efficiently measure cardiac output promote implementation in general obstetric care, in order to reduce the burden of preeclampsia. 


\section{REFERENCES}

1. Tranquilli AL, Dekker G, Magee L, Roberts J, Sibai BM, Steyn W, et al. The classification, diagnosis and management of the hypertensive disorders of pregnancy: A revised statement from the ISSHP. Pregnancy Hypertens 2014; 4: 97-104.

2. Kloosterman GJ. [Intrauterine growth and intrauterine growth curves]. Maandschr Kindergeneeskd 1969; 37: 209-225.

3. van Oostwaard MF, Langenveld J, Schuit E, Papatsonis DN, Brown MA, Byaruhanga RN, et al. Recurrence of hypertensive disorders of pregnancy: an individual patient data metaanalysis. Am J Obstet Gynecol 2015; 212: 624 e621-617.

4. Duckitt $K$ and Harrington D. Risk factors for pre-eclampsia at antenatal booking: systematic review of controlled studies. BMJ 2005; 330: 565.

5. Dekker GA and Sibai BM. Etiology and pathogenesis of preeclampsia: current concepts. Am J Obstet Gynecol 1998; 179: 1359-1375.

6. Scholten RR, Sep S, Peeters L, Hopman MT, Lotgering FK and Spaanderman ME. Prepregnancy low-plasma volume and predisposition to preeclampsia and fetal growth restriction. Obstet Gynecol 2011; 117: 1085-1093.

7. Stekkinger E, Scholten R, van der Vlugt MJ, van Dijk AP, Janssen MC and Spaanderman ME. Metabolic syndrome and the risk for recurrent pre-eclampsia: a retrospective cohort study. BJOG 2013; 120: 979-986.

8. Ford ES, Giles WH and Mokdad AH. Increasing prevalence of the metabolic syndrome among u.s. Adults. Diabetes Care 2004; 27: 2444-2449.

9. Hirode $\mathrm{G}$ and Wong RJ. Trends in the Prevalence of Metabolic Syndrome in the United States, 2011-2016. JAMA 2020; 323: 2526-2528.

10. Immink MM, Koole S, Bekker MN, Groenendaal F, Kemmeren JM, de Melker
$\mathrm{HE}$, et al. Background incidence rates of adverse pregnancy outcomes in the Netherlands: Data of 2006-2018. Eur J Obstet Gynecol Reprod Biol 2021; 256: 274-280.

11. Koopmans CM, Bijlenga D, Groen H, Vijgen SM, Aarnoudse JG, Bekedam DJ, et al. Induction of labour versus expectant monitoring for gestational hypertension or mild pre-eclampsia after 36 weeks' gestation (HYPITAT): a multicentre, open-label randomised controlled trial. Lancet 2009; 374: 979-988.

12. Ebbing C, Rasmussen S, Skjaerven R and Irgens LM. Risk factors for recurrence of hypertensive disorders of pregnancy, a population based cohort study. Acta Obstet Gynecol Scand 2016

13. Duley L, Meher S, Hunter KE, Seidler AL and Askie LM. Antiplatelet agents for preventing pre-eclampsia and its complications. Cochrane Database Syst Rev 2019; 2019

14. Hofmeyr GJ, Lawrie TA, Atallah AN and Torloni MR. Calcium supplementation during pregnancy for preventing hypertensive disorders and related problems. Cochrane Database Syst Rev 2018; 10: CD001059.

15. Chappell LC, Seed P, Enye S, Briley AL, Poston $\mathrm{L}$ and Shennan $\mathrm{AH}$. Clinical and geographical variation in prophylactic and therapeutic treatments for pre-eclampsia in the UK. BJOG 2010; 117: 695-700.

16. de Haas S, Ghossein-Doha C, van Kuijk SM, van Drongelen J and Spaanderman ME. Physiologic adaptation of plasma volume during pregnancy: a systematic review and meta-analysis. Ultrasound Obstet Gynecol 2017; 49(2): 177-187.

17. Meah VL, Cockcroft JR, Backx K, Shave $\mathrm{R}$ and Stohr EJ. Cardiac output and related haemodynamics during pregnancy: a series of meta-analyses. Heart 2016; 102: 518-526.

18. Savu O, Jurcut R, Giusca S, van Mieghem T, Gussi I, Popescu BA, et al. Morphological 
and functional adaptation of the maternal heart during pregnancy. Circ Cardiovasc Imaging 2012; 5: 289-297.

19. Clark SL, Cotton DB, Pivarnik JM, Lee W, Hankins GD, Benedetti TJ, et al. Position change and central hemodynamic profile during normal third-trimester pregnancy and post partum. Am J Obstet Gynecol 1991; 164: 883-887.

20. Bamber JH and Dresner M. Aortocaval compression in pregnancy: the effect of changing the degree and direction of lateral tilt on maternal cardiac output. Anesth Analg 2003; 97: 256-258.

21. de Haas S, Ghossein-Doha C, Geerts L, van Kuijk SM, van Drongelen J and Spaanderman ME. Cardiac remodelling during normotensive and hypertensive complicated pregnancies: a systematic review and meta-analysis. Ultrasound Obstet Gynecol 2017; 50(6): 683-696.

22. Melchiorre K, Sharma R, Khalil $A$ and Thilaganathan B. Maternal Cardiovascular Function in Normal Pregnancy: Evidence of Maladaptation to Chronic Volume Overload. Hypertension 2016; 67: 754-762.

23. Chapman AB, Zamudio S, Woodmansee W, Merouani A, Osorio F, Johnson A, et al. Systemic and renal hemodynamic changes in the luteal phase of the menstrual cycle mimic early pregnancy. Am J Physiol 1997; 273: F777-782.

24. Conrad KP, Petersen JW, Chi YY, Zhai X, Li $\mathrm{M}$, Chiu KH, et al. Maternal Cardiovascular Dysregulation During Early Pregnancy After In Vitro Fertilization Cycles in the Absence of a Corpus Luteum. Hypertension 2019; 74: 705-715.

25. Spaanderman ME, Willekes C, Hoeks AP, Ekhart TH and Peeters LL. The effect of pregnancy on the compliance of large arteries and veins in healthy parous control subjects and women with a history of preeclampsia. Am J Obstet Gynecol 2000; 183: $1278-1286$.
26. Leo $\mathrm{CH}$, Jelinic $\mathrm{M}, \mathrm{Ng} \mathrm{HH}$, Marshall $\mathrm{SA}$, Novak J, Tare M, et al. Vascular actions of relaxin: nitric oxide and beyond. $\mathrm{Br} J$ Pharmacol 2017; 174: 1002-1014.

27. Spaanderman ME, Meertens M, van Bussel M, Ekhart TH and Peeters LL. Cardiac output increases independently of basal metabolic rate in early human pregnancy. Am J Physiol Heart Circ Physiol 2000; 278: H1585-1588.

28. Jaffe R, Jauniaux E and Hustin J. Maternal circulation in the first-trimester human placenta--myth or reality? Am J Obstet Gynecol 1997; 176: 695-705.

29. Duvekot JJ, Cheriex EC, Pieters FA, Menheere PP and Peeters LH. Early pregnancy changes in hemodynamics and volume homeostasis are consecutive adjustments triggered by a primary fall in systemic vascular tone. Am J Obstet Gynecol 1993; 169: 1382-1392.

30. Linde T, Sandhagen B, Hägg A, Mörlin C, Wikström $B$ and Danielson BG. Blood viscosity and peripheral vascular resistance in patients with untreated essential hypertension. J Hypertens 1993; 11: 731-736.

31. Whittaker PG, Macphail S and Lind T. Serial hematologic changes and pregnancy outcome. Obstet Gynecol 1996; 88: 33-39.

32. Jarvis SS, Shibata S, Bivens TB, Okada Y, Casey BM, Levine BD, et al. Sympathetic activation during early pregnancy in humans. J Physiol 2012; 590: 3535-3543.

33. Okada Y, Best SA, Jarvis SS, Shibata S, Parker RS, Casey BM, et al. Asian women have attenuated sympathetic activation but enhanced renal-adrenal responses during pregnancy compared to Caucasian women. J Physiol 2015; 593: 1159-1168.

34. Usselman CW, Skow RJ, Matenchuk BA, Chari RS, Julian CG, Stickland MK, et al. Sympathetic baroreflex gain in normotensive pregnant women. J Appl Physiol (1985) 2015; 119: 468-474.

35. Usselman CW, Wakefield PK, Skow RJ, Stickland MK, Chari RS, Julian CG, et al. 
Regulation of sympathetic nerve activity during the cold pressor test in normotensive pregnant and nonpregnant women. Hypertension 2015; 66: 858-864.

36. Valensise $H$, Vasapollo B, Gagliardi $G$ and Novelli GP. Early and late preeclampsia: two different maternal hemodynamic states in the latent phase of the disease. Hypertension 2008; 52: 873-880.

37. Easterling TR, Benedetti TJ, Schmucker BC and Millard SP. Maternal hemodynamics in normal and preeclamptic pregnancies: a longitudinal study. Obstet Gynecol 1990; 76: 1061-1069.

38. Rang S, van Montfrans GA and Wolf H. Serial hemodynamic measurement in normal pregnancy, preeclampsia, and intrauterine growth restriction. Am J Obstet Gynecol 2008; 198: 519 e511-519.

39. Foo FL, Mahendru AA, Masini G, Fraser A, Cacciatore S, Maclntyre DA, et al. Association Between Prepregnancy Cardiovascular Function and Subsequent Preeclampsia or Fetal Growth Restriction. Hypertension 2018; 72: 442-450.

40. Khaw A, Kametas NA, Turan OM, Bamfo JE and Nicolaides $\mathrm{KH}$. Maternal cardiac function and uterine artery Doppler at 11-14 weeks in the prediction of pre-eclampsia in nulliparous women. BJOG 2008; 115: 369-376.

41. Laitinen T, Hartikainen J, Niskanen L, Geelen $\mathrm{G}$ and Lansimies E. Sympathovagal balance is major determinant of shortterm blood pressure variability in healthy subjects. Am J Physiol 1999; 276: H12451252.

42. Easterling TR, Brateng D, Schmucker B, Brown Z and Millard SP. Prevention of preeclampsia: a randomized trial of atenolol in hyperdynamic patients before onset of hypertension. Obstet Gynecol 1999; 93: 725-733.

43. Tun WM, Yap $\mathrm{CH}$, Saw SN, James JL and Clark AR. Differences in placental capillary shear stress in fetal growth restriction may affect endothelial cell function and vascular network formation. Sci Rep 2019; 9: 9876.

44. Vasapollo B, Novelli GP, Gagliardi G, Tiralongo GM, Pisani I, Manfellotto D, et al. Medical treatment of early-onset mild gestational hypertension reduces total peripheral vascular resistance and influences maternal and fetal complications. Ultrasound Obstet Gynecol 2012; 40: 325331.

45. Rothberger S, Carr D, Brateng D, Hebert M and Easterling TR. Pharmacodynamics of clonidine therapy in pregnancy: a heterogeneous maternal response impacts fetal growth. Am J Hypertens 2010; 23: 12341240 .

46. NHG-Standaard. Cardiovasculair risicomanagement (M84). Version 4.0

47. Brown MJ. Hypertension and ethnic group. BMJ 2006; 332: 833-836.

48. Messerli FH and Grossman E. beta-Blockers in hypertension: is carvedilol different? Am J Cardiol 2004; 93: 7B-12B.

49. Bakris G. An in-depth analysis of vasodilation in the management of hypertension: focus on adrenergic blockade. J Cardiovasc Pharmacol 2009; 53: 379-387.

50. Chrysant SG, Frohlich ED, Adamopoulos PN, Stein PD, Whitcomb WH, Allen EW, et al. Pathophysiologic significance of "stress" or relative polycythemia in essential hypertension. Am J Cardiol 1976; 37: 1069-1072.

51. Safar ME, London GM, Levenson JA, Kheder MA, Aboras NE and Simon AC. Effect of alpha-methyldopa on cardiac output in hypertension. Clin Pharmacol Ther 1979; 25: 266-272.

52. Vetrovec GW. Hemodynamic and electrophysiologic effects of first- and secondgeneration calcium antagonists. $A m \mathrm{~J}$ Cardiol 1994; 73: 34A-38A.

53. Borow KM, Neumann A, Lang RM, Ehler D, Valentine-Bates B, Wolff A, et al. Noninvasive assessment of the direct action 
of oral nifedipine and nicardipine on left ventricular contractile state in patients with systemic hypertension: importance of reflex sympathetic responses. J Am Coll Cardiol 1993; 21: 939-949.

54. Duley L, Meher S and Jones L. Drugs for treatment of very high blood pressure during pregnancy. Cochrane Database Syst Rev 2013: CD001449.

55. Abalos E, Duley L, Steyn DW and Gialdini C. Antihypertensive drug therapy for mild to moderate hypertension during pregnancy. Cochrane Database Syst Rev 2018; 10: CD002252.

56. von Dadelszen $P$ and Magee LA. Fall in mean arterial pressure and fetal growth restriction in pregnancy hypertension: an updated metaregression analysis. J Obstet Gynaecol Can 2002; 24: 941-945.

57. Abalos E, Duley L and Steyn DW. Antihypertensive drug therapy for mild to moderate hypertension during pregnancy. Cochrane Database Syst Rev 2014: CD002252.

58. de Haas S, Mulder EG, Mohseni Z, Schartmann N, Abo Hasson F, Alsadah F, et al. Blood Pressure Adjustments Throughout Healthy and Hypertensive Pregnancy: A Systematic Review and Meta-analysis. Submitted manuscript

59. Fagard $\mathrm{RH}$, Celis $\mathrm{H}$, Thijs $\mathrm{L}$ and Wouters $\mathrm{S}$. Regression of left ventricular mass by antihypertensive treatment: a meta-analysis of randomized comparative studies. Hypertension 2009; 54: 1084-1091.

60. Magee LA, Singer J, von Dadelszen P and Group CS. Less-tight versus tight control of hypertension in pregnancy. N Engl J Med 2015; 372: 2367-2368.

61. Magee LA, von Dadelszen P, Singer J, Lee T, Rey E, Ross S, et al. The CHIPS Randomized Controlled Trial (Control of Hypertension in Pregnancy Study): Is Severe Hypertension Just an Elevated Blood Pressure? Hypertension 2016; 68: 1153-1159.

62. Stott D, Bolten M, Paraschiv D, Papastefanou I, Chambers JB and Kametas NA.
Longitudinal hemodynamics in acute phase of treatment with labetalol in hypertensive pregnant women to predict need for vasodilatory therapy. Ultrasound Obstet Gynecol 2017; 49: 85-94.

63. Chaffin DG and Webb DG. Outcomes of pregnancies at risk for hypertensive complications managed using impedance cardiography. Am J Perinatol 2009; 26: 717 721.

64. Bosio PM, McKenna PJ, Conroy R and O'Herlihy C. Maternal central hemodynamics in hypertensive disorders of pregnancy. Obstet Gynecol 1999; 94: 978-984.

65. Easterling TR, Carr DB, Brateng D, Diederichs $C$ and Schmucker B. Treatment of hypertension in pregnancy: effect of atenolol on maternal disease, preterm delivery, and fetal growth. Obstet Gynecol 2001; 98: 427-433.

66. Mei S, Gu H, Wang Q, Zhang S and Zeng Y. Pre-eclampsia outcomes in different hemodynamic models. J Obstet Gynaecol Res 2008; 34: 179-188.

67. Armstrong $\mathrm{S}$, Fernando $\mathrm{R}$ and Columb $\mathrm{M}$. Minimally- and non-invasive assessment of maternal cardiac output: go with the flow! Int J Obstet Anesth 2011; 20: 330-340.

68. Cornette J, Laker S, Jeffery B, Lombaard $H$, Alberts A, Rizopoulos D, et al. Validation of maternal cardiac output assessed by transthoracic echocardiography against pulmonary artery catheterization in severely ill pregnant women: prospective comparative study and systematic review. Ultrasound Obstet Gynecol 2017; 49: 25-31.

69. Vinayagam D, Patey O, Thilaganathan B and Khalil A. Cardiac output assessment in pregnancy: comparison of two automated monitors with echocardiography. Ultrasound Obstet Gynecol 2017; 49: 32-38.

70. McNamara H, Barclay $P$ and Sharma V. Accuracy and precision of the ultrasound cardiac output monitor (USCOM 1A) in pregnancy: comparison with three-dimen- 
sional transthoracic echocardiography. $\mathrm{Br}$ J Anaesth 2014; 113: 669-676.

71. Jansen JR, Schreuder JJ, Settels JJ, Kloek JJ and Versprille A. An adequate strategy for the thermodilution technique in patients during mechanical ventilation. Intensive Care Med 1990; 16: 422-425.

72. Stevens JH, Raffin TA, Mihm FG, Rosenthal $\mathrm{MH}$ and Stetz CW. Thermodilution cardiac output measurement. Effects of the respiratory cycle on its reproducibility. JAMA 1985; 253: 2240-2242.

73. Vinayagam D, Thilaganathan B, Stirrup O, Mantovani E and Khalil A. Maternal hemodynamics in normal pregnancy: reference ranges and role of maternal characteristics. Ultrasound Obstet Gynecol 2018; 51: 665-671.

74. Mahendru AA, Foo FL, McEniery CM, Everett TR, Wilkinson IB and Lees CC. Change in maternal cardiac output from preconception to mid-pregnancy is associated with birth weight in healthy pregnancies. Ultrasound Obstet Gynecol 2017; 49: 78-84.

75. Vonck S, Staelens AS, Lanssens D, Tomsin $\mathrm{K}$, Oben J, Dreesen P, et al. Low Volume Circulation in Normotensive Women Pregnant with Neonates Small for Gestational Age. Fetal Diagn Ther 2019; 46: 238-245.

76. Bamfo JE, Kametas NA, Chambers JB and Nicolaides KH. Maternal cardiac function in fetal growth-restricted and non-growthrestricted small-for-gestational age pregnancies. Ultrasound Obstet Gynecol 2007; 29: 51-57.

77. Valensise H, Vasapollo B, Novelli GP, Giorgi $G$, Verallo P, Galante A, et al. Maternal and fetal hemodynamic effects induced by nitric oxide donors and plasma volume expansion in pregnancies with gestational hypertension complicated by intrauterine growth restriction with absent enddiastolic flow in the umbilical artery. Ultrasound Obstet Gynecol 2008; 31: 55-64.

78. Groten T, Lehmann T, Schleussner E and Group PS. Does Pentaerytrithyltetranitrate reduce fetal growth restriction in pregnancies complicated by uterine mal-perfusion? Study protocol of the PETN-study: a randomized controlled multicenter-trial. BMC Pregnancy Childbirth 2019; 19: 336.

79. Rep A, Ganzevoort W, Bonsel GJ, Wolf H and de Vries JI. Psychosocial impact of early-onset hypertensive disorders and related complications in pregnancy. Am J Obstet Gynecol 2007; 197: 158 e151-156.

80. Roes EM, Raijmakers MT, Schoonenberg M, Wanner N, Peters WH and Steegers EA. Physical well-being in women with a history of severe preeclampsia. J Matern Fetal Neonatal Med 2005; 18: 39-45.

81. Engelhard IM, van Rij M, Boullart I, Ekhart TH, Spaanderman ME, van den Hout MA, et al. Posttraumatic stress disorder after pre-eclampsia: an exploratory study. Gen Hosp Psychiatry 2002; 24: 260-264.

82. Seeho SK, Algert CS, Roberts CL and Ford JB. Early-onset preeclampsia appears to discourage subsequent pregnancy but the risks may be overestimated. Am J Obstet Gynecol 2016; 215: 785 e781-785 e788.

83. Schaaf JM, Bruinse HW, van der LeeuwHarmsen L, Groeneveld E, Koopman C, Franx A, et al. Reproductive outcome after early-onset pre-eclampsia. Hum Reprod 2011; 26: 391-397.

84. De Kat AC, Hirst J, Woodward M, Kennedy $S$ and Peters SA. Prediction models for preeclampsia: A systematic review. Pregnancy Hypertens 2019; 16: 48-66.

85. Berks D, Hoedjes $M$, Raat $H$, Franx A, Looman CWN, Van Oostwaard MF, et al. Feasibility and effectiveness of a lifestyle intervention after complicated pregnancies to improve risk factors for future cardiometabolic disease. Pregnancy $\mathrm{Hy}$ pertens 2019; 15: 98-107.

86. Aune D, Saugstad OD, Henriksen T and Tonstad S. Physical activity and the risk of preeclampsia: a systematic review and meta-analysis. Epidemiology 2014; 25: 331343. 
87. Mostello D, Jen Chang J, Allen J, Luehr L, Shyken J and Leet T. Recurrent preeclampsia: the effect of weight change between pregnancies. Obstet Gynecol 2010; 116: 667-672.

88. Scholten RR, Thijssen DJ, Lotgering FK, Hopman MT and Spaanderman ME. Cardiovascular effects of aerobic exercise training in formerly preeclamptic women and healthy parous control subjects. Am J Obstet Gynecol 2014; 211: 516 e511-516 e511.
89. Scholten RR, Hopman MT, Lotgering FK and Spaanderman ME. Aerobic Exercise Training in Formerly Preeclamptic Women: Effects on Venous Reserve. Hypertension 2015; 66: 1058-1065. 




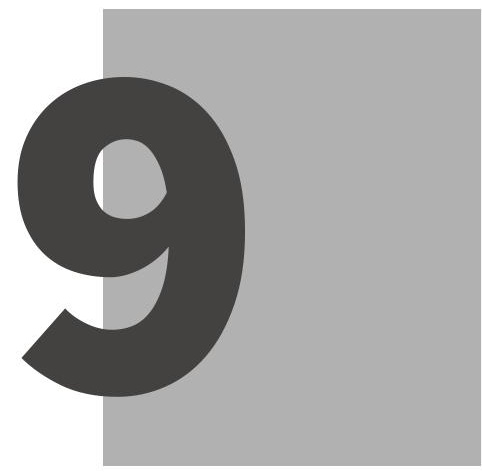

Impact 

This chapter addresses the possible impact and relevance of this thesis for our society. The general aim is to describe hemodynamic adjustments in normotensive and hypertensive pregnancy, and to propose strategies to optimize the use of maternal hemodynamic parameters in the prevention of gestational vascular complications, amongst preeclampsia, HELLP syndrome and foetal growth restriction, as current preventive measures fall short. In this chapter, the financial and social burden of preeclampsia are delineated as well as the potential financial and social gain that preventing this disease can achieve.

Preeclampsia, a hypertensive vascular disorder, complicates $4.6 \%$ (95\% Cl 2.7-8.2\%) of all pregnancies worldwide. ${ }^{1}$ In the Netherlands, 167.588 women delivered in the year 2019, meaning that over 7700 women recently experienced this gestational complication. ${ }^{2}$ Incidences are on the rise, possibly as a consequence of increasing prevalence of cardiovascular risk factors among women in the reproductive age, including elevated BMI (and concurrent dyslipidaemia, glucose handling disorders and high blood pressure) and advanced maternal age at gestation..$^{2-4}$ Preeclampsia is a major cause of maternal and neonatal mortality and morbidity. ${ }^{5}$ Remotely, it associates with early development of cardiovascular and metabolic diseases in affected women, and in their offspring in case of impaired foetal growth and preterm birth. To date, there is no definite treatment for preeclampsia other than delivery, with associated neonatal risks of iatrogenic preterm birth. In Western world countries, the direct medical care costs of a preeclamptic pregnancy can amount to $€ 22.360$ extra compared to an uncomplicated pregnancy. ${ }^{6}$ Based on Dutch economic findings in a group of formerly preeclamptic women receiving comparable intensive outpatient follow up throughout gestation (€8047), accounting for the additional costs made for normogram-guided care (€336/pregnancy trajectory) and the reduction in clinical outcome made -preeclampsia (costs €3720), which is also the primary variable together with preterm birth on additional direct costs- this kind of care is estimated to be at least cost effective or even less expensive than current care. ${ }^{7}$ On the short term, the primary drivers of the incremental costs are infant costs, especially in preterm and extreme preterm birth when admittance to a neonatal intensive care unit is necessary. These expenses neither include future costs to the healthcare system of preeclampsia-associated health problems for women and offspring, nor indirect costs and costs associated with lost productivity.

\section{Effect on mental health}

Pregnancies complicated by preeclampsia have great impact on physical and mental health of the parents, especially for the mother. Many women experience preeclampsia as a traumatic life event, particularly in preeclampsia with severe features necessitating hospital admission to an obstetric high- or intensive-care unit, combined with an 
unexpected emergency delivery -often a ceasearean section- and birth of a premature child. This is possibly followed by admission of the neonate to the intensive care unit, or in the most severe cases, offspring handicap or infant loss. High levels of stress following this (severe) illness and/or adverse neonatal outcomes may develop into more severe psychological disorders, including post-traumatic stress disorder and depression, which, in turn affects cognitive functioning and well being. ${ }^{8,9}$ Physical and mental health complaints might interfere with resumption of everyday life, affecting work obligations, leisure activities and family commitments. ${ }^{10}$

In the research agenda of 2020-2023 of the NVOG (Dutch Society of Obstetrics and Gynaecology), the challenges in the development of preventive and treatment options for preeclampsia are outlined. The limited availability of predictors, and limited possibilities of early diagnosis are emphasized. This agenda suggests that future research should focus on unravelling the pathophysiologic pathways leading to preeclampsia and foetal growth restriction, determination of (bio)markers and imaging for early diagnosis, and to evaluate preventive and therapeutic interventions on maternal and offspring outcomes during pregnancy. This thesis is in line with these goals, with deviant hemodynamic adjustments in early pregnancy as contributor and impressionable factor. Deviant hemodynamic adjustments during pregnancy is assessable by monitoring cardiac output next to blood pressure measurements. To date, minimal- and non-invasive techniques are available to assess cardiac output in an outpatient obstetric clinic. We highlighted the USCOM, an efficient non-invasive method to determine cardiac output. Although absolute values of the USCOM are not interchangeable with values measured by transthoracic echocardiography, this 'point-of-care' method is a suitable and attainable option to get an impression of the hemodynamic balance in hypertensive pregnant women. The prospects of the use of the hemodynamic (im)balance to prevent preeclampsia are outlined in this thesis.

\section{Personalized care}

Personalized drug treatment in gestational hypertension is likely to improve obstetric outcomes. The study protocol in this thesis outlines a theoretical background of appropriate antihypertensive medication choice based on the hemodynamic parameters that determine blood pressure. Correcting the imbalance between cardiac output and total peripheral vascular resistance with appropriate counteracting drugs normalizing hemodynamic functioning may prevent disease evolvement from mild and moderate hypertension to severe hypertension and preeclampsia. Previous studies showed that improved blood pressure control in pregnancy is achieved when choice of medication is based on cardiac output. ${ }^{11,12}$ As cardiac output assessment is not yet standardly feasible in obstetric clinics, we also developed a treatment algorithm to personalize antihyper- 
tensive treatment with readily available parameters (mean arterial pressure and heart rate). Pending the results of our randomized controlled trial with this treatment scheme, obstetricians may in ahead use the presented algorithm in daily clinical practice to make a more substantiated choice of antihypertensive agent in gestational hypertension.

In this thesis, we provide evidence that treatment of hemodynamic imbalances towards healthy, physiological hemodynamic values, even before blood pressure rises, substantially improved recurrence rates of preeclampsia and HELLP syndrome without any disadvantageous offspring effects. In-depth insight in timing and magnitude of physiological adjustments in cardiac output and peripheral vascular resistance is necessary to employ this strategy in daily clinical practice. Therefore, we executed a systematic review and meta-analysis to summarize all available data in current literature on hemodynamic parameters, and we provided reference values of physiological adjustments during pregnancy. We presented both mean difference relative to non-pregnant values and absolute hemodynamic values throughout gestation. The former makes usability in clinical practice method- and device-independent.

The experience of a complicated pregnancy influences couples' decision-making about future family planning. A first pregnancy complicated by preeclampsia results in lower rate of subsequent pregnancies compared to women without preeclampsia, although not in case of perinatal death. ${ }^{13,14}$ Reasons for not achieving a subsequent pregnancy are fear of recurrent disease and preterm delivery. To date, available preventive measures, and optimal monitoring and intervention strategies in women at risk for this pregnancy complication are limited. Provided care-as-usual during pregnancy greatly depends on patients' preference and physicians' common practice. As a consequence, health care consumption in the subsequent pregnancy after early onset preeclampsia and/or HELLP syndrome greatly varies between individual cases, ranging between 5 and 37 outpatient visits. ${ }^{7}$ Our presented cardiovascular monitoring and modification program during the subsequent pregnancy in formerly preeclamptic women not only reduces the incidence of recurrent preeclampsia, it also make the control frequency more uniform and predictable, and may improve feeling of control of the parents during the next pregnancy.

\section{Dissemination}

Various efforts to disseminate the knowledge gained from our studies to different target groups were initiated. All of the studies and the protocol presented in this thesis have been published in diverse international journals, and most of them as open access publications to spread the findings to the international research community and clinical practices. In addition, most findings have been presented at national and international conferences that hosted many physicians and researchers from the Netherlands and 
across the globe. The systematic review and meta-analysis on hemodynamic adjustments during pregnancy is part of a designed series of reviews and meta-analyses on physiological adjustments of maternal cardiovascular and cardiometabolic parameters during pregnancy. Results of all review subjects are intended to be published in a reference book for (medical) students and specialists.

A non-pregnant cardiovascular and cardiometabolic risk factor assessment in Maastricht is accessible to all women in the country who experienced a pregnancy complicated by hypertension, preeclampsia and/or associated adverse events. From 2013 onwards, all these women are invited to participate in the -still ongoing-cardiovascular program during their pregnancy with modulation of deviant hemodynamic adjustments, in addition to regular care. More than half of the formerly preeclamptic women participating in this program are referred by physicians from other hospitals. Results of every single evaluation, and advices for pharmacological modulation of abnormal hemodynamic adjustments are explained to the parental couple and the referring physician. Therefore, many obstetricians in the country are informed about this early treatment strategy, and this is likely to enhance implementation of the program in other hospitals. Moreover, one of the women participating in the cardiovascular program during pregnancy was reported for the television program "Dokters van Morgen" (Physicians of Tomorrow), which was broadcasted on national television in November 2020. In this program, innovations and new insights in health care are highlighted, and the program was selected for the hypertension episode. Every other year, our research group together with patient support group "Hart voor HELLP” organizes a patient conference, where results of our (ongoing) studies are elucidated. Unfortunately, the planned conference for 2020 could not take place due to the regulations regarding the COVID-19 pandemic. 


\section{REFERENCES}

1. Abalos E, Cuesta C, Grosso AL, Chou D and Say L. Global and regional estimates of preeclampsia and eclampsia: a systematic review. Eur J Obstet Gynecol Reprod Biol 2013; 170: 1-7.

2. CBS Statline, https://opendata.cbs.nl/ statline/\#/CBS/nl/dataset/37422ned/ table?dl=3FAD4 (accessed 31 August 2020).

3. Immink MM, Koole $\mathrm{S}$, Bekker $\mathrm{MN}$, Groenendaal F, Kemmeren JM, de Melker $\mathrm{HE}$, et al. Background incidence rates of adverse pregnancy outcomes in the Netherlands: Data of 2006-2018. Eur J Obstet Gynecol Reprod Biol 2021; 256: 274-280.

4. RIVM. Volksgezondheidenzorg.info, https://www.volksgezondheidenzorg.info/ onderwerp/overgewicht/cijfers-context/ trends\#node-trend-obesitas-volwassenen (accessed 31 August 2020).

5. Schutte JM, Steegers EA, Schuitemaker NW, Santema JG, de Boer K, Pel M, et al. Rise in maternal mortality in the Netherlands. BJOG 2010; 117: 399-406.

6. Moran PS, Wuytack F, Turner M, Normand C, Brown S, Begley C, et al. Economic burden of maternal morbidity - A systematic review of cost-of-illness studies. PLoS One 2020; 15: e0227377.

7. Delahaije DH, Smits LJ, van Kuijk SM, Peeters LL, Duvekot JJ, Ganzevoort W, et al. Care-as-usual provided to formerly preeclamptic women in the Netherlands in the next pregnancy: health care consumption, costs and maternal and child outcome. Eur J Obstet Gynecol Reprod Biol 2014; 179: 240-245.
8. Engelhard IM, van Rij M, Boullart I, Ekhart TH, Spaanderman ME, van den Hout MA, et al. Posttraumatic stress disorder after pre-eclampsia: an exploratory study. Gen Hosp Psychiatry 2002; 24: 260-264.

9. Baecke M, Spaanderman ME and van der Werf SP. Cognitive function after pre-eclampsia: an explorative study. J Psychosom Obstet Gynaecol 2009; 30: 58-64.

10. Hoedjes M, Berks D, Vogel I, Franx A, Duvekot JJ, Steegers EA, et al. Poor health-related quality of life after severe preeclampsia. Birth 2011; 38: 246-255.

11. Easterling TR, Benedetti TJ, Schmucker BC and Carlson KL. Antihypertensive therapy in pregnancy directed by noninvasive hemodynamic monitoring. Am J Perinatol 1989; 6: 86-89.

12. Stott D, Papastefanou I, Paraschiv D, Clark $K$ and Kametas NA. Serial hemodynamic monitoring to guide treatment of maternal hypertension leads to reduction in severe hypertension. Ultrasound Obstet Gynecol 2017; 49: 95-103.

13. Seeho SK, Algert CS, Roberts CL and Ford JB. Early-onset preeclampsia appears to discourage subsequent pregnancy but the risks may be overestimated. Am J Obstet Gynecol 2016; 215: 785 e781-785 e788.

14. Schaaf JM, Bruinse HW, van der LeeuwHarmsen L, Groeneveld E, Koopman C, Franx A, et al. Reproductive outcome after early-onset pre-eclampsia. Hum Reprod 2011; 26: 391-397. 


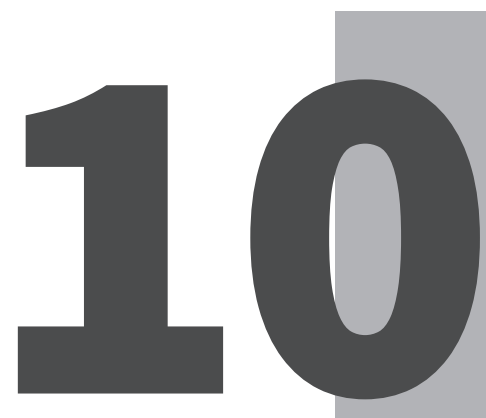

Summary

Samenvatting 



\section{SUMMARY}

Preeclampsia is a pregnancy complication characterized by hypertension along with de novo proteinuria or other signs of maternal organ dysfunction in previously normotensive women, or superimposed upon chronic hypertension. It is a leading cause of maternal and neonatal morbidity and mortality in the Western world. Delivery of foetus and placenta is currently the only definite treatment of preeclampsia, with associated neonatal risks as a consequence of iatrogenic preterm delivery. The effect of deferred delivery in preeclamptic pregnancies on postpartum maternal cardiovascular recovery and health is yet underexplored. A lot of effort is put on researches on interventions to prevent and adequately treat gestational hypertensive complications. The main focus of this thesis is on hemodynamic adjustments to pregnancy, the association with gestational hypertensive complications and following related opportunities to prevent (recurrent) preeclampsia.

Healthy pregnancy is accompanied by major hemodynamic changes that preserve and benefit the uteroplacental circulation. A first-trimester drop in systemic vascular resistance triggers several compensatory mechanisms, such as an increase in blood volume and cardiac output, to meet the metabolic demands of the growing foetus and to maintain blood pressure. Women destined to develop gestational hypertensive complications including preeclampsia often exhibit non-physiological hemodynamic adjustments long before overt clinical disease. The more commonly occurring gestational hypertension and late-onset preeclampsia are mostly preluded by exaggerated early rise in cardiac output, whereas a shallow rise and absent drop in peripheral vascular resistance in the first half of pregnancy predisposes to the much less prevalent early-onset preeclampsia along with impaired foetal growth. Enhanced insight in timing and magnitude of physiological hemodynamic adjustment patterns in normotensive pregnancies might help to recognize deviant adjustments preceding preeclampsia. The following step is to explore the possibilities to modify deviant adjustment patterns to prevent preeclampsia.

Chapter $\mathbf{1}$ is a general introduction about preeclampsia, the basics of blood pressure and blood pressure regulation and hemodynamic adaptation patterns during pregnancy. The aims and outlines of this thesis are described in this chapter.

Delivery of foetus and placenta is currently the only definite treatment of preeclampsia and scheduled birth is clinically dependent on severity of maternal disease, foetal condition and gestational age at diagnosis. Before 34 weeks of pregnancy, this decision often presents a management dilemma because premature birth increases the risk of neonatal morbidity and mortality, whereas deferred delivery puts the mother 
at jeopardy from deterioration of the preeclamptic condition and associated adverse foetal complications, including stillbirth. The effect of expectant management of severe, early-onset preeclampsia on postpartum maternal cardiovascular recovery and health are yet underexplored. Chapter $\mathbf{2}$ describes an observational study which evaluated the association between duration of gestational disease exposure from diagnosis to delivery on offspring outcome on the one hand, and maternal cardiovascular, renal and metabolic health in the postpartum period on the other hand. Pregnancy prolongation after diagnosis resulted in a higher absolute neonatal birthweight, and a decrease in infant mortality by $5 \%$ per day extension. Pregnancy prolongation was associated with a $2 \%$ per day elevated risk of moderately increased albuminuria, but not with aberrant cardiac geometry, cardiac systolic or diastolic dysfunction, persistent hypertension or metabolic syndrome. These results emphasize the importance of monitoring renal barrier function, especially in women whose pregnancy is prolonged by several days to weeks. Moreover, the outcomes substantiate the answer to a very practical question from formerly preeclamptic women wondering whether a prolonged temporizing management plan affected their remote cardiovascular health.

Chapter 3 presents an observational study on the recurrence rates of preeclampsia and related complications in the past decades. Increased recognition of cardiovascular and metabolic risk factors contributing to the development of preeclampsia offers the possibility to counsel on lifestyle changes before pregnancy. In addition, diverse other measures to prevent recurrent preeclampsia have been evaluated and implemented in clinical practice including daily low-dose aspirin and calcium supplementation during the subsequent pregnancy. In an observational cohort study of women who had an extensive non-pregnant cardiovascular risk factor assessment after their first preeclamptic pregnancy, recurrence rates of preeclampsia did not decline over the past two decades. However, in the same era, foetal and neonatal outcomes improved substantially. This study underpins the need to extend, improve and implement strategies to reduce the incidence of (recurrent) preeclampsia in high-risk women.

Chapter $\mathbf{4}$ is a systematic review and meta-analysis to delineate adjustments in cardiac output, its determinants stroke volume and heart rate, and total peripheral vascular resistance during singleton normotensive and hypertensive pregnancies. In-depth insight in timing and magnitude of hemodynamic adjustments during normotensive pregnancy may aid in identifying women at risk for gestational hypertensive complications. In normotensive pregnancies, cardiac output increased from the first weeks on, reaching its highest level in the early third trimester (mean difference compared to nonpregnant reference values: $1.47 \mathrm{~L} \cdot \mathrm{min}^{-1}, 95 \% \mathrm{Cl} 1.24-1.70 \mathrm{~L} \cdot \mathrm{min}^{-1}$ ). Both stroke volume and heart rate contribute to this increase. Stroke volume reduced slightly from the early 
third trimester until term, and heart rate reached a steady state, resulting in a slightly decreasing cardiac output towards the end of pregnancy. In parallel to cardiac output, total peripheral vascular resistance decreased from the first trimester progressively until its early third trimester nadir (mean difference of -316 dyne $\cdot \mathrm{sec} \cdot \mathrm{cm}^{-5}, 95 \% \mathrm{Cl}-368$ to $-265 \mathrm{dyne} \cdot \mathrm{sec} \cdot \mathrm{cm}^{-5}$ ) after which it increased slightly at term. Pregnancies ending in hypertension or preeclampsia show an altered hemodynamic response to conception. In addition to a higher baseline cardiac output, the initial increase in cardiac output is more pronounced, although this is not sustained as in normotensive pregnancies. Moreover, the rise in cardiac output predominantly originates from an increased heart rate rather than in combination with stroke volume. Total peripheral vascular resistance values did not change throughout hypertensive gestation. Monitoring hemodynamic adaptation patterns next to blood pressure measurements in early pregnancy might aid in identifying women with high risk at gestational hypertensive complications. This may enhance possibilities to initiate general preventive measures, or intervention by tailored modulation of hemodynamic parameters.

Recognition of underlying circulatory profile in mild to moderate gestational hypertension might result in a more substantiated choice of antihypertensive drugs. Chapter 5 describes a study protocol delineating a randomized controlled trial on the effect of personalized treatment in mild to moderate gestational hypertension to prevent severe hypertension and/or preeclampsia. For its well-established maternal benefits, international and national guidelines recommend to treat blood pressure when it reaches the threshold of severe hypertension (systolic or diastolic blood pressure $\geq 160$ or $\geq 110 \mathrm{mmHg}$ respectively). Effectiveness of antihypertensive medication in mild to moderate hypertension (systolic blood pressure between 140 and $160 \mathrm{mmHg}$ or diastolic blood pressure between 90 and $110 \mathrm{mmHg}$ ) is subject of debate and medication is not uniformly initiated because of inconsistent effects on maternal outcomes and alleged adverse foetal consequences. However, disappointing outcomes of previous studies might be explained by a stepwise medication selection without consideration of the underlying circulatory profile and mechanism of action of the first-line antihypertensive agent. Blood pressure is regulated within narrow boundaries by neural and humoral mediated alteration of cardiac output and vascular resistance, and is only changing when these determinants are unable to compensate deteriorations. As such, elevated blood pressure can be lowered by reducing cardiac output, vascular resistance or by a combination. Hypertensive women with a high-cardiac-output, low-vascular-resistance circulatory profile might profit most from beta-blockage, while reducing cardiac output may be detrimental in low-cardiac-output, high-vascular-resistance women. The latter women may instead benefit from vasodilation by calcium channel blockers or reduction in peripheral resistance by central-acting alpha agonists as first-line therapy. In this cur- 
rently ongoing randomized controlled trial, personalized antihypertensive treatment based on maternal circulatory profile is compared with generally practiced expectant management in women with mild to moderate hypertension during pregnancy. Personalized treatment in the medication arm is guided on hemodynamic profile using a simple treatment algorithm using mean arterial pressure and heart rate to allow easy implementation in daily clinical practice. The primary outcome is the incidence of severe hypertension and/or preeclampsia; secondary outcomes are maternal and offspring outcomes and complications.

An observation study of an innovative antenatal care program is outlined in Chapter 6. As women destined to develop gestational hypertensive complications often exhibit different hemodynamic adjustment patterns to pregnancy, tailored pharmacological circulatory modulation might result in improved pregnancy outcomes. This treatment strategy was evaluated in an observational study. Primiparous women with a history of preeclampsia admitted to a non-pregnant cardiovascular and metabolic risk factor assessment were invited to participate in a longitudinal program during their second pregnancy, additive to regular antenatal care. In this program, tailored antihypertensive medication was advised to women with non-physiological adjustments. In short, women with an exaggerated cardiac output rise effectuated by a high heart rate were advised a dual-acting betablocker. Women with a persistent high peripheral vascular resistance were advised a dihydropyridine calcium channel blocker, and a centrally acting sympatholytic agent was primarily indicated when heart rate and vascular resistance were equally high. We showed that physiologic normogram-guided care and tailored pharmacological intervention directed to correct underlying hemodynamic imbalance halved the risk of recurrent preeclampsia, without unfavourable effects on offspring outcome. This clinically relevant decrease in recurrent preeclampsia along with the reassuring offspring effects may facilitate implementation of this simple diagnose and treatment paradigm into large multicentre clinical trials and clinical practice.

Insight in hemodynamic parameters is essential for the understanding of the preclinical and clinical stages of gestational hypertensive complications. Currently, assessment of hemodynamic parameters beyond arterial pressure is not standardly available and performed in all obstetric departments. Chapter $\mathbf{7}$ describes the comparison between two different non-invasive methods to measure cardiac output and its determinants. Transthoracic echocardiography is widely used in pregnancy, but this method is labourintensive, expertise-dependent, and results are not readily available. The Ultrasonic Cardiac Output Monitor (USCOM) might be a suitable alternative, as this 'point-of-care' device determines cardiac output quick and easy, and it requires little training to use competently. The results of this study show that absolute cardiac output values of 
echocardiography and USCOM should not be used interchangeably. All determinants of cardiac output (i.e. stroke volume calculated by the product of velocity time integral and outflow tract diameter, and heart rate) had some degree of disagreement between the two methods. Optimizing USCOM measurements by, amongst other strategies, selecting only high-quality images resulted only in limited improvement in agreement. Application of USCOM measurements in daily obstetric practice necessitates method-specific reference values. Future research could focus on the clinical consequences of, and decision-making following the measured cardiac output for the separate techniques.

Chapter 8 elaborates on the findings of this manuscript, and contains a discussion wherein wider implications and suggestions for future research are given. 



\section{SAMENVATTING}

Preeclampsie is een complicatie in de zwangerschap die ernstige gevolgen voor de gezondheid van moeder en het (ongeboren) kind kan hebben. Kenmerkend voor preeclampsie zijn hypertensie in combinatie met eiwitverlies via de urine of andere tekenen van maternale orgaanschade. Daarnaast wordt het geassocieerd met foetale groeibeperking.

De enige behandeling voor preeclampsie is het inleiden van de bevalling, met bijbehorende risico's en gevolgen van een mogelijke iatrogene vroeggeboorte van dien. Er is nog weinig bekend over de effecten van uitstel van de bevalling op de maternale cardiovasculaire gezondheid na de bevalling. Het lijkt geassocieerd te zijn met ernstige cardiovasculaire aandoeningen in de eerste tien jaar na de bevalling. Mede hierom is er op wetenschappelijk gebied veel aandacht voor het voorkomen van preeclampsie door specifieke risicofactoren aan te pakken. Dit proefschrift richt zich voornamelijk op de hemodynamische aanpassingen van het hart- en vaatstelsel van de vrouw in de zwangerschap in relatie tot preeclampsie.

Onderdeel van preeclampsie zijn afwijkende aanpassingen van de bloedsomloop vroeg in de zwangerschap. Normaliter ondergaat het maternale hart- en vaatstelsel substantiële veranderingen in de zwangerschap, die onder meer nodig zijn om het ongeboren kind via de placenta van zuurstof en voedingsstoffen te voorzien. Een initiële verlaging van de vaatweerstand wordt gecompenseerd door een toename van het plasmavolume en het hartminuutvolume om de bloeddruk op peil te houden. Een bovenmatige toename van het hartminuutvolume is gerelateerd aan preeclampsie die zich laat in de zwangerschap manifesteert, terwijl een geringe toename van het hartminuutvolume in combinatie met het uitblijven van een daling in vasculaire weerstand juist geassocieerd is met preeclampsie vroeg in de zwangerschap, vaak in combinatie met foetale groeivertraging.

Met gedetailleerde kennis over de fysiologische zwangerschapsaanpassingen van het hart- en vaatstelsel is het mogelijk om afwijkende hemodynamische profielen die mogelijk preeclampsie voorspellen, te herkennen. Daarop aansluitend onderzochten we de mogelijkheden om via gepersonaliseerde medicatie afwijkende zwangerschapsaanpassingen bij te sturen om zo preeclampsie te voorkomen.

Hoofdstuk 1 is een algemene introductie over zwangerschapsvergiftiging, de basisprincipes van bloeddruk en bloeddrukregulatie, en hemodynamische aanpassingen in de 
loop van de zwangerschap. Het hoofdstuk beschrijft de opzet en doelstellingen van dit proefschrift.

De enige definitieve behandeling van preeclampsie is bevalling van het kind en de placenta. Het moment van bevalling is afhankelijk van de ernst van preeclampsie, de foetale conditie en de zwangerschapstermijn. Bij een zwangerschapsduur korter dan 34 weken geeft dit een klinisch dilemma voor artsen: enerzijds kan bij uitstel van de bevalling het ongeboren kind verder ontwikkelen en groeien, waarbij er minder kans is op neonatale mortaliteit en morbiditeit. Anderzijds kan de preeclampsie bij uitstel van de bevalling verergeren, en kunnen er acute complicaties optreden met negatieve gevolgen voor moeder en het ongeboren kind, waaronder doodgeboorte. De gevolgen van uitstel van bevalling op de cardiovasculaire gezondheid en herstel van de moeder in de postpartum periode zijn in bestaand onderzoek nog onderbelicht.

In hoofdstuk 2 staan de gevolgen van (langdurige) zwangerschapsvoortzetting op foetale en neonatale uitkomsten, en de maternale cardiovasculaire, renale en metabole functie in de postpartum-periode beschreven. Zwangerschapsverlenging geeft een hoger geboortegewicht en een lagere kans op neonatale sterfte. Verlenging van zwangerschap bleek niet gerelateerd aan een afname in de relatieve groei, waardoor de gedachte dat de baarmoeder van vrouwen met zwangerschapsvergiftiging suboptimaal is voor de foetale groei niet onderschreven kon worden. Er werd geen verschil gevonden in de prevalentie van hypertensie, afwijkende cardiale geometrie of abnormale metabole functies tussen vrouwen die vlak na de diagnose zijn bevallen en vrouwen waarbij de bevalling dagen tot weken is uitgesteld. Wel is er per dag zwangerschapsverlening een $2 \%$ hogere kans op een matig verhoogde albuminurie in de postpartum-periode, zonder dat dit effect heeft op andere parameters die de nierfunctie beschrijven.

Hoofstuk 3 bespreekt een observationele studie naar de herhaling van preeclampsie en gerelateerde complicaties in een volgende zwangerschap in de afgelopen decennia. Omdat er steeds meer bekend wordt over (subklinische) preconceptionele cardiovasculaire en metabole risicofactoren kunnen zorgverleners vrouwen beter informeren over mogelijkheden om deze risicofactoren aan te pakken, bijvoorbeeld met leefstijlaanpassingen. Daarnaast is er in de afgelopen jaren steeds meer duidelijkheid gekomen over de werkzaamheid van preventieve maatregelen om preeclampsie te voorkomen, zoals dagelijks laag-gedoseerde aspirine en calciumsuppletie in de zwangerschap. In een groep vrouwen met een uitgebreide evaluatie van hun risicofactoren en bijpassende persoonlijke adviezen nam de incidentie van recidiverende preeclampsie in de afgelopen 20 jaar niet af. In dezelfde periode traden er wel minder vaak foetale en neonatale complicaties op. Deze studie benadrukt hiermee de noodzaak om op zoek te blijven 
naar manieren om preeclampsie te voorkomen en om effectieve maatregelen sneller te implementeren in de klinische praktijk.

Hoofdstuk 4 is een systematische review en meta-analyse om de aanpassingen van de hartfunctie en de perifere vaatweerstand gedetailleerd in kaart te brengen in zowel ongecompliceerde als hypertensief-gecompliceerde zwangerschappen. Nog niet eerder was er een overkoepelende studie naar het hartminuutvolume, bestaande uit hartslag en slagvolume, en de totaal perifere vaatweerstand in zowel timing als omvang in de zwangerschap ten opzichte van waardes buiten de zwangerschap. Het hartminuutvolume in normotensieve zwangerschappen neemt al vroeg toe en stijgt tot het einde van het tweede trimester. Zowel een stijging in de hartslag als in het slagvolume dragen bij aan deze toename. Parallel daaraan neemt de vaatweerstand af tot aan het derde trimester. Dan neemt het slagvolume lichtelijk af en stabiliseert de hartslag, wat zorgt voor een dalend hartminuutvolume tegen het einde van de zwangerschap. Het hemodynamische aanpassingspatroon in hypertensief gecompliceerde zwangerschappen verloopt substantieel anders. Er is een grotere toename in hartminuutvolume, bovenop een hoger hartminuutvolume voor de zwangerschap. Echter, in dit geval daalt het hartminuutvolume na het eerste trimester sterk. Tegelijkertijd is er gedurende de gehele zwangerschap geen daling van de vaatweerstand. Het herkennen van een afwijkend aanpassingspatroon in de vroege zwangerschap kan vrouwen met een verhoogd risico op hypertensie identificeren. Dit kan de mogelijkheden voor preventie- en interventiemaatregelen verbeteren.

Hoofdstuk 5 beschrijft een studieprotocol voor gepersonaliseerde behandeling van zwangerschapshypertensie. Internationale en nationale richtlijnen voor de behandeling van zwangerschapshypertensie zijn conservatief en pas bij ernstige zwangerschapshypertensie, dat wil zeggen een systolisch bloeddruk $\geq 160 \mathrm{mmHg}$ en/of een diastolische bloeddruk $\geq 110 \mathrm{mmHg}$, wordt medicamenteuze behandeling strikt geadviseerd. De voordelen van antihypertensiva bij milde tot matige hypertensie zijn minder evident, en daardoor wordt medicatie niet standaard geadviseerd. De tegenvallende resultaten van onderzoek naar behandeling van milde tot matige zwangerschapshypertensie zouden verklaard kunnen worden door het gebruik van een stapsgewijs medicatieplan. Hierbij wordt er geen rekening gehouden met het onderliggend hemodynamisch profiel en het primaire werkingsmechanisme van de verschillende soorten antihypertensiva. Bloeddruk is de resultante van het hartminuutvolume en de perifere vaatweerstand, en hypertensie kan gepaard gaan met een hoog hartminuutvolume/lage vaatweerstand hemodynamisch profiel, of juist een laag hartminuutvolume/hoge vaatweerstand hemodynamisch profiel. De antihypertensiva die geadviseerd worden in de zwangerschap kunnen onderscheden worden door hun werking op het hartminuutvolume of de 
vaatweerstand. Theoretisch gezien zou een hoge bloeddruk met een hoog hartminuutvolume het best behandeld worden met een antihypertensiva die het hoge hartminuut volume tempert, zoals een bètablokker. Anderzijds zou een vaatverwijder beter passen bij hypertensie in combinatie met een verhoogde vaatweerstand. De hypothese van deze studie luidt dat het gepersonaliseerd voorschrijven van antihypertensiva resulteert in minder progressie naar ernstige hypertensie en/of preeclampsie in vergelijking met vrouwen zonder medicamenteuze behandeling, zoals nu vaak gedaan wordt.

Hoofdstuk 6 beschrijft een observationele studie van een innovatief zorgtraject, waarbij de hemodynamische zwangerschapsaanpassingen vanaf het eerste trimester gemonitord en bijgesteld werden. Vrouwen die al eerder een zwangerschapsvergiftiging doormaakten, werden na een uitgebreide cardiovasculaire risicofactor-analyse in de postpartum-periode uitgenodigd om tijdens hun volgende zwangerschap deel te nemen aan dit zorgtraject in aanvulling op normale zwangerschapscontroles. Op vier vastgestelde momenten, bij 12, 16, 20 en 30 weken zwangerschapsduur, ondergingen deze vrouwen diverse onderzoeken om hun hemodynamische aanpassingen aan de zwangerschap in kaart te brengen. Bij een afwijkend aanpassingspatroon kregen vrouwen een gepersonaliseerd medicatieadvies gericht op het corrigeren van de disbalans in hartminuutvolume en vaatweerstand. De uitkomsten van de tweede zwangerschap werden vergeleken met vrouwen die na de uitgebreide evaluatie niet deelnamen aan dit aanvullende zorgtraject. De kans op herhaling van preeclampsie halveerde, zonder dat er verschillen tussen de groepen waren in maternale of foetale complicaties, of geboortegewicht en -percentiel van de neonaat. Een gerandomiseerde, placebogecontroleerde studie is de logische volgende stap om de resultaten van deze studie te bevestigen.

Voor implementatie van gedetailleerde hemodynamische zwangerschapsaanpassingen-monitoring en -bijsturing is het noodzakelijk dat het hartminuutvolume in de praktijk makkelijk gemeten kan worden. In de afgelopen jaren zijn hiervoor nieuwe niet-invasieve apparaten ontwikkeld. In hoofdstuk $\mathbf{7}$ worden twee verschillende methodes vergeleken. Hartechografie is een veelgebruikte, niet-invasieve methode om het hartminuutvolume te meten. Echter is deze methode arbeidsintensief, moet het door een deskundige uitgevoerd worden en de resultaten zijn met deze methode niet direct beschikbaar. Een alternatief is de Ultrasonic Cardiac Output Monitor (USCOM) methode, een 'point-of-care' apparaat waarmee het hartminuutvolume snel en gemakkelijk te meten is door een sensor vanuit de suprasternal notch op het uitstroomgebied van het hart te richten. De bevindingen van dit onderzoek laten zien dat de absolute hartminuutvolumewaardes die verkregen zijn met een hartecho, niet een-op-een te vergelijken zijn met de waardes gemeten met de USCOM. Alle parameters waaruit het hartminuutvolume bestaat, zoals slagvolume en hartslag, dragen bij aan het verschil in 
waardes tussen de twee methodes. Hierdoor wordt de vergelijking tussen de methodes niet beter door relatief constante parameters te combineren. Ook met het toepassen van verschillende maatregelen om de optimale USCOM-meting te verkrijgen leidde niet tot een betere overeenkomst tussen de twee methodes. Methode-specifieke referentiecurves zijn daarom noodzakelijk voor klinisch gebruik.

In hoofdstuk $\mathbf{8}$ worden de bevindingen van dit proefschrift bediscussieerd, en worden suggesties voor toekomstig onderzoek aangedragen. De behandeling van verhoogde bloeddruk in de zwangerschap wordt vergeleken met de behandeling van hypertensie buiten de zwangerschap, waarbij de afkapwaarde voor behandeling lager ligt en het soort antihypertensivum dat voorgeschreven wordt, wel afhangt van kenmerken van de patiënt. Door het hemodynamisch profiel in de zwangerschap te monitoren en gepersonaliseerde behandeling in te zetten, kan preeclampsie voorkomen worden. 



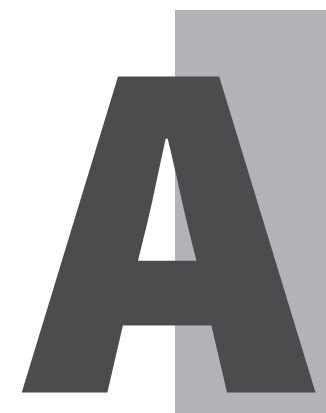

List of publications

Curriculum vitae Acknowledgements 



\section{LIST OF PUBLICATIONS}

- Sciatti E, Mohseni Z, Orabona R, Mulder EG, Prefumo F, Lorusso R, Frusca T, Ghossein-Doha C, Spaanderman MEA. Maternal myocardial dysfunction after hemolysis, elevated liver enzymes, and low platelets syndrome: a speckle-tracking study. J Hypertens. 2021 Jun 23.

- Mulder EG, Ghossein-Doha C, Cauffman E, Lopes van Balen VA, Schiffer VMMM, Alers RJ, Oben J, Smits L, van Kuijk SMJ, Spaanderman MEA. Preventing Recurrent Preeclampsia by Tailored Treatment of Nonphysiologic Hemodynamic Adjustments to Pregnancy. Hypertension. 2021 Jun;77(6):2045-2053.

- Mulder E, de Haas S, Mohseni Z, Schartmann N, Abo Hasson F, Alsadah F, van Kuijk S, van Drongelen J, Spaanderman M, Ghossein-Doha C. Cardiac output and peripheral vascular resistance during normotensive and hypertensive pregnancy - a systematic review and meta-analysis. BJOG. 2021 Feb 25.

- Mulder E, Ghossein-Doha C, Appelman E, van Kuijk S, Smits L, van der Zanden R, van Drongelen J, Spaanderman M. Study protocol for the randomized controlled EVA (early vascular adjustments) trial: tailored treatment of mild hypertension in pregnancy to prevent severe hypertension and preeclampsia. BMC Pregnancy Childbirth. 2020 Dec 12;20(1):775.

- Mulder EG, Ghossein-Doha C, Crutsen J, Van Kuijk S, Thilaganathan B, Spaanderman M. Effect of pregnancy prolongation in early-onset pre-eclampsia on postpartum maternal cardiovascular, renal and metabolic function in primiparous women: an observational study. BJOG. 2021 Jan;128(1):121-129.

- Orabona R, Mohseni Z, Sciatti E, Mulder EG, Prefumo F, Lorusso R, Frusca T, Ghossein-Doha C, Spaanderman MEA. Maternal myocardial dysfunction after normotensive fetal growth restriction compared with hypertensive pregnancies: a speckle-tracking study. J Hypertens. 2020 Oct;38(10):1955-1963.

- Mulder EG, Basit S, Oben J, van Kuijk S, Ghossein-Doha C, Spaanderman M. Accuracy and precision of USCOM versus transthoracic echocardiography before and during pregnancy. Pregnancy Hypertens. 2019 Jul;17:138-143.

- Mulder EG, Ghossein-Doha C, Froeling MFEM, van Kuijk SMJ, Spaanderman MEA. Recurrence rates of preeclampsia over the past 20 years in women assessed for nonpregnant cardiovascular risk factors. Pregnancy Hypertens. 2018 Oct;14:150-155.

- Ellerbrock J, Bohnen JMHA, Lopes van Balen VA, Mulder EG, Aardenburg R, Spaanderman MEA. Homeostatic model assessment of beta cell function predicting abnormal oral glucose tolerance testing in pregnancy: a systematic review and meta-analysis. Gynecol Endocrinol. 2017 Dec;33(12):911-917. 



\section{CURRICULUM VITAE}

Eva Mulder werd op 23 juli 1987 geboren te Zwolle. Ze behaalde in 2005 haar Vwo-diploma bij het Agnieten College, locatie Meander in Zwolle en studeerde daarna geneeskunde aan de Rijksuniversiteit Groningen. Hier ontving ze haar MSc in 2013.

Na haar afstuderen werkte Eva als arts niet in opleiding tot specialist bij het Transmuraal Vrouwen Dagcentrum van de afdeling Obstetrie en Gynaecologie in het Maastricht Universitair Medisch Centrum. Parallel startte ze haar promotietraject onder begeleiding van Marc Spaanderman en Chahinda Ghossein-Doha waarvan het resultaat hier voor u ligt. Sinds september 2020 is Eva in opleiding tot arts Maatschappij \& Gezondheid, profiel infectieziektebestrijding. 



\section{DANKWOORD}

Na mijn studie geneeskunde in Groningen verhuisde ik van het noorden naar het uiterste zuiden. Als net afgestudeerde arts kreeg ik bij het Transmuraal Vrouwen Dagcentrum van het MUMC+ de mogelijkheid om werk in de kliniek met wetenschappelijk onderzoek te combineren. Het was een samenspel dat voor mij goed werkte. Een omgeving waar ik aan het einde van de dag mijn klinische taken afrondde, om vervolgens door te gaan met onderzoek. Een omgeving met meer directe werkzaamheden in de kliniek, waar ik tegelijk via mijn onderzoek geduldig bijdroeg aan nieuwe inzichten voor diezelfde werkzaamheden. Elke dag gaf zo kansen voor de valorisatie van mijn onderzoeksresultaten.

Ik ben niet alleen trots op het afronden van mijn proefschrift, maar ook trots dat ik mocht meebouwen aan deze mooie afdeling met goede zorg in het MUMC+. Een spannende en toch wel uitzonderlijke plek tussen polikliniek en kliniek in. Het voelde voor mij als een plek voor unieke zorg in Nederland. Naast trots, overheerst ook de dankbaarheid naar veel mensen die mij in staat stelden dit proefschrift af te ronden.

Allereerst wil ik alle patiënten en hun partners bedanken dat ze vanuit alle windstreken van Nederland (en zelfs van ver daarbuiten!) langskwamen voor zorg, informatie en deelname aan de wetenschappelijke onderzoeken. Bijzonder dat ze ons hun verhalen en ervaringen toevertrouwden. Samen maken we het mogelijk om de (na)zorg rond zwangerschapsvergiftiging weer een stap verder te brengen.

Mijn promotieteam verdient veel dank voor de inspirerende begeleiding. Marc, Chahinda en Sander, samen boden jullie me een veilige haven om open op onderzoek uit te gaan en een plek om mijn data en conclusies te bevragen en te bediscussiëren.

Marc, je daagde me uit mijn eigen grenzen te verleggen. Inhoudelijk, maar zeker zo vaak met belangrijke levenslessen. Je gaf me handvatten om me te ontwikkelen als volwaardig medisch onderzoeker en professional. Met jou als supervisor voelde ik me een gewaardeerde medewerker én collega. Ik bewonder hoe je er altijd voor alle patiënten was; betrokken was bij ieder van hen. En bedankt dat je altijd met mijn grapjes meelacht :).

Chahinda, voor sommige mensen is the sky the limit, maar jij plakt er nog een heel universum bij aan! Ik heb grote bewondering voor de manier waarop je projecten aanpakt en vormgeeft. En hoe jij in overvolle restaurants een tafel weet te bemachtigen. Je leerde me dat het verhaal dat van jezelf is, ook andere mensen steun en comfort kan geven. Onze bijpraatmomenten over het onderzoek, het werk en het leven had ik niet willen 
missen. Erg fijn dat onze vriendschap ook nu - na mijn vertrek uit Maastricht - nog altijd voor boeiende, inspirerende, kunstzinnige en melige conversaties en belevenissen leidt.

Sander, methodologische en statistische rots in de branding: altijd geduldig om uitleg te geven bij de data en de mogelijke analyses die we daar op los konden laten. Je gaf me hierdoor het vertrouwen dat ik dit begreep en zelf ook kon. Tevens een groot dankjewel voor je interesse, zowel in de vooruitgang van de onderzoeken als in het leven buiten de ziekenhuismuren, en het delen van je werkervaring bij de GGD.

De beoordelingscommissie ben ik dankbaar voor de inzet om mijn proefschrift te beoordelen. Dank prof. Gyselaers, prof. Kruitwagen, prof. Lees, prof. Teunissen en prof. Vernooy voor jullie tijd en expertise. Ik verheug me erop mijn onderzoek tegenover jullie te verdedigen en ik ben benieuwd of jullie in mijn verzameling artikelen nog nieuwe inzichten hebben opgedaan.

Veel dank aan mijn mede-auteurs: Basky Thilaganathan, Joris van Drongelen, Luc Smits en Rogier van der Zanden voor jullie kritische blik, scherpe meelezen en inventieve aanvullingen. Jullie specifieke farmacologische, statistische, en inhoudelijke kennis heeft de inhoud van de artikelen naar een hoger niveau getild.

Lieve dames van het TVDC, Betul, Caroline, Cecile, Gonny, Lonneke, Marie-Jeanne, Monique, Nathalie, Stella, Yolanda en Yvonne, wat kijk ik met veel plezier terug op onze samenwerking en wat ben ik jullie onwijs dankbaar voor alle hulp en gezelligheid, ook buiten het werk om. Door de verscheidenheid aan mensen en talenten waren we een topteam, en altijd bereid om de zorg nog beter te maken! Ik ben heel blij dat ik daar onderdeel van mocht zijn.

Veronica, wat heb ik geboft met jou als collega in mijn eerste baan als arts: ik mocht meeliften op je kennis en ervaring en ik kon een voorbeeld nemen aan je omgang met patiënten. Je stond (en staat!) altijd klaar om te helpen én om leuke dingen te doen naast het werk. Ik kijk met heel veel voldoening en plezier terug op onze samenwerking met daarbij vele avondjes ziekenhuiseten, sparmomenten en de borrels bij Thembi en elders. Een heel groot dankjewel! Stéphanie, het was altijd fijn om bij jou op de uni binnen te stappen. Dat kon altijd, op elk moment. Ontspanning, en een oase van rust en relativering op het moment dat dit nodig was. Bedankt voor de pret en gezelligheid, altijd een luisterend oor, goede adviezen en de (zeer belangrijke) introductie in verschillende Limburgse tradities. Voor het aantal rondes bananengateau en vlaai kom ik graag langs op je verjaardag! Veronique, gelijk na je afstuderen kwam je Veronica en mij versterken met de artsentaken op het TVDC, en wat pakte je de werkzaamheden 
snel op! Binnen no-time maakte jij de mooiste (3D-) echo's. De afgelopen jaren deelden we veel, hadden we veel lol, en had ik altijd het volste vertrouwen in jou als collega en onderzoeker. Jij bent creatief en fixt het altijd. Hoe relaxed dat je als paranimf die skills meebrengt. En niet te vergeten: superbedankt voor de logeerplek mét tandenborstel. Nicki, ik heb altijd vol bewondering gekeken hoe jij je promotieonderzoek combineerde met je studie. Inmiddels weet ik dat dit niet alleen voortvloeide uit hard werken, maar ook een (voor mij soms jaloersmakend!) sterk staaltje projectmanagement. Dankjewel voor je behulpzaamheid, 'attentheid' en gezelligheid. Jonas, enthousiaste gangmaker, zonder jou waren de grappen een stuk degelijker geweest en hadden we in de unikamers veel minder gelachen. En dankzij jou en je (geleende) boormachine kregen de hangdingen in mijn huis hun plekje. Dank voor al het (werk)plezier dat je meebrengt! Eri, je vaatfunctiekamer was altijd het toonbeeld van georganiseerdheid, waar het altijd even fijn binnenstappen was. Dankjewel voor de prettige samenwerking. Jolien, koningin van de hartecho's. Door de korte lijntjes kon er altijd wat geschoven en geprioriteerd worden met de resultaten van de (poli)klinische patiënten. Heel erg bedankt voor alle (extra) metingen die je hebt uitgevoerd voor de onderzoeken, en je altijd snelle suggesties voor verbetering van de artikelen. Indira, wat een toewijding voor onderzoek kwam er met jou in het team. Ik vind het knap hoe jij je eigen pad uitstippelt om dichtbij jezelf te blijven. Dankjewel voor je belangstelling en vrolijkheid.

Gedurende dit traject mocht ik met veel studenten samenwerken. Andrew, Annemijn, Astrid, Bettina, Ella, Evine, Fatimah Abo Hasson, Fatimah Alsadah, Fleur, Janneke, Jori, Laura, Lauren, Linda, Niklas, Nina, Shumaila en Zenab: jullie hulp bij de verschillende onderzoeksprojecten en zorgtrajecten was onmisbaar. Dank voor al jullie enthousiasme en (vrije) tijd. Sander de Haas, review- in combinatie met R-expert. Wat hébben we een tijd zitten in het $2 x$ updaten van de search en analyses, maar ik ben heel trots op het resultaat. Het bloeddrukartikel gaan we ook gepubliceerd krijgen! Dankjewel voor je prettige manier van samenwerken, je geduld, en het perfectioneren van de R-codes. Mieke, fijne en blije ad-hoc huisgenoot! Ik ken weinig mensen die zo snel schakelen van serieuze onderwerpen, naar iets volledigs anders en weer terug. Jij weet altijd een interessante kijk en interesses te delen en toe te voegen, zowel voor mijn onderzoek als privé. Jammer dat we vorig jaar niet naar Canada konden afreizen, maar wie weet krijgen we nog eens een herkansing! Salwan, dankjewel voor het meedenken met mijn onderzoeksprojecten tijdens de Periscoop, en je behulpzaamheid in de kliniek. Ik ken niemand die met zoveel enthousiasme en toewijding zoveel studenten en projecten managet. Daarnaast vond ik het superleuk om mee te mogen naar Berlijn! Denise, Emma, Esther, Jorne, Laura, Robert-Jan en Veronique: de oorsprong van ons app-groepje is me ontschoten, maar de naam "Eten PhDers gyn" illustreert genoeg. Geen pluslunch, krokettenlunch, afscheids- en nieuwjaarsborrels of pizzameeting in het MUMC+ zonder 
onze vertegenwoordiging. En in aanvulling vele (goede) koffies, traktaties, our own home-made sushi en barbecueën met $35+{ }^{\circ} \mathrm{C}$. Dankjulliewel voor het meedenken, meeleven en meejuichen met alle uitdagingen op onderzoeksgebied, maar bovenal voor het plezier, de ontspanning en de gezelligheid tussendoor. Heel veel succes met (het afronden van) jullie promotietrajecten en vervolgcarrières!

Ivar, dankjewel voor de prettige (opleidings)gesprekken en voor het laatste zetje om mijn discussie in te leveren. Dames en Wim van IZB-kernteam GGD Drenthe, dank voor de zachte landing afgelopen jaar tijdens mijn start binnen een nieuw specialisme.

Lieve Rolin, tweelingzusje-to-be totdat jij op tijd geboren werd. Hoe ver we zo nu en dan ook bij elkaar vandaan wonen, we weten elkaar altijd te vinden en daar ben ik je heel dankbaar voor! Al decennia deel ik met jou lief en soms wat leed en kan ik praten over alles wat ik wil bespreken. Superleuk dat jij en Max - de beste en meest geduldige en zorgzame nachtchef die ik ken - altijd de deur hebben openstaan én in zijn voor alles: van knusse Risiko- en Carcassonne-weekendjes tot Eurovision songfestival, en wonderlijke en brullende ervaringen op de beste campsites!

Robbert, altijd blij en enthousiast om activiteiten te ondernemen, en Katrin, vaak initiatiefnemer van die tot-in-de-puntjes goed georganiseerde jonge tradities: dank voor jullie vriendschap, de tripjes op de ski's en racefiets, en goede gesprekken met bijbehorende discussies. Het is alweer bijna tijd voor de evaluatie van onze goede voornemens! Dank dat jullie me hier elk jaar mee scherp houden ;)!

Kyra, dankjewel voor je nuchtere kijk en droge humor, jij maakt de allerbeste woordspelingen! Ik ken je niet anders dan oprecht en recht-voor-zijn-raap. Dat helpt om te relativeren. Met het mosschilderij aan de muur kan ik elke dag van de creativiteit van jou en Bart genieten. Bart, dankjewel voor je onuitputtelijke interesse en geduld als je weer eens door (bijna) allemaal artsen bent omringd. Gelukkig zorgt een (nog-altijd onopgeloste) crimibox voor de nodige afleiding.

Linda, een toevallige ontmoeting op station Zwolle met Kyra en jou resulteerde in een voor mij dierbare vriendschap. Wat hebben wij tijdens ons wekelijkse hardlooprondje veel stoom afgeblazen. En daarna samen eten, een spelletje spelen, een puzzel leggen of een hippo haken (hoor jij ook hetzelfde bejaardentehuis roepen?). Ik voelde me altijd welkom bij jou en Emile. Of het nu bij oud \& nieuw, een overbruggingsperiode tijdens een verhuizing of jullie prachtige bruiloft was. En Linda, ik vond het een hele eer jouw paranimf te mogen zijn. Ik heb met heel veel plezier en vol trots naast je gestaan in de 
aula aan de Minderbroedersberg. Dat gaan we gewoon nog een keer doen maar dan met de rollen omgedraaid!

Arjen, altijd fanatiek. Onderlinge competitie was er vanaf de collegebanken, en jij zorgde ervoor dat ik altijd net nog een beetje beter mijn best wilde doen. Dankjewel voor de tijd die we samen doorbrachten, en daarmee ook voor je bijdrage aan mijn promotietraject.

Maurice, parallel promotiemaatje, dankjewel voor de eerste wegwijs-in-het-zuiden en het samen optrekken op onderzoekspad! Hoe toevallig dat we elkaar tijdens de introdag in het MUMC+ troffen nadat we enkele weken daarvoor tegelijk afstudeerden in Groningen. Onze jaarlijkse after-graduation date wordt vanaf nu ook een post-PhD party. Heel veel succes met je laatste loodjes!

Alieske, dankjewel voor alle blijheid en openheid die je aan mijn leven en de wereld toevoegt. Aan onverwachte belevenissen geen gebrek, waar we achteraf altijd veel plezier om hebben. Ook dank voor je zeer motiverende steun in het hippo-project.

Femke, als je Cupido op Wikipedia opzoekt, staat jouw foto erbij! Een voorrecht dat ik jouw ondernemingszin en avonturendrift heb mogen meemaken. Ik heb het als waardevol ervaren hoe jij jouw leven én de mensen in jouw leven met anderen deelt.

Alieske, Harrie, Hendrik-Jan, Iris, Jessica, Karin, Lianne, Linda, Machiel, Martine, Miranda, Rianne, Tamar, Thomas en Shalton in wisselende samenstelling, dank voor de fijne gesprekken, de relativering en het uitwisselen van perspectieven elke drie weken in Maastricht of elders in het heuvelland. Dat gaf keer op keer nieuwe inzichten, en inspiratie voor het leven.

Linda D, superleuke bijna-buurvrouw en BONI-bezorger. Dank dat je de afgelopen maanden naar me uitkeek tijdens de laatste loodjes van mijn proefschrift.

Lieve pap en mam, ik wil jullie voor zoveel bedanken. Jullie boden zo'n veilige basis. Altijd 'hoe', nooit 'nee'. Ik heb altijd het gevoel gehad dat er alle ruimte was om zelf te ontdekken en wijzer te worden, met jullie als groot vangnet. Ik vind het superleuk dat jullie zo creatief en ondernemend zijn, en met elkaar op avontuur blijven gaan. Albertus, de eigenschap om er net even een tandje erbij te doen en de (sportieve) grens op te zoeken komt absoluut van jou: elke fietser voor ons moet immers ingehaald worden. Ankie, jij maakt altijd ruimte en tijd vrij voor nét dat beetje extra aandacht op momenten dat dit heel welkom is, dankjewel! 
Lieve zus(jes), wat hebben we een fijne band. Met heel veel leuks, en af en toe een kritische noot, maar vooral om elkaar scherp te houden. Als het erop aankomt weet ik dat jullie me onvoorwaardelijk steunen. En ik jullie. Ik ben heel erg trots op jullie. Ann, je 100\% toewijding aan verschillende projecten is bewonderingswaardig, of het nu (vrijwilligers)werk is, een nieuwe opleiding, of de komst van een pup. Suus, wat hebben wij het gezellig samen in 'het groene vakje'. Je zorgt voor alles en iedereen, op zoveel meer vlakken dan het koek-en-zopie. En ook al mijn planten (in nood) zijn blij met je. Michael, geduchte tegenstander met ticket-to-ride. Die kwaliteit komt vast door jouw kennis van Griekenland en omgeving. Je bent een zeer welkome familie-aanvulling! Es, je zit vol bruisende ideeën en ondernemingslust, en dat levert leuke belevenissen op. Je openhartigheid en oprechtheid komen altijd met een vleugje humor en dat maakt het fijn sparren.

Jannita \& Frits, Koert \& Jenny, oma Troed, Esther \& Tim, jullie lieten me super welkom voelen in de schoonfamilie. Jullie kunnen geïnteresseerd en zo oprecht mee blij zijn en meegenieten van de kleine stapjes vooruit in de afgelopen jaren. Heel erg bedankt voor de etentjes, logeermogelijkheden en weekendjes weg.

Allerleukste Jalmar, wat maak jij het leven makkelijk! Enthousiast en vol vertrouwen maak jij van de kleinste dingen een feestje, zelfs het indienen van een artikel gaat niet ongemerkt voorbij. Tegelijkertijd kan ik ook altijd erg genieten van onze serieuze discussies, en geeft jouw wereldbeeld mij vaak weer nieuwe inzichten. Gekscherend zeggen we wel eens dat dit proefschrift veel eerder klaar was geweest als ik jou niet had leren kennen, maar ik zou onze tijd voor geen goud willen missen. Een oneindig groot dankjewel! 